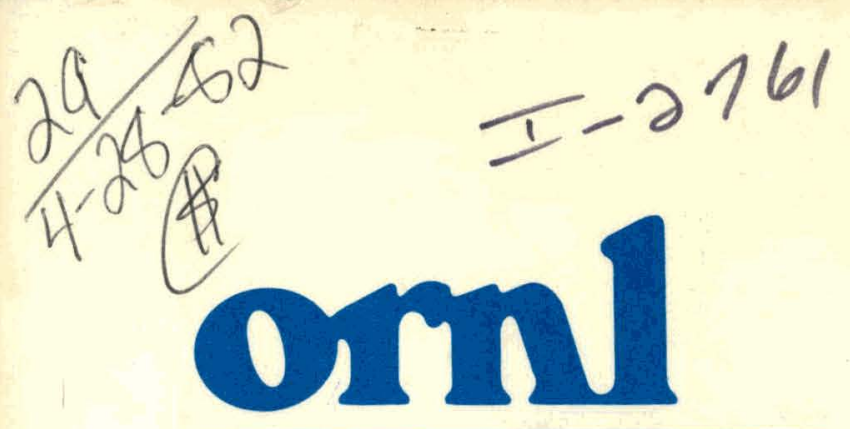

\section{OAK RIDGE NATIONAL LABORATORY}

\section{UNION CARBIDE}

ORNL/TM-7837

\title{
Heavy-Metal Toxicity Phenomena in Laboratory-Scale ANFLOW Bioreactors
}

\author{
A. L. Rivera
} \section{DO NOT MICROFILM
COVER}

OPERATED BY

UNION CARBIDE CORPORATION FOR THE UNITED STATES DEPARTMENT OF ENERGY 


\section{DISCLAIMER}

This report was prepared as an account of work sponsored by an agency of the United States Government. Neither the United States Government nor any agency Thereof, nor any of their employees, makes any warranty, express or implied, or assumes any legal liability or responsibility for the accuracy, completeness, or usefulness of any information, apparatus, product, or process disclosed, or represents that its use would not infringe privately owned rights. Reference herein to any specific commercial product, process, or service by trade name, trademark, manufacturer, or otherwise does not necessarily constitute or imply its endorsement, recommendation, or favoring by the United States Government or any agency thereof. The views and opinions of authors expressed herein do not necessarily state or reflect those of the United States Government or any agency thereof. 


\section{DISCLAIMER}

Portions of this document may be illegible in electronic image products. Images are produced from the best available original document. 
Printed in the United States of America. Available from National Technical Information Service

U.S. Department of Commerce 5285 Port Royal Road, Springfield, Virginia 22161

NTIS price codes-Printed Copy: A12; Microfiche A01

This report was prepared as an account of work sponsored by an agency of the United States Government. Neither the United States Government nor any agency thereof, nor any of their employees, makes any warranty, express or implied, or assumes any legal liability or responsibility for the accuracy, completeness, or usefulness of any information, apparatus, product, or process disclosed, or represents that its use would not infringe privately owned rights. Reference herein to any specific commercial product, process, or service by trade name, trademark. manufacturer, or otherwise, does not necessarily constitute or imply its endorsement, recommendation, or favoring by the United States Government or any agency thercof. The views and opinions of authors expressed herein do not necessarily state or reflect those of the United States Government or any agency thereof. 


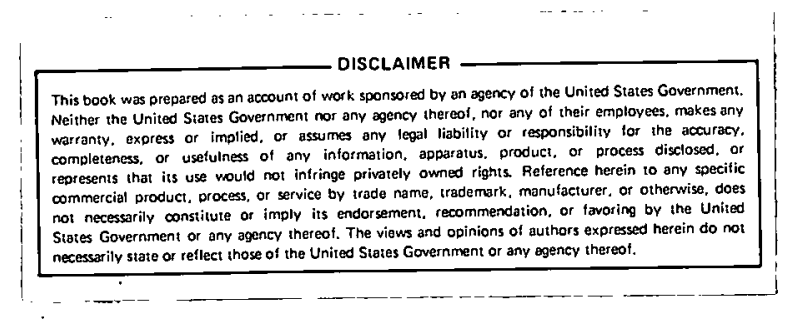

ORNL / TM-7837

Contract No. W-7405-eng-26

CHEMICAL TECHNOLOGY DIVISION

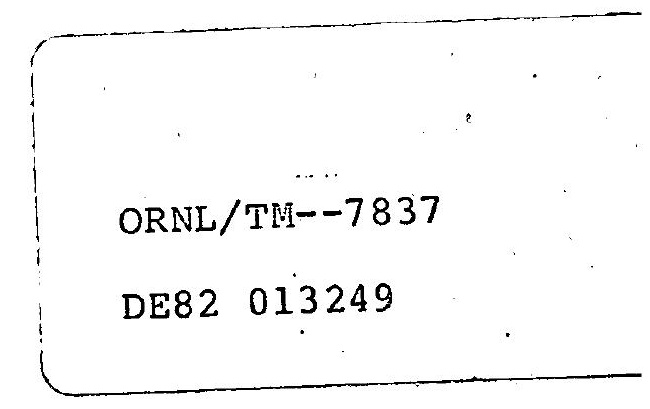

HEAVY-METAL TOXICITY PHENOMENA IN LABORATORY-SCALE ANFLOW BIOREACTORS

\author{
A. L. Rivera
}

This report was prepared as a dissertation and submitted to the Faculty of the Graduate School of Northwestern University in partial fulfillment of the degree of Doctor of Philosophy in the Department of Environmental Engineering.

Date Published - April 1982

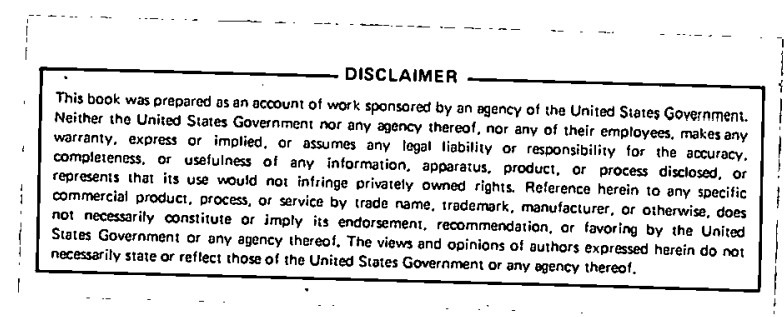
OAK RIDGE NATIONAL LABORATORY
Oak Ridge, Tennessee 37830
operated by
UNION CARBIDE CORPORATION
for the
DEPARTPENT OF ENEKCY


THIS PAGE

WAS INTENTIONALLY

LEFT BLANK 


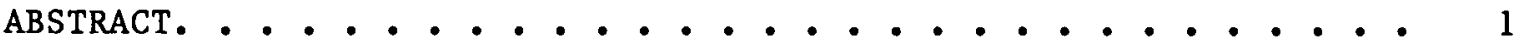

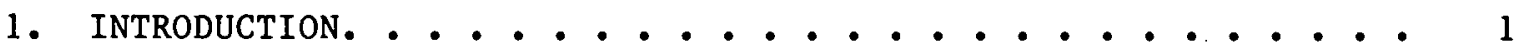

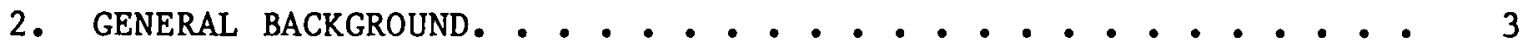

2.1 The ANFLOW Process .................. 3

2.1.1 Studies with Synthetic Wastewaters....... 3

2.1.2 Studies with Industrial Wastewaters ...... 4

2.1.3 Studies with Municipal Wastewaters. ...... 6

2.2 Overview of Anaerobic Digestion Processes....... 8

2.3 Overview of Toxicity Phenomena in Anaerobic Processes. . 12

3. DEVELOPMENT OF MODELS OF THE ANFLOW SYSTEM WHICH REFLECT

TOXICITY EFFECTS. ................... 18

3.1 General Perspective.............. 18

3.2 Kinetic Model for Removal of Soluble COD . . . . . 20

3.2.1 Lumped-Parameter Model for Global Analysis. . . . 20

3.2.2 Regional Model for Local Analyses ....... 32

4. RESEARCH OBJECTIVES AND SCOPE ............... 34

5. DESCRIPTION OF EXPERTMENTAL PROGRAM .......... 38

5.1 Experimental System. ............. 38

5.1.1 Laboratory-Scale Anflow Bioreactors ...... 38

5.1.2 Experimental Setup ........... 38

5.2 Overview of Experimental Program Development ..... 42

5.2.1 Synthetic Substrate Development ....... 45

5.2.2 Startup and Steady-State Operation ...... 48

5.2.3 Residence Time Distribution Experiments ..... 48

5.2 .4 Tox1c1ty Experlments. ........... 48 
5.3 Data Acquistition and Analysis. . . . . . . . 48

5.3.1 Average Residence Time and Reactor Dispersion

Number. . . . . . . . . . . . . 48

5.3.2 Monitoring Bioreactor Response to Toxicity. . . . 58

5.3.2.1 Chemical Oxygen Demand . . . . . 58

$5.3 .2 .2 \mathrm{pH} /$ Alkalinity.......... 59

5.3.2.3 Gas Production and Composition ..... 59

5.3.3 Bioreactor Performance for Soluble Zinc Removal . 61

5.3.4 Sample Collection and Treatment . . . . . . 64

5.3.5 Sorption Factors and Distribution of Zinc . . . 65

5.3.6 Determining Global and Regional First-Order Rate

Constants . . . . . . . . . . . 70

6. RESULTS AND DISCUSSION OF RESULTS . . . . . . . . . 70

6.1 Average Residence Time and Reactor Dispersion Number . . 71

6.2 The Phenomena of Toxicity as Described by the Dispersion

Model with First Order Kinetics... . . . . . . . 83

6.2.1 Global Phenomena. . . . . . . . . . 83

6.2.2 Regional Phenomena............. 90

6.3 Bioreactor Response to Tuxictty as Reflected in

Uperational Parameters . . . . . . . . . . . 96

6.3.1 Chemical Oxygen Demand. . . . . . . . 96

6.3.2 Gas Production and Composition. . . . . . . 112

6.3.3 Acetic and Propionic Acid Profiles. ...... 120

6.3.4. pH and Alkalinity ............ 127

6.4 Bioreactor Performance for Soluble Zinc Removal. . . . . 138

6.5 Sorption Factors and Distribution of Zinc Under Step-
Feeding Conditions....................... 141

6.6 Overview of the Recovery Phenomena . . . . . . . . 148 
7. SUMMARY AND CONCLUSIONS . . . . . . . . . . . . . 154

8. RECOMMENDATIONS FOR FUTURE STUDY. . . . . . . . . . . 158

9. APPENDIXES. . . . . . . . . . . . . . . 161

A. DATA FOR TOXICITY EXPERIMENT NO. 1. . . . . . . . 162

B. DATA FOR TOXICITY EXPERIMENT NO. 2. . . . . . . . 176

C. DATA FOR TOXICITY EXPERIMENT NO. 3. ......... 196

D. COMPUTER CODES. .................... 221

10. LIST OF REFERENCES . . . . . . . . . . . . . . 233 


\section{THIS PAGE}

\section{WAS INTENTIONALLY \\ LEFT BLANK}




\section{LIST OF TABLES}

TABLE

PAGE

2.1. Common Volatile Acid Intermediates . . . . . . . . 10

2.2. Heavy-Metal Toxicity Limits for Anaerobic Digestion. . . - 17

2.3. Solubility Products of Some Metal Salts at $18^{\circ} \mathrm{C}$. . . . . 19

3.1. Factors that Could Modify the Characteristic Parameters of an ANFLOW Bioreactor................. 31

5.1. Summary of the Two Synthetic Substrates Used During the Experimental Program .................. 47

5.2. Summary of the Toxicity Experiments Performed and the Process Conditions Used. . . . . . . . . . . 49

5.3. Summary of Residence Time Distribution Experiments . . . . 54

5.4. Summary of Collection and Treatment of Samples for Chemical Analyses. . . . . . . . . . . . 65

6.1. Summary of the Results Obtained from the Residence Time Distribution Experiments. . . . . . . . . 75

6.2. Summary of the Characteristic Parameters for Global and Regional Kinetic Models. . . . . . . . . . 84

6.3. Distribution of Zinc in ANFLOW Bioreactor Solids During Toxicty Experiment No. 3. . . . . . . . . 147

6.4. Basic Aspects of the Phenomena of Toxicity and the Engineering Significance of Their Study. . . . . . . 149 


\section{THIS PAGE}

\section{WAS INTENTIONALLY LEFT BLANK}


2.1. Anaerobic digestion of organic wastes. . . . . . . 9

2.2. General effects of salts or other materials on biological reactions................ 14

3.1. Elemental volume in an ANFLOW bioreactor ........ 23

3.2. Solutions to equation (3-12) for different reactor dispersion numbers . . . . . . . . . . . . . .

3.3. Remaining soluble chemical oxygen demand fraction as function of $\overline{\mathrm{Kt}}$ for different dispersion numbers as predicted by equation (3-28) . . . . . . . . . . . . .

3.4. Kinetic models used to study the phenomena of toxicity on laboratory-scale ANFLOW bioreactors: (a) global model, (b) regional or local model. . . . . . . . . . .

5.1. ANFLOW bioreactor designed and built by Oak Ridge National Laboratory to perform basic supportive research for pilotscale processes. . . . . . . . . . . . . . .

5.2. Schematic diagram of the ANFLOW bioreactor . . . . . . . 40

5.3. Schematic diagram of the basic components of the experimental setup used during the experimental program. . . .

5.4. Schematic diagrams of the feed supply systems used during the experimental program: (a) during start-up, steady-state and toxicity experiment No. 1, (b) during toxicity experiments No. 2 and No. 3. . . . . . . . . . . . .

5.5. Schematic diagram of the main phases of the experimental program. . . . . . . . . . . . . . . . . . .

5.6. Experimental setup to continuously sample the bioreactor effluent during an RTD experiment. . . . . . . . . .

5.7. Experimental setup to analyze the effluent samples containing fluorescein dye. . . . . . . . . . . . . . .

5.8. $\mathrm{pH}$ dependence of fluorescein dye fluorescence. Dye concentration $=2 \mathrm{mg} / \mathrm{L} . . . . . . . . . . . . . .$.

5.9. Percent emission as function of fluorescein dye concentration. . . . . . . . . . . . . . . .

5.10. Calibration curve for the chemical oxygen demand analysis. . . . . . . . . . . . . . . . . 
5.11. Experimental setup used to obtain the callbration curve shown on Fig. 5.12. . . . . . . . . . .

5.12. Calibration curves for the gas chromatograph used to determine the composition of the off-gas from the ANFLOW bioreactors. .................

5.13. Schematic diagram of the sampling method developed to obtain solids samples from the ANFLOW bioreactors. The collected sample will contain fixed-film as well as suspended solids. . . . . . . . . . . . . .

5.14. Experimental method used to characterize zinc in ANFLOW solids as organically bound and precipitated (mainly carbonate and sulfidc). . . . . . . . . . . . .

6.1. Fluorescein dye concentration (percent emission) against the natural logarithm of $t$ (in minutes) for bioreactor

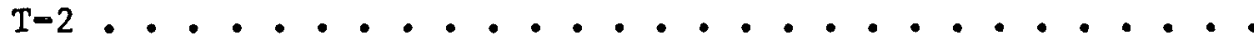

6.2. Fluorescein dye concentration (percent emission) against the natural logarithm of $t$ (in minutes) for control bioreactor. . . . . . . . . . . . .....

6.3. Fluorescein dye concentration (percent emission) against the natural logarithm of $t$ (in minutes) for bioreactor

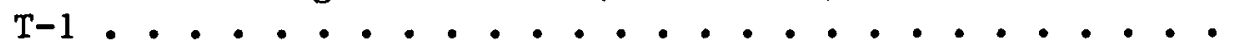

6.4. Comparison between the experimental RTD fur bioreactor $\mathrm{T}-2$ and the theoretical RTD based on a reactor dispersion number of 0.92 obtalned from the time of peak concentration method .......................

6.5. Comparisun between the experimental BTD for bioreaclur I-1 and the theoretical RTD based on a reactor dispersion number of 0.64 obtained from the time of peak concentration method.........................

6.6. Comparison between the experimental RTV for control bioreactor and the theoretical RTD baocd on a leactor dispersion number of 0.64 obtained from the time of peak concentration method...................

6.7. Comparison between the experimental RTD for bioreactor $\mathrm{T}-1$ and the theoretical RTD based on a reactor dispersion number of 0.33 obtained from the variance method...

6.8. Comparison between the experimental RTD for bioreactor T-2 and the theoretical RTD based on a reactor dispersion number of 0.35 obtained from the variance method ... 
6.9. Comparison between the experimental RTD for control bioreactor and the theoretical RTD based on a reactor dispersion number of 0.33 obtained from the variance method. .................... 81

6.10. Global first-order rate constants for control and test (T-1) bioreactors during toxicity experiment No. 1. . . .

6.11. Global first-order rate constants for control and test (T-1) bioreactors during toxicity experiment No. 2. . . .

6.12. Global first-order rate constants for control and test ( $\mathrm{T}-2)$ bioreactors during toxicity experiment No. 3. . . .

6.13. Reponse pattern of an ANFLOW bioreactor to a heavy metal injected as a shock load. . . . . . . . . . . .

6.14. Global and regional first-order rate constants for test (T-1) bioreactor during toxicity experiment No. 1. The constants were calculated from the soluble chemical oxygen demand profiles. . . . . . . . . . . .

6.15. Global and regional first-order rate constants for test (T-2) bioreactor during toxicity experiment No. 2. The constants were calculated from the soluble chemical oxygen demand profiles. . . . . . . . . . . . .

6.16. Global and regional first-order rate constants for test (T-2) bioreactor during toxicity experiment No. 3. The constants were calculated from the soluble chemical oxygen demand profiles: . . . . . . . . . . .

6.17. Global first-order rate constants for control and test (T-1) bioreactors during toxicity experiment No. 1. The constants were calculated from the soluble chemical oxygen demand profiles. . . . . . . . . . . . .

6.18. Global first-order rate constants for control and test (T-1) biorector during toxicity experiment No. 2. The constants were calculated from the soluble chemical oxygen demand profiles. . . . . . . . . . . . .

6.19. Clobal first-order rate constants for control and test (T-2) bioreactors during toxicity experiment No. 3. The constants were calculated from the soluble chemical oxygen demand profiles. ................

6.20. Global and regional first-order rate constants for control bioreactor during toxicity experiment No. 1 . The conslauls wele calculated from the soluble chimiral. oxygen demand profiles. . . . . . . . . . . . . 
6.21. Global and regional first-order rate constants for control bioreactor during toxicity experiment No. 2. The constants were calculated from the soluble chemical oxygen demand profiles................ 100

6.22. Global and regional first-order rate constants for control bioreactor during toxicity experiment No. 3 . The constants were calculated from the soluble chemical oxygen demand profiles................ 101

6.23. Soluble chemical oxygen demand in bioreactor effluent during toxicity experiment No. 1 . (Influent $\operatorname{COD}=$

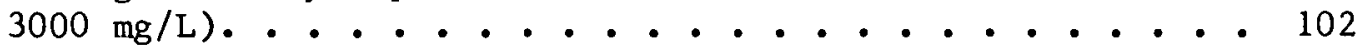

6.24. Soluble chemical oxygen demand in test $(\mathrm{T}-1)$ and control bioreactor effluents during toxicity experiment No. 2. (Influent $\mathrm{COD}=3000 \mathrm{mg} / \mathrm{L}) . \ldots \ldots$

6.25. Soluble chemical oxygen demand in test ( $\mathrm{T}-2)$ and control bioreactor effluents during toxicity experiment No. 3 . $($ Influent $\mathrm{COD}=3000 \mathrm{mg} / \mathrm{L}) . . . . . . . . .104$

6.26. Soluble chemical oxygen demand profiles for. test bioreactor ( $T-1$ ) during toxicity experiment No. 1. Also shown is the average profile for control bioreactor. (Influent COD $=3000 \mathrm{mg} / \mathrm{L}) . . . . . . . . .106$

6.27. Soluble chemical oxygen demand profiles for test bioreactor ('l-1) during toxicity experiment No. 2. Also shown is the average profile for control bioreactor. $($ Influent $C O D=3000 \mathrm{mg} / \mathrm{L}) . . . . . . . . . .107$

6.28. Soluble chemical oxygen demand profiles for test bioreactor during toxicity experiment No. 3 . Also shown are the concentrations of zinc in the feed, and the time when the profile was done relative to the time when the particular concentration was first introduced in the feed. (Influent $\mathrm{COD}=3000 \mathrm{mg} / \mathrm{L}$ ) . . . . . . . 108

6.29. Soluble chemical oxygen demand profiles for control bioreactor during toxicity experiment No. 1. (Influent

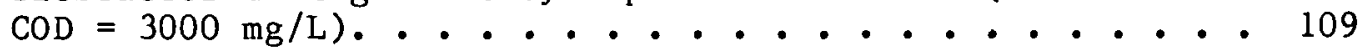

6.30. Soluble chemical oxygen demand for control bioreactor during toxicity experiment No. 2. (Influent $\mathrm{COD}=$

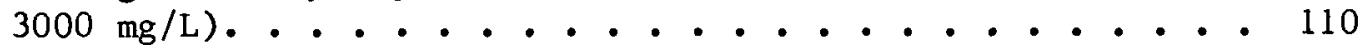

6.31. Soluble chemical oxygen demand profiles for control bioreactor during toxicity experiment No. 3. (Influent

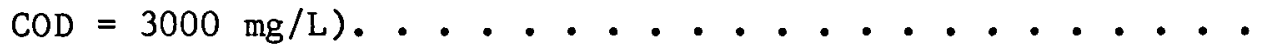


6.32. Gas production rate for control and test ( $\mathrm{T}-1)$

bioreactors during toxicity experiment No. 1. . . . . . 113

6.33. Methane and carbon dioxide percentages in the off-gas

of control and test $(\mathrm{T}-1)$ bioreactors during toxicity

experiment No. 1. . . . . . . . . . . . . 114

6.34. Gas production rate for control and test (T-1)

bioreactors during toxicity experiment No. 2. . . . . 115

6.35. Methane and carbon dioxide percentages in the off-gas

of control and test ( $\mathrm{T}-1$ ) bioreactors during toxicity

experiment No. 2................ 116

6.36. Gas production rate for control and test ( $\mathrm{T}-2)$

bioreactors during toxicity experiment No. 3. . . . . 117

6.37. Methane and carbon dioxide percentages in the off-gas

of control and test ( $\mathrm{T}-2$ ) bioreactors during toxicity

experiment No. 3. . . . . . . . . . . . . 118

6.38. Acetic acid profiles for test bioreactor during toxicity

experiment No.1................ . 121

6.39. Propionic acid profiles for test bioreactors (T-1)

during toxicity experiment No. 1. . . . . . . . . 122

6.40. Acetic acid profiles for test (T-1) bioreactor during

toxicity experiment No. 2............. 123

6.41. Propionic acid profiles for test bioreactor ( $T-1$ ) during toxicity experiment No. 2 . . . . . . . . . . 124

6.12. Acetic acid profiles for test bioreactor during toxicity experiment No. 3. Also shown are the concentrations of zinc in the feed and the time when the profile was done relative to the time when the particular concentration

was first introduced in the feed. . . . . . . . . 125

6.43. Propionic acid profiles for test bioreactor during toxicity experiment No. 2. Also shown are the concentrations of zinc in the feed and the time when the profile was done relative to the time when the particular concentration was first introduced in the feed. . . . . 126

6.44. Propionic acid profiles for control bioreactor during toxicity experiment No. l. . . . . . . . . . 128

6.45. Acetic acid profiles for control bioreactor during cox1c1ty experlment Nó. $1 . . . . . . . . . . . .$. 
6.46. Average volatile acid profiles for control bioreactor during toxicity experiment No. 1. . . . . . . . 130

6.47. Acetic acid profiles for control bioreactor during toxicity experiment No. 2.............. 131

6.48. Propionic acid profiles for control bioreactor during toxicity experiment No. 2.............. 132

6.49. Average volatile acid profiles for control bioreactor during toxicity experiment No. 2. . . . . . . . 133

6.50. Acetic acid profiles for control bioreactors during toxicity experiment No. 2............. 134

6.51. Propionic acid profiles for control bioreactor during toxicity experiment No. 3 ............ 135

6.52. Average volatile acid profiles for control bioreactor during toxicity experiment No. 3. . . . . . . . 136

6.53. Soluble zinc concentration in test ( $T-2)$ and control bloreactor effluents during toxicity experiment No. 3 . . 139

6.54. Soluble zinc in test ( $\mathrm{T}-1$ ) bloreactor effluent during toxicity experiment No. 2............. 140

6.55. Soluble zinc profiles for test $(T-2)$ bioreactor during toxicity experiment. Nn. 3, Timee given refer to tlie Llule when the profile was done relative to the time when the particular concentration was first introduced in the feed..................... 142

6.56. Sorption factor profiles for test ( $T-2)$ bioreactor during toxicity experiment No. 3. Times given refer to the time when the profile was done relative to the time when the particular concentration was first introduced . . . . . 143

6.57. Freundlich-type relationship between the sorption factor and the soluble zinc concentration when plotted in log$10 g$ paper................... 145

6.58. Freundlich equation describing the relationship between the soluble zinc concentration and the amount of zinc sorbed by the solids in an ANFLOW hioreactor. The colids would include fixed-films as well as suspended masses . . 146

6.59. Simple model for a fixed-film in an ANFLOW bioreactor. The film is formed by a heterogeneous mixture of acid and methane formers ............... 152 


\section{ACKNOWLEDGMENTS}

In any work of this kind there are many contributors who merit acknowledgement but remain anonymous because of the large number and the limited space available. I would like to take this opportunity to express my appreciation to a number of friends who have made very special contributions to the completion of this dissertation; amongst whom I am particularly indebted to:

The Graduate Committee, Dr. B. A. G. Lewis, Dr. H. Cember, Dr. R. S. Gemme11, Dr. J. A. FitzPatrick, and Dr. R. K. Genung for they kindly afforded me the benefit of their comments and criticisms.

Dr. H. Cember, for his support, advice, and encouragement during my graduate studies at Northwestern University; for his invaluable assistance obtaining the financial support for this undertaking.

Dr. R. K. Genung, for his invaluable collaboration in many general matters, his helpful suggestions on improving the original manuscript; for suggesting this undertaking and providing advice, and encouragement in getting it under way.

The Chemical Technology Division at Oak Ridge National Laboratory, which is operated by Union Carbide Corporation for the U.S. Department of Energy, for their financial support and for providing all the necessary materials and technical expertise.

Mr. H. L. Jennings, for his collaboration and technical assistance ae engineering technician. 
$x v 1$

Miss R. Hamley, for typing the drafts and final copy, for her suggestions in improving the final report, and for maintaining a pleasant working atmosphere.

Mrs. J. Posey and Mrs. D. Snow for their encouragement and assistance.

To my dear wife Marta, for her constant encouragement, moral support and love; and for my children: Luis Eduardo, Mayra Lynn, and Carlos Alberto for all the time we could not enjoy together. 


\author{
A. L. Rivera
}

\title{
ABSTRACT
}

Oak Ridge National Laboratory (ORNL) has developed an energy-conserving wastewater treatment system based on an anaerobic, upflow (ANFLOW) bioreactor. Since many applications of the ANFLOW process could involve the treatment of wastewaters contalning heavy metals; the potentially toxic effects of these metals on the biological processes occurring in ANFLOW columns (primarily acetogenesis and methanogenesis) were investigated.

Both step and pulse inputs of zinc ranging from 100 to $1000 \mathrm{mg} / \mathrm{L}$ were added to synthetic wastewaters being treated in ANFLOW columns with $0.057-\mathrm{m}^{3}$ volumes. Column responses were used to develop descriptive models for toxicity phenomena in such systems. It was found that an inhibition function could be defined and used to modify a model based on plingflow with axial dispersion and first-order kinetics for soluble substrate removal. The inhibitory effects of zinc on soluble substrate removal were found to be predominantly associated with its sorption by biosolids. Sorption inftially occurred in the lower regions of the column, but was gradually observed in higher regions as the sorption capacity of the lower regions was exhausted. Sorption phenomena could be described with the Freundich equation.

Sorption processes were accompanied by shifts of biological processes to regions higher in the columns. A regenerative process was observed when feeding of wastewaters without zinc was resumed. It was postulated that regeneration could be based on sloughing of layers of biofilms, or other biosolids involved in zinc sorption, followed by continued growth of lower layers of biofilms not involved in heavy-metal sorption.

\section{INTRODUCTION}

Oak Ridge National Laboratory (ORNL) has developed an energy-conserving wastewater treatment system based on an anaerobic, upflow 
(ANFLOW) bioreactor that utilizes films of bacteria fixed to inert, stationary packing material. The treatment process is based on passing wastewaters upward through the bioreactor for continuous treatment by gravitational settling, biophysical filtration, and biological decomposition. The ANFLOW process has been demonstrated using municipal sewage with a pilot plant bioreactor designed to process $19 \mathrm{~m}^{3} / \mathrm{d}$ (5000 gpd). 1

Conceptual designs for total treatment systems processing up to $3800 \mathrm{~m}^{3} / \mathrm{d}(1.0 \mathrm{million} \mathrm{gpd})$ of wastewater were developed based on the performance of the pilot-plant bioreactor. These systems were compared to activated-sludge treatment systems under secondary treatment requirements and were found to consume as little as $30 \%$ of the energy required by the activated sludge systems. The economic advantages of the process result from the elimination of operating energy requirements associated with the aeration of aerobic-based processes and with the significant decrease of sludge-handling costs required with conventional activatedslüge treatment systems. Methane produced by anaerobic fermentation processes occurring during the biological decomposition of carbonaceous wastes also represented a significant and recoverable energy production. term as wastewater flow rates approaches $3800 \mathrm{~m}^{3} / \mathrm{d}$.

To support commercialization of the process, ORNL is continuing process development efforts with both laboratory studies and a $190-\mathrm{m}^{3} / \mathrm{d}$ (50,000-gpd) pilot study based on the results of the previous $19-\mathrm{m}^{3} / \mathrm{d}$ pilot system. Since many applications of the ANFLOW process could involve the treatment of wastewaters containing heavy metals, the need to define potentially toxic effects of these metals on the biological processes occurring in ANFLOW columns was identified as a required support- 
ing research study. It was anticipated that the information generated from such a study would be required for both future design exercise and for planning approaches to operation and control of such systems.

The research program which was developed for use in the above study had the following four general objectives:

1. to investigate the expression of toxicity within the ANFLOW column (i.e., under what conditions and on what biological reactions do effects occur),

2. to define the mechanisms (1.e., sorption or precipitation) by which heavy metals are removed from the liquid phase, and to consider the ultimate fate of these metals within the column,

3. to develop models of the ANFLOW system which reflect toxicity effects, and

4. to investigate regenerative mechanisms by which the ANFLOW column can resume normal operation after exposure to toxic heavy metals.

The research program was designed to emphasize the development of methods, models, and definitions of mechanisms rather than to conduct a survey of varying effects among several metals.

\section{GENERAL BACKGROUND}

\subsection{The ANFLOW Process}

\section{1,1 Studies with Synthetic Wactewaters}

Early anaerobic column investigations were conducted by Young and McCarty ${ }^{2}$ using dilute synthetic wastewater with low suspended solids. 
At $25^{\circ} \mathrm{C}$ and with a $36-\mathrm{h}$ detention time, greater than $90 \%$ of the chemical oxygen demand (COD) of the wastewater was removed with the anaerobic, upflow bioreactor. The solids accumulation rate was reported to be a function of the influent characteristics. It was suggested that the performance of the bioreactor might improve if a high-void-fraction packing was used. Additionally, it was reported that the off-gases of these bioreactors were $75 \%$ methane.

E1-Shafie and Bloodgood ${ }^{3}$ investigated anaerobic, upflow bioreactors operated in series. With synthetic feeds again being used, these researchers found that the percent removal of organics was constant regardless of the organic load applied to the system. Fisher 4 also reported satisfactory treatment of a dilute synthetic waste (60 to $80 \% \mathrm{COD}$ removal at $32^{\circ} \mathrm{C}$ ) for anaerobic, upflow bioreactor operated with detention times varying from 0.5 to $2 \mathrm{~d}$. One bioreactor in this study which received concentrated synthetic feed was reported to fail because of unspecified inhibition effects.

\subsubsection{Studies with Industrial Wastewaters}

The use of anaerobic, upflow bioreactors for industrial wastewater treatment has generally involved warm $\left(30\right.$ to $37^{\circ} \mathrm{C}$ ) waste streams with high carbon content. As a result, anaerobic biomass reaction rates have been increased as has been the quantity of methane-rich off-gas produced.

Industrial wastewaters investigated have contained both soluble and insoluble components. Soluble wastes are generated from the organic chemicals and textiles industries, for example, while food processing 
and pharmaceutical industries discharge significant quantities of raw wastewater solids. Plummer ${ }^{5}$ evaluated bench-scale anaerobic, upflow bioreactors for treatment of a food processing waste. Four bioreactors were packed with a mixture of Raschig rings and berl saddles. A $94 \%$ removal of blological oxygen demand (BOD) was achieved with this waste. Although hacterial growth rates were high, no column plugging occurred. Solids were retained in the column for periods ranging from 4 to $163 \mathrm{~d}$. Plummer suggested that hydraulic loading would be limited by biomass washout. It was reported that the effluent suspended solids separated readily by gravity settling.

Jennett and Dennis 6 operated a $15.2-\mathrm{cm}(6-\mathrm{in}$.$) diam anaerobic, up-$ flow column to treat a high-strength, low-solids pharmaceutical waste. At $35^{\circ} \mathrm{C}$ the column reduced the raw waste $\operatorname{COD}(1250$ to $16,000 \mathrm{mg} / \mathrm{L})$ by 94 to $98 \%$. The filter operated over 6 months without sludge removal while operating at a COD loading rate of 0.22 to $3.528 \mathrm{~kg} \operatorname{COD} / \mathrm{d}-\mathrm{m}^{3}$ (13.8 to 220 ib COD/1000 $3 \mathrm{ft}-\mathrm{d})$.

Results from pilot-scale anaerobic filtcrs, 1.22 and $2.44-\mathrm{m}$ bed depths packed with 3.8-cm (1.5-in.) rock, were reported by Pailthrop' for primary clarifier supernatant from a potato processing plant. The supernatant $B O D$ and suspended solids values were 1700 and $650 \mathrm{mg} / \mathrm{L}$, respectively. At $0.96 \mathrm{~kg} \mathrm{BOD} / \mathrm{d}-\mathrm{m}^{3}(601 \mathrm{~b} \mathrm{BOD} / 1000 \mathrm{cu} \mathrm{ft}-\mathrm{d})$ and $20^{\circ} \mathrm{C}$, the $2.44-\mathrm{m} \cdot(8-\mathrm{ft})$ upflow column produced $75 \%$ BoD removal. The performance of the $1.22-$ and $2.44-m$ columns were similar.

Results for the first commercial size anaerobic, upflow bioreactors were reportcd by Taylor 8 and separately hy kichter and Machle. 9 Thiee, 
$6.1-m(20-f t)$ high, 9.1-m (30-ft) diam anaerobic filters were packed with $2.5-$ to $7.5-\mathrm{cm}\left(1-\right.$ to $\left.3-1 \mathrm{n}_{\text {. }}\right)$ rock for pretreatment of wheat starchgluten plant wastewater for discharge to a city treatment facility. The raw wastewater BOD and suspended solids values were 7290 and $4000 \mathrm{mg} / \mathrm{L}$, respectively. COD removal ranged from 75 to $80 \%$ for a raw waste at $29.4^{\circ} \mathrm{C}\left(85^{\circ} \mathrm{F}\right)$. Economic comparisons between this system and an aerobic system showed that the use of anaerobic technology reduced costs by 50 to $80 \%$.

\subsubsection{Studies with Municipal Wastewaters}

Early investigation of upflow contact processes coupled with anaerobic treatment of municipal wastewaters demonstrated that such approaches could be used to provide some gasification of the wastes and some solids removal.10-12 These processes depended primarily on filtering phenomena but did provide a basis for pursuing the development of anaerobic bioreactors.

Coulter ${ }^{10}$ and Pretorius ${ }^{13}$ investigated anaerobic treatment of sewage using multistage systems that included upflow clarifiers followed by packed-bed columns. The coulter system included an unstirred contactor with a subsequent upflow rock filter, whereas Pretorius used a mixed contactor digestor with a settling chamber and sludge return stone-sand uptlow filter. Using medium-strength sewage, Pretorius obtained a $90 \%$ reduction of COD in $24 \mathrm{~h}$ at a temperature of $20^{\circ} \mathrm{C}$; 60 to $65 \%$ of incoming solids accumulated in the digester and had to be removed periodically. The major part of the gasification was found to occur in the biophysical filter. More recent work by Pretorius 14 also demonstrated 
that since the anaerobic nature of his first stage, as opposed to aerob1c processes, produced electron donors, an efficient denitrifying stage could be added to extend the treatment possible with the overall process.

Griffith and Compere 15 extended the work of Young and McCarty with detailed laboratory studies using columns with volumes of $0.057 \mathrm{~m}^{3}$ (2 $\mathrm{ft}^{3}$ ), high void-volume packing, and synthetic feeds. These studies were conducted with low-strength wastes at $20^{\circ} \mathrm{C}$. Their work was given impetus by early nitrogen starvation tests conducted on columns; these tests showed that the decay coefficients of the columns were lower than would be expected from calculations and suggested the presence of a very stable biomass in the columns. These researchers reported reductions in BOD of greater than $80 \%$ for residence times of approximately $8 \mathrm{~h}$. Griffith and Compere also performed studies with these columns in the field using dilute raw sewage with total organic carbon (TOC) concentrations of 30 to $100 \mathrm{mg} / \mathrm{L}$ at temperatures in the range 15 to $25^{\circ} \mathrm{C}$. Results of these studies showed that the columns were capable of adapting to the low-temperature, low-strength feeds while retaining their ability to significantly reduce the pollutant concentration and to generate off-gas with a methane content approaching $70 \%$. They also showed that the columns were capable of reducing the total suspended solids (TSS) content by more than $70 \%$. The implied advantages of this flow process over conventional anaerobic digestion processes, which could require 10 to $30 \mathrm{~d}$ of holdup for equivalent treatment, were very significant. 
The research projects described above demonstrated that upflow anaerobic, fixed-film bioreactors could clearly provide efficient treatment of high- or medium-strength wastewaters with off-gases having high methane contents. The residence times required were significantly lower than those required for conventional technology, and operating energy requirements were also anticipated to be greatly lowered. Sludge removal requirements would be related to the rate of solids accumulation in the bioreactor. Data indicated that such bioreactors would also efficlently treat low-strength, low-temperature wastewaters. The potential for developing a needed, near-term technology for wastewater treatment based on an anaerobic, fixed-film bioreactor led ORNL to a pilot-plant development and demonstration project for realistic evaluation of a total process.

\subsection{Overview of Anaerobic Digestion Processes}

'The anaerobic digestion of complex organis. wastes is normally considered to consist of reactions occurring in series as illustrated in Fig. 2.1. In the first stage (commonly known as waste conversion), the complex organics are changed in form by a group of facultative and anaerobic bacteria commonly termed the acid formers. Complex materials such as fats, proteins, and carbohydrates are hydrolyzed, fermented and blologically converted to simple organic materials. For the most part, the end products of this first-stage conversion are organic fatty acids (Table 2.1). Acid-forming hacteria bring about these initial conversions to obtain the small amounts of energy released for growth, and a small portion of the waste is converted to cells. Although no waste 
ORNL-DWG 81-153

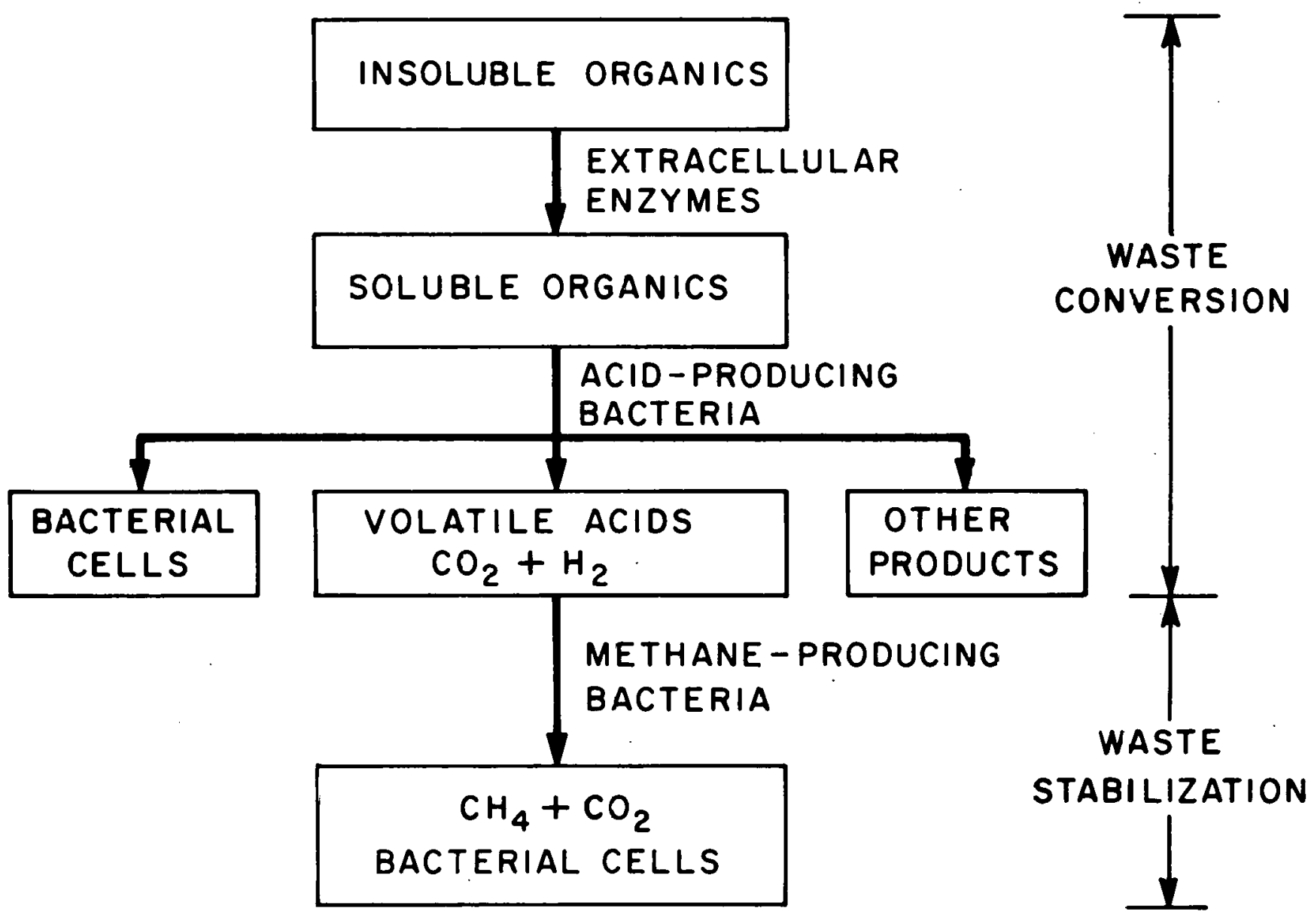

Figure 2.1. Anaerobic digestion of organic wastes. 
stabilization occurs during the first stage of treatment, this stage is required to convert the organic matter into a form suitable for the second stage of treatment.

Waste stabilization occurs in the second stage of methane fermentation. During this stage, the organic acids are converted into the gaseous end products, carbon dioxide and methane by special bacteria termed methanogens, or methane formers. These methanogens are strictly anaerobic, and even small quantities of oxygen are harmful to them.

Table 2.1. Common Volatile Acid Intermediates

\begin{tabular}{ll}
\hline \multicolumn{1}{c}{ Acid } & Chemical Formula \\
\hline Formic acid & $\mathrm{HCOOH}$ \\
Acetic acid & $\mathrm{CH}_{3} \mathrm{COOH}$ \\
Propionic acid & $\mathrm{CH}_{3} \mathrm{CH}_{2} \mathrm{COOH}$ \\
Butyric acid & $\mathrm{CH}_{3} \mathrm{CH}_{2} \mathrm{CH}_{2} \mathrm{COOH}$ \\
Valeric acid & $\mathrm{CH}_{3} \mathrm{CH}_{2} \mathrm{CH}_{2} \mathrm{CH}_{2} \mathrm{COOH}$ \\
Isovaleric acid & $\left(\mathrm{CH}_{3}\right)_{2} \mathrm{CHCH}_{2} \mathrm{COOH}$ \\
Caproic arid & $\mathrm{CH}_{3} \mathrm{CH}_{2} \mathrm{CH}_{2} \mathrm{CH}_{2} \mathrm{CH} 2 \mathrm{CUOH}$
\end{tabular}

There are several different groups of bacteria among the methane formers, and each group is characterized by its ability to ferment a relatively limited number of organic compounds. In the complete fermentation of complex materials, several different groups of methane-producing bacteria are required.

The most important methane formers use acetic and propionic acids as substrates. They grow quite slowly, require an optimum $\mathrm{pH}$ range of 6.8 
to 7.4 , and sludge retention times of four days or longer are required for their growth. 16 These bacteria carry out the major portion of waste stabilization. Their slow growth and low rate of acid utilization is normally considered to represent the rate-limiting step around which anaerobic treatment processes should be designed.

As there are different methane-forming bacteria, there are also different acid-forming hacteria. Waste stabilization requires a balanced interaction among all these organisms. The establishment and maintenance of this balance are normally controlled through monitoring of the concentration of volatile acids, a varying (i.e., dynamic) parameter. The volatile acids are the short-chain organic acids listed in Table 2.1. These acids are considered to be the most common intermed1ate compounds of importance in anaerobic treatment, and most of the methane formed from this process results from fermentation of these acids by methane bacteria.

The two major volatile acid intermediates formed in anaerobic treatment are acetic and propionic acid.17-19 Acetic acid is the most important volatile acid formed from the decomposition of cumplex organics and is the source of approximately $70 \%$ of the methane produced during anae robic treatment. 20

Most of the remaining methane produced during anaerobic treatment is formed from the reduction of carbon dioxide. Here, hydrogen, which is removed from organic compounds by enzymes, reduces carbon dioxide to methane gas. The carbon dioxide functions as a hydrogen or electron aceptor, fust ds uxygen in aerobir treatment. These two major mechanisms of methane formation can be represented as the following: 
1. Acetic acid cleavage:

$$
\mathrm{CH}_{3} \mathrm{COOH}+\mathrm{CH}_{4}+\mathrm{CO}_{2}
$$

2. Carbon dioxide reduction:

$$
\mathrm{CO}_{2}+8 \mathrm{H} \rightarrow \mathrm{CH}_{4}+2 \mathrm{H}_{2} \mathrm{O}
$$

\subsection{Overview of Toxicity Phenomena} in Anaerobic Processes

No previous data have been published on the performance of ANFLOW bioreactors in the treatment of wastewaters containing toxic concentrations of heavy metals $(\mathrm{Ni}, \mathrm{Cu}, \mathrm{Zn}, \mathrm{Cd}, \mathrm{Hg}$, and $\mathrm{Pb}$ are among the most common heavy metals of significance in municipal-industrial waste water treatment). Most previously published research on the toxic effects of heavy metals in anaerobic processes has emphasized suspended-growth processes such as anaerobic digester systems rather than fixed-film systems such as ANFLOW.

Early investigatione conducted In the 1920 s and 1930 s identified four different behaviors resulting from the effects of cations on anaerobic processes: toxicity, stimulation, synergism, and antagonism all of them concentration dependent. These will be discussed below. In general, it was found that all cations produce toxicity in any organism at some level, but the relative toxicity of the cations varied when compared on a weight-weight basis. The toxicity of heavy metals were found to depend on concentration in the soluble form rather than on the total concentration in the system. Mechanisins of heavy-metal removal under aerobic conditons have been studied. Four distinct processes were enumerated by Cheng: 21 (1) adsorption, (2) incorporation into cells, (3) 
precipitation and subsequent entrapment of the precipitate in the biofloc, and finally (4) chelation of soluble metal species by organic and inorganic ligands. These four processes can also be considered to be the major mechanisms for heavy-metal removal under anaerobic conditions. In the case of an ANFLOW bioreactor, the entrapment of precipitates can also occur in the fixed-films.

The term toxic is relative, and the concentration at which a material becomes toxic or inhibitory may vary from a fraction of a mg/L to several thousands $\mathrm{mg} / \mathrm{L}$. Figure 2.2 indicates the general effects that result from the addition of most substances to biological systems. At very low concentrations, stimulation of activity usually occurs. This stimulatory concentration may range from only a fraction of a mg/L for heavy-metal salts to more than $100 \mathrm{mg} / \mathrm{L}$ for sodium or calcium salts.22 As the concentration is increased above the stimulatory concentration, the rate of biological activity begins to decrease. A point is then reached where inhibition is apparent and the rate of blological activity is less than that achleved in the absence of the material. Finally, at some higher concentration, the biological activity approaches zero. Heavy metals are considered to be toxic because they can be present in wastes at a concentration of a few milligrams per liter, which is several orders of magnitude above their range of activity stimulation. 23 Their potential to induce toxicity in anaerobic treatment processes depends on their fate within the bioreactor.

Microorganisms usually have the ability to adapt or acclimate to some exteut to inhibitory concentrations of most materials. The extent 
14

ORNL DWG 81-152

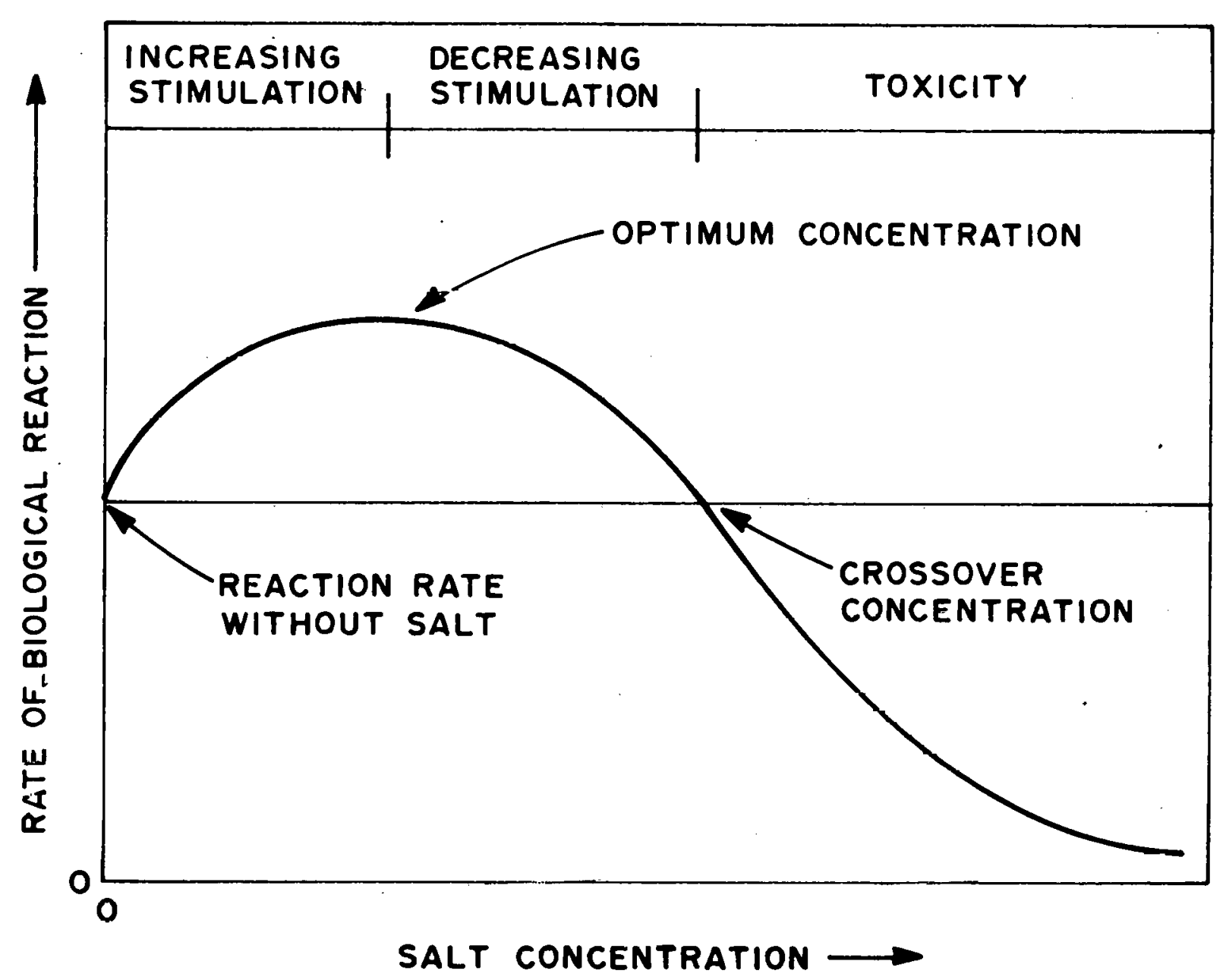

Figure 2.2. General effects of salts or other materials on biological reactions. 
of adaptation is relative, and in some cases the activity after acclimation may approach that obtained in the absence of the inhibitory material, but in other cases, the activity following acclimation may be much less than was present prior to inhibition.

Toxic concentrations reported in the literature, even for the same metal, vary widely. Explanations for these variations, under anaerobic conditions, may involve the many different factors, such as $\mathrm{pH}$, alkalinity, concentrations of inorganic and/or organic complexing agents, and the presence of other heavy metals (synergistic/antagonistic effects) which modify the toxic effects of heavy metals. A primary effect of these factors is to limit the avallability of heavy metals by precipitation, or by keeping them in solution (solubilization).

As would be expected then, the toxicity of a heavy metal in anaerobic digestion processes depends upon the various chemical forms which that metal may assume under anaerobic conditions and near-neutral pH values. For instance, heavy metals in the precipitated form are of little consequence to biological systems in terms of toxicity. Lawrence and McCarty24 fed sulfates of copper, zinc, nickel, and tron lu laboratory digesters and found little evidence of effects on digester performance in terms of reduced gas production. When metal chloride salts were substituted for the sulfates, thereby eliminating the sulfide precursor, marked reduction lil digester performance was observed. It was concluded that the toxicity of heavy metals depends on their concentration in the soluble form and not on their total concentration in the system. 
Lawrence and McCarty, 24 when investigating the role of sulfides in preventing heavy metal toxicity, also found that gas production was the inftial parameter affected by heavy-metal toxicity. The volatile-acid concentration began to rise only after the gas production was noticeably reduced. They also noted that when their digesters began to fail, the percentage of methane decreased significantly.

Hayes and Theis 25 showed that toxic effects occurred when a large buildup of metals exists in close association to the cell mass. Metals included in the study included cadmium, chromium(VI), chromium(III), copper, lead, nickel, and zinc. The digesters were fed sludge from an activated-sludge treatment plant; these aerobic sludges were incubated with solution metals before being introduced into the anaerobic environment. Treatment times in the anaerobic digesters ranged from 5 to 20 d. This study concluded that extracellular heavy metals accounted for less than $1 \%$ of the total digester metals for all studies; ooluble metals (those passing a $0,22-\mu m$ filter) were alsó insignificant, except for nickel for which 1 to $3 \%$ of the total was found in the filtrate. The major portions of the heavy metals were distributed between the precipitated and intracellular components of the digesters, with 30 to $60 \%$ of the total (depending upon the metal) found in the intracellular fraction of the digested sludge.

Metal uptake curves generated were similar to adsorption isotherms with the point of nonlinearity coinciding with the onset of toxic conditions. Toxic effects were found to coincide with the near maximum uptake of metals by bacteria. After establishment of stable baseline parameters, the digesters were dosed with the particular heavy metal in a pulse and stepwise fashion. Among the parameters used as indicators 
for digester response to heavy-metal loadings were: gas production rate, gas composition $\left(\% \mathrm{CH}_{4}\right), \mathrm{pH}$, alkalinity, volatile acids, and total organic carbon (TOC). Normally, step feeding was accomplished at heavymetal concentrations ranging from 10 to $100 \mathrm{mg} / \mathrm{L}$, whereas pulse (slug) feeding was performed at heavy-metal concentrations from a few hundreds to several thousands $\mathrm{mg} / \mathrm{L}$. The order of decreasing toxicity on a weight-weight or molar basis was $\mathrm{Ni}>\mathrm{Cu}>\mathrm{Zn}$. Control strategies for minim1zation of the impact of heavy metals in anaerobic digestion will be those which result in a reduced degree of metal association with the biomass. In this study the inhibitory level of a heavy metal was defined as that level at which a decrease in gas production first became evident. Toxic levels were taken to be the concentrations at which total gas production was reduced by $70 \%$ from baseline (see Table 2.2 ).

Table 2.2. Heavy-Metal Toxicity Limits for Anaerobic Digestiona

\begin{tabular}{|c|c|c|c|}
\hline \multirow[b]{2}{*}{$\begin{array}{l}\text { Heavy } \\
\text { Metal }\end{array}$} & \multicolumn{2}{|c|}{ Step-Fed } & \multirow{2}{*}{$\begin{array}{l}\text { Pulse-Fed } \\
\text { Toxic Limit } \\
\text { (mg/L) }\end{array}$} \\
\hline & $\begin{array}{l}\text { Tnhibiting } \\
\text { Concentration } \\
(\mathrm{mg} / \mathrm{L})\end{array}$ & $\begin{array}{l}\text { Toxic Limit } \\
(\mathrm{mg} / \mathrm{L})\end{array}$ & \\
\hline $\operatorname{Cr}($ III $)$ & 130 & 260 & $<200$ \\
\hline $\mathrm{Cr}(\mathrm{VI})$ & 110 & 420 & $<180$ \\
\hline $\mathrm{Cu}$ & 40 & 70 & $<50$ \\
\hline $\mathrm{Ni}$ & 10 & 30 & $>30$ \\
\hline $\mathrm{Cd}$ & - & $>20$ & $>10$ \\
\hline $\mathrm{Pb}$ & 340 & $>340$ & $>250$ \\
\hline $\mathrm{Zn}$ & 400 & 600 & $<1700$ \\
\hline
\end{tabular}

as presented by Hayes and Thesio in "The Distribution of Heavy Metals in Anaerobic Digestion", J. Water Pollut. Control Fed., 19iz, Pp. 6172 . 
Two major sets of processes are known to be capable of removing sufficient heavy metals from solution to prevent inhibition of anaerobic digestion. One involves the interaction of the metal with the hydrogen sulfide/sulfide system and the other its interaction with the carbon dioxide/carbonate system. 26 These two processes can be illustrated as: sulfide

$$
\begin{array}{lllllll}
\mathrm{H}_{2} \mathrm{~S} & \stackrel{\mathrm{HS}^{-}}{+} & + & \mathrm{S}^{=} & + & \mathrm{MS} & + \\
& & + & & + \\
\mathrm{H}^{+} & & \mathrm{H}^{+} & & \mathrm{M}^{++} &
\end{array}
$$

carbonate

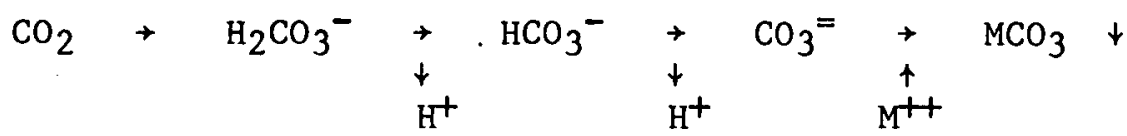

Hydrogen sulfide is an end-product of anaerobic metabolism and its precursors include the sulfate ion $\left(\mathrm{SO}_{4}=\right)$. The activity of carbonate ions present in anaerobic treatment is contrnl.1ed by the $\mathrm{pH}$ and the dissolved carbon dioxide.

Table 2.3 shows the solubility products of some metal sulfides and carbonates. 27 The relative values of the solubility products for sulfides and carbonates emphasizes hnth the higlı insolubility of the metal sulfides and the fact that sulfide is a stronger precipitant than carbonate.

3. DEVELOPMENT OF MODELS OF THE ANFLOW SYSTEM WHICH REFLECT TOXICITY EFFECTS

\subsection{General Perspective}

A description of the ANFLOW System under normal conditions can be developed using nonideal flow models and first-order kinetics for the 
Table 2.3. Solubility Products of Some Metal Salts at $18^{\circ} \mathrm{C}^{\mathrm{a}}$

\begin{tabular}{lcc}
\hline $\mathrm{Salt}$ & $\begin{array}{c}\text { Solubility } \\
\text { Product }\end{array}$ & $\begin{array}{c}\text { Solub1lity } \\
(\mathrm{mg} / \mathrm{L})\end{array}$ \\
\hline $\mathrm{Cu}_{2} \mathrm{~S}$ & $2 \times 10^{-47}$ & $3 \times 10^{-11}$ \\
$\mathrm{CuS}$ & $8.5 \times 10^{-45}$ & $9 \times 10^{-18}$ \\
$\mathrm{PbS}$ & $3.4 \times 10^{-28}$ & $4 \times 10^{-9}$ \\
$\mathrm{CoS}$ & $3.0 \times 10^{-26}$ & $2 \times 10^{-8}$ \\
$\mathrm{NiS}$ & $1.4 \times 10^{-24}$ & $1 \times 10^{-7}$ \\
$\mathrm{ZnS}$ & $1.2 \times 10^{-23}$ & $3 \times 10^{-7}$ \\
$\mathrm{FeS}$ & $3.7 \times 10^{-19}$ & $5 \times 10^{-5}$ \\
$\mathrm{CdCO}_{3}$ & $5 \times 10^{-12}$ & 0.4 \\
$\mathrm{ZnCO}_{3}$ & $6 \times 10^{-11}$ & 1.0 \\
$\mathrm{FeCO}_{3}$ & $3 \times 10^{-11}$ & 0.6 \\
$\mathrm{PbCO}_{3}$ & $1.5 \times 10^{-13}$ & 0.1 \\
\hline
\end{tabular}

${ }^{a}$ Handbook of Chemistry and Physics, 61st edition, 1980-1981, CRC Press Inc.

${ }^{b}$ Calculated from the solubility product. 
removal of soluble COD. A more accurate description should reflect the growth phenomena in the system by incorporating a model such as that of Monod.16,27,28 This model is well known and has been discussed in relation to anaerobic systems by Kugelman 29 and others. However, the use of this model would require the evaluation of yield constants (grams biomass produced per gram substrate removed), specific growth rates, specific decay rates, and reaction rate constants. Techniques for evaluating these terms in mixed-culture, mixed-substrate, fixed-film systems such as ANFLOW have not been developed and were beyond the scope of this work. The kinetic parameters, for instance, always depend on environmental conditions, the kind of waste being treated, and the concentration of the waste, among other things.

It was therefore necessary to use an alternative approach to develop a model of the ANFLOW system, particularly one which could be used to follow inhibition and toxicity effects, A plug-flow avdel with superimposed axial-dispersion and firgt-urder kinetics served to describe soluble COD removal. By a novel approach, variations in characteristic first-order rate constants were used to monitor the local and global toxicity phenomena resulting from the introduction of a heavy-metal toxicant into the system. The development of this model is described below.

\subsection{Kinetic Model for Removal of Soluble COD}

\subsubsection{Lumped-Parameter Model for Global Analysis}

The performance of a bloreactor depends not only on the relevant intrinsic kinetics of the reaction processes, but also on the physical 
processes occurring on the reactor. The physical processes, such as mass transfer occurring within a multiphase system such as ANFLOW (1iquid, gas, and solid or biological phases) depend very significantly upon the mixing characteristics in the phases involved.

The two extremes of mixing in a flow reactor are plug flow and complete mixing. In the first case, there is no axlal mixing, and all elements of fluid within the reactor have identical velocities and residence times. For example, the flow in a packed-bed reactor with very large ratio of reactor length to tube (and packing) diameter can be approximated by a plug-flow model. The contrasting model for complete mixing would be applied for instance to very vigorously stirred batch reactors.

The nature of mixing in the majority of actual reactors falls intermediate to these two extremes. The deviations may be caused by factors such as nonuniform velocity profiles, by velocity fluctuations due to molecular or turbulent diffusion, by short-circuiting, bypassing, and channeling of fluid, by the presence of stagnant regions of fluid caused by the reactor shape and intervals, or by the recycllus of fluid within the reactor as a result of agitation. Furthermore in an ANFLOW bioreactor, mixing is caused by the rising gas bubbles $\left(\mathrm{CH}_{4}+\mathrm{CO}_{2}\right)$ produced from the anaerobic stabilizatinn of the organic waste.

The mixing characteristics of a reactor can be qualititively evaluated by fitting appropriate models to the residence-time distribution (RTD) data. Many types of models can be used to characterize nonideal flow patterns within vessels. The simplest mudels (c.g., axial disperoion motel, or simple dispersion model, or the tanks-in-series model) 
contain only a single parameter correlating the RTD data. More complex models use two, three, or even four parameters to correlate RTD data.

The axial dispersion model, used in this work, characterizes the backmixing by a single one-dimensional Fick's-law-type diffusion equation. The constant of proportionality in this equation is commonly known as the axial dispersion coefficient. The assumption that all the mixing processes follow a Fick's-law-type diffusion equation, regardless of the actual mechanism, becomes, of courec; incieasingly inapplicable with large degrees of mixing. However, since the model characterizes the degree of mixing (or residence time distribution data) by a single parameter, its simplicity has made it one of the most widely-used mode1s.

Using the axial dispersion model, the continuity equation governing the behavior of an ANFLOW bioreactor can he derived by cunsidering a realiur of length $\underline{\mathrm{L}}$, through which a fluid is flowing at a constant and uniform velocity $\underline{\mathrm{u}}$. The reactants are mixed in the axial direction (direction of flow) as a result of a concentration gradient and diffusion and eddy dispersion. The reactants are assumed perfectly mixed in the radial direction, and the rate of reaction is $\underline{r(C)}$. An elemental volume normal to the direction of flow is illustrated in Fig. 3.1.

The basic material balance for a reactant with concentration $\underline{c}$ in the elemental volume $\underline{V}$ shown in Fig. 3.1 is given by:

$$
\text { Input }=\text { Output }+ \text { Disappearance }+ \text { Accumulation by Reaction }
$$


ORNL-DWG 81-155

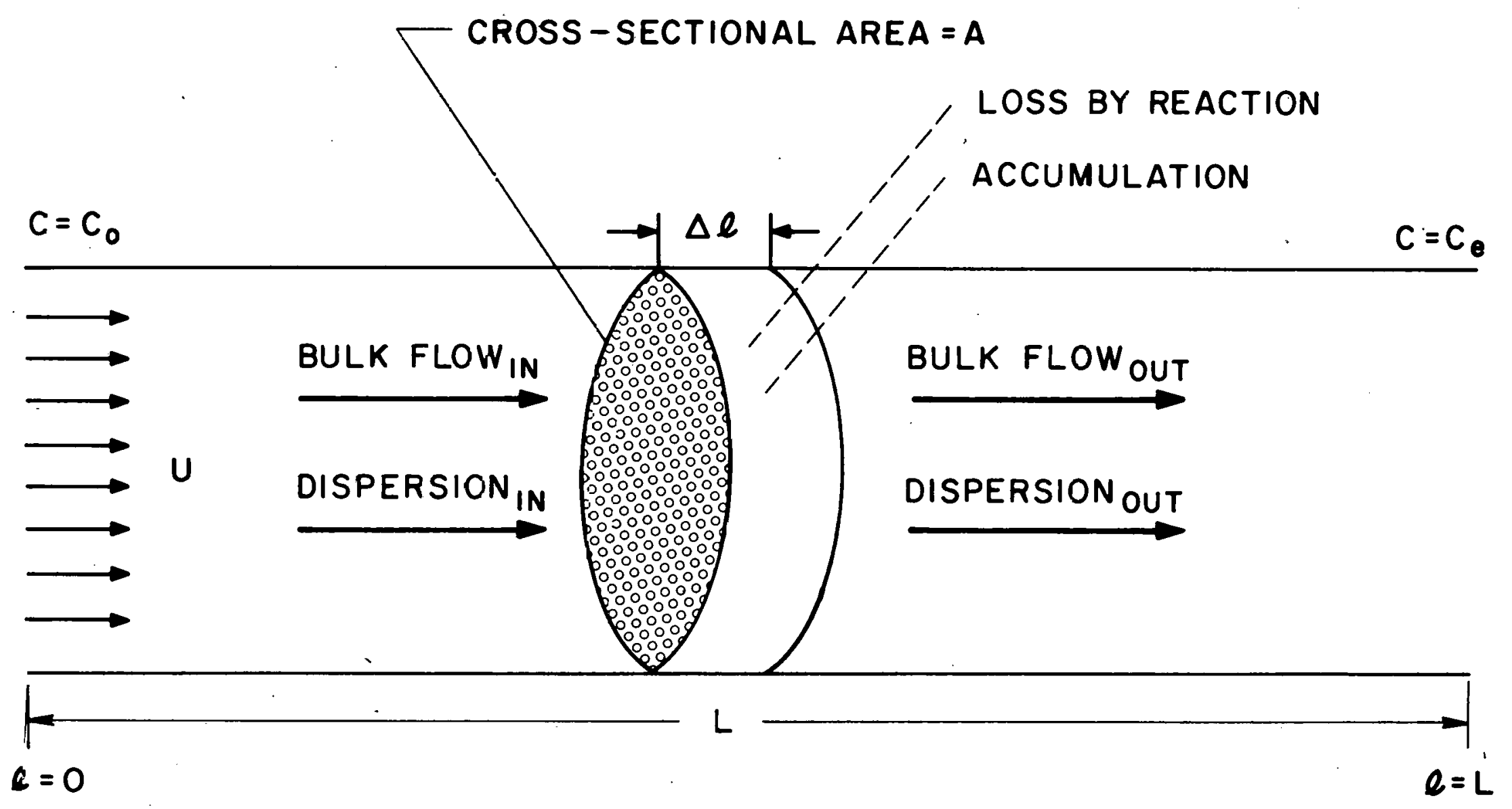

Figure 3.1. Elemental volume in an ANFLOW bioreactor. 
or

(Out-In $)_{\text {bulk flow }}+(\text { Out-In })_{\text {axial dispersion }}+$

Disappearance by Reaction + Accumulation $=0$

The individual terms in equation (3-2) in mol/time or $\mathrm{mg} / \mathrm{time}$ are as follows,

1. Entering by bulk flow

$$
\begin{aligned}
& =(\text { mass } / \text { volume }) \times \text { (volumetric flow rate) } \\
& =(\text { mass } / \text { volume }) \times(\text { flow velocity) } \times(\text { cross-sectional area } A) \\
& =C_{\text {In }} \mathrm{uA}
\end{aligned}
$$

2. Similarly, leaving by bulk flow

$$
=C_{\text {Out }} \mathrm{uA}
$$

3. Entering by axial dispersion, from the dispersion model

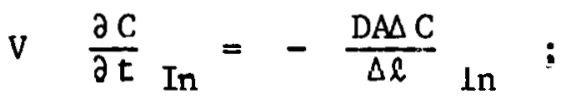

where $D$ is the dispersion coefficient.

4. Slmilarly, leaving by axial dispersion

$$
\text { V } \quad \frac{\partial C}{\partial t} \underset{\text { Out }}{=}-\frac{D A \Delta C}{\Delta l} \text { Out }
$$

5. Dissappearance by reaction

$$
=V[-r(C)]=A \Delta \ell[-r(C)]
$$

6. Accumulation

$$
=V \frac{\partial C}{\partial t}=A \Delta l \frac{\partial C}{\partial t}
$$

After substituting the individual termo, equalion (3-2) becomes

$$
u\left[C_{\text {Out }}-C_{\text {In }}\right] A-D\left[\left(\frac{\Delta C}{\Delta l}\right) \text { Out }-\left(\frac{\Delta C}{\Delta l}\right) \text { In }\right] A+A \Delta l[-r(C)]+A \Delta l \frac{\Delta C}{\partial t}=0
$$


dividing by $A \Delta \ell$ and taking limits as $\Delta l \rightarrow 0$ equation (3-9) becomes

$$
u \frac{\partial C}{\partial l}-D \frac{\partial^{2} C}{\partial l^{2}}+[-r(C)]+\frac{\partial C}{\partial t}=0
$$

In dimensionless form, by letting

$$
Z=\ell / L
$$

Equation $(3-10)$ becomes

$$
(D / u L) \frac{\partial^{2} C}{\partial Z^{2}}-\frac{\partial C}{\partial z}+(L / u) r(C)-\frac{\partial C}{\partial t}=0
$$

The dispersion characteristics of the bioreactor can be obtained, as generally recommended, by injecting a conservative tracer at $Z=0$ and monitoring its temporal concentration at $Z=1$. If $C$ is the concentration of a conservative tracer, the effluent response curve to a pulse Input may be obtained from the solution to equation $(3-11)$, where $r(C)=$ 0 , and the axial dispersion coefficient and the average fluid velocity are assumed to be constant over the length of the reactor. This solution has been given by Thomas and $\mathrm{McKee}^{31}$ and is of the form:

$E(\theta)=\frac{C}{C_{T}}=2 \sum_{i=1}^{\infty} \mu_{i}\left[\frac{\alpha \sin \mu_{i}+\mu_{i} \cos \mu_{1}}{\alpha^{2}+2 \alpha+\mu_{1}^{2}}\right] \exp \left[\alpha-\frac{\left(\alpha^{2}+\mu_{1}^{2}\right) \theta}{2 \alpha}\right]$,

where: $C=$ Concentration of tracer in effluent, $\mathrm{mg} / \mathrm{L}$

$\mathrm{C}_{\mathrm{T}}=$ mass of tracer injected divided by the bioreactor volume, $\mathrm{mg} / \mathrm{L}$

$\mu_{i}=a$ root to the equation

$\mu_{1}=\cot ^{-1}\left[\left(\mu_{1} / \alpha-\alpha / \mu_{1}\right) / 2\right]$

or

$$
\begin{aligned}
& \mu_{1}^{2}-2 \mu_{1} \alpha \frac{\cos \mu_{i}}{\sin \mu_{i}}-\alpha^{2}=0 \\
& \theta=t / t \text {, redured time } \\
& \alpha=0.5[1 /(\mathrm{D} / \mathrm{uL})] \\
& \mathrm{E}(\theta)=\text { exit age distribution so that } \int_{0}^{\infty} \mathrm{E}(\theta) \mathrm{d} \theta=1
\end{aligned}
$$


Figure 3.2 illustrates the solution of equation (3-12). The dimensionless group (D/uL), characterizes the vessel response to a tracer and is called the reactor dispersion number. It varies from zero for ideal plug flow to infinity for ideal mixed reactors and is the reciprocal of the Peclet number for mass transfer. To characterize the flow between the extremes represented by these two ideals, a curve is selected from the family of theoretical curves that most closely fits an experimental observation. The fit of experimental data is based on equating the variances of the two curves about the center of gravity of the distribution. This center of gravity is also defined as the mean residence time for the bioreactor and is calculated as:

$$
\bar{t}=\frac{\int_{0}^{\infty} t C d t}{\int_{0}^{\infty} C d t} .
$$

The variance about the centroid is

$$
\pi_{t}{ }^{2}=\frac{\int_{0}^{\infty}(t-\bar{t}) C d t}{\int_{0}^{\infty} C d t} .
$$

The relationship between the dispersion number $(\mathrm{D} / \mathrm{uL})$ and the variance of the theoretical curve has been obtaincd by Van der Laan. 32 These. relationships are difficult to obtain and depend on the vessel inlet and outlet conditions. For a closed vessel,

$$
\sigma_{t}^{2} / \bar{t}^{2}=2\left[(D / u L)-(n / u L)^{2}(1-\exp (-1 /(D / u L)))\right] \text {. }
$$

Thus by measuring the response to a conservative pulse tracer, $\bar{t}$ and $\sigma_{t}{ }^{2}$ can be used to calculate a $(\mathrm{D} / \mathrm{uL})$ group which matches the variance between the dispersion model theoretical curve and the observed data. Although the above method can give a simple evaluation of the reactor dispersion number, the tailing in the residence time distribution curve 
ORNL DWG 81-150

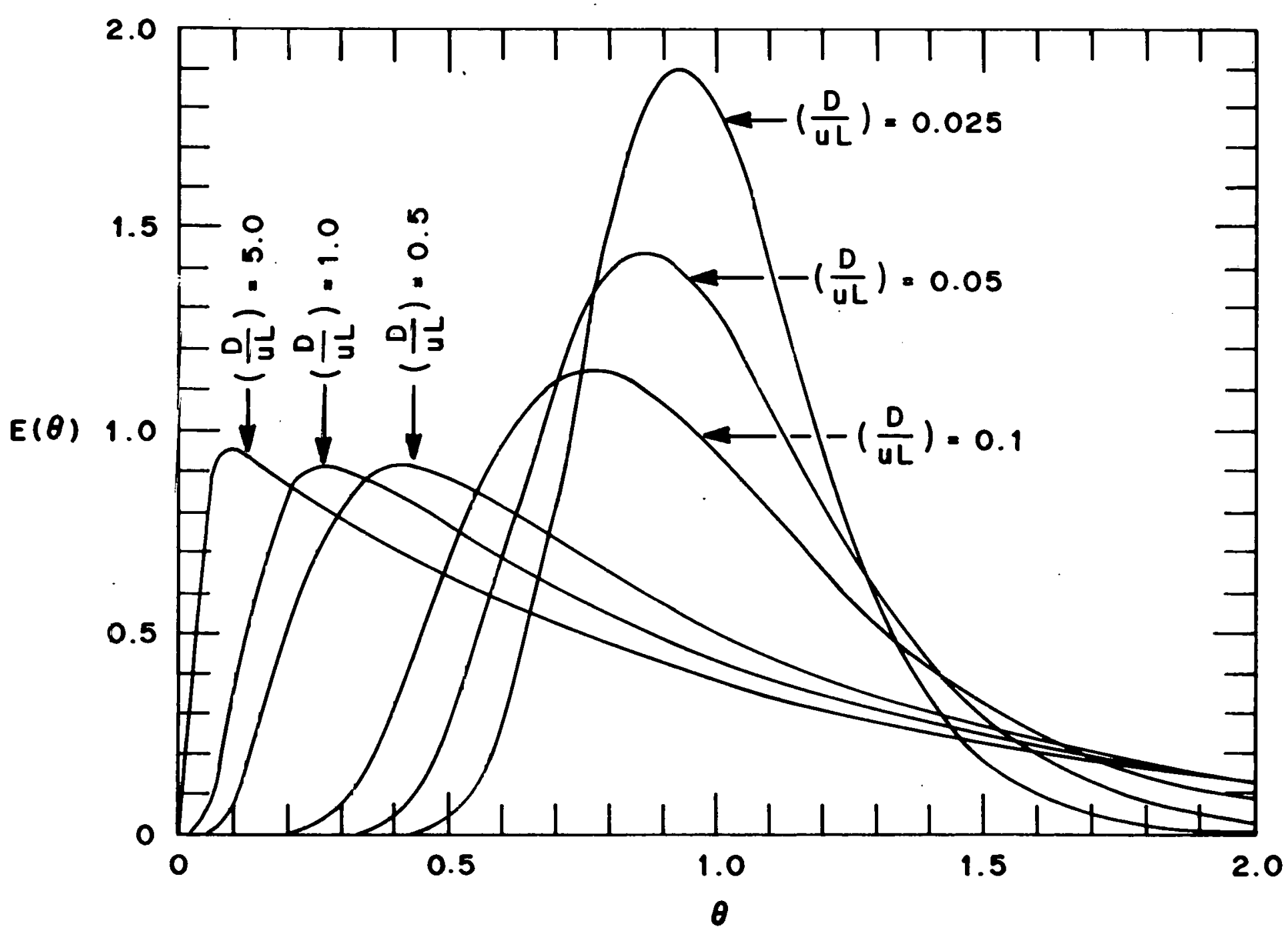

Figure 3.2. Solutions to equation (3-12) for different reactor dispersion numbers. 
can cause significant inaccuracy in the evaluation of the reactor dispersion number.

The time of peak exit concentration approach is another way of determining the reactor dispersion number. This method suggested by the work of Levenspiel and $\operatorname{Smith}^{33}$ and developed by Timpany ${ }^{34}$ relates the reactor dispersion number $(D / u L)$ with the time of peak exit concentration $\left(\theta_{p}=t_{p} / t\right)$. The time of peak exit concentration can be obtained from equation (3-12) by setting the differential of $E(\theta)$ equal to zero and solving for the $\theta p=t_{p} / \bar{t}$ value associated with each $(D / u L)$. Timpany developed a set of empirical relationships that approximate this solution and they are in the form:

$$
(D / u L)=0.2(\theta p)^{-1.34} \text {, }
$$

where

$$
\begin{aligned}
& 0.03<\theta p<0.3 \text {, and } \\
& (D / u L)=4.027(10)^{-2.09}(\Theta p),
\end{aligned}
$$

where

$$
0.3<0 p<0.8
$$

After the mixing characteristics of an ANkLOW bioreactor have been fitted to the dispersion model and a dispersion number obtained, it is possible to calculate the steady-state response of this same bioreactor to an input of a soluble organic waste. The steary-statc equalion is obtained from equation (3-11) where

$$
\begin{aligned}
r(C) & =K C^{n}, \\
\frac{\partial C}{\partial t} & =0, \\
f & =C_{e} / C_{O},
\end{aligned}
$$




$$
\begin{aligned}
& C=\text { soluble Chemical Oxygen Demand (COD), } \\
& f=\text { remaining soluble COD fraction, } \\
& C_{o}=\text { influent soluble COD, } \\
& C_{e}=\text { effluent soluble COD. } \\
& (D / u L) \frac{d^{2} f}{d z^{2}}-\frac{d f}{d z} \times(L / u) C_{o} n-1 f^{n}=0
\end{aligned}
$$

assuming first-order rate kinetics $(n=1)$, equation $(3-26)$ becomes

$$
(D / u L) \frac{d^{2} f}{d Z^{2}}-\frac{d f}{d z}-K(L / u) f=0 .
$$

Equation (3-27) has been solved analytically by Wehner and Wilhelm ${ }^{35}$ for a reactor with arbitrary entrance and exit conditions. The resulting expression, evaluated at $\mathrm{Z}=1$, is as follows:

$$
f=\left(C_{e} / C_{o}\right)=\frac{4 a \exp (1 / 2 d)}{(1+a)^{2} \exp } \frac{(a / 2 d)-(1-a)^{2} \exp (-a / 2 d)}{(1,}
$$

where: $a=(1+4 \bar{k} \bar{d})^{1 / 2}$

$$
\begin{aligned}
& \bar{t}=L / u \\
& d=(D / u L) .
\end{aligned}
$$

Equation (3-28) relates the soluble COD fraction $f$ to functions of mixing levels, hydraulic residence times and first-order reaction rate constants. Figure 3.3 shows the relationship between $(f)$ and $(\overline{K t})$ for different reactor dispersion numbers (d).

Equation (3-28) reduces to the ideal plug flow and mixed reactors when $d=0$ and $d=\infty$,

$$
\begin{aligned}
& f=e^{-\overline{K \bar{t}}} \text { for } d=0, \\
& f=\frac{1}{1+k \bar{t}} \text { for } d=\infty .
\end{aligned}
$$


ORNL DWG $80-1754$

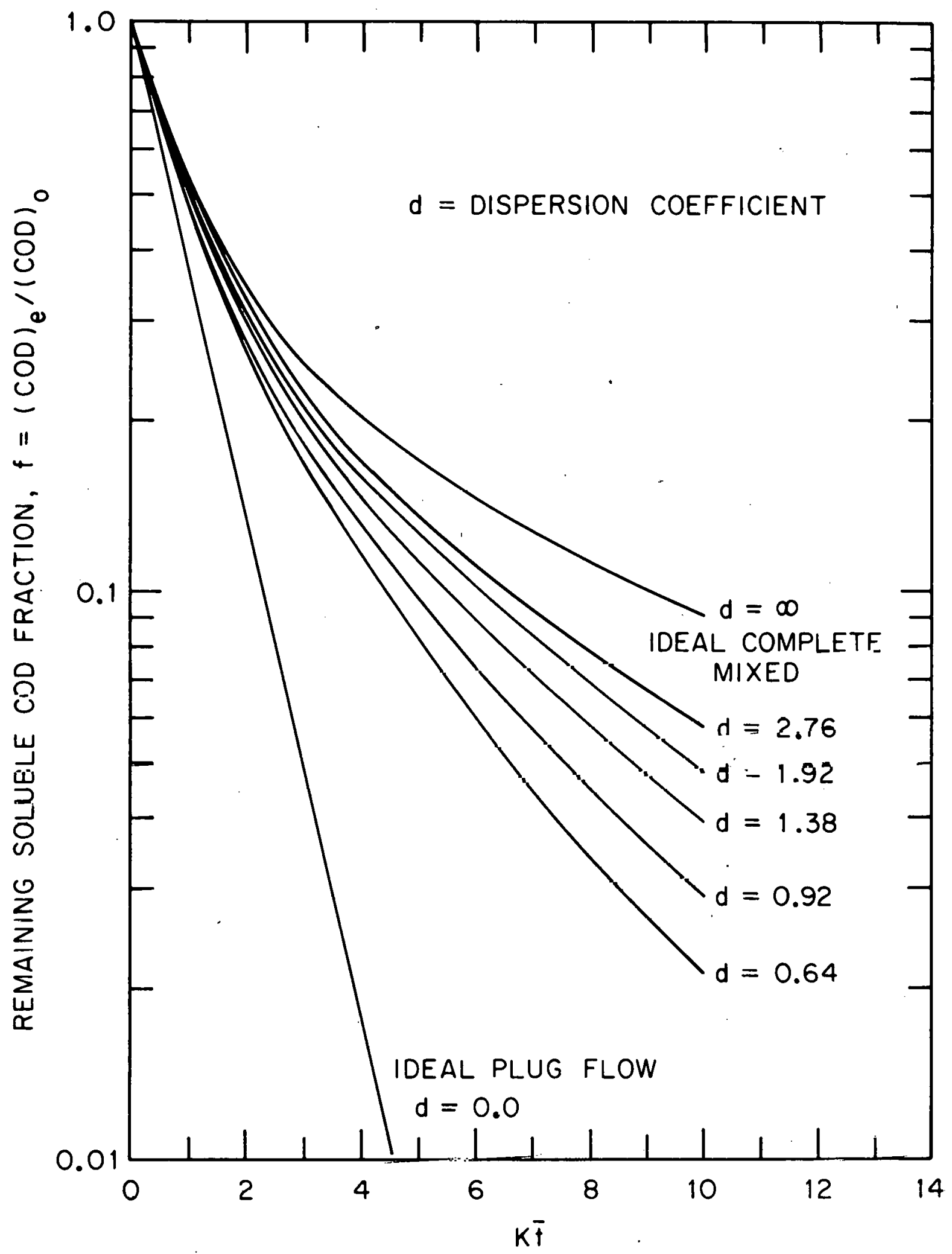

Figure 3.3. Remaining soluble chemical oxygen demand fraction as function of $\mathrm{Kt}$ for different dispersion numbers as predicted by equation (3-28). 
Equation (3-28) describes the soluble COD removal in an ANFLOW bioreactor with three parameters (i.e., a hydraulic residence time $(\bar{t})$, a characteristic dispersion number (d) and a characteristic first-order rate constant $(K))$. The first-order rate constant can be seen as an Indicator of blological activity (in the ANFLOW bioreactor, mainly by the methane formers). Thus $\mathrm{K}$ could be used to characterize the biochemical phenomena and $\bar{t}$ and $d$ to characterize the physical phenomena.

The set of variables that can modify the performance of an ANFLOW bioreactor can be grouped in two major categories: The ones that affect $K$ and the ones that affect $\bar{t}$ or $d$ (see Table 3.1).

Table 3.1. Factors That Could Modify the Characteristic Parameters of an ANFLOW Bioreactor

\begin{tabular}{ll}
\hline Parameter & Modifying Factor \\
\hline $\mathrm{K}$ & Organic loading rate \\
& Temperature \\
& Avallability of nutrients \\
& Inhibitory substances \\
& pH/Alkalinity \\
& Kind of waste \\
& Hydraulic loading rate \\
\hline
\end{tabular}

Equation (3-28) was used to study the toxicity phenomena on laboratory-scale ANFLOW bioreactors by determining the variations of $\mathrm{K}$ with time, where $\bar{t}$ and $d$ were assumed to be constants during a toxicity experiment. This black-box approach, or lumped-parameter model, describes the effects of heavy metals or any other inhibicory ayent on the 
overal1 performance of an ANFLOW bioreactor for soluble COD removal (see Figure 3.4).

\subsubsection{Regional Model for Local Analyses}

A second approach, which in this report will be called the regional model, divides an ANFLOW bioreactor into regions of different biological activity. Each region is characterized by a first-order rate constant whose magnitude is proportional to the biological activity of that region. The biological activity is measured by the soluble COD removal of the region.

This regional approach is simply the use of equation (3-28) to describe the performance of different regions of an ANFLOW bioreactor (see Figure 3.4). Mathematically it is expressed as follows:

$$
f\left(k_{0}, \bar{t}_{0}, d_{0}\right)=\prod_{i=1}^{N} f_{i}\left(k_{i}, \bar{t}_{i}, d_{i}\right)
$$

Where the subscrint $n$ referc to the uverall system, and

$$
\begin{aligned}
& i=1,2,3 \ldots N \text {, number of regions } \\
& L_{0}=\sum_{i=1}^{N} L_{i} \\
& \bar{t}_{0}=\sum_{i=1}^{N} \bar{t}_{i} \\
& \quad(\text { diameter })_{0}=(\text { diameter) } i \text { for a cylindrical vessel }
\end{aligned}
$$

Based on experimental observations from this study, an ANFLOW bioreactor was divided into three regions $(N=3)$. For this particular case, equation (3-31) becomes

$$
f\left(K_{0}, \bar{t}_{0}, d_{0}\right)=\prod_{i=1}^{3} f_{i}\left(K_{i}, \bar{t}_{i}, d_{i}\right)
$$


ORNL-DWG $81-154$
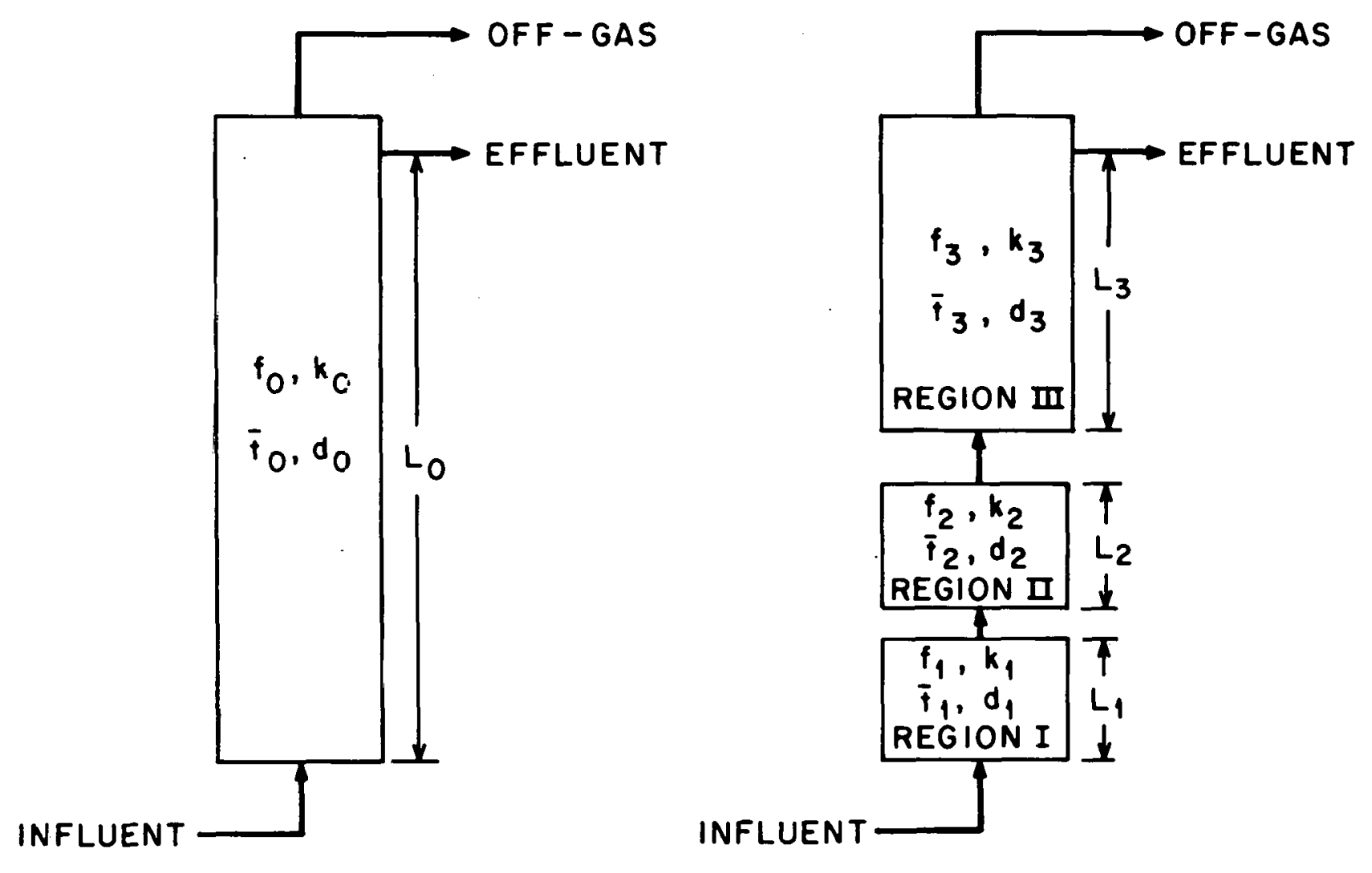

\section{(a)}

(b)

Figure 3.4. Kinetic models used to study the phenonena of toxicity on laboratory-scale ANFLOW bioreactors: (a) global model, (b) regional or local model. 
It is important to mention that $\mathrm{N}$ in equation (3-31) is arbitrary and depends on the particular application of the ANFLOW system and is best determined for each application from actual data.

The use of the regional model to study the phenomena of toxicity in ANFLOW bioreactors involves determining $K_{0}, K_{1}, K_{2}, K_{3}$ during a toxicity experiment, assuming the average residence times and the dispersion numbers remain constant. However, the use of the regional model requires that $\bar{t}_{1}, \bar{t}_{2}, \bar{t}_{3}, d_{1}, d_{2}, d_{3}$ be known. Because of a lack of experimental data for these parameters and since the axial-dispersion coefficient and the average fluid velocity were assumed to be constants, the following equations:

$$
\begin{aligned}
& \mathrm{d}_{\mathrm{i}}=\left(\mathrm{L}_{\mathrm{o}} / \mathrm{L}_{\mathrm{i}}\right) \mathrm{d}_{0} \\
& \overline{\mathrm{t}}_{1}=\left(\mathrm{L}_{\mathrm{i}} / \mathrm{L}_{0}\right) \overline{\mathrm{t}}_{0},
\end{aligned}
$$

which result from mathematical simplifications, were used to estimate the dispersion number and the average residence time for each region.

\section{RESEARCH OBJECTIVES AND SCOPE}

The successful stabilization of organic wastes by anaerobic treatment processes has been shown to depend on maintaining an environment favorable to the organisms involved. Toxicity-producing materials such as heavy metals are known to cause retardation or complete cessation of the internal processes on which the performance of these waste treatment systems depends. It is generally accepted that basic knowledge on the phenomena of toxicity from heavy metals or any other toxicant is very important and should be considered in the development, operation, and 
control of any biological waste treatment process. This is particularly important in anaerobic waste treatment processes since the key group of bacteria, the methane formers, are very sensitive to heavy metals and other environmental stresses.

The fixed-film, packed-bed ANFLOW bioreactor is being developed for application in the treatment of municipal and/or industrial. organicwastes. In the development of this process, research needs were identified for the gathering of fundamental information on the mechanistics of toxicity from heavy metals. This basic information is considered to be of particular significance when the ANFLOW process is used for the treatment of organic wastes from industrial sources.

It was the main objective of this research project to investigate the phenomena of toxicity in laboratory-scale ANFLOW bioreactors. Specific goals to be accomplished during the project can be summarized as follows: (1) to study the phenomena of toxicity in laboratory-scale ANFLOW bioreactors by monitoring their performance in the treatment of a synthetic waste to which a heavy metal was added in both pulse and step fashions, (2) to develop a model with a lump parameter that could describe bioreactor performance in terms of soluble substrate removal and also reflect the inhibitory effects of heavy metals, (3) to study the incorporation of heavy metals into biomasses in ANFLOW bioreactors, (4) to investigate the removal of heavy metal in a fixed-film packed-bed bioreactor under anaerobic conditions, (5) to identify the operational parameters that would indicate the onset of unbalanced conditions associated with inhibition or toxicity and the need for early control 
action, and (6) to identify the existance of any regenerative mechanism as a reponse from toxicity.

In order to achieve these research objectives, an experimental program was developed. One of the first steps in the experimental program was the selection of the heavy metal țo be studied. Common heavy metals produced by industrial sources, such as the metal plating industry among others, include nickel, copper, and zinc. ${ }^{36-40}$ These metals have received much general attention with respect to their toxic effects on biological treatment processes.21,24,41-44 Zinc was the heavy metal chosen because it was considered to be suitable if there was a need for using radioactive tracers during the experimental work. Zinc has a radioisotope, $\mathrm{Zn}-65$, with physical characteristics suitable for tracer studies. Among the desired characteristics are the ease of detection and a relatively long half-life. Zinc-65 emits a gamma-ray of $1.115 \mathrm{MeV}$ and has a half-life of 245 days. 45

The experimental approach used in this research study was the induction of inhibition or toxicity using zinc as the toxicant. To induce toxicity efficiently, zinc was introduced as zinc chloride thereby eliminating the sulphate ion precursor of hydrogen sulfide. In a chloride form this heavy metal has a higher potential of inducing toxicity. Zinc was introduced in both pulse (slug) and step (continuous) fashions. A pulse or slug involved high heavy-metal concentrations for a time period of about one hydraulic residence time. A step, or continuous change, involved the gradual increase in heavy-metal concentration - each concentration maintained for much longer time (several residence times). 
Since there is no single parameter which will always indicate the onset of unbalanced conditions, several parameters must be monitored for evaluating bioreactor performance. The variables used to evaluate reactor performance were:

1) Bioreactor Effluent:
a) Soluble COD
b) $\mathrm{pH} /$ Alkalinity
c) Soluble zinc

2) Bioreactor Off-Gas:
a) Gas production rate
b) Gas composition

3) Bioreactor Profiles:
a) Acetic and propionic acids
b) Soluble COD
c) Soluble zinc (step only)
d) Sorption factors (step only)

The dispersion model with first-order kinetics was used to characterize the global and regional or local performance characteristics of ANFLOW bloreactors in terms of soluble COD removal. The first-order "rate constant defined by this model was used to study the k1netic aspects of the global and regional toxicity phenomena from heavy metals on this system. 
CHAPTER 5. DESCRIPTION OF EXPERIMENTAL PROGRAM

\subsection{Experimental System}

\subsubsection{Laboratory-Scale Anflow Bioreactors}

The bioreactors, designed and built by ORNL to perform basic supportive research for pilot-scale processes, consisted of plexiglas cylinders $1.98 \mathrm{~m}$ long and $0.19 \mathrm{~m}$ in diameter $(6.5 \mathrm{ft}$ long and $8 \mathrm{in}$. in diameter) as shown in Figures 5.1 and 5.2. The packed-bed, $1.83 \mathrm{~m}$ long (6 $f t)$, consisted of $2.54-\mathrm{cm}$ (1-in.) Raschig rings randomly dispersed within the column. The influent is introduced at the bottom of the column and is evenly distributed across the bottom cross-sectional area by means of a diffuser plate. The effluent, taken at the upper end of the packed bed, is discharged to the drain system.

- Eleven sample ports are located along the bioreactor at $15.24-\mathrm{cm}$ (6-in.) intervals. The effluent was taken as sample port number 12 . Samples were taken from different sections of the bioreactor to determine regional differences in substrate removal rates, heavy-metal removal, volatile acid production and utilization, and sorption factors.

Three bloreactors were involved in the experimental phase of this project. The same control bioreactor was used for all toxicity experiments. The other two, identified as $\mathrm{T}-1$ and $\mathrm{T}-2$, were subject to induced toxicity in both pulse and step fashions respectively.

\subsubsection{Experimental Setup}

The basic components of the experimental setup used during this research project (see Figure 5.3) included a feed supply system, feed 

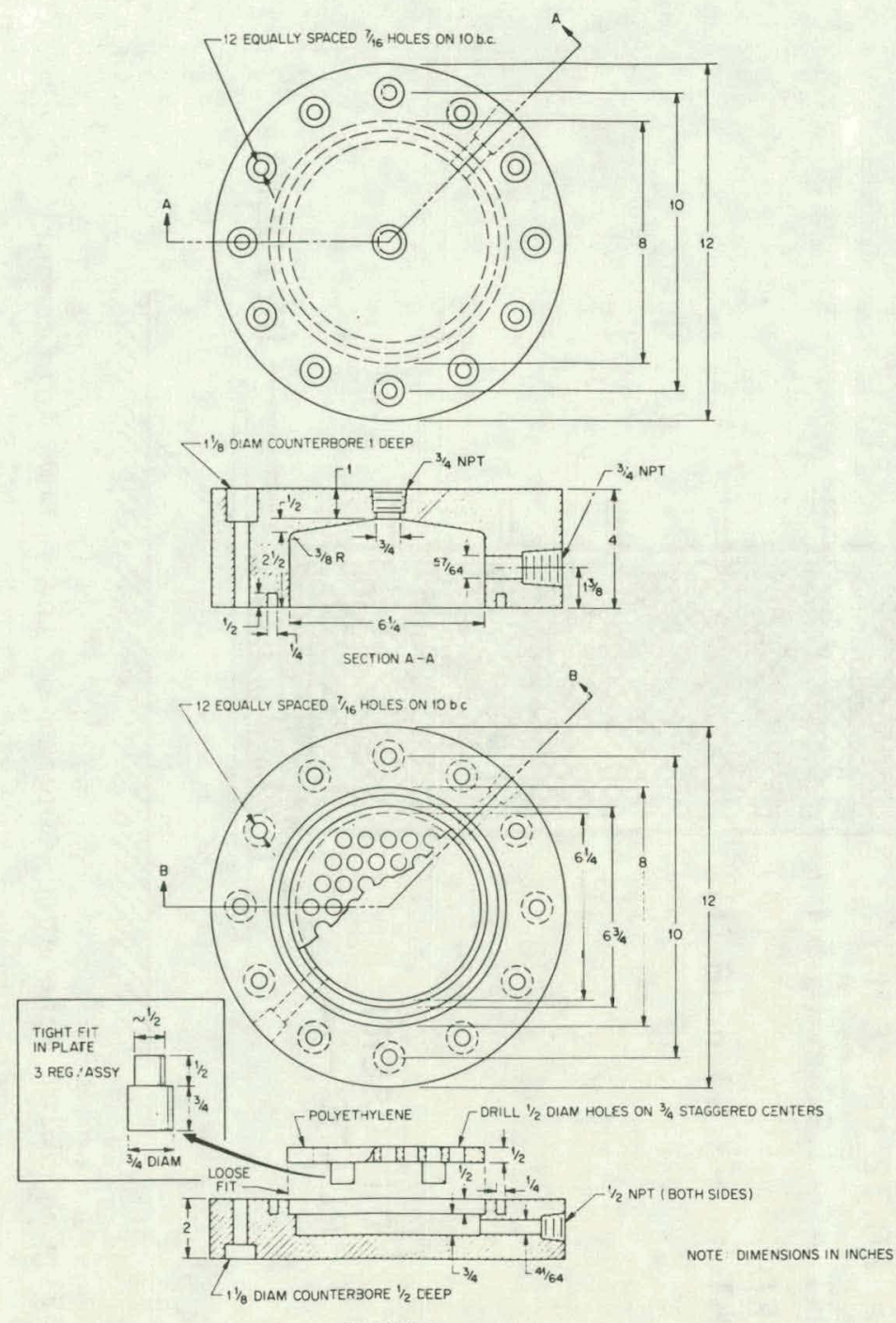

SECTION B-B
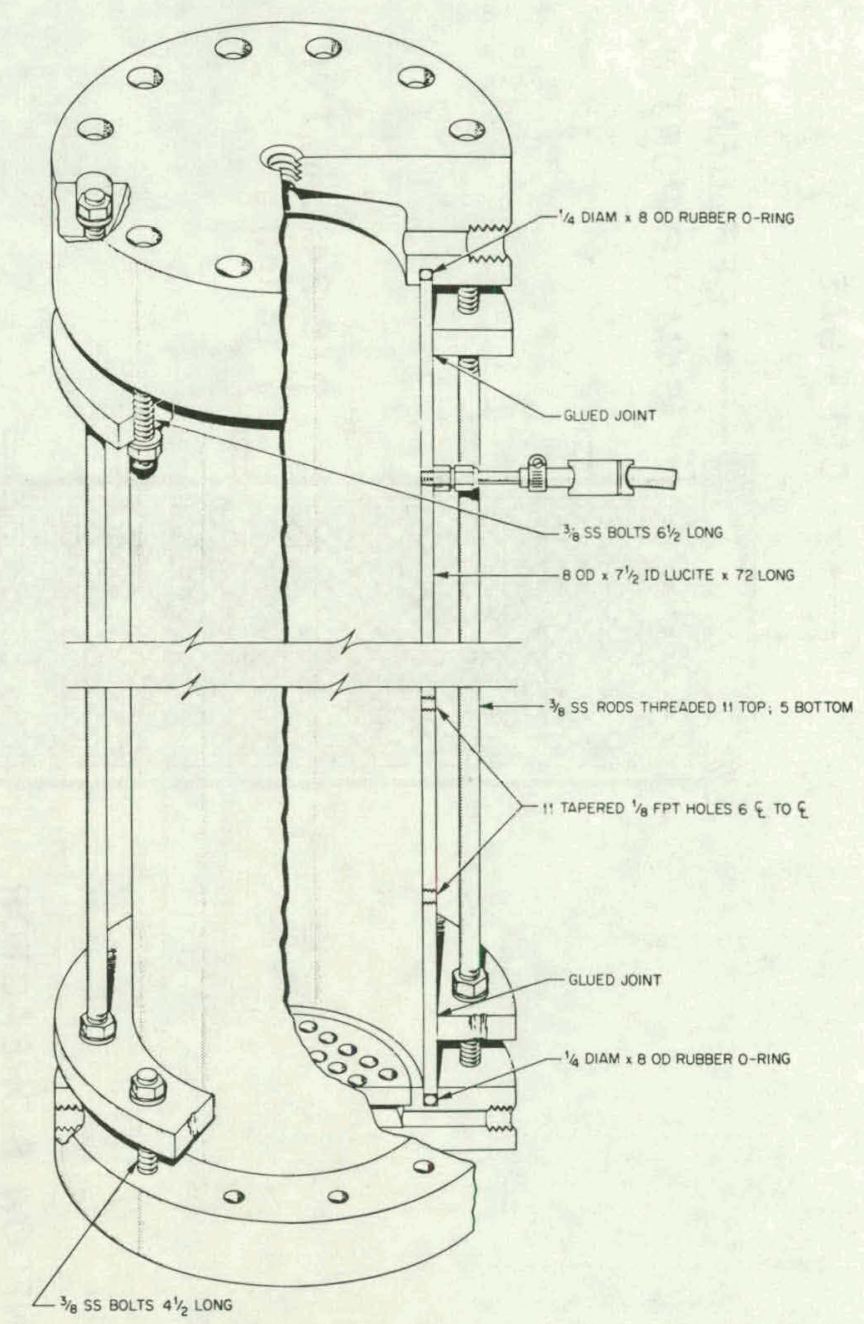

Figure 5.1. ANFLOW bioreactor designed and built by Oak Ridge National Laboratory to perform basic supportive research for pilotscale processes. 
ORNL DWG 80-1766

\section{ANFLOW BIOREACTOR}

O. D. $=20.32 \mathrm{~cm}$ (8 in.)

HEIGHT $=\sim 1.98 \mathrm{~m}(6.5 \mathrm{ft})$

PACKED

HEIGHT $=\sim 1.83 \mathrm{~m}(6 \mathrm{ft})$
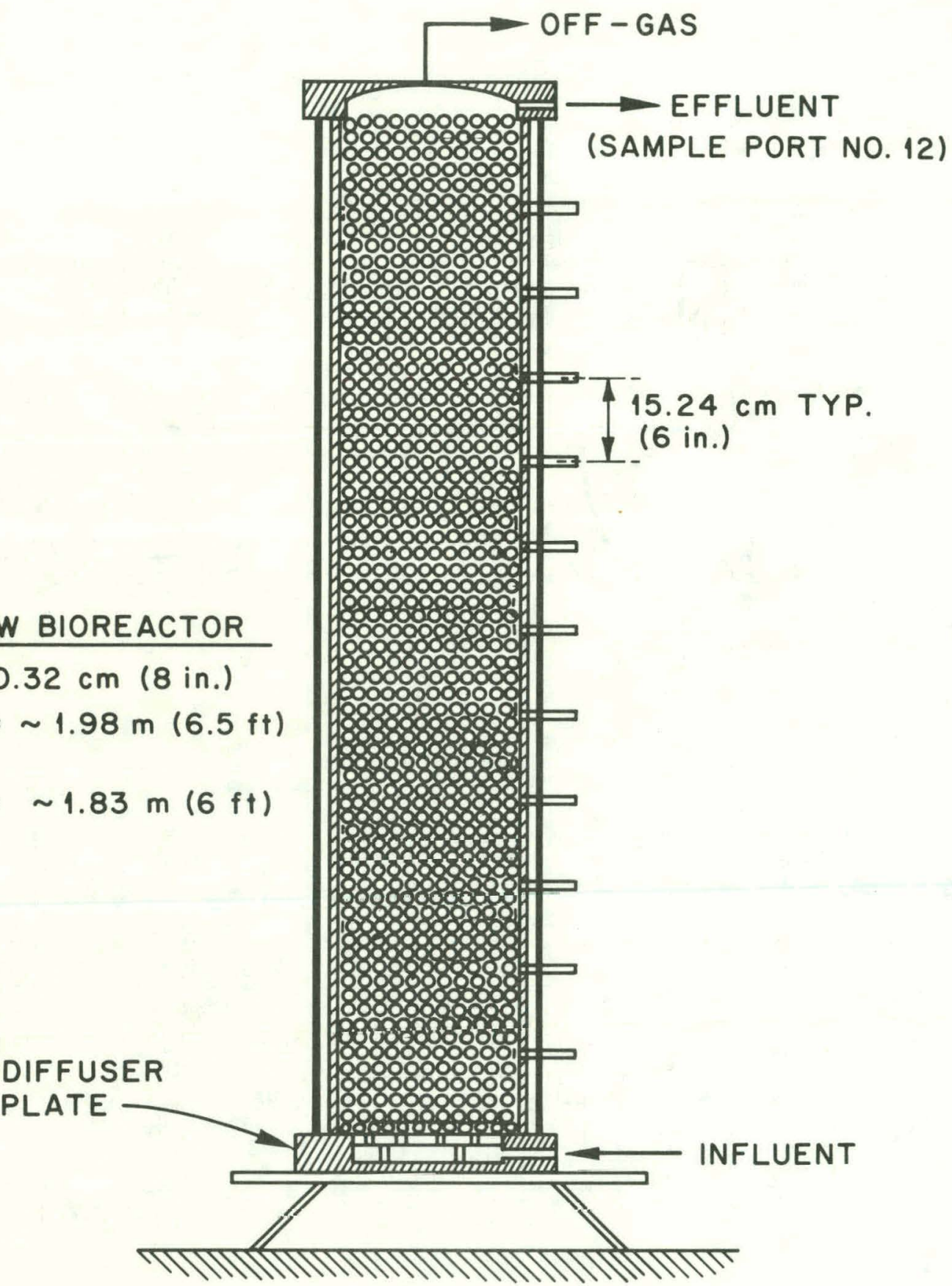

Figure 5.2. Schematic diagram of the ANFLOW bioreactor. 
ORNL DWG 80-1750

TO VENT

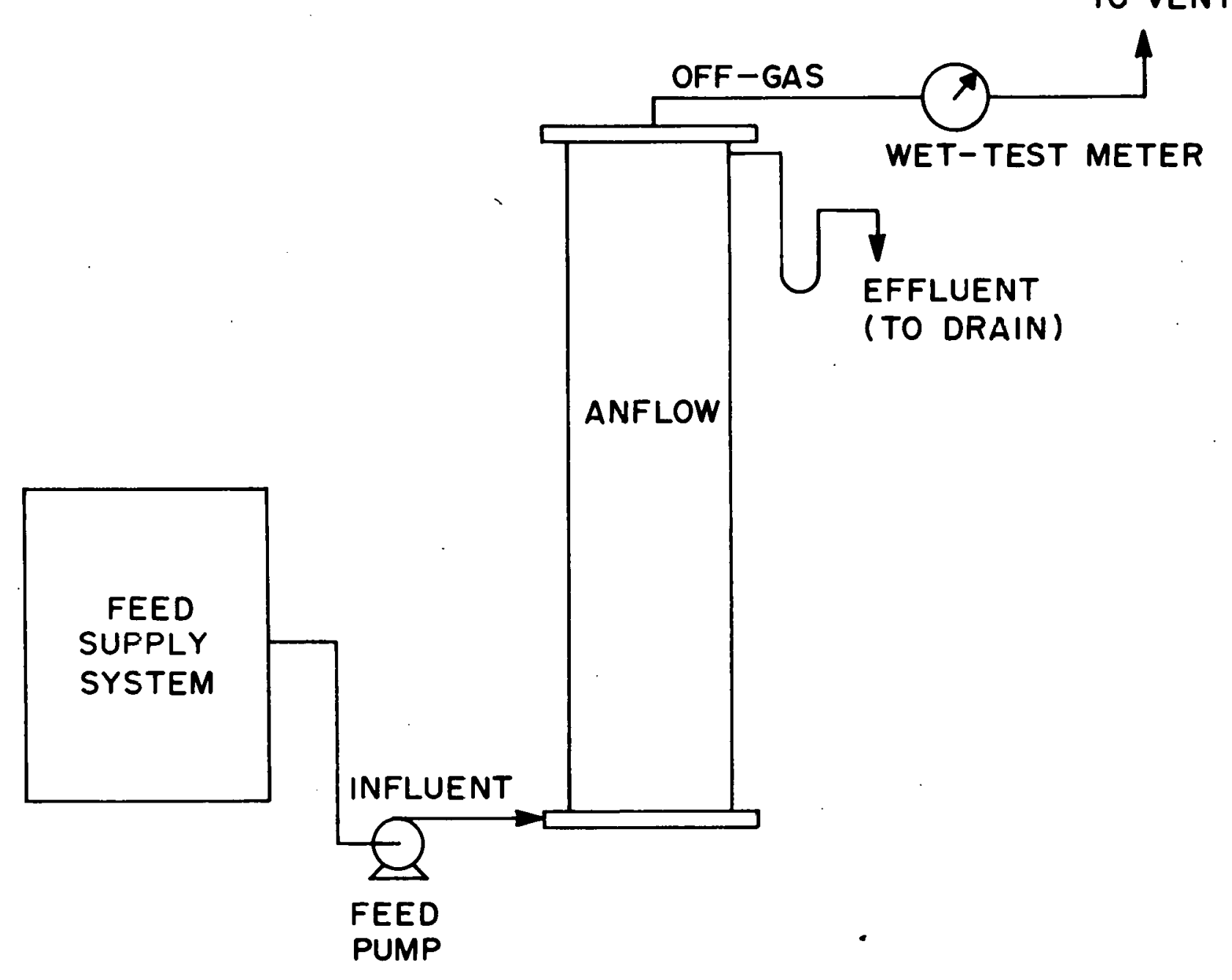

Figure 5.3. Schematic diagram of the basic components of the experimental setup used during the experịmental program. 
pump, ANFLOW bioreactor, and a wet-test meter to measure the off-gas production from the bioreactor.

Two different feed supply systems were used during the experimental work (see Figure 5.4). The first one, used during startup, steady-state approach and first toxicity experiment, included a feed tank with a capacity of about $1000 \mathrm{~L}$ and a flow and temperature $\left(\mathrm{T}=25^{\circ} \mathrm{C}\right)$-controlled surge tank. With this procedure the feed solution $(\sim 600 \mathrm{~L})$ lasted for about 1 week. It is important to point out that this synthetic feed solution was also used for another research project on the ammonia production on these systems. Operational problems associated with keeping the heavy metal from precipitating and the decrease of the soluble. COD from $100 \%$ to about 80 to $85 \%$, caused by bacterial growth in the feed lines, led to the development of an alternative feed-supply system. It was decided then to make the feed solution on a daily basis and used a 55-gal drum as the feed-sunply systom with no teillperature contro1 (see Figure 5.4(a)). This feed-supply system was used for the rest of the experimental work mainly toxicity experiments No. 2 and No. 3.

The feed-supply systems were common to all bioreactors, identified as test-1 (T-1), test-2 (T-2), and control bioreactor.

\subsection{Overview of Experimental Program Development}

This research project was developed in phases as shown in F1gure 5.5. The most relevant phases were:

1. synthetic substrate development, 


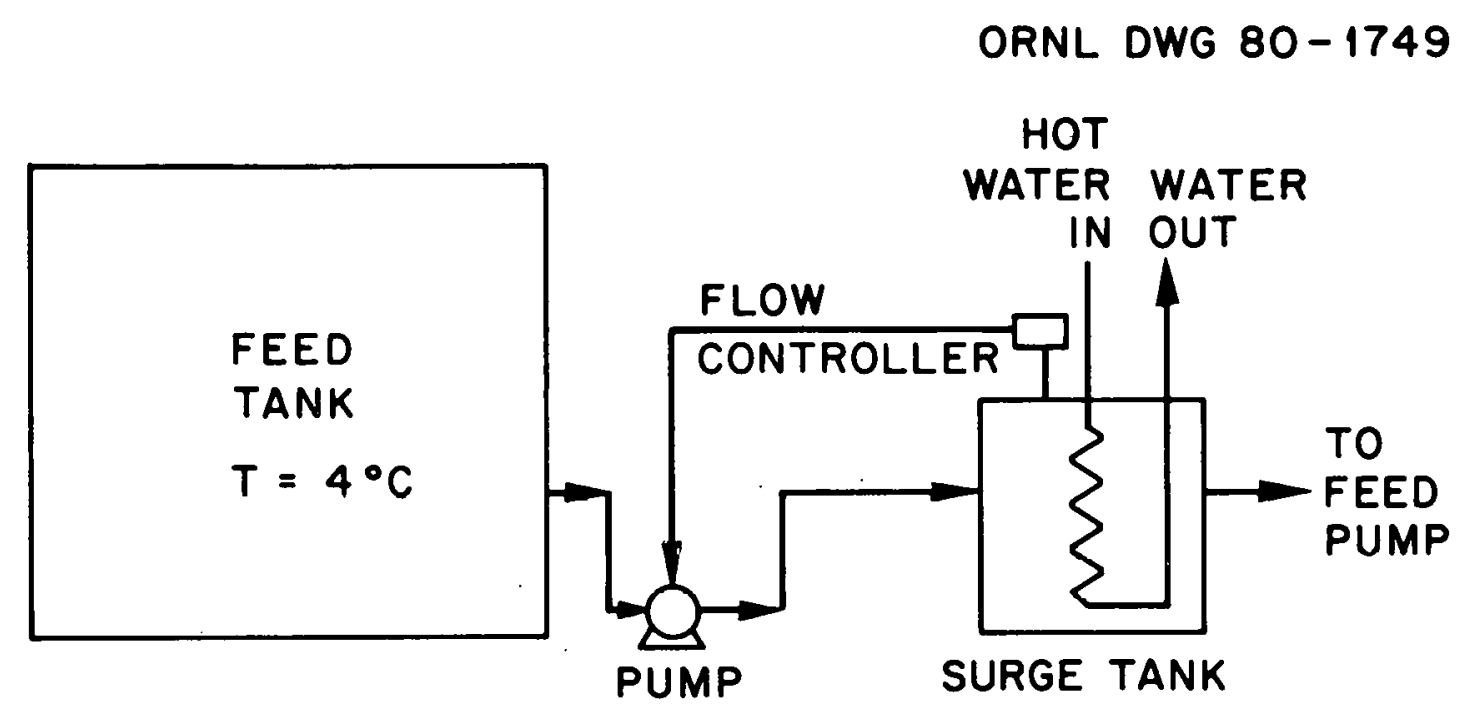

(a)

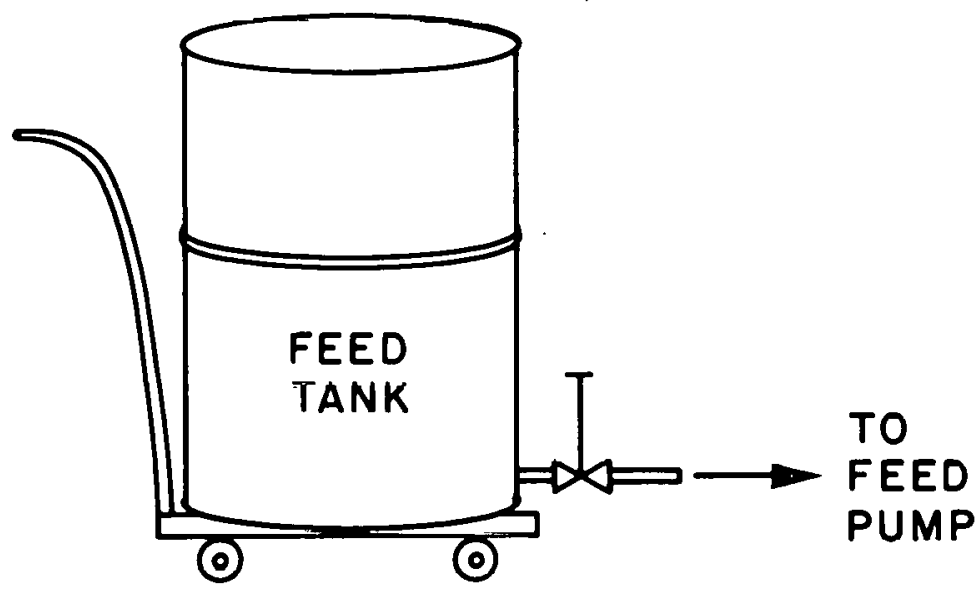

(b)

Figure 5.4. Schematic diagrams of the feed supply systems used during the experimental program: (a) during startup, steady-state and toxicity experiment No. 1, (b) during toxicity experiments No. 2 and No. 3. 
ORNL DWG $80-1748$
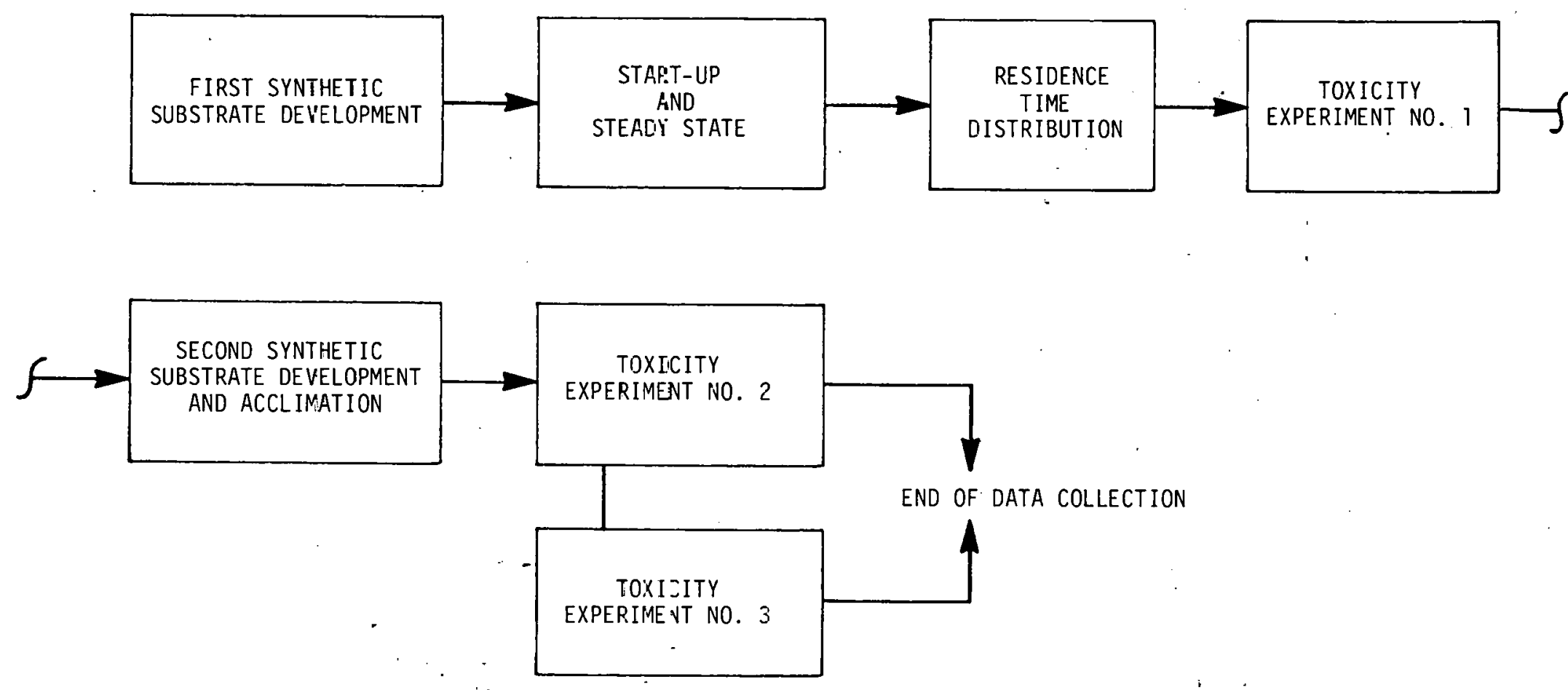

Figure 5.5. Schematic diagram of the main phases of the experimental program. 
2. startup and steady-state operation,

3. residence time distribution, and

4. toxicity experiments.

A brief discussion of each phase is found in Sects. 5.2.1 to 5.2 .4 respectively.

\subsubsection{Synthetic Substrate Development}

The toxicity phenomena studies were carried out using two specially developed substrates. This procedure was adopted to establish basic experimental conditions for the evaluation of heavy-metals effects. The absence of complicating factors in the substrate allow the establishment of basic heavy-metal effects. The relationship for toxicity obtained in this study will be those due to the presence of the heavy metal under study. It would be a rare situation to have a waste with characteristics similar to the synthetic substrates to be used. Most wastes are rather complicated solutions and could contain various substances which could produce alterations in the toxic effects of heavy metals. Furthermore, the presence of different heavy metals could result in synergiotic or antagonistic efferts that would enhance or prevent toxic effects.

Since organic wastes frequently are composed of fats, carbohydrates, or proteins in various combinations, a complex protein-carbohydrate mixture was initially selected as the synthetic substrate for the ANFLOW bioreactor toxicity studies. Nutrient broth, an almost pure protein, and glucose, a pure carbohydrate were combined in equal COD quantities to make $" 1$ the first concentrated feed. Sufficient nitrogen and phosphorus should be available in the nutrient broth for the resulting 
anaerobic growth, and no additional substances should be required. This substrate has been used by Yound and McCarty 46 when evaluating the anaerobic filter for waste treatment.

Four solutions containing different quantities of nutrient broth were dissolved in distilled water and analyzed for their COD content. The same procedure was followed for glucose (dextrose). It was found that the COD content per gram of substance was $937 \pm 66 \mathrm{mg}$ for nutrient broth and $1097 \pm 41 \mathrm{mg}$ for glucose. Sodium bicarbonate was added to help buffer the system during the startup and inhibitory operations.

It was found, during the first toxicity experiment, that zinc precipitated from solution (probably as carbonate and hydroxide forms). It became necessary to develop a second synthetic substrate with a substance that would keep the heavy metal in a soluthle form during the experiment, especially under continuous operation. This substance shall complex the heavy metal and he biodegradable. Sodium citrate was the substance chosen because 1 (1) had been used to complex heavy metals, 21 (2) was suspected to be biodegradable, and (3) was in good supply.

It was experimentally found that $3 \mathrm{~g}$ per $\mathrm{L}$ of sodium citrate was sufficient to complex and keep in a soluble form $1000 \mathrm{mg}$ per $\mathrm{L}$ of zinc. The COD-equivalent of $3 \mathrm{~g}$ of sodium citrate were incorporated in the synthet1c substrate. In order to keep the same feed strength at 3000 mg per L COD, the nutrient broth and glucose amounts were decreased, but their relative $C O D$ proportions were maintained as in the first synthetic substrate. Table 5.1 summarizes the synthetic substrates used in the experimental work. 
Table 5.1. Summary of the Two Synthetic Substrates Used During the Experimental Program

\begin{tabular}{|c|c|c|c|c|c|}
\hline $\begin{array}{l}\text { Syathetic } \\
\text { Substrate }\end{array}$ & $\begin{array}{c}\text { COD } \\
\text { (mg/L) }\end{array}$ & Component & $\begin{array}{l}\mathrm{COD} / \mathrm{g} \text { of } \\
\text { Substance }\end{array}$ & $\begin{array}{l}\text { COD } \\
\text { Substrate in } \\
(\mathrm{mg} / \mathrm{L})\end{array}$ & $\begin{array}{c}\text { Grams of } \\
\text { Substance Required } \\
\text { to Make COD }\end{array}$ \\
\hline \multirow{2}{*}{1} & \multirow{2}{*}{3000} & Nutrient broth & $937 \pm 66^{1}$ & 1500 & 1.6009 \\
\hline & & Glucose (dextrose) & $1097 \pm 41^{2}$ & 1500 & 1.3674 \\
\hline \multirow{3}{*}{2} & \multirow{3}{*}{3000} & Nutrient broth & $937 \pm 66$ & 771 & 0.8228 \\
\hline & & Glucose (dextrose) & $1097 \pm 41$ & 771 & 0.7028 \\
\hline & & Sodium citrate & $486 \pm 11^{3}$ & 1458 & 3.0 \\
\hline
\end{tabular}

The bicarbonate alkalinity of both synthetic substrates was $2000 \mathrm{mg} / \mathrm{L}$ as $\mathrm{CaCO}_{3}$ ( 40 . meq. $\mathrm{L}$ ), made by dissolving 3.36 grams of sodium bicarbonate $\left(\mathrm{NaHCO}_{3}\right)$ per liter of solution.

\footnotetext{
1 Average of four samples.

Average of four samples.

3 Average of six samples.
} 


\subsubsection{Startup and Steady-State Operation}

The laboratory-scale ANFLOW bioreactors used in this study have been seeded with digester sludge and operated for some time. At the time of starting the experimental work, it was about 3 months since the last time they were fed. The start-up transition to steady-state lasted about 2-3 weeks. They were then operated at steady-state for about 2 months to obtain baseline data on their performance.

\subsubsection{Residence Time Distribution Experiments}

A residence time distribution experiment was performed on each of the three bioreactors used in this study to obtain the average residence time and reactor dispersion numbers. These two parameters were needed in order to use the dispersion model with first-order kinetics to describe the inhibitory effects of zinc.

\subsubsection{Toxicity Experiments}

Thiee bas1c coxicity experiments were performed during this study. The experiments and the process conditions used are summarized in Table 5.2. The shock-load or slug fed toxicity experiments were completed from inhibition to bioreactor recovery. The continuous step function, because of a lack of time, was not completed to recovery, and ended at the stage where the inhibitory effects were caused by a continuous feeding of $1000 \mathrm{mg} / \mathrm{L} \mathrm{Zn}$.

\subsection{Data Acquisition and Analysis}

\subsubsection{Average Residence Time and Reactor Dispersion Number}

The RTD experiments were performed using the estimulus-response technique. This was done by injecting a slug containing $100 \mathrm{~mL}$ of 1000 
Table 5.2. Summary of the Toxicity Expertments Performed and the Process Conditions Used.

\begin{tabular}{|c|c|c|c|c|c|c|c|}
\hline $\begin{array}{c}\text { Toxlc1ty } \\
\text { Experiment }\end{array}$ & $\begin{array}{l}\text { Characteristics } \\
\text { of Input } \\
\text { Function }\end{array}$ & Bioreactor & $\begin{array}{c}\text { Temperature } \\
{ }^{\circ} \mathrm{C}\end{array}$ & $\begin{array}{l}\text { Flow Rate } \\
(\mathrm{m} 1 / \mathrm{min})\end{array}$ & $\begin{array}{l}\text { Average } \\
\text { Residence } \\
\text { Time (h) }\end{array}$ & $\begin{array}{l}\text { Synthetic } \\
\text { Feed }\end{array}$ & $\begin{array}{c}\text { Organic } \\
\text { Loading } \\
\mathrm{kg}^{-1} \mathrm{COD}_{\text {day }} \mathrm{m}^{-3}\end{array}$ \\
\hline 1 & $\begin{array}{l}\text { Slug of } 1000 \mathrm{mg} / \mathrm{L} \\
\mathrm{Zn} \text { as } \mathrm{ZnCl} 2 \text { for } \\
42 \text { hours. Soluble } \\
\text { zinc }=60-15 \%\end{array}$ & $\mathrm{~T}-1$ & $20-25$ & 10.5 & 43.8 & 1 & $\begin{array}{c}1.64 \\
(102.4)\end{array}$ \\
\hline 2 & $\begin{array}{l}\text { Slug of } 1001 \mathrm{mg} / \mathrm{L} \\
\mathrm{Zn} \text { as } \mathrm{ZnCl}_{2} \\
\text { for } 42 \text { hours } \\
\text { soluble } \mathrm{Zn}=100 \%\end{array}$ & $\mathrm{~T}-1$ & $25-35$ & 10.5 & 43.8 & 2 & $\begin{array}{c}1.64 \\
(102.4)\end{array}$ \\
\hline 3 & $\begin{array}{l}100 \mathrm{mg} / \mathrm{L} \mathrm{Zn} \text { as } \\
\mathrm{ZnCl}_{2} \text { for } 35 \text { days } \\
300 \mathrm{mg} / \mathrm{L} \mathrm{Zn} \text { as } \\
\mathrm{ZnCl}_{2} \text { for } 26 \text { days } \\
1000 \mathrm{mg} / \mathrm{L} \mathrm{2n} \text { as } \\
\mathrm{ZnCl}_{2} \text { for }: 3 \text { days }\end{array}$ & $T-2$ & $25-35$ & 10.5 & 40.9 & 2 & $\begin{array}{c}1.76 \\
(109.7)\end{array}$ \\
\hline & & Control & $\begin{array}{l}\text { Same as } \\
\mathrm{T}-1 \text { and } \\
\mathrm{T}-2\end{array}$ & 10.5 & 46.6 & $\begin{array}{l}\text { Same as } \\
\mathrm{T}-1 \text { and } \\
\mathrm{T}-2\end{array}$ & $\begin{array}{c}1.55 \\
(96.4)\end{array}$ \\
\hline
\end{tabular}

1. Number in parenthesis are the organic loadings in lb coD/day/l000ft ${ }^{3}$; based on the void volume.

2. Organic loading calculated as, $0 . L_{0}=\frac{C .024 \times \text { feed soluble } \operatorname{COD}(=3000 \mathrm{mg} / \mathrm{L})}{\mathrm{t}(\mathrm{h})}$; conversion factor to SI units $=62.3$. 
$\mathrm{mg} / \mathrm{L}$ fluorescein dye at the bottom of the bioreactor and monttoring its concentration in the bioreactor effluent (see Figure 5.6). This dye was chosen because it was used before on the $19-\mathrm{m}^{3} /$ day pilot plant, and the equipment necessary for its determination was readily available. The volume and the concentration of the injected pulse are experimental values obtained from a set of combinations of volumes and concentrations. The experiments were performed on a side bioreactor with the same design as the bioreactors used in this research, but it was not in operation. It was found that injecting $100 \mathrm{ml}$ of $1000 \mathrm{mg}$ per $\mathrm{L}$ of fluorescein dye (100 mg) produced a peak dye concentration in the bioreactor effluent of about 2 to $3 \mathrm{mg} / \mathrm{L}$.

The dye in the effluent was determined by sampling the effluent on a continuous basis. At preset time intervals the effluent was pumped into individual test tubes in a fraction collector. The dye concentration in each test tube was determined. using a fluoreoccnee spectrophotometer (Perkin Elmer Model 203) and the experimental setup shown in Figure 5.7 . Before pumping the effluent sample (about $30 \mathrm{ml}$ ) into the fluorescence spectrophometer, the $\mathrm{pH}$ of the sample was ralsed to $\mathrm{pH}>8$ with a few drops of $50 \% \mathrm{w} / \mathrm{w} \mathrm{NaOH}$ to enhance the fluorescence properties of fluorescein dye.47 The $\mathrm{pH}$ dependence of fluorescein dye fluorescence for the conditions of the experiment is shown in Figure 5.8. The fluorescence spectrophotometer was calibrated (excitation wavelength $=490 \mathrm{~nm}$, emission wavelength $=520 \mathrm{~nm}$ ) with standards made of different concentrations of fluorescein dye. In general, the calibration curve has a straight portion from low \% emissions to about $30 \%$ emission. This range expressed in $\mathrm{mg} / \mathrm{L}$ depends on what dye concentration is chosen to be $100 \%$ 
ORNL DWG 80-1747

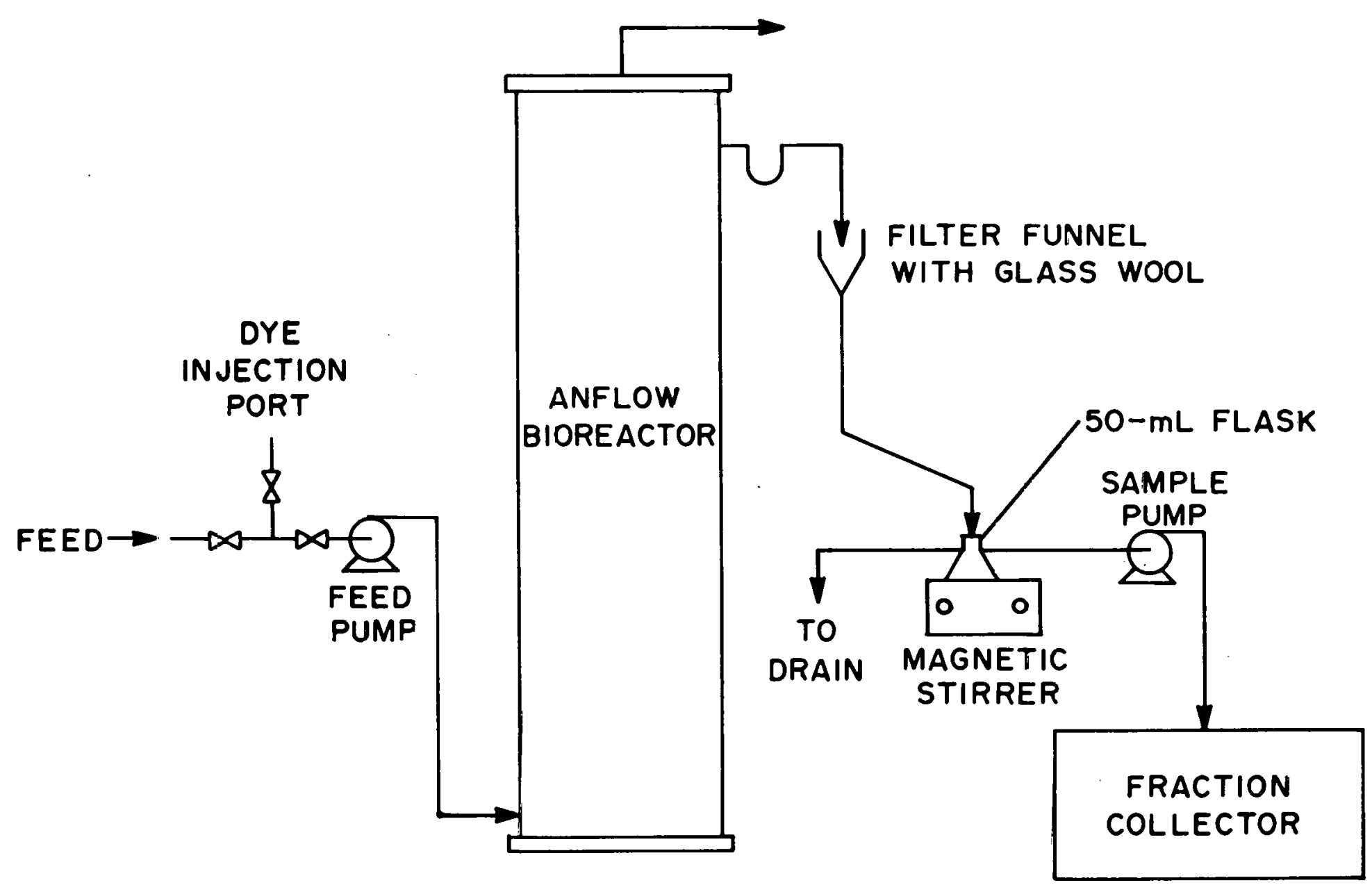

Figure 5.6. Experimental setup to continuously sample the bioreactor effluent during an RTD experiment. 
ORNL DWG 80-1765

FLUORESCENCE SPECTROPHOTOMETER

50 wt \% $\mathrm{NoOH}$

TO RAISE $\mathrm{pH} \geq 8$

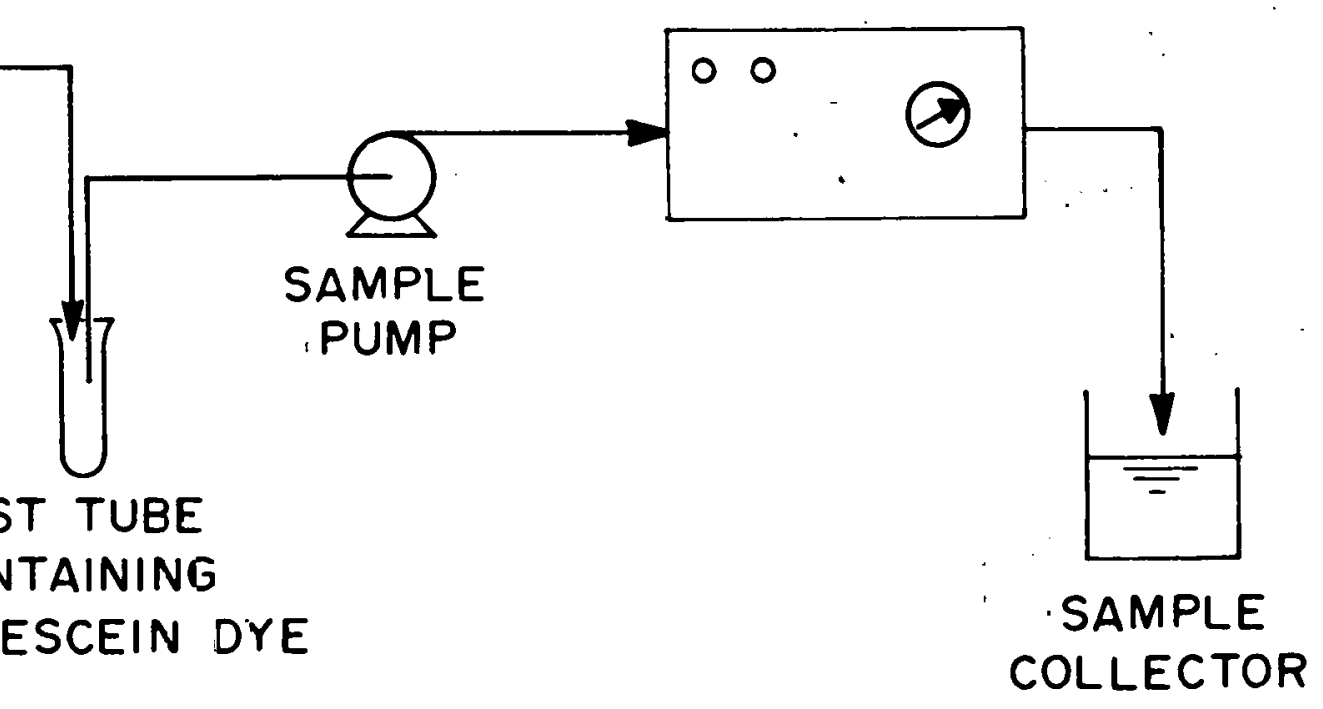

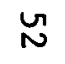

Figure 5.7. Experimental setup to analyze the effluent samples containing fluorescein dye. 


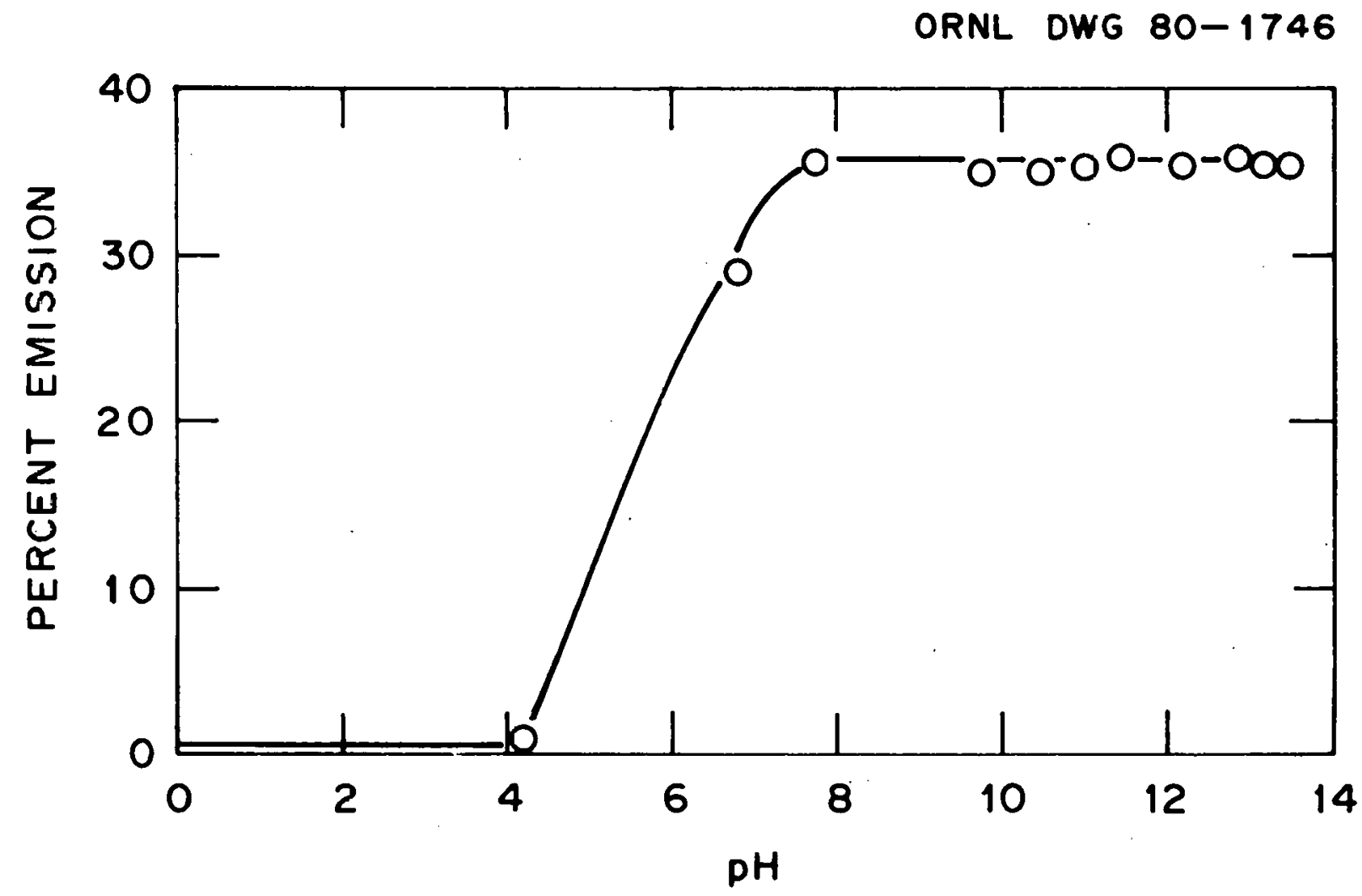

Figure 5.8. $\mathrm{pH}$ dependence of fluorescein dye fluorescense. Dye concentration $=2 \mathrm{mg} / \mathrm{L}$. 
emission. For the experimental conditions of this research (an expected peak dye concentration of less than $3.5 \mathrm{mg} / \mathrm{L}) 10 \mathrm{mg} / \mathrm{L}$ was chosen to represent $100 \%$ emission (see Figure 5.9).

The first preset time interval used in the sampling process was 10 min. In the tail portion of the RTD curve, where the concentration of the dye changed very slowly, this time was increased to $20 \mathrm{~min}$. After the completion of the first RTD experiment, it was decided that 30 -min sampling intervals were sufficient for the first portion of the RTD curve and 60-min intervals for the tail portion. The times and number of data points collected in each RTD experiment are summarized in Table 5.3 .

Table 5.3. Summary of Residence Time Distribution Experiments

\begin{tabular}{|c|c|c|c|c|c|}
\hline Bioreactor & $\begin{array}{c}\text { First } \\
\text { Time } \\
\text { Intervà } \perp \\
\Delta t_{1}(\min )\end{array}$ & $\begin{array}{c}\text { Second } \\
\text { Time } \\
\text { Interval } \\
\Delta t_{2}(\min )\end{array}$ & $\begin{array}{l}\text { Number } \\
\text { of } \\
\text { Data } \\
\text { Points } \\
\text { with } \Delta t_{1}\end{array}$ & $\begin{array}{l}\text { Number } \\
\text { of } \\
\text { Data } \\
\text { Points } \\
\text { with } \Delta t_{2}\end{array}$ & $\begin{array}{c}\text { Total } \\
\text { Number } \\
\text { of } \\
\text { Data Points }\end{array}$ \\
\hline $\mathrm{T}-1$ & 10 & 20 & 580 & 182 & 762 \\
\hline $\mathrm{T}-2$ & 30 & 60 & 151 & 93 & 244 \\
\hline Control & 30 & 60 & 145 & 95 & 240 \\
\hline
\end{tabular}

The average residence time was calculated with a computer code deve1oped based on a computational method for equations (3-18) and (3-19) as suggested by Levenspie1.29 If the continuous distribution is measured only at a number of equidistant points, then equations (3-18) and (3-19) for the experimental conditions used, become: 


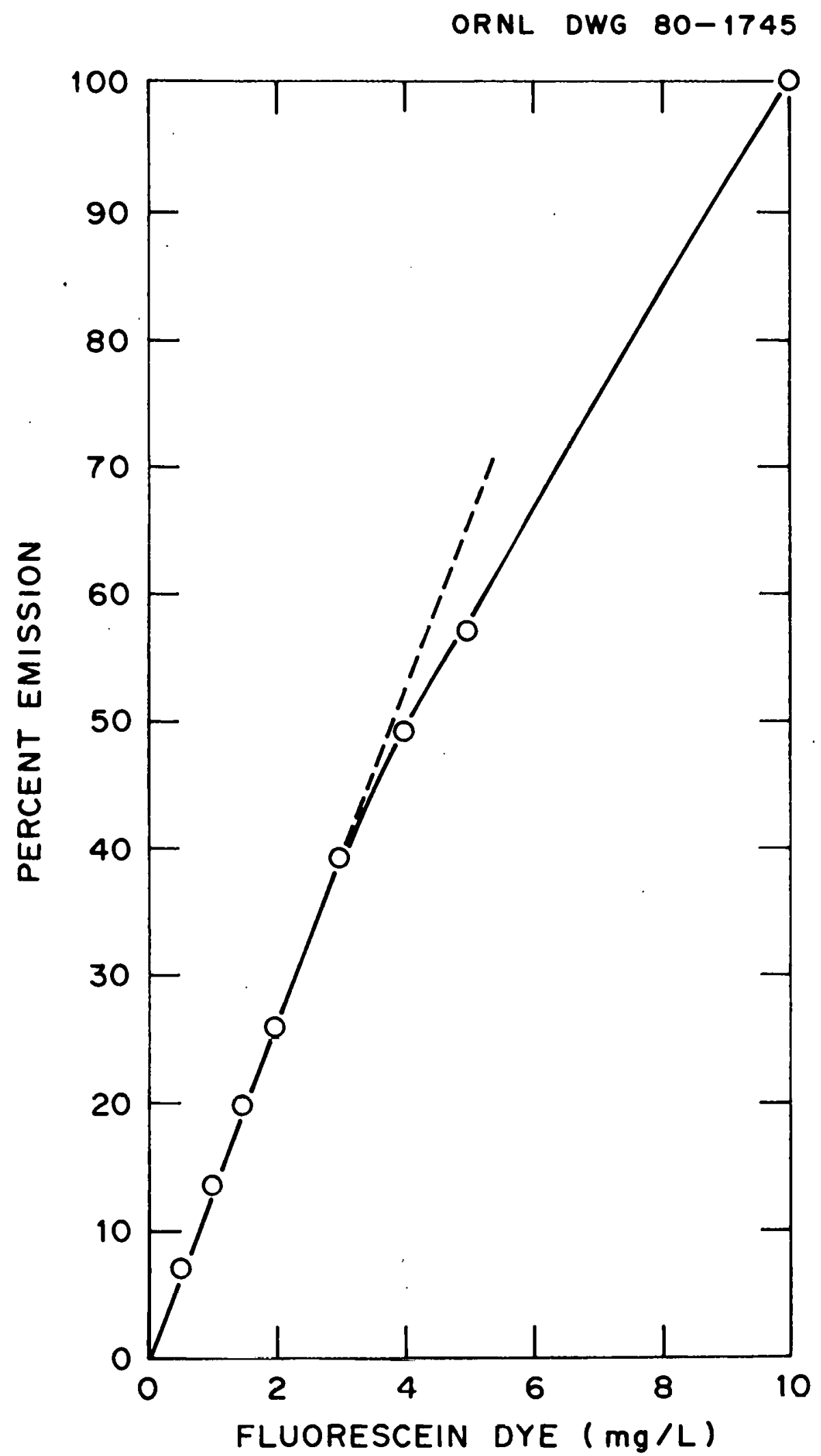

Figure 5.9. Percent emission as function of fluorescein dye concentration. 


$$
\bar{t}=\frac{\sum_{1}^{N_{1}} t_{i} C_{i} \Delta t_{1}+\sum^{N_{2}} \sum_{i=N_{1}+1} t_{i} C_{i} \Delta t_{2}}{\sum_{1}^{N_{1}} C_{i} \Delta t_{1}+\sum_{1=N_{1}+1}^{N_{2}} C_{i} \Delta t_{2}}
$$

and

$$
\sigma_{t}^{2}=\frac{\sum_{1=1}^{N_{1}}\left(t_{i}-\bar{t}\right)^{2} C_{i} \Delta t_{1}+\sum_{i=N_{1}+1}^{N_{2}}\left(t_{i}-\bar{t}\right)^{2} C_{i} \Delta t_{2}}{\sum_{i=1}^{N_{1}} C_{i} \Delta t_{1}+\sum_{1=N_{1}+1}^{N_{2}} C_{i} \Delta t_{2}}
$$

which simplifies to

$$
\sigma_{t}^{2}=\frac{\sum^{\sum_{1}^{N_{1}} t_{i}{ }^{2} C_{i} \Delta t_{1}+\sum_{i=N_{1}+1}^{N_{2}} t_{i}{ }^{2} C_{i} \Delta t_{2}}}{\sum^{N_{1}} C_{i} \Delta t_{1}+\sum_{i=N_{1}+1}^{N_{2}} C_{i} \Delta t_{2}}-\bar{t}^{2}
$$

where: $t_{i}=\Delta t_{1 / 2}$, for $i=0$

$$
\begin{aligned}
& t_{i}=t_{i-1}+\Delta t_{1}, \text { for } 1 \leq 1 \leq N_{1} \\
& t_{1}=t_{N_{1}}+\left(\frac{\Delta t_{1}+\Delta t_{2}}{2}\right), \text { for } 1=N_{1}+1 \\
& t_{1}=t_{1-1}+\Delta t_{2}, \text { for } N_{1}+2 \leq 1 \leq N_{2} \\
& N_{1}=\text { number of data points with } \Delta t_{1} \\
& N_{2}=\text { number of data points with } \Delta t_{2}
\end{aligned}
$$

The reactor dispersion number for each bioreactor was calculated usIng the variance method and the time of peak concentration method. The varlance method was included in the same computer code used to calculate the average residence time.

The time of peak concentration was calculated on the assumption that the RTD was log-normally distributed. The equation that describes the 
distribution of $t$ when $t$ is log-normally distributed is given as:

$$
f(t)=\frac{1}{t \sigma_{1 n} \sqrt{2 \pi}} \exp \left[-1 / 2\left[\frac{\ln \left(t / t_{g}\right)}{\sigma_{1 n}}\right]^{2}\right]
$$

for $t \geq 0$,

where $t_{g}$ is the geometric average time and $\sigma_{1 n}$ is the geometric standard deviation when $t$ is in logarithmic units.

The relationships between the time at peak concentration $\left(t_{p}\right)$ and the geometric average residence time $\left(t_{g}\right)$ is obtained by setting the differential of $f(t)$ equal to zero and solving for $t_{p}$. The resulting equation,

$$
t_{p}=t_{g} \exp \left(-\sigma_{1 n}\right),
$$

was used to calculate $t_{p}$ and $\theta p=t_{p} / \bar{t}$ and from equations $(3-21)$ or (3-22) a reactor dispersion number is obtained.

A computer code was developed to calculate $t_{g}$ and $\sigma_{1 n}$ from the RTD data. This computer code is similar to the one that calculates the arithmetic average residence time $(\bar{t})$ except that $\operatorname{lnt}_{i}$ is used instead of $t_{i}$. After substituting, equations $(5-1)$ and $(5-3)$ are expressed as:

$$
\begin{aligned}
& \overline{\ln t}=\frac{\sum_{i=1}^{N_{1}} \operatorname{lnt} t_{i} C_{i} \Delta t_{1}+\sum_{i=N_{1}+1}^{N_{2}} \operatorname{lnt} t_{i} C_{i} \Delta t_{2}}{\sum_{i=1}^{N_{1}} C_{i} \Delta t_{1}+\sum_{i=N_{1}+1}^{N_{2}} C_{i} \Delta t_{2}} \\
& t_{g}=\exp (\overline{\ln t}) \\
& \sigma_{1 n}^{2}=\frac{\sum_{i=1}^{N_{1}}\left(1 n t_{i}\right)^{2} C_{i} \Delta t_{1}+\sum_{i=N_{1}+1}^{N_{2}}\left(1 n t_{i}\right)^{2} C_{i} \Delta t_{2}}{\sum_{i=1}^{N_{1}} C_{i} \Delta t_{1}+\sum_{i=N_{1}+1}^{N_{2}} C_{i} \Delta t_{2}}
\end{aligned}
$$


The theoretical dispersion curve or RTD for a reactor with a given dispersion number ( $D / U L$ ) was calculated using a computer code based on equation (3-12). It was found that 50 (and even less) roots were enough to characterize the theoretical RTD curve. This method represents an alternative to the variance and the time of peak concentration methods. The use of the method involves a trial and error operation. The reactor dispersion number is that dispersion number that describes the theoretical RTD curve that most closely fits the experimental residence time distribution curve.

\subsubsection{Monitoring Bioreactor Response to Toxicity}

Bioreactor response was monitored by determining soluble COD in the effluent, $\mathrm{pH}$, alkalinity, gas production, gas composition, acetic and propionic acid profiles, and soluble COD profiles. The chemical analyses required to evaluate these parameters were performed following the basic procedures established in the Standard Methods for Water and Wastewater Analysis. 48 Reagent-grade materials were used in the chemical analyses. A brief description of each analysis is found in Sects. 5.3.2.1 to 5.3.2.5. The procedures for sample collection and treatment are covered in Sects. 5.3.2.6.

5.3.2.1 Chemical oxygen demand. The chemical oxygen demand (COD) analysis is a measure of the oxygen-equivalent of that portion of the organic matter in a sample that is susceptible to oxidation by a strong oxidant. The COD was determined using the EPA-approved Ampule COD Method, 49 COD range 25 to $900 \mathrm{mg} / \mathrm{L}$. The organic matter is oxidized in a sealed $10-\mathrm{mL}$ expendable ampule, which contains premixed reagents, at 
$150 \pm 2^{\circ} \mathrm{C}$ for $2 \mathrm{~h}$ ( $30 \mathrm{~min}$ in this research). The COD of the sample is determined using a Coleman Mode1 295 spectrophotometer at $600 \mathrm{~nm}$ by measuring the concentration of the $\operatorname{Cr}($ III) ion. The path length of the ampules is $1.59 \mathrm{~cm}$.

The use of this method depends on establishing a calibration curve that relates the COD of known samples with their measured absorbance. The recommended standard, potassium acid phthalate (KHP) has a COD content of $10,000 \mathrm{mg} / \mathrm{L}$ per every $8.5034 \mathrm{~g}$ or $1.176 \mathrm{~g} \mathrm{COD} / \mathrm{g} \mathrm{KHP}$. A typical COD standard curve is shown in Figure 5.10. This curve was checked weekly using 200-, 500-, and 800-mg/L COD standards. If the COD of the sample was suspected to be higher than $900 \mathrm{mg} / \mathrm{L}$, sample dilutions were made in order to bring its concentration down to the operating range.

5.3.2.2 pH/Alkalinity. Sample $\mathrm{pH}$ was measured with a Microprocessor Ionalyzer Model 901 and a pH electrode.

The alkalinity content of the samples was determined by titrating $50 \mathrm{ml}$ of the sample with $0.1 \mathrm{~N} \mathrm{HCl}$ to $\mathrm{pH} 4$. The alkalinity in milligrams per liter as $\mathrm{CaCO}_{3}$ was calculated frum

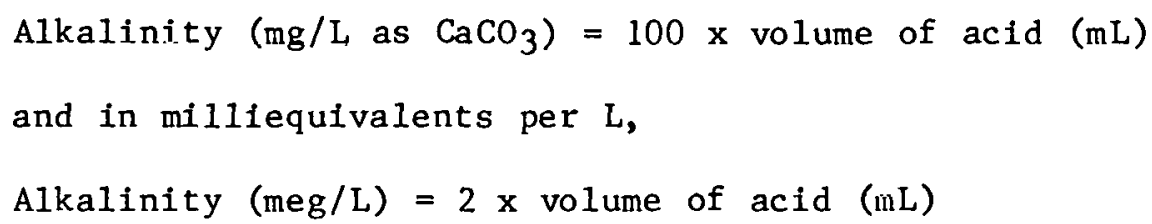

5.3.2.3 Gas production and composition. The cumulative gas production in each bioreactor was measured with a wet-test meter, located in the off-gas line. The gas production rate was calculated using the difference between two cumulative gas production readings and llit time interval betwecn them. 
ORNL DWG 80-1752

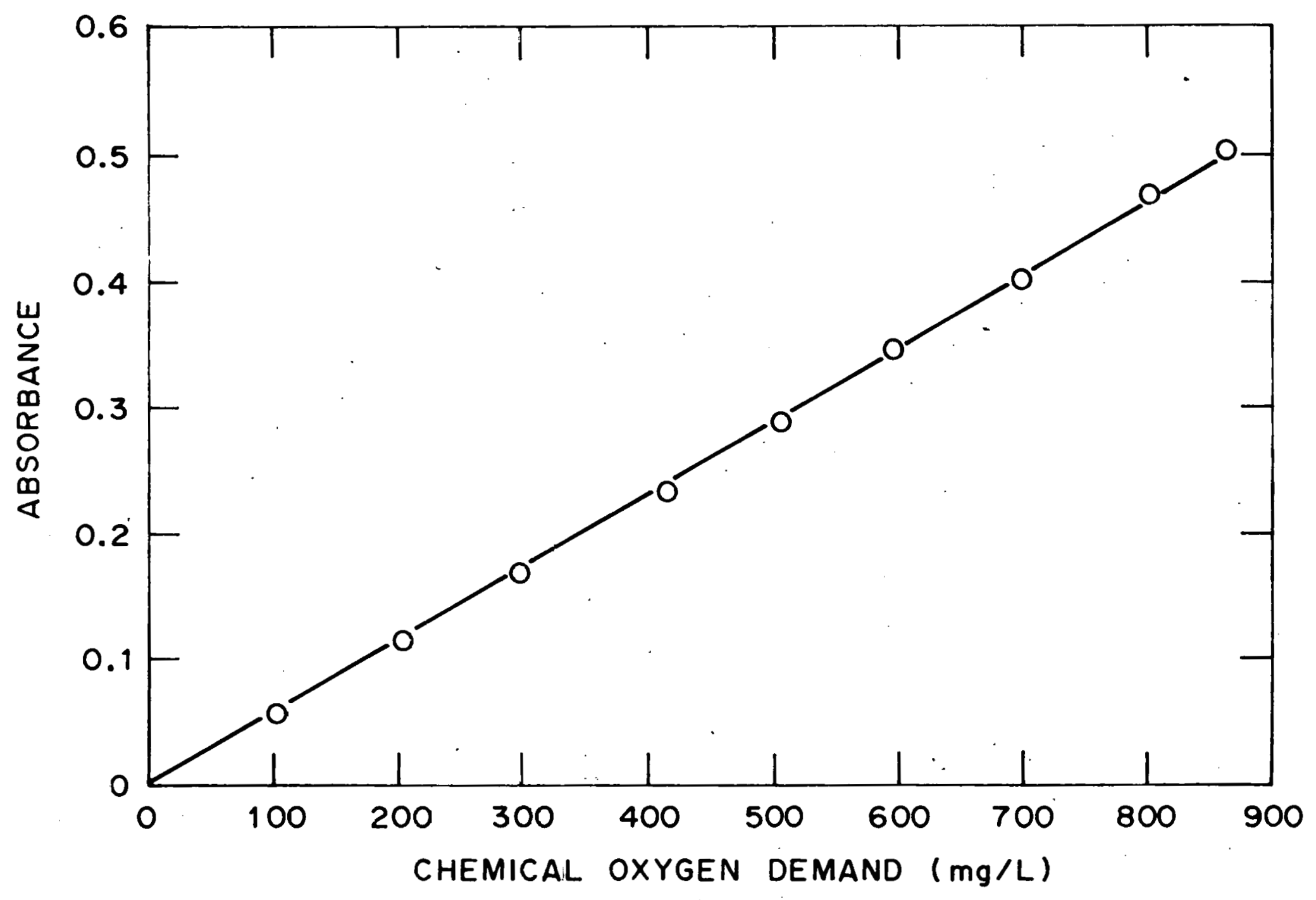

Figure 5.10. Calibration curve for the chemical oxygen demand analysis. 
The composition of the major components in the off-gas, mainly methane, carbon dioxide, and air $\left(\mathrm{N}_{2}+\mathrm{O}_{2}\right)$ were determined using a Bendix Gas Chromatograph Mode1 80491 with a Porapak-Q packing. A calibration curve was obtained for each one of these gases by injecting a series of gas samples with volumes of $20,40,60,80$ and $100 \mu \mathrm{L}$ with a pressure-locked syringe (see Figure 5.11). The respon'se of the system was found to be linear and reproducible using the peak heights as the criteria. By injecting $100 \mu \mathrm{L}$ of a gaseous mixture, the peak heights for each component will correspond to their respective volume percentages in the sample. It was found, however, that the system response changed from time to time but always maintained the linearity and proportionality for each gas. It was decided, then, to obta1n a calibration and correct the gas percentages to $100 \%$. The calibration curves obtained for methane, carbon dioxide, and air are shown in Figure 5.12.

Acetic and propionic acids, chosen to study the phenomena of toxic1ty in ANFLOW bioreactors, were analyzed using a Shimadzu Gas Chromatograph Model GC-Mini 1 with a Carbopack C/0.3\% Carbowax 20 M/O. $1 \% \mathrm{H}_{3} \mathrm{PO}_{4}$. Their concentration in $\mathrm{mg} / \mathrm{L}$ were calculated by comparing their peak areas (using the paper-weight method) with samples containing a mixture of each acid in equal proportions. The standard mixtures used were 100 , 250,450 and $1000 \mathrm{mg} / \mathrm{L}$ of each acid. At least two replicates were obtained for each sample analyzed.

\subsubsection{Bloreactor Performance for Soluble Zinc Removal.}

Effluent and bioreactor profile samples containing zinc analyzed using atomfe absorplion spectrophotometry (AAS) with an AAS Varian Techtron Mode1 1200, an acetylene-air mixture, a wavelength of $213.9 \mathrm{~nm}$, and 
ORNL DWG 80-1744

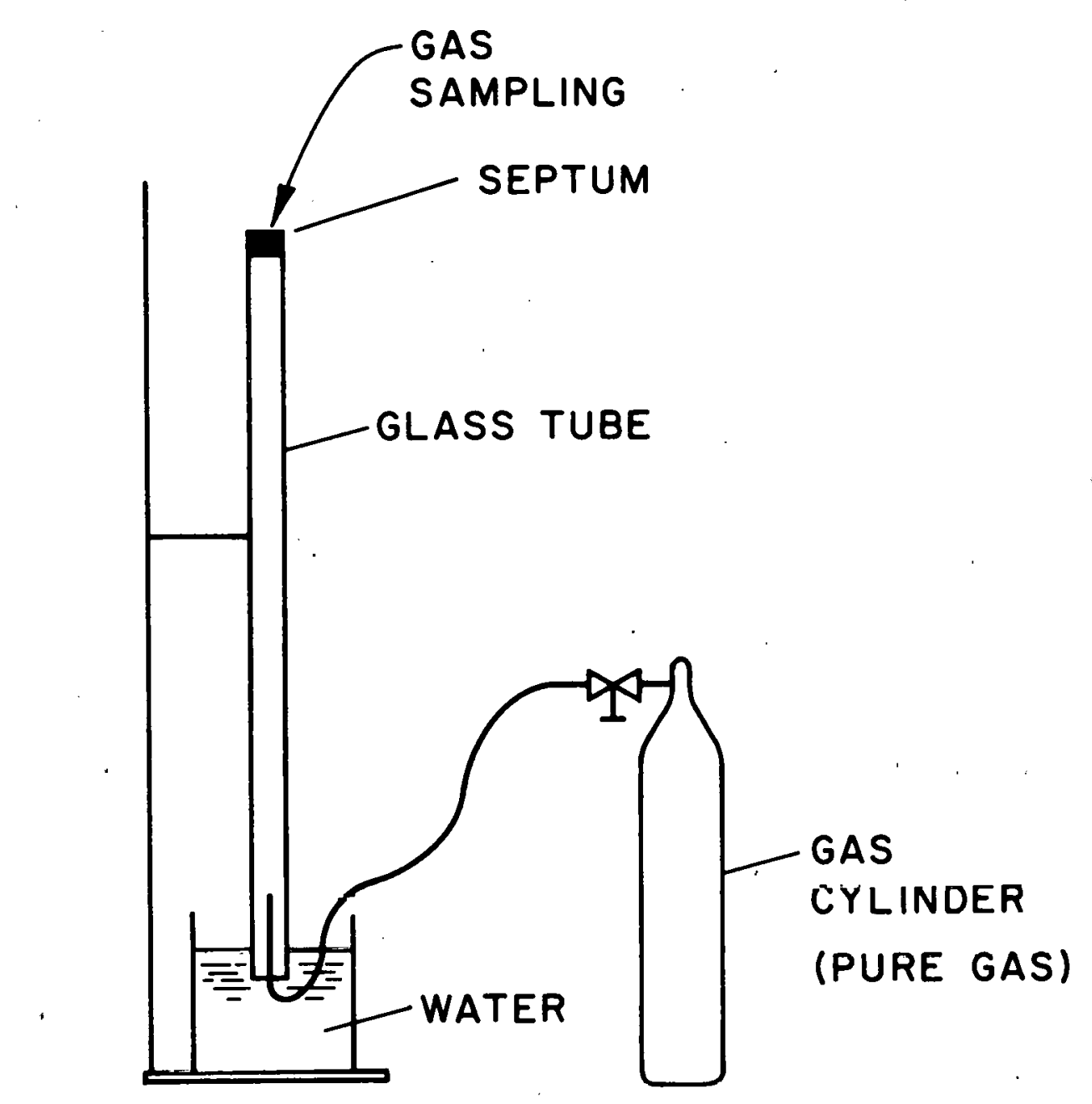

Figure 5.11. Experimental setup used to obtain the calibration curve shown on Fig. 5.12. 
ORNL DWG $80-1743$

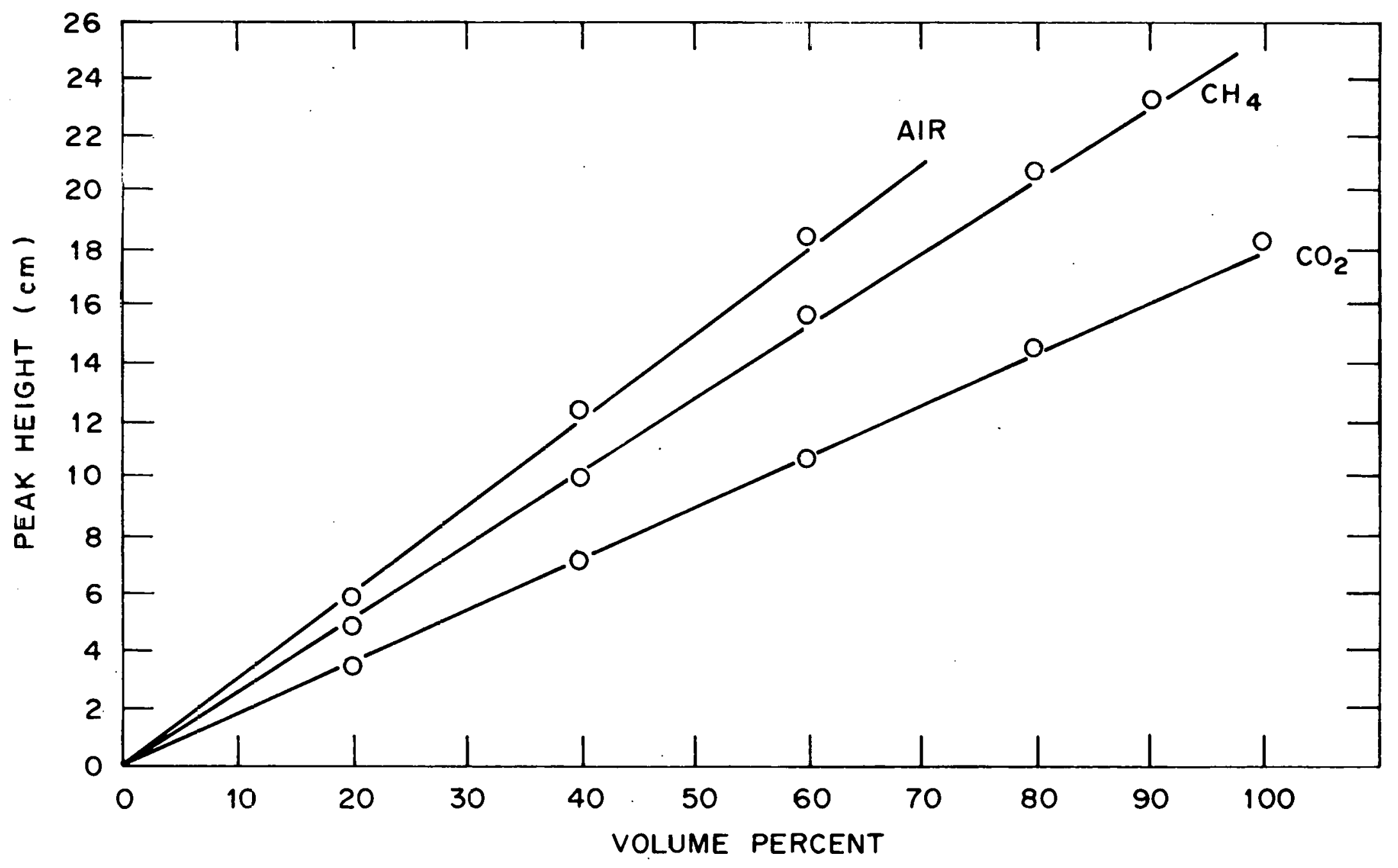

Figure 5.12. Calibration curves for the gas chromatograph used to cetermine the composition of the off-gas from the ANFLOW bioreactors. 
a lamp current of $5 \mathrm{~mA}$. The optimum working range under these conditions is 0.05 to $2.0 \mathrm{mg} / \mathrm{L}$ zinc. 50 A callbration curve was obtained in every analysis by combining the absorbance of a series of samples with known concentration before and after the analysis of the unknown sample. The standard curve was obtained using standards containing $0.2,0.4$, $0.8,1.2,1.6$, and $1.8 \mathrm{mg} / \mathrm{L}$ zinc. To simplify the management of the data gathered, a linear regression equation of the form, $y=a x+b$ (where $\mathrm{x}=$ absorbance and $\mathrm{y}=$ concentration of zinc in $\mathrm{mg} / \mathrm{L}$ ), was obtained for every analysis and used to calculate the concentration of zinc in the samples. A typical regression coefficient of 0.9999 was not uncommon .

Soluble zinc is considered as that remaining in the supernatant after centrifuging the sample at $10,000(16,300 \times \mathrm{g}) \mathrm{rpm}$ for $15 \mathrm{~min}$. Total zinc was determined after wet digestion (with sulfuric and nitric acids) of a representative portion of the sample.

\subsubsection{Sample Collection and Treatment}

The collection and treatment of the samples for the chemical analyses discussed in the previous sectiono are suminarized in Table 3.4 .

\subsubsection{Sorption Factors and Distribution of Zinc}

Solids (suspended and fixed-film) were nhtained at different heiglils of the column using the vacuum technique shown in Figure 5.13. This technique consisted of inserting a sampling probe $(60.96 \mathrm{~cm} \cdot 1$ ong and $0.32 \mathrm{~cm}$ inside diameter) across the packed bed. By rotating and moving 1t, from one end to the other of the column, solids were vacuumed into a $500-\mathrm{mL}$ flask. About 150 to $300 \mathrm{~mL}$ were collected during the operation. 
Table 5.4. Summary of Collection and Treatment of Samples for the Chemical Analyses

\begin{tabular}{|c|c|c|c|c|}
\hline Sample & $\begin{array}{l}\text { Kind of } \\
\text { Sample }\end{array}$ & $\begin{array}{l}\text { Chemical } \\
\text { Analysis }\end{array}$ & $\begin{array}{l}\text { Treatment of } \\
\text { Sample for } \\
\text { Analysis }\end{array}$ & $\begin{array}{l}\text { Treatment of } \\
\text { Sample for } \\
\text { Preservation }\end{array}$ \\
\hline \multirow{5}{*}{ Effluent } & \multirow{5}{*}{$\begin{array}{l}\text { Composite } \\
1-1.5 \mathrm{~h}\end{array}$} & Soluble COD & $\begin{array}{l}\text { Centrifugation at } \\
\text { ln, non rpm for } 15 \\
\text { min }\end{array}$ & $\begin{array}{l}\text { Add concentrated } \\
\mathrm{H}_{2} \mathrm{SO}_{4} \text { to } \mathrm{pH}<2 \text {, and } \\
\text { stored at a } \\
\text { temperature }=4^{\circ} \mathrm{C}\end{array}$ \\
\hline & & $\mathrm{pH}$ & None & $\begin{array}{l}\text { Always analyzed } \\
\text { immediately after } \\
\text { collection }\end{array}$ \\
\hline & & Alkalinity & None & Same as above \\
\hline & & Soluble zinc & $\begin{array}{l}\text { Centrifugation at } \\
10,000 \mathrm{rpm} \text { for } 15 \\
\text { min }\end{array}$ & Same as above \\
\hline & & Total zinc & $\begin{array}{l}\text { Wet digestion with } \\
\text { concentrated } \\
\mathrm{H}_{2} \mathrm{SO}_{4} \text { and } \mathrm{HNO}_{3}\end{array}$ & Same as above \\
\hline $\begin{array}{l}\text { off-gas, } \\
\text { sample taken } \\
\text { in gas line } \\
\text { at top-end } \\
\text { of bioreactor }\end{array}$ & Grab & Gas composition & None & None \\
\hline \multirow{3}{*}{$\begin{array}{l}\text { Rioreactor } \\
\text { profile }\end{array}$} & \multirow{3}{*}{ Grab } & Soluble COD & $\begin{array}{l}\text { Centrifugation at } \\
10,000 \text { rpm for } 15 \\
\text { min }\end{array}$ & $\begin{array}{l}\text { Add concentrated } \\
\mathrm{H}_{2} \mathrm{SO}_{4} \text { to } \mathrm{pH}<2, \cdot \\
\text { and stored at a } \\
\text { temperacure }=4^{\circ} \mathrm{C}\end{array}$ \\
\hline & & Volattle aclils & Sanc ar ahove & $\begin{array}{l}\text { Add concentrated } \\
\text { formic acid to } \mathrm{pH} \\
\text { <2, and otored at a } \\
\text { Lemperature }-4^{\circ} \mathrm{C}\end{array}$ \\
\hline & & Soluble zinc & Same as above & $\begin{array}{l}\text { Analyzed Immedlately } \\
\text { after collection }\end{array}$ \\
\hline
\end{tabular}




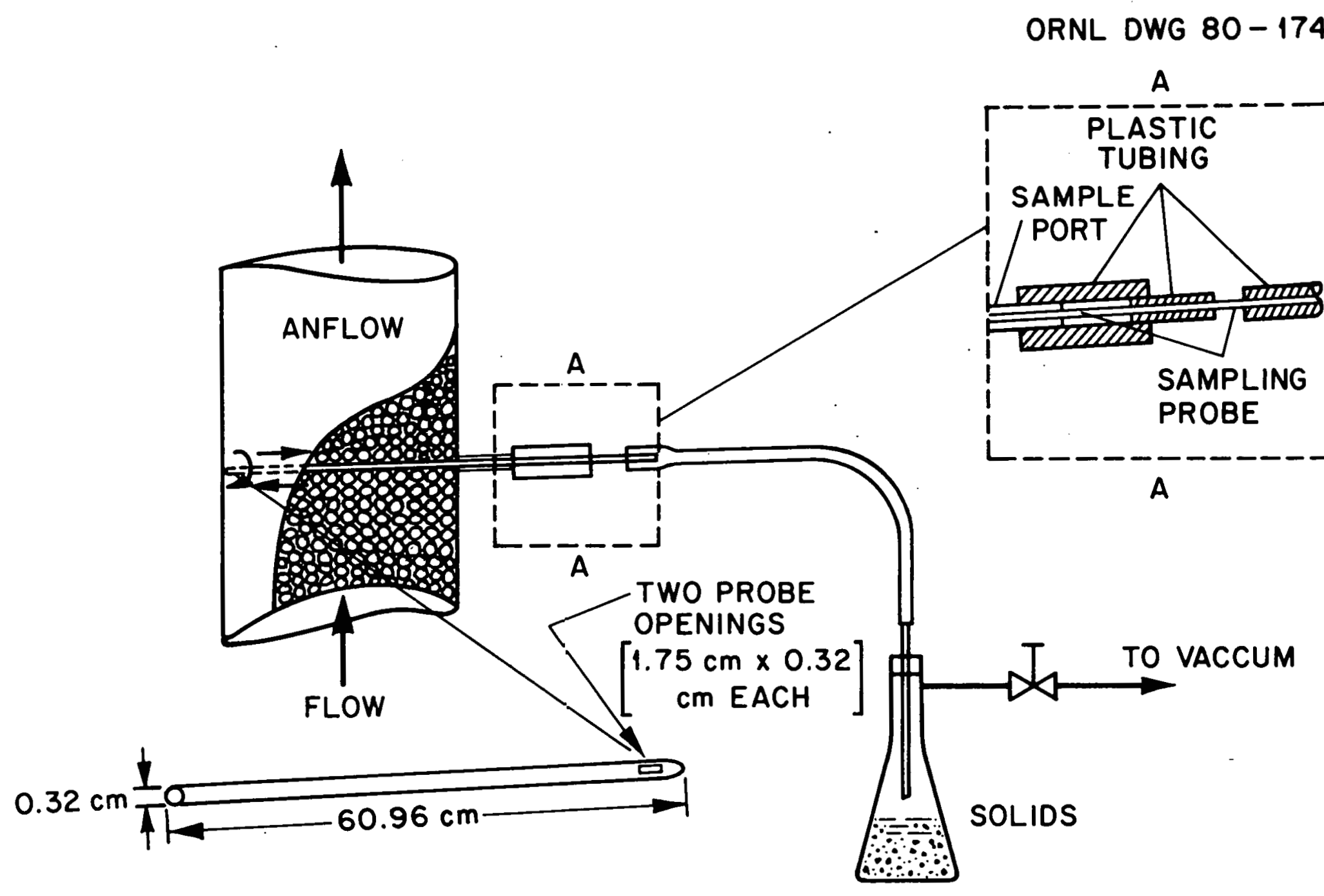

Figure 5.13. Schematic diagram of the sampling method developed to obtain solids samples from the ANFLOW bioreactors. The collected sample will contain fixed-film as well as suspended solids. 
The sampling probe was thin enough to follow a tortuous sampling path if necessary. Liquid was prevented from leaking out of the column by connecting tubing sections where the inside diameter of one section was equal to the outside diameter of the other (See section A-A on Figure 5.13). After collection, the solids were centrifuged at $10,000 \mathrm{rpm}$ $(16,300 \mathrm{xg})$ for $15 \mathrm{~min}$ and air-dried in a hood for 2 to 3 days. At the end of the drying period they were ground and stored in a desiccator for future analysis.

Weighed amounts of dry solids were wet-digested, and their zinc content was determined. This was done by suspending the solids in an acid solution made of $30 \mathrm{~mL}$ of deionized distilled water and $20 \mathrm{~mL}(10 \mathrm{~mL}$ each) of concentrated sulfuric and nitric acids. After adding a few glass beads, this mixture was boiled until the solution was clear and white fumes appeared. After cooling, this solution was filtered using a porcelain filtering funnel and diluted to $1000 \mathrm{~mL}$ or any other suitable volume. This final solution was analyzed for the zinc content.

The sorption factor as defined in this report is an indicator of the degree of association of a heavy metal with the dry solids. This factor was calculated using the following equation:

$$
S F_{T}=\left(\frac{C \times V}{W}\right) \times\left(\frac{1000}{65.37}\right)
$$

where: $\quad \mathrm{SF}_{\mathrm{T}}=$ sorption factor, moles zinc/kg dry solids

$$
\begin{aligned}
(\mathrm{CxV}) & =\text { milligrams of zinc recovered from digestion of solids } \\
\mathrm{C} & =\text { concentration of zinc in final solution, mg } / \mathrm{L} \\
\mathrm{V} & =\text { volume of final solution, } \mathrm{L} \\
\mathrm{W} & =\text { milligrams of dry solids digested } \\
65.37 \mathrm{~g} / \mathrm{mol} & =\text { atomic weight of zinc }
\end{aligned}
$$


An extraction method was developed to characterize the heavy metal. A simplified version of the method used by Stover et al.51 was used to characterize zinc in two fractions: organically bound (associated with the biosolids) and precipitated (sulphides and carbonates). The method, shown in Figure 5.14 involves the extraction of zinc by suspending a weighed amount of dry solids in $100 \mathrm{~mL}$ of a 0.1 M tetrasodium pyrophosphate $\left(\mathrm{Na}_{4} \mathrm{P}_{2} \mathrm{O}_{7}\right)$ solution: This mixture was shaken at $200 \mathrm{rpm}(1-\mathrm{in}$. stroke) for $24 \mathrm{~h}$ in a New Brunswick Scientific water-bath rotary shaker. At the end of shaking period this mixture was centrifuged at $10,000 \mathrm{rpm}$ for $15 \mathrm{~min}$ and the supernatant was analyzed for zinc content. The amount of zinc in the supernatant was mainly that fraction of zinc organically bound in the sollds. (These authors claimed that sodium pyrophosphate removes organically bound heavy metals and has a.low extractive power for metals in a carbonate or sulfide form. Tetrasodium pyrophosphate is also widely used by workers in the Soll Sciences to exliacl metals from soil samples. $52-34$ That amount of metal removed with $\mathrm{Na}_{4} \mathrm{P}_{2} \mathrm{O}_{7}$ is generally characterized as organically bound.) Wet digestion of the remaining solids provided the fraction of zinc that was in a precipitated form.

The sorption factors for each one of the fractions was calculated using equations (5-4) and (5-5). The organically bound zinc is calculated, in terms of percentages, as:

$$
\% \text { organically bound } \mathrm{Zn}=\frac{\mathrm{SF}_{\mathrm{O}}}{\mathrm{SF}_{\mathrm{O}}+\mathrm{SF}_{\mathrm{p}}} \times 100
$$


ORNL DWG 80-1751

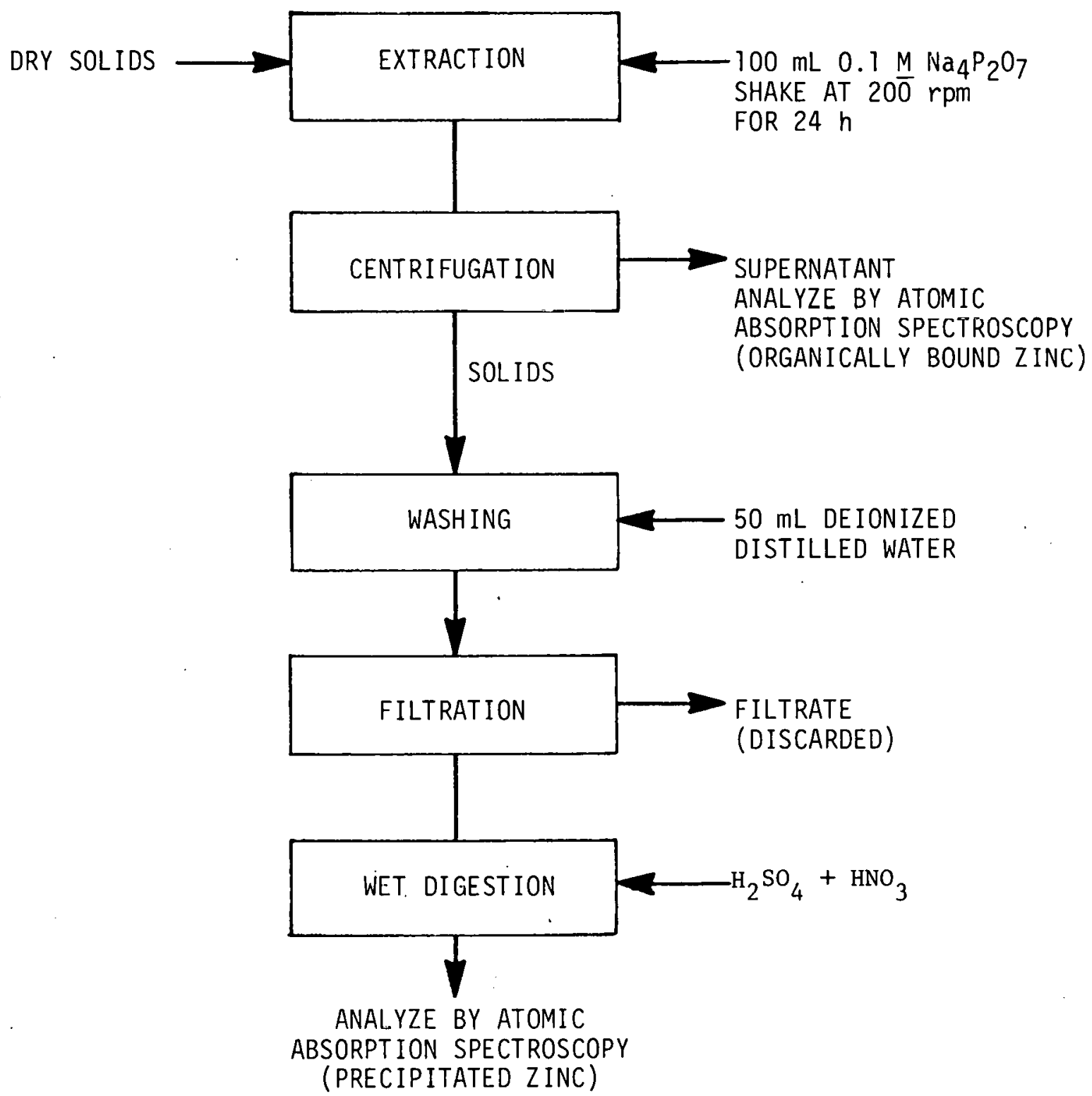

Figure 5.14. Experimental method used to characterize zinc in ANFLOW solids as organically bound and precipitated (mainly carbonate and sulfide). 
and the percent precipitated zinc, as:

$$
\% \text { precipitated } \mathrm{Zn}=\frac{\mathrm{SF}_{\mathrm{p}}}{\mathrm{SF}_{\mathrm{O}}+\mathrm{SF}_{\mathrm{p}}} \times 100
$$

\subsubsection{Determining Global and Regional First Order Rate Constants}

The global and regional first-order rate constants were calculated by trial and error using a computer code to solve equation (3-28). The remaining soluble COD fraction for the overall model was simply the effluent soluble COD divided by 3000 ( $3000 \mathrm{mg} / \mathrm{L}$ was taken as the influent soluble COD for all computations). For the regional model the remaining soluble COD fractions were obtained from the soluble COD profiles performed during the toxicity experiments. This was done by considering that the effluent from the first region (sample port No. 1) was the influent for the second region, and the effluent from the second region (sample port No. 4) was the influent for the last region.

\section{RESULTS AND DISCUSSION OF RESUL'IS}

This section summarizes the results obtained after studying the phenomena of toxicity from zinc, as zinc chloride $\left(\mathrm{ZnCl}_{2}\right)$, in laboratory-scale ANFLOW bioreactors. It begins in Section 6.1 with the results obtained from the residence time distribution experiments, mainly the average hydraulic residence time and the reactor dispersion number. After determining these two characteristic parameters, the first-order rate constant was calculated from the plugflow with dispersion model. This kinetic parameter was used to characterize the phenomena of toxicity. 
Section 6.2 describes the bioreactor response from toxicity as described by the first-order rate constant. Bioreactor response to toxicity as reflected by operational parameters such as effluent soluble COD, soluble COD profiles, gas production rate, gas composition, acetic and propionic acid profiles, and $\mathrm{pH}$ and alkalinfty is covered in Section 6.3. Section 6.4 describes the bioreactor performance for soluble zinc removal, and Section 6.5 covers the sorption factors and distribution of zinc under step-feeding conditions. Possible association of these phenomena with the phenomena of toxicity is included. This chapter concludes with some discussions about the phenomena of recovering from inhibition or toxiclty (see Section 6.6).

\subsection{Average Residence Time and Reactor Dispersion Number}

To test the assumption that the RTD curves were log-normally distributed, the concentration of fluorescein dye (as $\%$ emission) was plotted against the logarithm of $t$ ( $t$ in minutes) as shown in Figures 6.1 and 6.3. As can be seen, they are reasonably normal, and equation (5.11) could be used to calculate the time of peak concentration $\left(t_{p}\right)$.

Table 6.1 summarizes the results obtained from the RTD experiments. It can be seen that the variance (VAR) method gave lower reactor dispersion numbers as compared to the time of peak concentration (TPC) method. The dispersion numbers differ by a factor of 2 to 3 .

To test which method gave better results the theoretical dispersioncurves described by the calculated dispersion numbers were obtained and compare with the experimental RTDs. As shown in Figures 6.4 to 6.9 the TPC method gave dispersion numbers that most closely described the experimental RTDs. 
ORNL DWG 80-1611

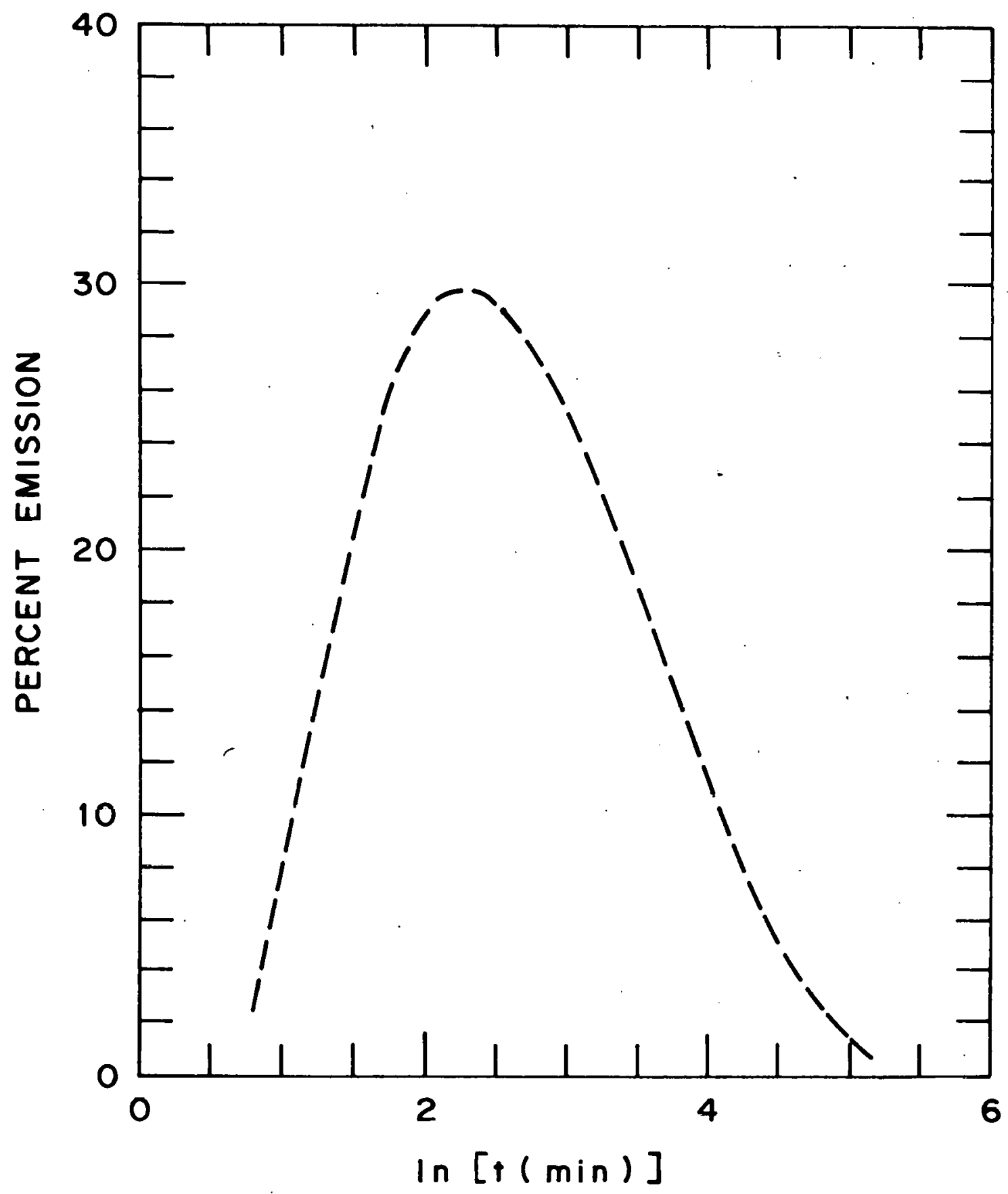

Figure 6.1. Fluorescein dye concentration (percent emission) against the natural logarithm of $t$ (in minutes) for bioreactor $\mathrm{T}-2$. 
ORNL DWG 80-1610

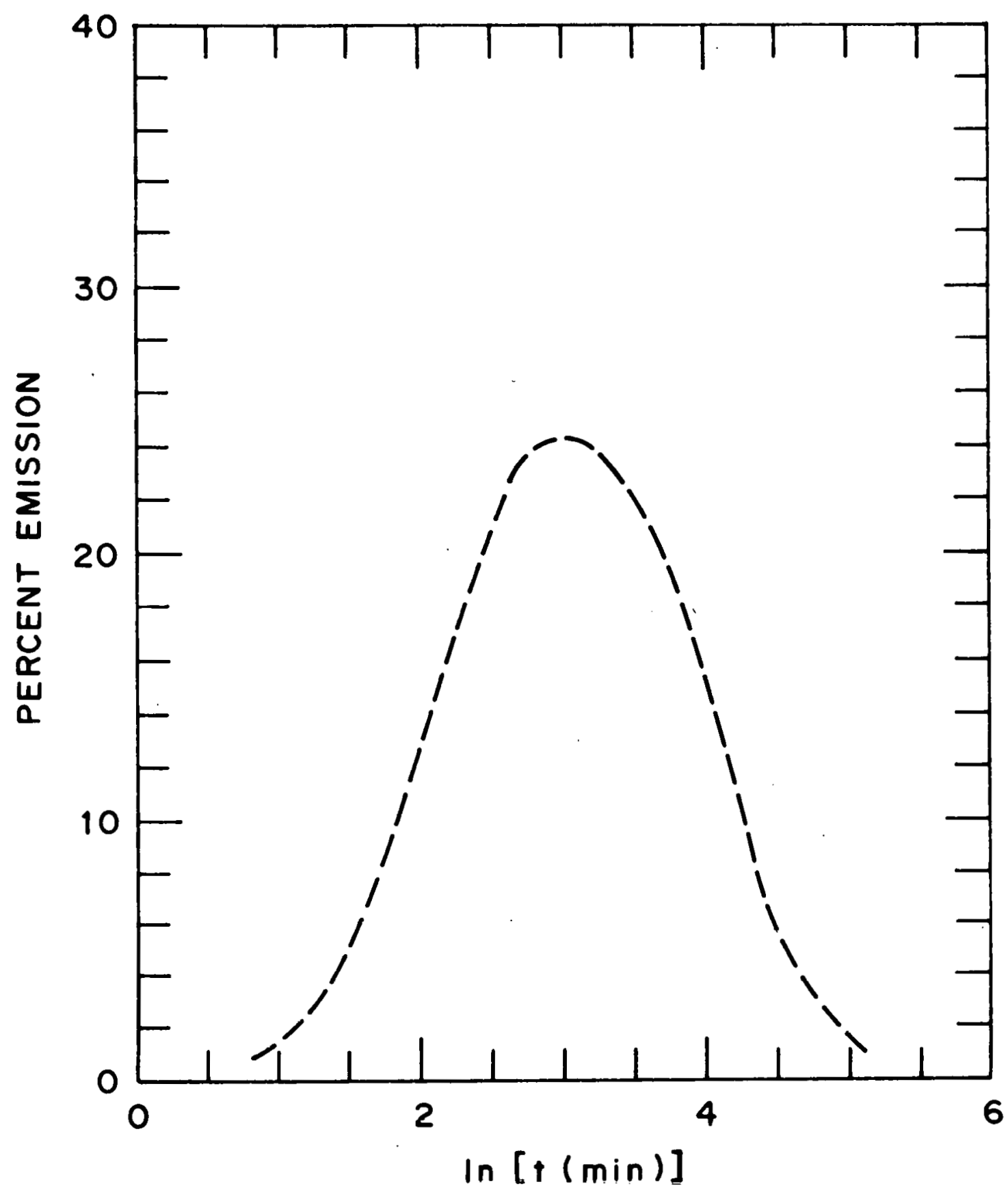

Figure 6.2. Fluorescein dye concentration (percent emission) against the natural logarithm of $t$ (in minutes) for control bioreactor. 
ORNL DWG 80-1609

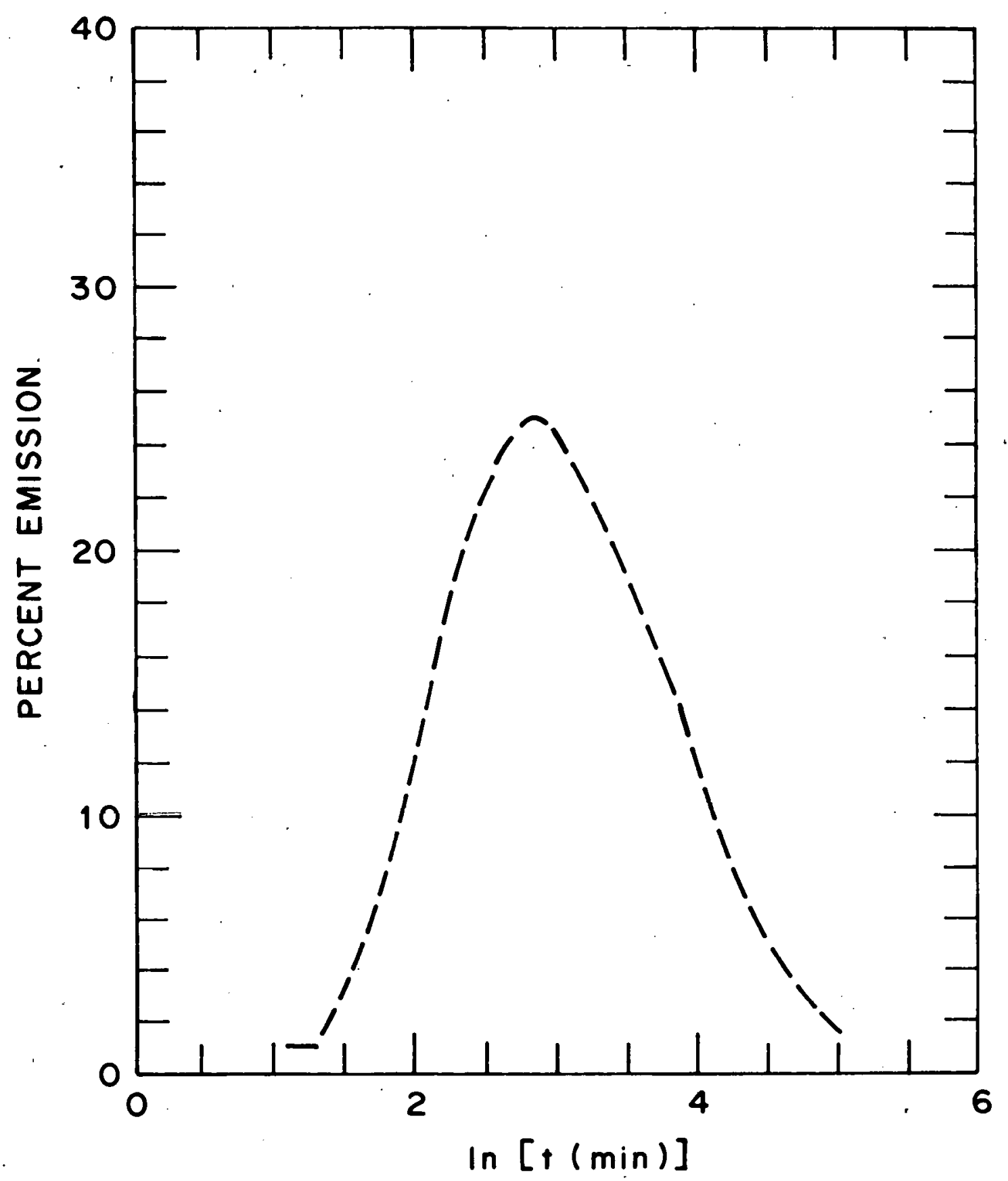

Figure 6.3. Fluorescein dye concentration (percent emission) against the natural logarithm of $t$ (in minutes) for bioreactor T-1. 
Table 6.1. Summary of the Results obtained from the Residence Time Distribution Experiments

\begin{tabular}{lllllllll}
\hline Bioreactor & $\begin{array}{c}t \\
(\mathrm{~h})\end{array}$ & $\begin{array}{l}\mathrm{t}_{\mathrm{g}} \\
(\mathrm{h})\end{array}$ & $\begin{array}{l}\sigma_{\mathrm{t}}{ }^{2} \\
\left(\mathrm{~h}^{2}\right)\end{array}$ & $\sigma^{2} \mathrm{n}$ & $\begin{array}{c}\mathrm{t}_{\mathrm{p}} \\
(\mathrm{h})\end{array}$ & $\theta_{\mathrm{p}}$ & $\begin{array}{c}(\mathrm{D} / \mathrm{uL})_{\text {VAR }}{ }^{\mathrm{a}} \\
(\mathrm{D} / \mathrm{uL})_{\mathrm{TPC}}^{\mathrm{b}}\end{array}$ \\
\hline $\mathrm{T}-1$ & 43.8 & 34.4 & 895.4 & 0.5177 & 16.8 & 0.38 & 0.33 & 0.64 \\
\hline $\mathrm{T}-2$ & 40.9 & 33.2 & 890.3 & 0.7412 & 12.5 & 0.31 & 0.35 & 0.92 \\
\hline Control & 46.6 & 36.8 & 979.1 & 0.5258 & 17.8 & 0.38 & 0.33 & 0.64 \\
\hline
\end{tabular}

a Variance method.

$\mathrm{b}_{\text {Time of }}$ peak concentration method. 
ORNL OWG 80-1620

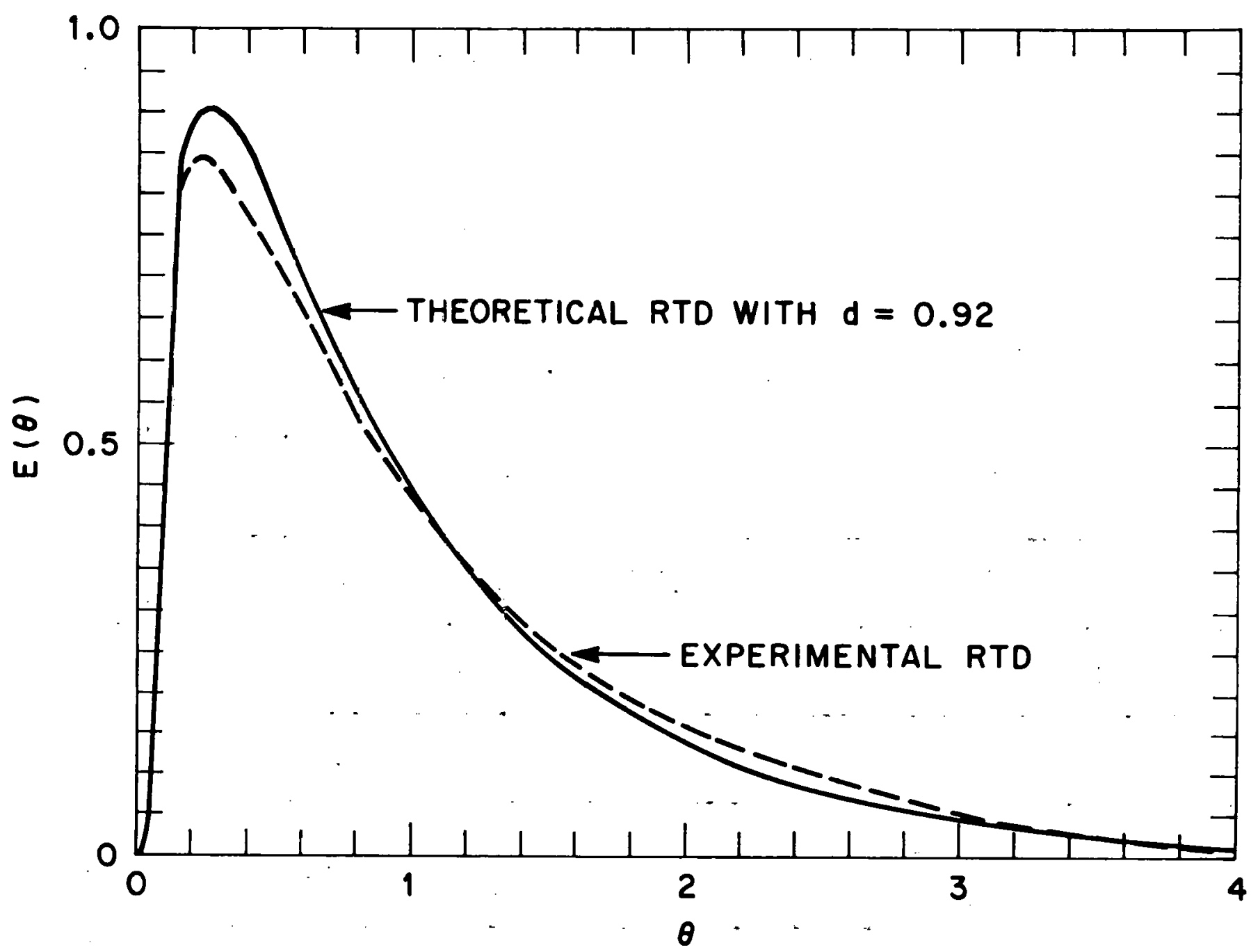

Figure 6.4. Comparisor between the experimental RTD for bioreactor $\mathrm{T}-2$ and the theoretical RTD based on a reactor dispersion number of 0.92 obtained from the time of peak concentration method. 
ORNL DWG 80-1615

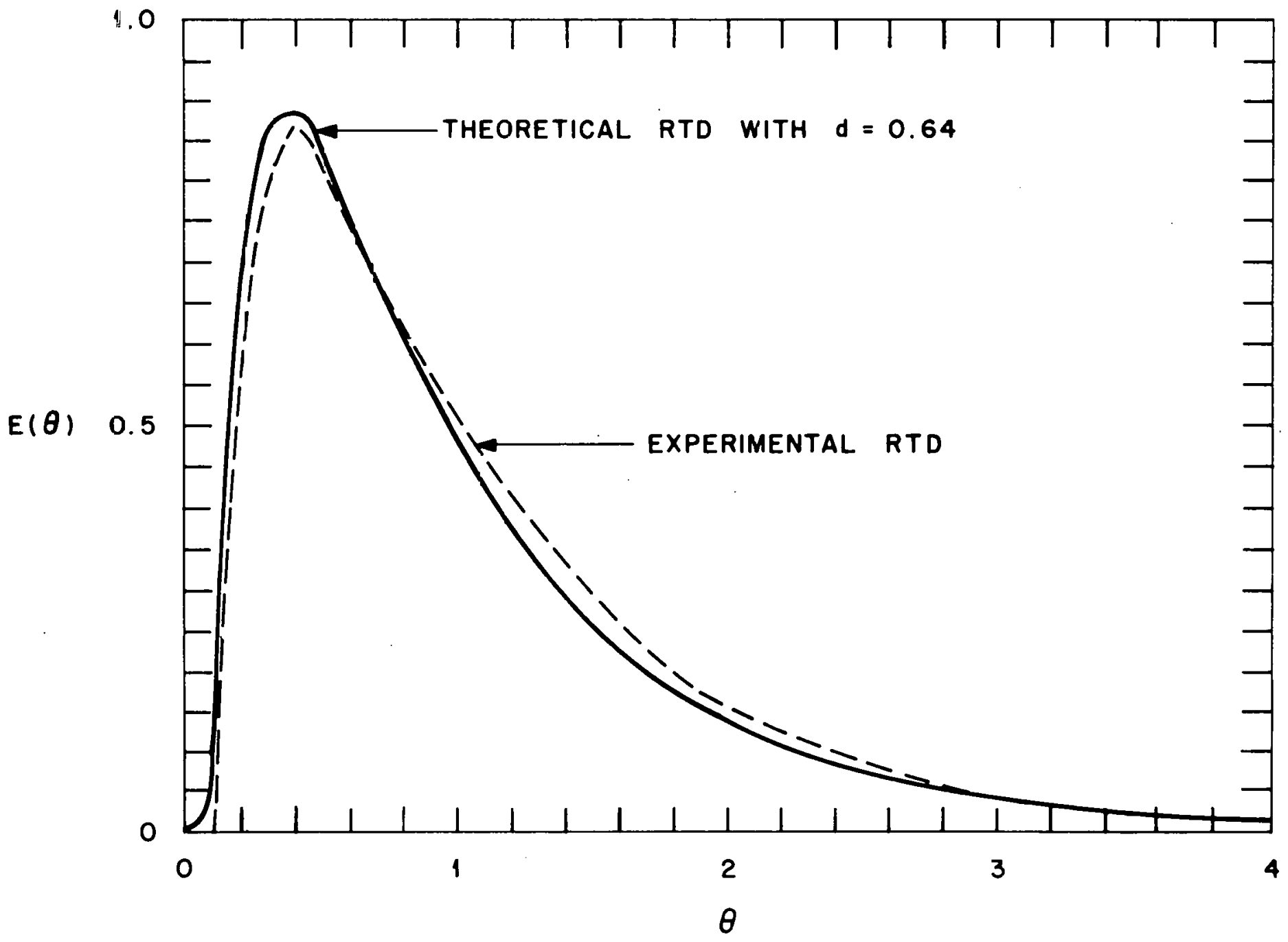

Figure 6.5. Comparison between the experimental RTD for bioreactor $\mathrm{T}-1$ and the theoretical RTD based on a reactor dispersion number of 0.64 obtained from the time of peak concentration method. 
ORNL DWG 80-1616

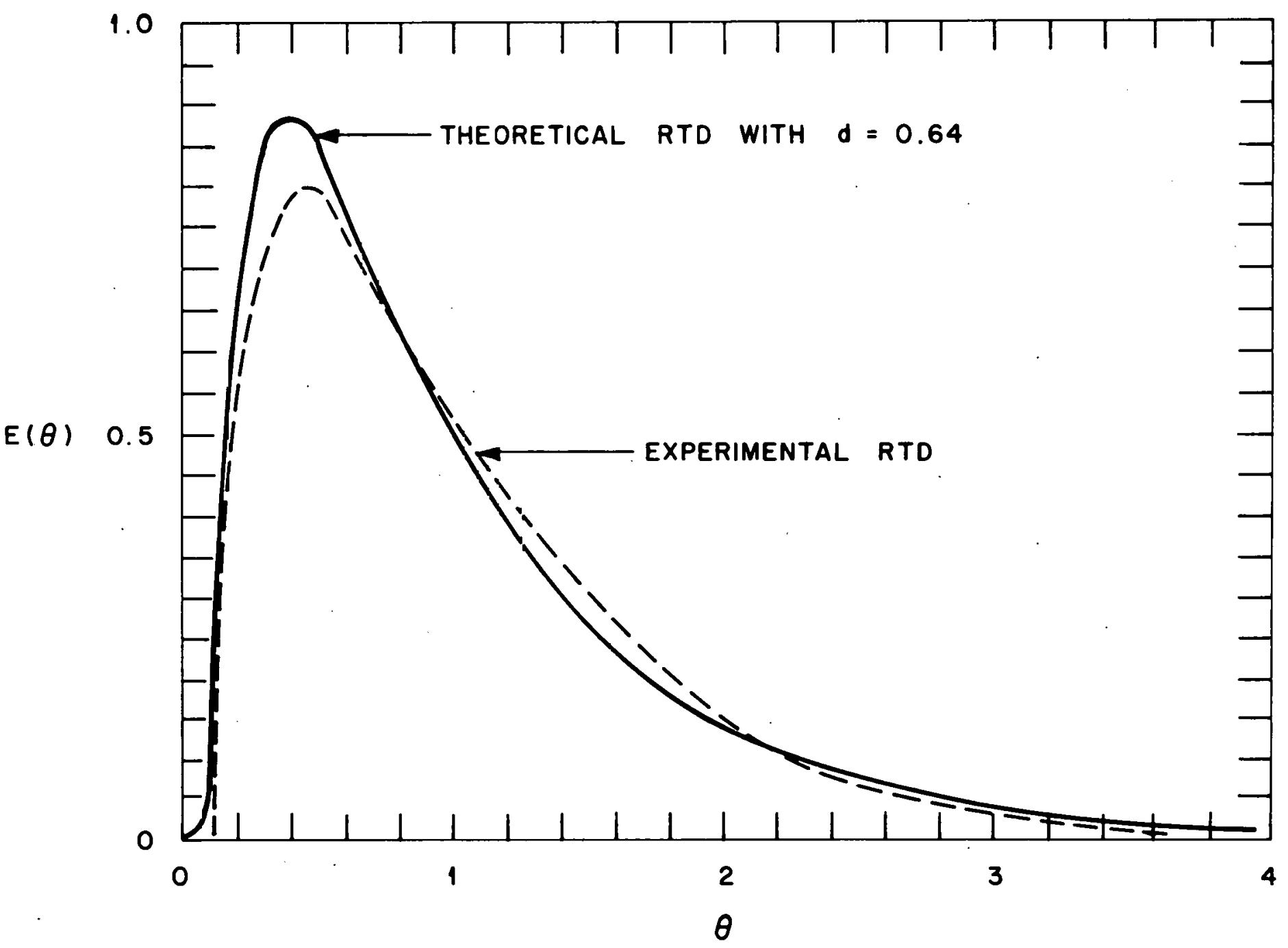

Figure 6.6. Comparison between the experimental RTD for control bioreactor and the theoretical RTD based on a reactor dispersion number of 0.64 obtained from the time of peak concentration method. 


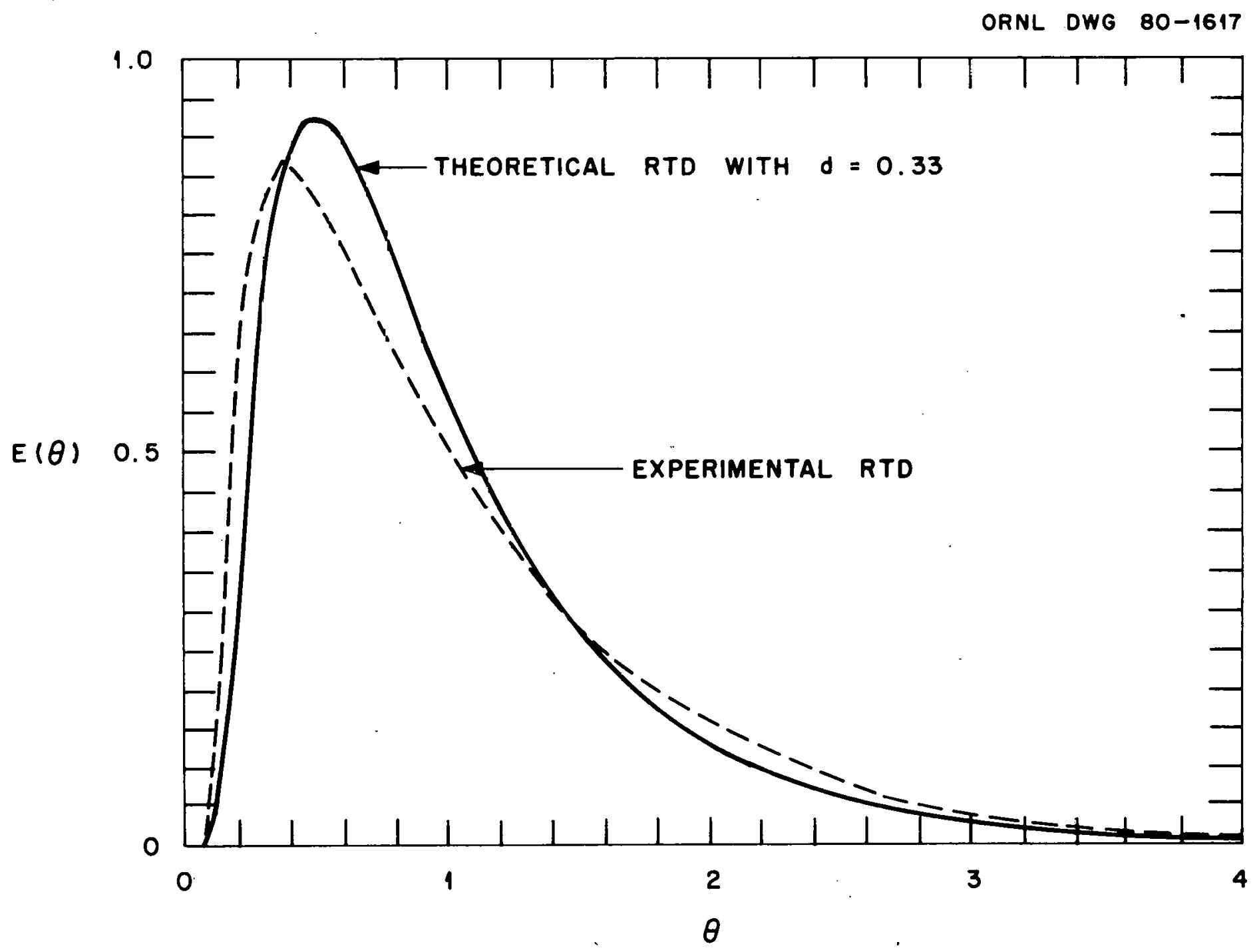

Figure 6.7. Comparison between the experimental RTD for bioreactor T-1 and the theoretical RTD based on a reactor dispersion number of 0.33 obtainec from the variance method. 
ORNL DWG 80-1618

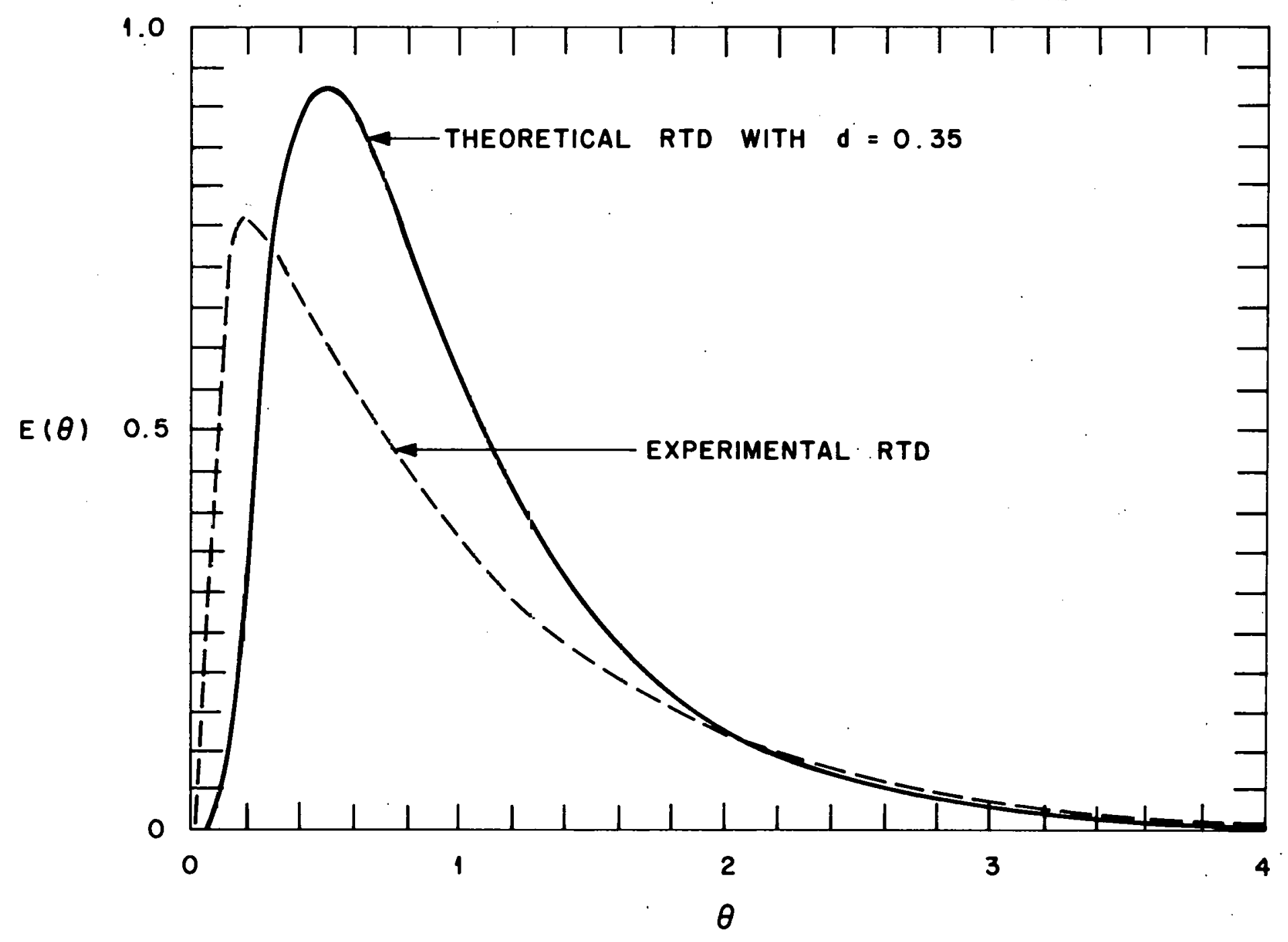

Figure 6.8. Comparisor between the experimental RTD for bioreactor T-2 and the theoretical RTD based on a reactor dispersion number of 0.35 obtained from the wariance method. 
ORNL DWG 80-1619

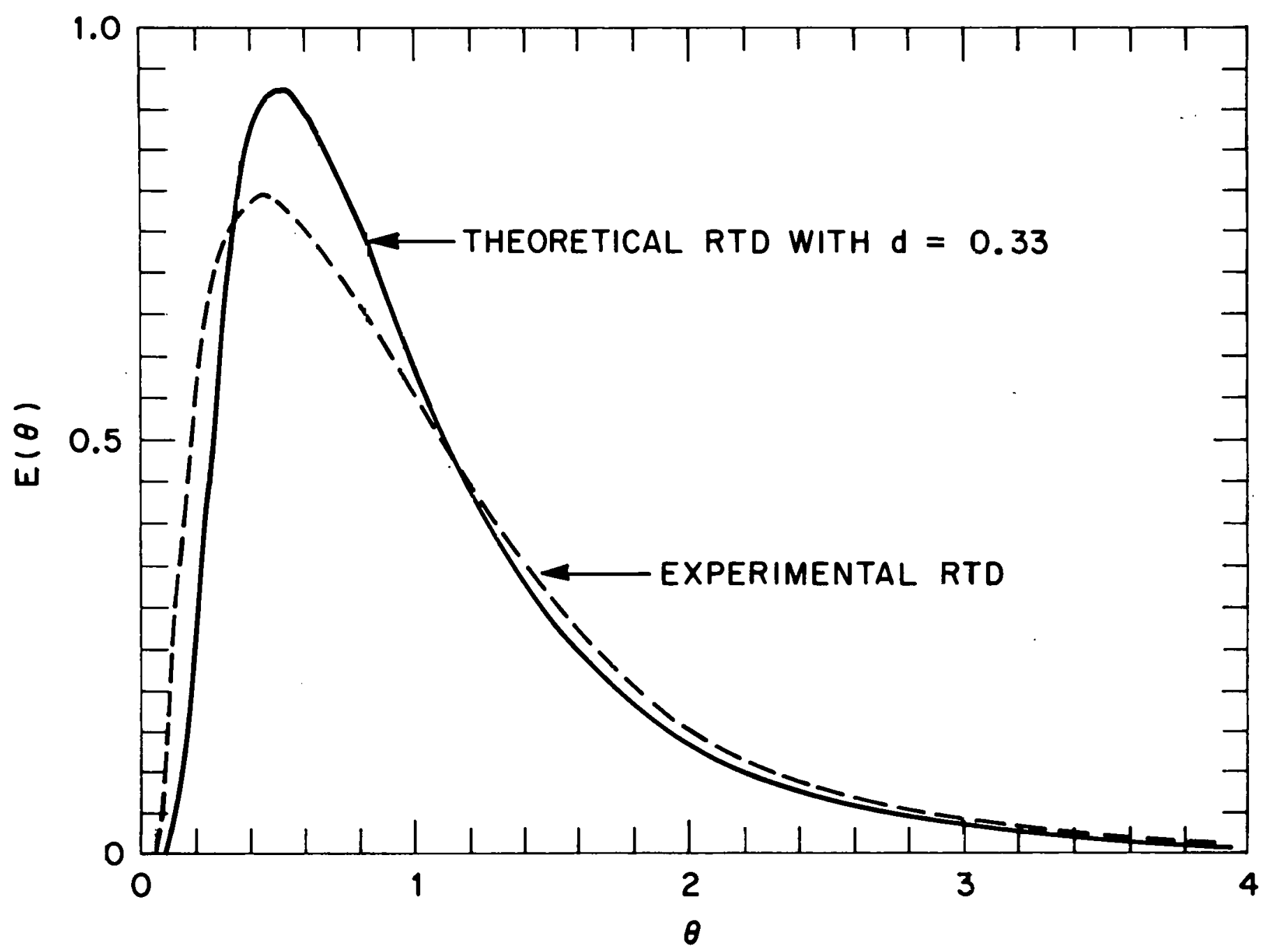

Figure 6.9. Comparison between the experimental RTD for control fioreactor and the theoretical RTD based on a reactor dispersion rumber of 0.33 obtained from the variance method. 
Even though the TPC method described the experimental RTD curves better than the VAR method some difference can be seen between the theoretical and experimental curves. Two factors that might explain the difference is the sorption/desorption phenomena between fluorescein dye and the packing-fixed-film system and the porosity of the packing. These two phenomena are not considered in the dispersion model. The porosity of the packing in a, packed bed is part of the liquid holdup system and contributes to the tailing in the RTD curve.29,30,55 Packing with high porosities can be considered as the main cause of the tailing phenomena in the RTD for these systems. This tailing in the RTD curves can cause some inaccuracies when the dispersion number is calculated from the variance method.60 Other models56-59 have been developed to account for these phenomena but they use three, four, or even more parameters to very closely describe experimental RTD curves.

An extensive study of hydraulic phenomena in ANFLOW biorcactors was beyond the scope of this work. Research in this area is suggested if the dispersion model is further developed to be incorporated as part of the design rriteria for ANFLOW bioleaclurs. In this research, however, the main objective in performing the RTD experiment was to determine the reactor dispersion number and average residence time. As seen from the results obtained, the time of peak concentration method gave a better estimate of the reactor dispersion number for the experimental conditions used. 
6.2 The Phenomena of Toxicity as Described by the Dispersion Model with First Order Kinetics

The response of an ANFLOW bioreactor to heavy metal-induced toxicity can be considered to depend, among other things, on the regional performance of the reactor under steady-state conditions (or free of inhibition), the toxic effects of the toxicant on the regional phenomena and the characteristics of the toxic input function. It seems to be a general trend for these bioreactors to have most of the hiological activity located on the lower sections of the vessel. The volume of such region depends mainly on the organic loading rate, avallability of nutrients, and environmental conditions.

Table 6.2 shows the characteristics parameters $t$ and $d$ for each bioreactor as needed to solve equation (3.28) for the global and regional first-order rate kinetic constants.

\subsubsection{Global Phenomena}

The response of the dosed ANFLOW bioreactors during the three toxicity experiments, as measured by the global first-order rate constant, are shown in Figures 6.10 to 6.12 . By comparing the response curves of toxicity experiments No. 1 and No. 2 (under shock-load conditions) two major observations can be made: (1) the degree of inhibition as measured by $\Delta K$ was higher with a larger amount of soluble zinc, and (2) the lower the value of $\mathrm{K}$ during the days following the introduction of the shock load the longer it took to recover. These two observations were anticipated since the potential of a heavy metal to induce toxicity increases with increase in the soluble fraction. 
Table 6.2. Summary of the Characteristic Parameters for Global and Regional Kinetic Models

\begin{tabular}{|c|c|c|c|c|c|c|c|c|c|c|c|c|}
\hline \multirow[b]{2}{*}{ Bioreactor } & \multicolumn{3}{|c|}{ Global } & \multicolumn{3}{|c|}{ Region I } & \multicolumn{3}{|c|}{ Region II } & \multicolumn{3}{|c|}{ Region III } \\
\hline & $L^{a}$ & $\overline{\mathrm{tb}}$ & $\mathrm{dc}$ & $\Xi$ & $\overline{\mathrm{t}}$ & $\mathrm{d}$ & $\mathrm{L}$ & $\bar{t}$ & $d$ & $\mathrm{~L}$ & $\bar{t}$ & d \\
\hline $\mathrm{T}-1$ & 1.83 & 43.8 & 0.64 & 0.15 & 3.7 & 7.68 & 0.46 & 11.0 & 2.56 & 1.22 & 29.2 & 0.96 \\
\hline $\mathrm{T}-2$ & 1.83 & 40.9 & 0.92 & 0.15 & 3.4 & 11.04 & 0.46 & 10.2 & 3.68 & 1.22 & 27.3 & 1.38 \\
\hline Control & 1.83 & 46.6 & 0.64 & 0.15 & 3.9 & 7.68 & 0.46 & 11.7 & 2.56 & 1.22 & 31.1 & 0.96 \\
\hline
\end{tabular}

$\mathrm{a}_{\mathrm{L}}=$ length of bioreactor region $(\mathrm{m})$.

$\mathrm{b} \overline{\mathrm{t}}=$ calculated regional average residence time $(h)$.

$c_{d}=(D / u L)=$ reactor dispersion number. 
ORNL DWG 81-65

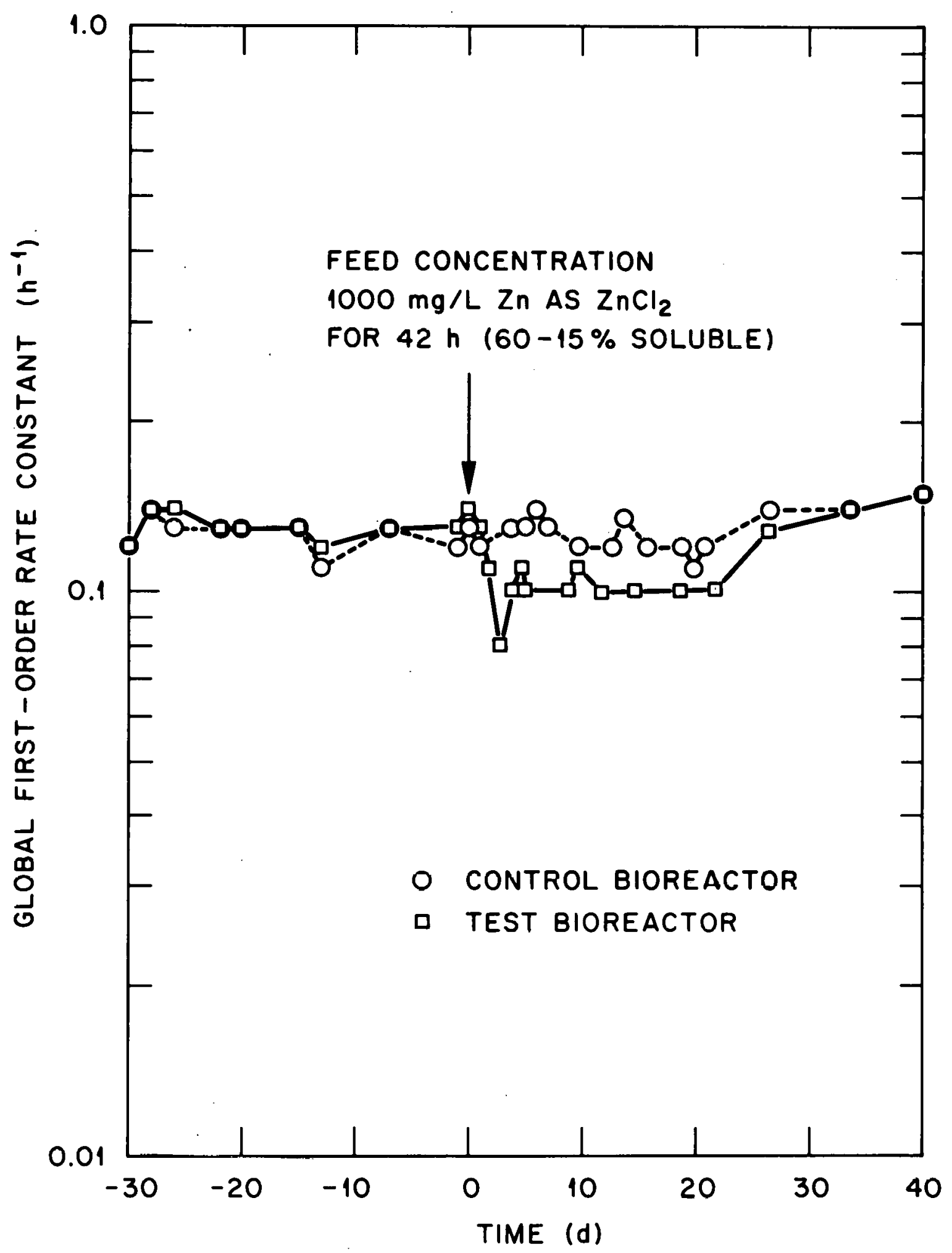

Figure 6.10. Global first-order rate constants for control and test ( $\mathrm{T}-1)$ bioreactors during toxicity experiment No. 1. 
ORNL DWG 81-62

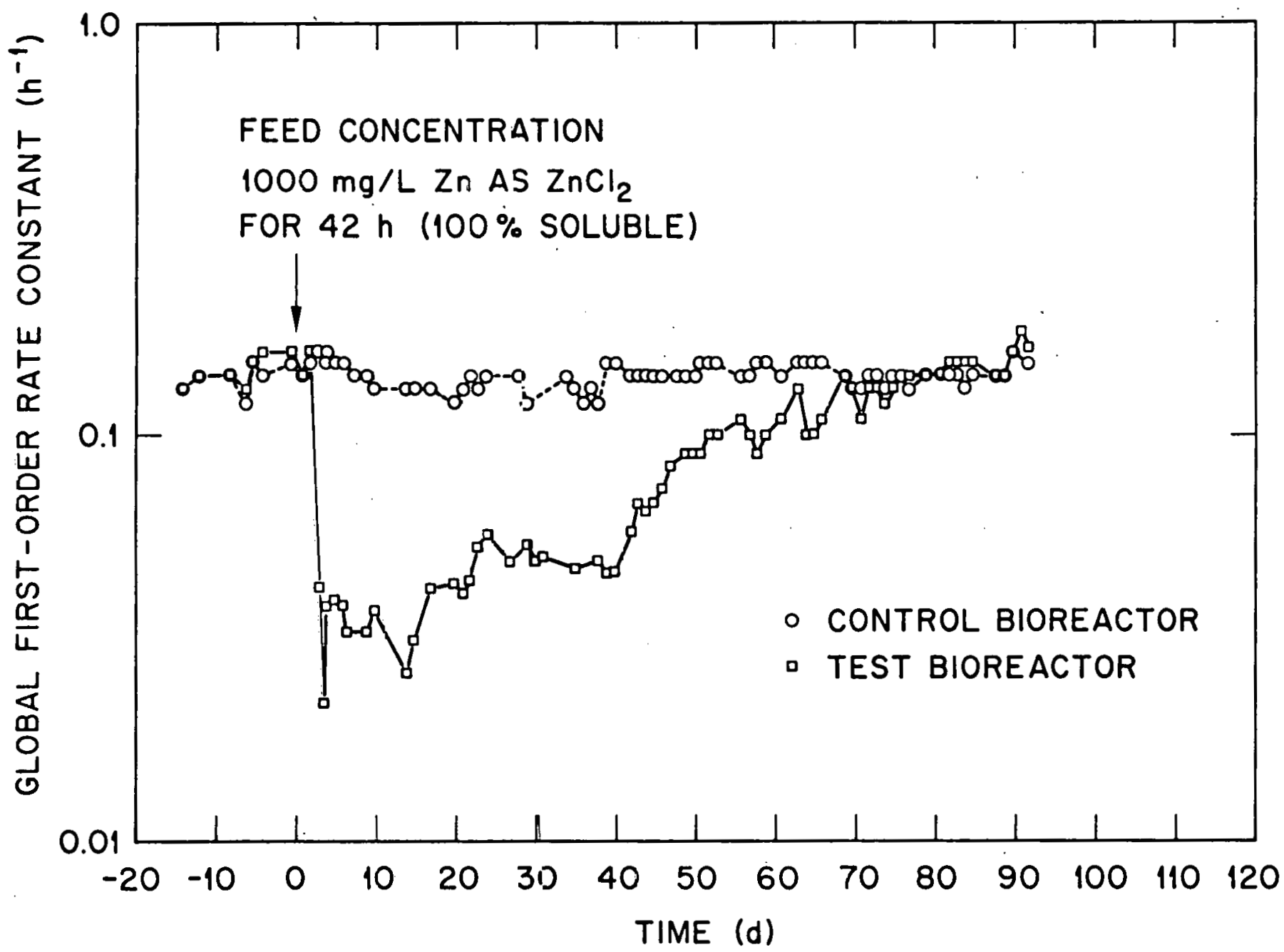

Figure 6.11. Global first-order rate constants for control and test $(\mathrm{T}-1)$ bioreactors during toxicity experiment No. 2 . 
ORNL DWG $81-66$

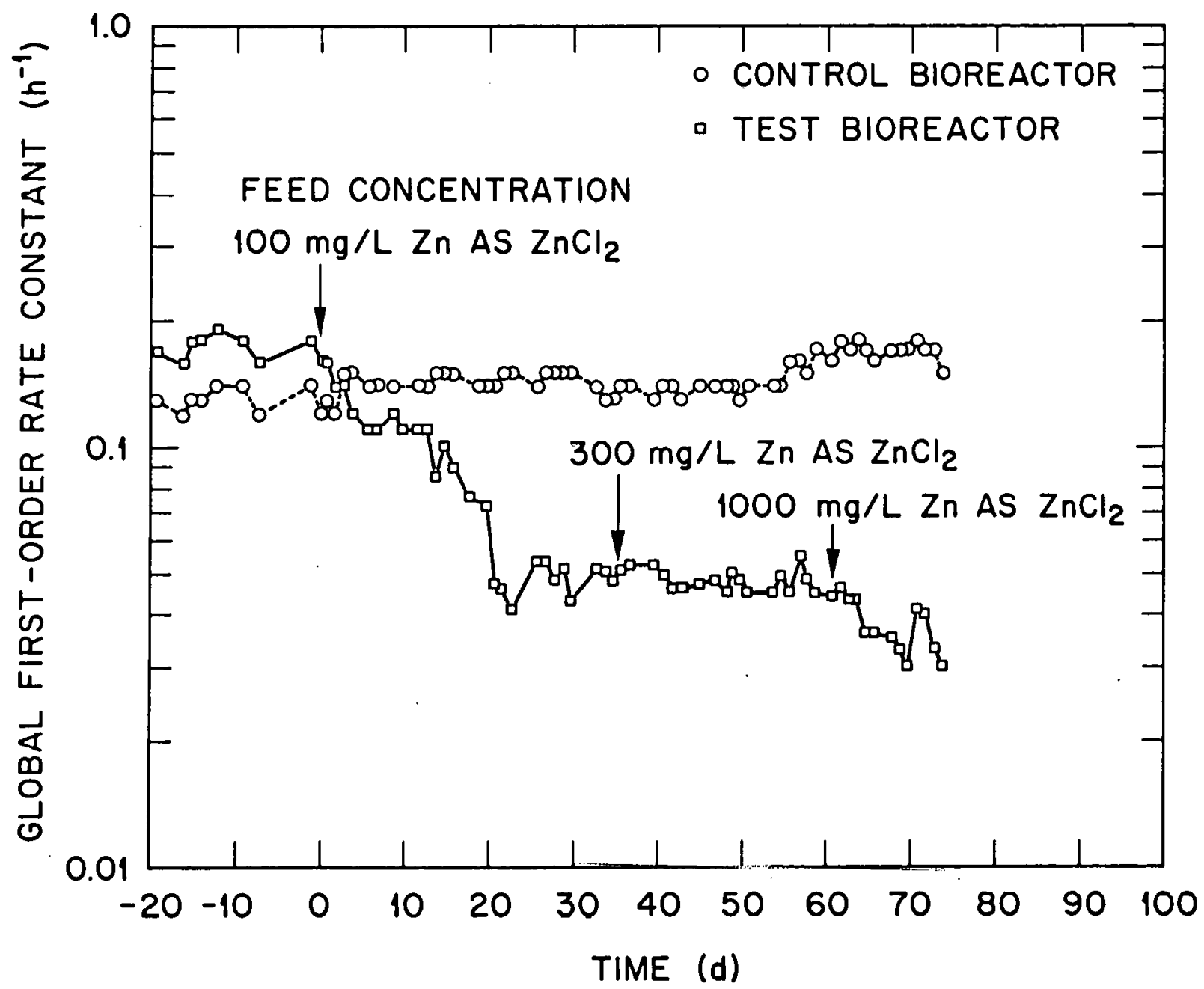

Figure 6.12. Global first-order rate constants for control and test (T-2) bioreactors during toxicity experiment No. 3. 
For toxicity experiment No. 3 (step function) there is a gradual decrease in the global first-order rate constant during the first 20 days (see Figure 6.12). From 20 to 60 days there was not so much change in reactor performance even though the concentration of the heavy metal in the feed solution was increased by a factor of 3 to $300 \mathrm{mg} / \mathrm{L}$. If Figure 6.12 were the only source of information it could be concluded that the system was developing some sort of acclimation to the inhibitory feed. Furthermore, when the concentration of zinc was increased to $1000 \mathrm{mg} / \mathrm{L}$ (a factor of about 3.3) there was not an immediate response as in shock-loading. The response pattern appears to follow the same trend as with $100 \mathrm{mg} / \mathrm{L}$. All these observations are complemented when the phenomena of toxicity is described with the regional kinetic model and its kinetic lump parameter, the local or reglonal first-order constant.

The response pattern for shock-loads in terms of the global firstorder rate constant can be generalized using Figure 6.13. Three parameters characterize the pattern: $t_{1}, t_{2}$, and $k_{m i n}$. The rate of inhibition and recovery can be expressed as:

$$
\begin{aligned}
& \text { rate of inhibition }=-\frac{d K}{d t} \text {, for } 0 \leq t \leq t_{1} \\
& \text { rate of recovery }=\frac{d K}{d t} \text {, for } t_{1} \leq t \leq t_{2}
\end{aligned}
$$

These parameters $\left(t_{1}, t_{2}, K_{\min }\right)$ depend among other things on the input function, regional phenomena, and flow characteristics.

An expression could be found to describe the variations of $K$ with time after the introduction of the shock-load (slug). An equation of the form, 
ORNL DWG 81-151

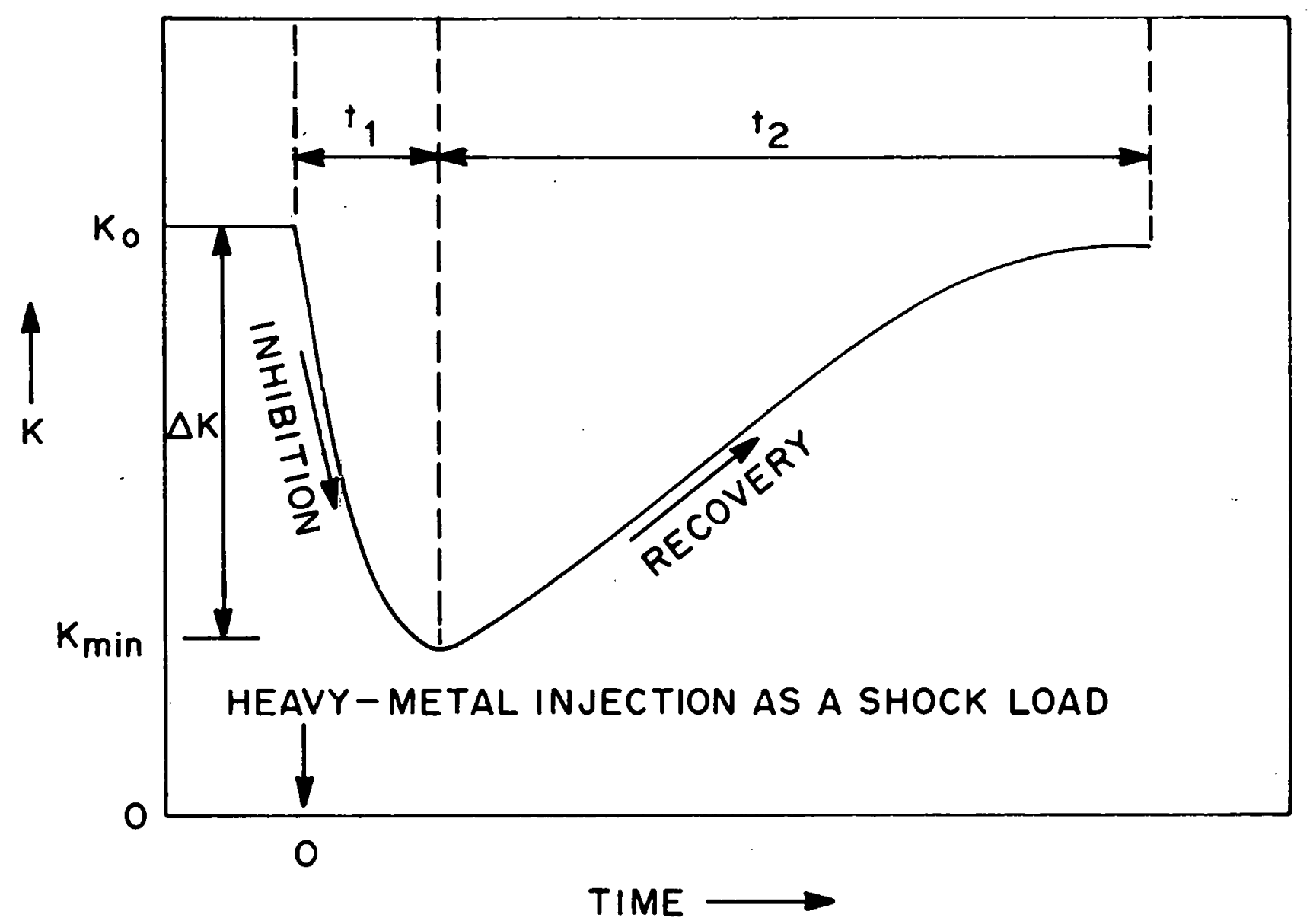

Figure 6.13. Reponse pattern of an ANFLOW bioreactor to a heavy metal injected as a shock load. 


$$
K(t)=\frac{K_{s s}}{I_{0} F_{\bullet}}
$$

where $\mathrm{K}_{\mathrm{SS}}$ is the global first-order rate constant at steady state, and I.F. Is an inhibition function (its general form could be determined with further research), could be used to describe the response pattern. A similiar approach for the study of inhibition from substrates on bacterial growth rates has been proposed by Andrews. 61

With Equation 6-3 a methodology is developed for a kinetic approach to the study of the phenomena of toxicity in biological treatment processes. The study of the phenomena of toxicity will involve an initial evaluation of the reactor dispersion number, average residence time, and the steady-state first-order constant. After the induction of toxicity, it will involve the development of an inhibition function that could describe the variations of $\mathrm{K}$. One property that the inhibition function should have is that it should reflect the conditions under which the induction of toxicity is made, either shock or step-test conditions. The process of developing such an inhibition function could provide useful information for a better understanding of the phenomena of toxicity.

\subsubsection{Regional Phenomena}

The steady-state performance of the laboratory-scale ANFLOW bioreactors could be considered as to consist of three reglons with decreasing biological activity as measured by soluble COD removal. The first region, with a volume of about $8 \%$ of the total volume, is a very biologically active region and is responsible for the removal of more than $70 \%$ of the soluble COD removed by the entire bioreactor. The second region, responsible for the removal of the remaining COD not removed by the 
first region, has a volume of about $25 \%$ of the total volume. The last region, with about $67 \%$ of the total volume, does not contribute to the overall soluble COD removal performance of the system. Instead, it may be considered as a region where biological decay or biosolids digestion are the predominant bioprocesses. This region, considered to be insignificant for the overall performance of the system under steady-state operation, might have some significance on the phenomena of toxicity.

As shown in Figures 6.14 to 6.17 , the response of the vessel depends on the degree of inhibition to the active region. The inactive region will begin to become active from the resulting increase in organic loading reaching this region of the vessel. The upper regions considered inactive (small $\mathrm{K}^{\prime} \mathrm{s}$ ) during steady-state operation now begin to see an increase in organic loading. With the increase in organic loading the biological activity of those regions begin to increase ( $\mathrm{K}$ increase). Even though the lower regions become inactive, from a soluble COD removal point of vlew, they still remove the heavy metal protecting the upper regions by decreasing the inhibitory potential of the waste.

Since the regional first-order rate constants were calculated from soluble COD profiles they do not represent a major source of detailed information as the global constants obtained from the effluent COD. To the extent they were measured they are, however, indicative of the dynamic phenomena occurring within the vessel. A better procedure to obtain enough data to describe the regional constants to the same extent as the global constants would be to sample the effluent of every region (from sample ports) on a da1ly basis or even more of ten if necessary. Composite sampling instead of grab sampling is recommended. 


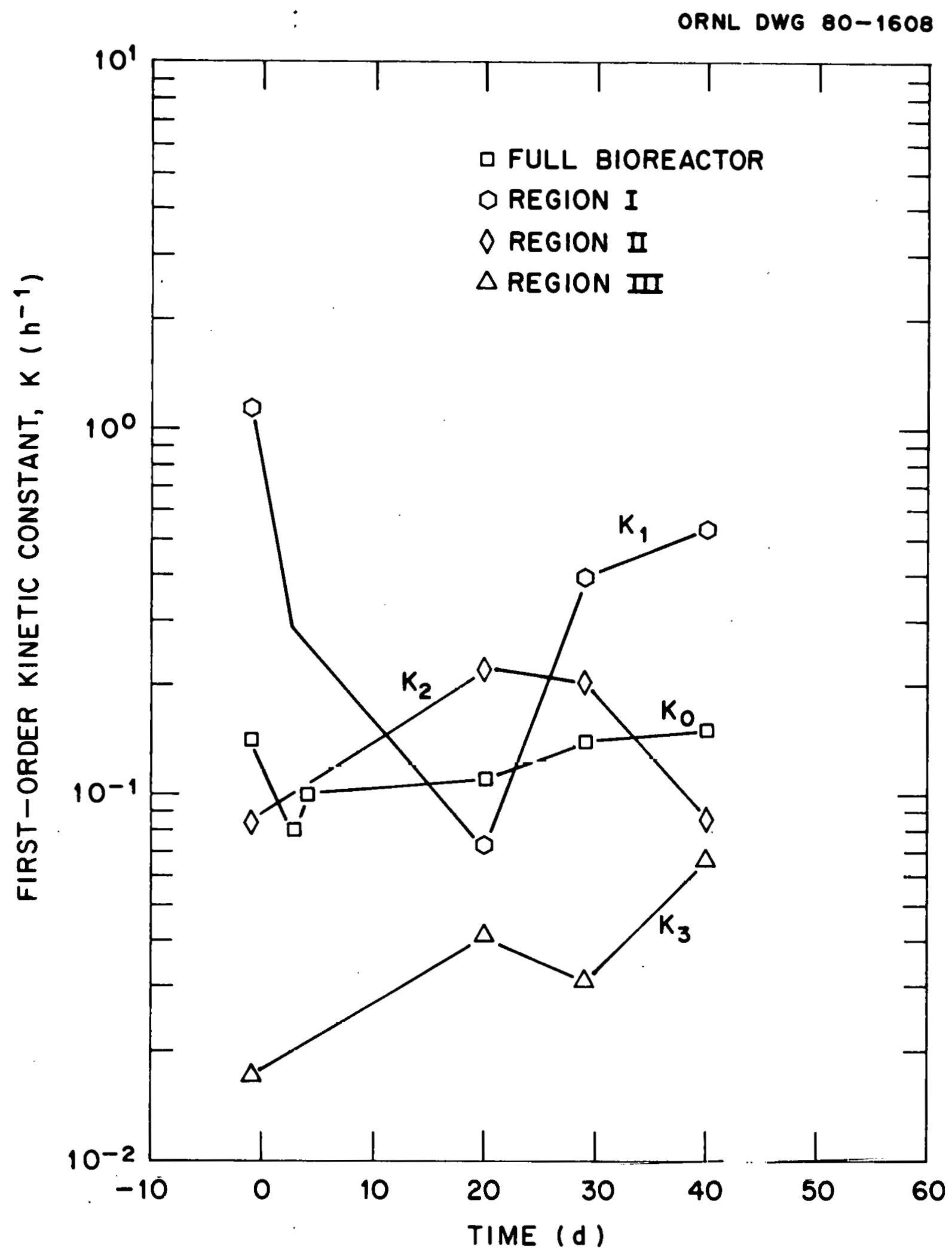

Figure 6.14. Global and regional first-order rate constants for test (T-1) bioreactor during toxicity experiment No. 1. The constants were calculated from the soluble chemical oxygen demand profiles. 
ORNL DWG 80-1606

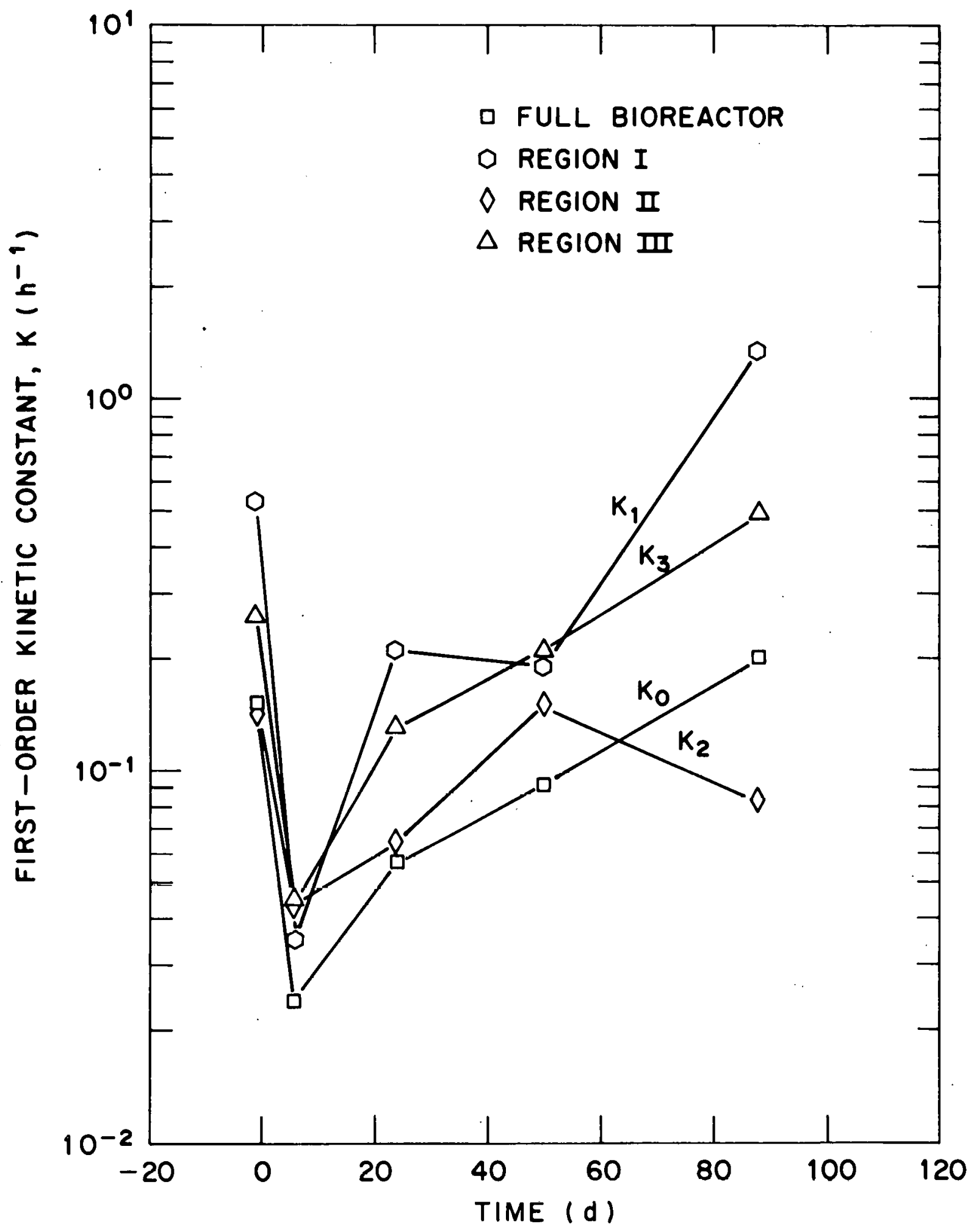

Figure 6.15. Global and regional first-order rate constants for LesL (T-2) bioreactor during toxicity pxpieriment No, 2, The cunslauls were calculated from the soluble chemical oxygen demand profiles. 
ORNL DWG 80-1607

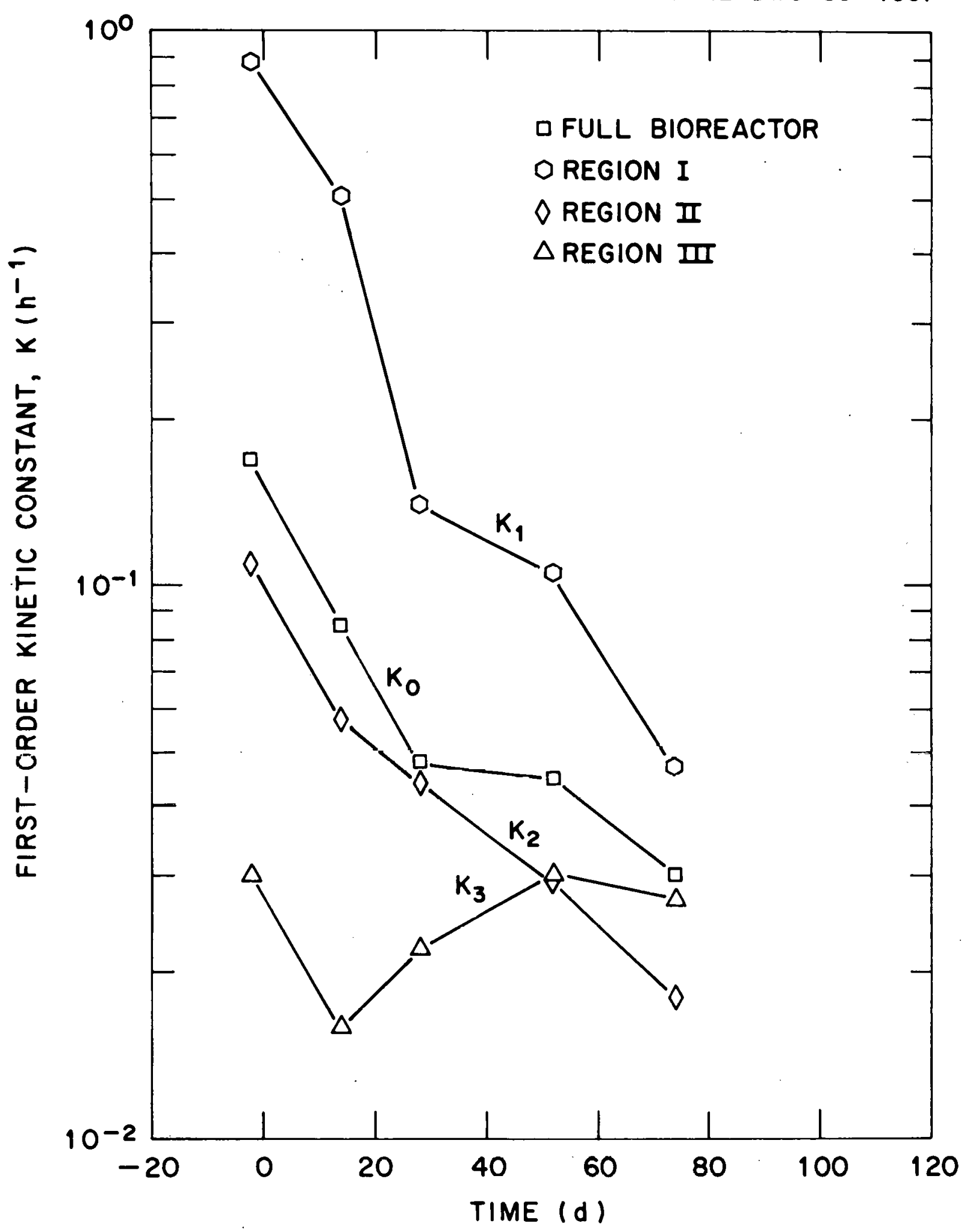

Figure 6.16. Global and regional first-order rate constants for test ( $\mathrm{T}-2)$ bioreactor during toxicity experiment No. 3. The constants were calculated from the soluble chemical oxygen demand profiles. 
ORNL DWG 80-1601

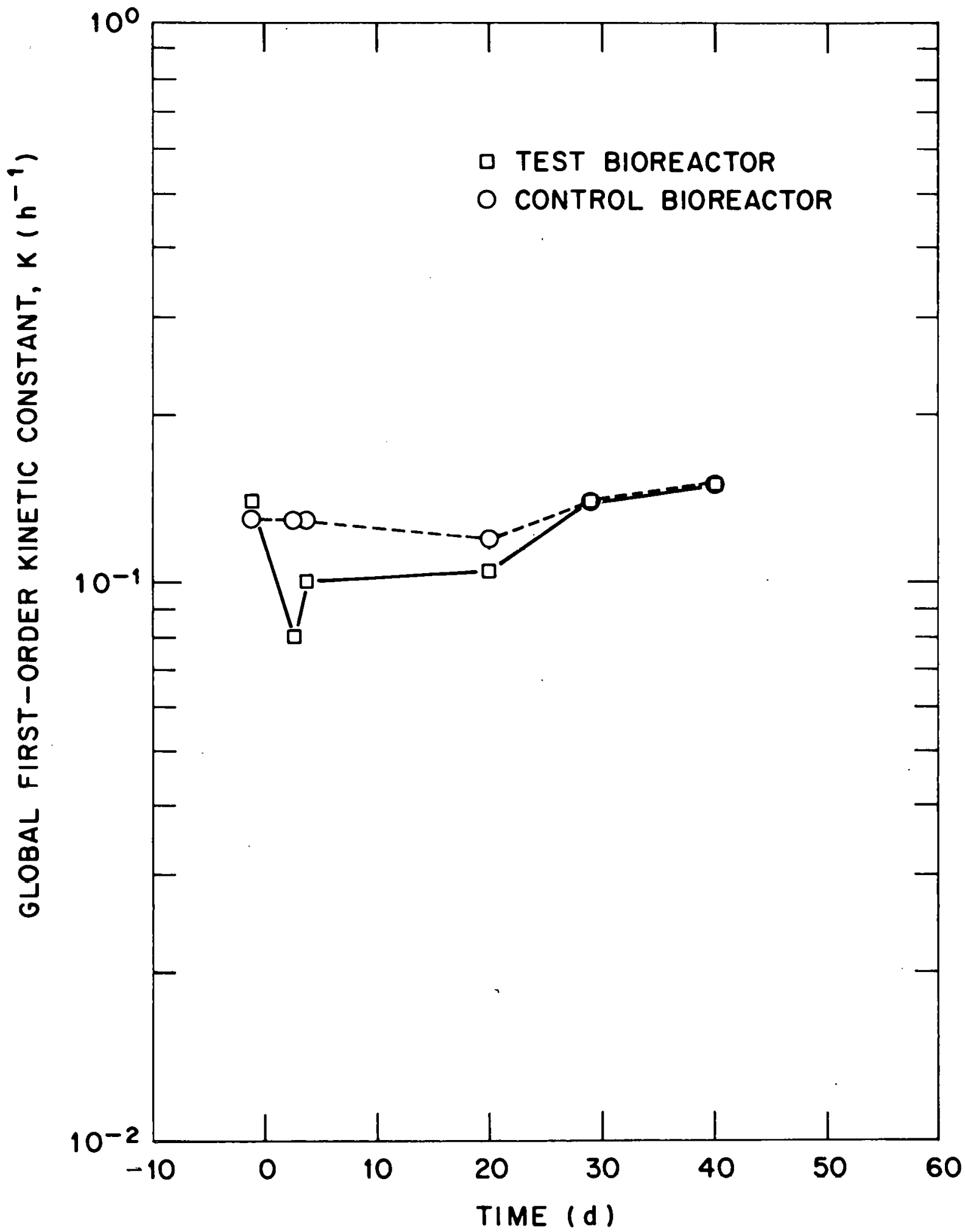

Figure 6.17. Global first-order rate constants for control and rest $(\mathrm{T}-1)$ bloreactors during toxicity experiment No. 1 . The constants were calculated from the soluble chemical oxygen demand profiles. 
The global kinetic constants are shown in Figures $6.17,6.18$, and 6.19. These figures could be compared with Figures 6.10 to 6.12 , respectively, to illustrate the difference in the amount of information provided by the sampling procedures. It can be seen that for the overall system both sampling procedures provided enough information. A closed look to Figures 6.14 to 6.16 indicates, however, that more data is required for a better description of the regional phenomena.

The information provided by studying the phenomena of toxicity regionally could be incorporated in the inhibition function defined by Equation (6-3). This could be done by the development of regional inhibition functions and combining them in a single expression which will result in the inhibition function for the entire vessel. As in steadystate operation, one particular region is anticipated to be the predominant contributor to the overall behavior.

The regional kinetic constants for the control bloreactor during all toxicity experiments are shown in Figures 6.20 to 6.22 . One major observation from these figures is the relative magnitude of the kinetic constants for each region which indicates the extent of the biological activity and the relative contribution of each region to the overall performance of the bioreactor.

\subsection{Bioreactor Response to Toxicity as Reflected in Operational Parameters}

\subsubsection{Chemical Oxygen Demand}

The transients for the soluble COD in the effluent of control and dosed bioreactors are shown in Figures 6.23 to 6.25 for all toxicity 
ORNL DWG 80-1599

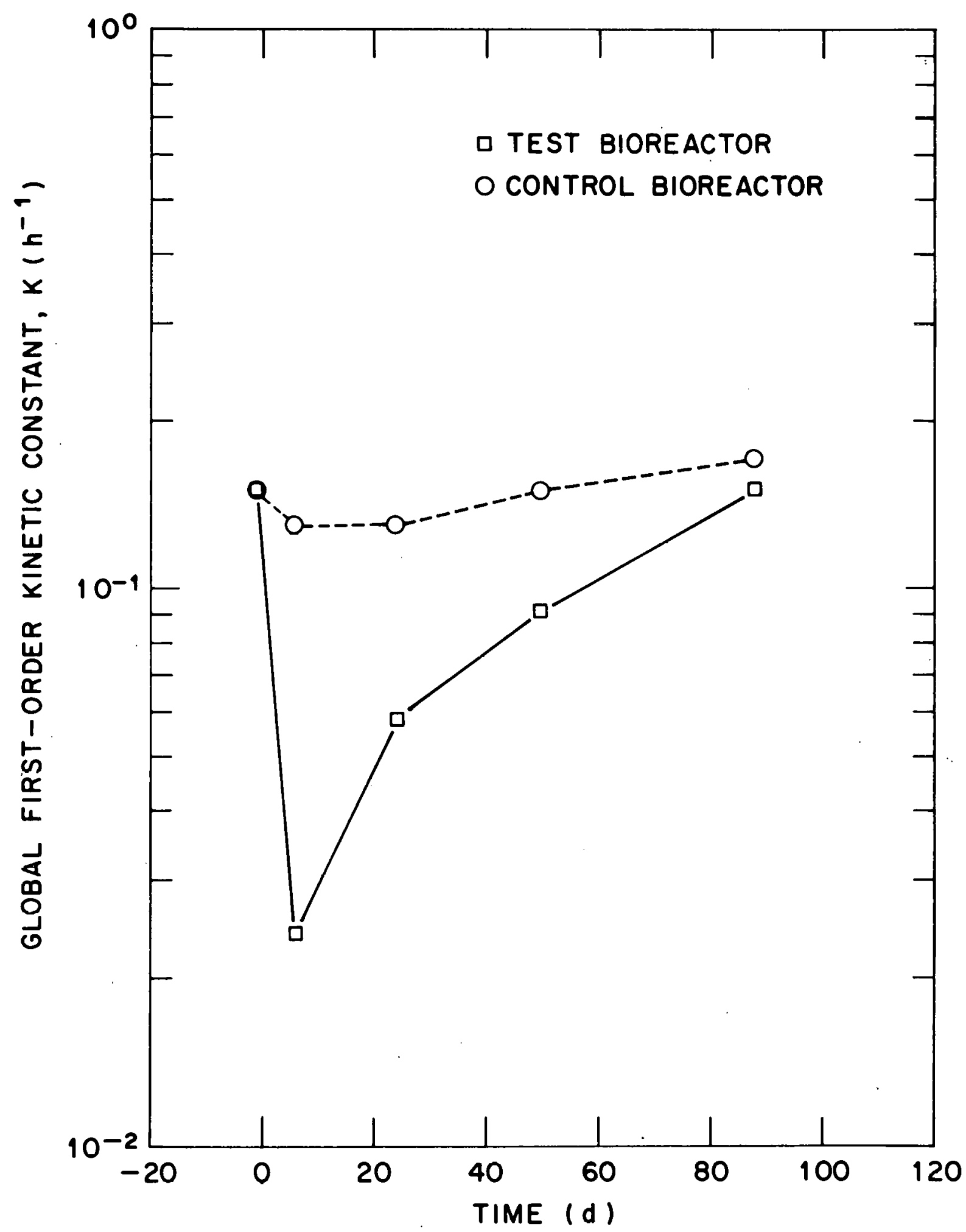

Figure 6.18, Global first-order rate constant.s for control and test ( $\mathrm{T}-1$ ) biorector during toxicity experiment No. 2. The cunstants were calculated from the soluble chemical oxygen demand profiles. 
ORNL DWG 80-1600

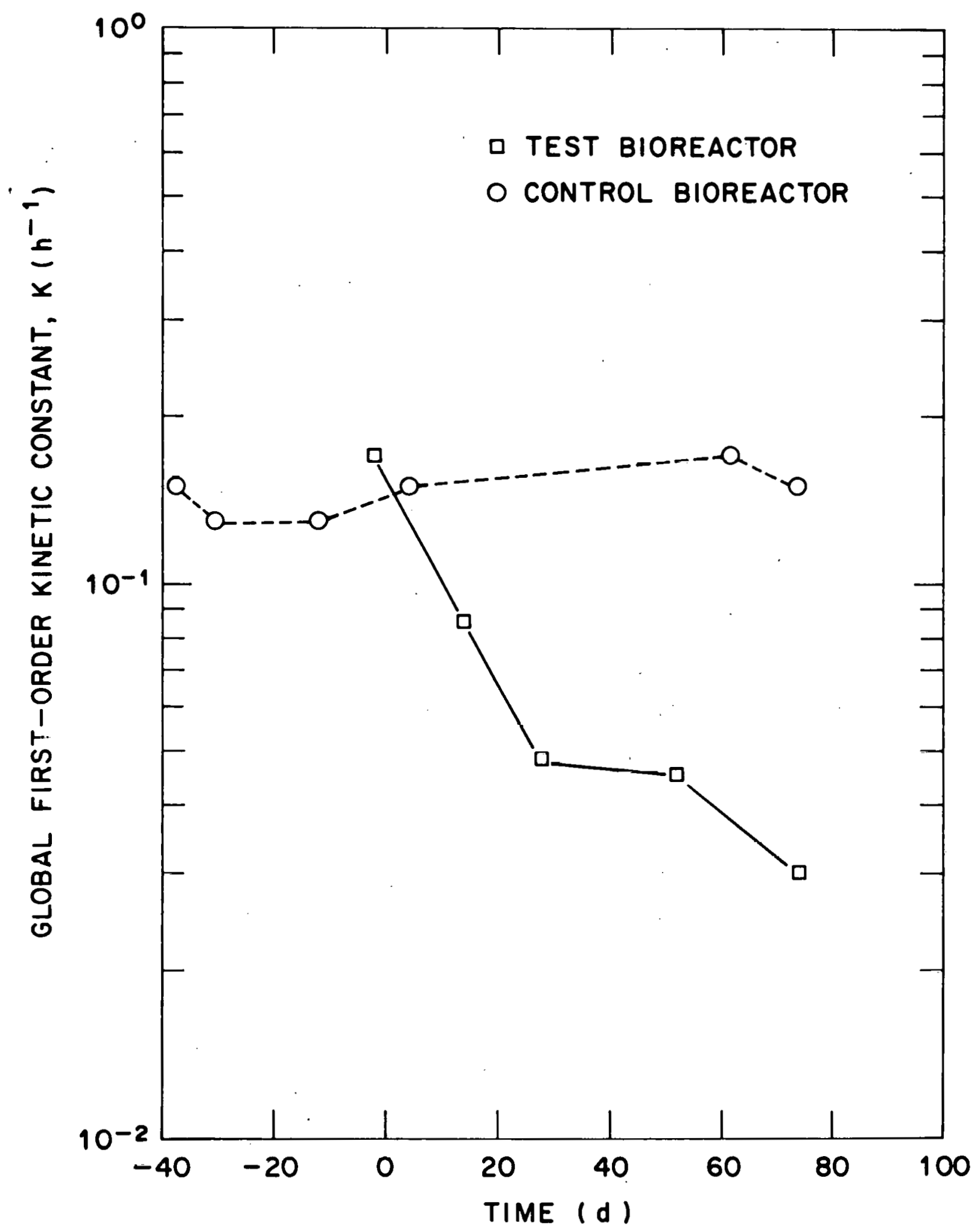

Figure 6.19. Global first-order rate constants for control and test ( $\mathrm{T}-2$ ) bioreactors during toxicity experiment, No. 3. The constants were calculated from the soluble chemical oxygen demand profiles. 


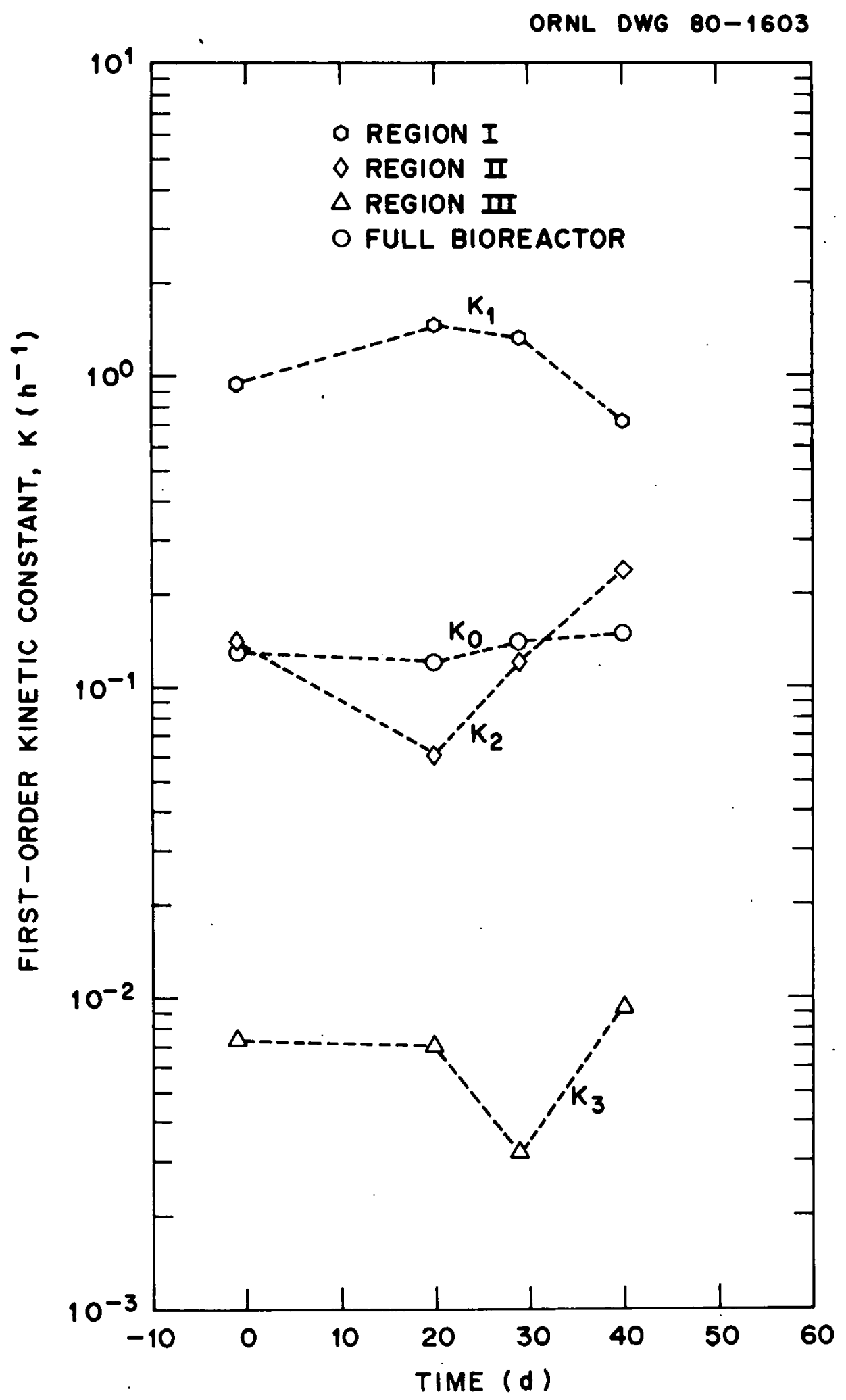

Figure 6.20. Global and regional first-order rate constants for control bioreactor luiring touicity expriment No. 1. The constants were calculated from the soluble chemical oxygen demand profiles. 
ORNL DWG 80-1604

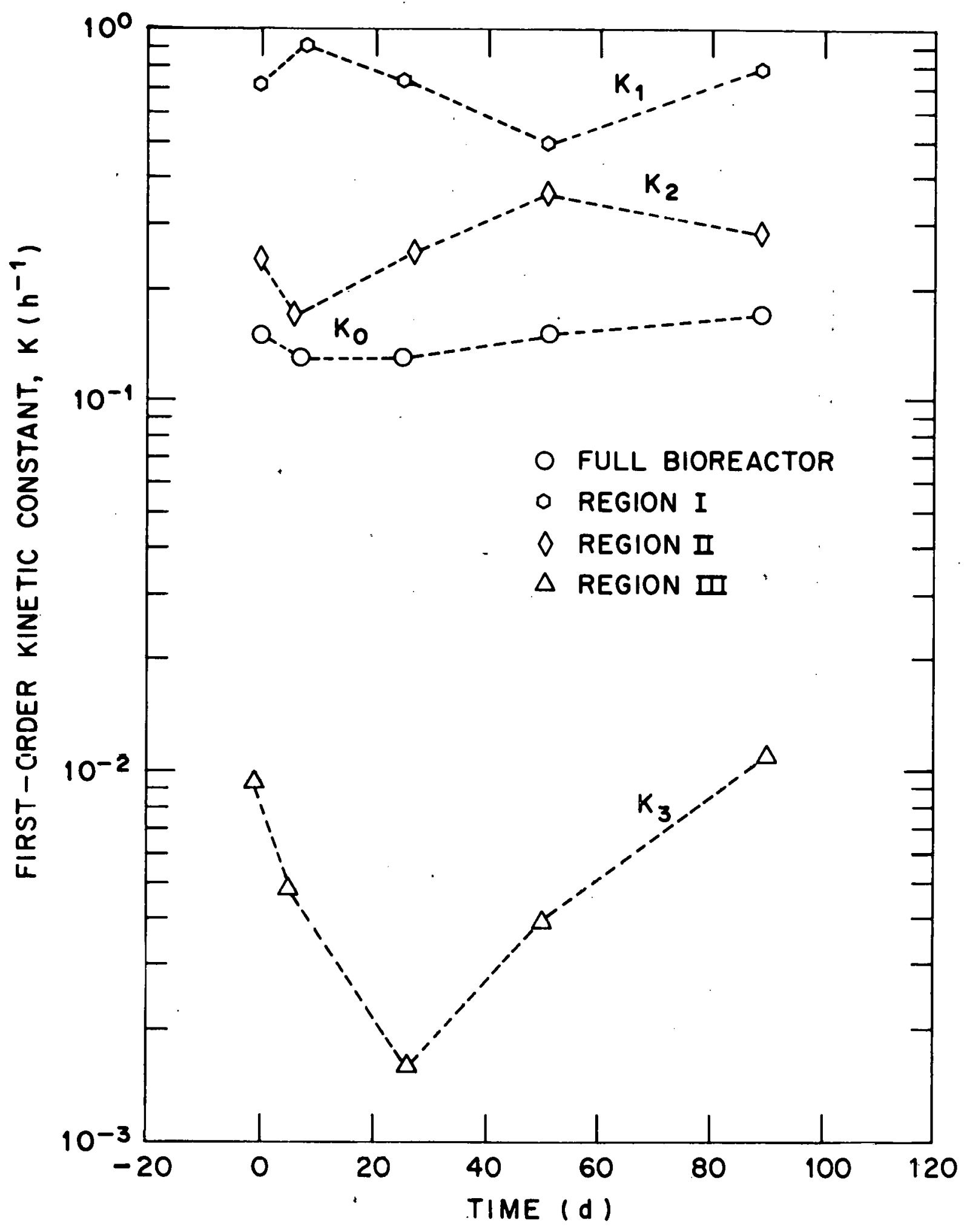

Figure 6.21. Global and regional first-order rate constants for control bioreactor during toxicity experiment No. 2 . The constants were calculated from the soluble chemical oxygen demand profiles. 
ORNL DWG 80-1605

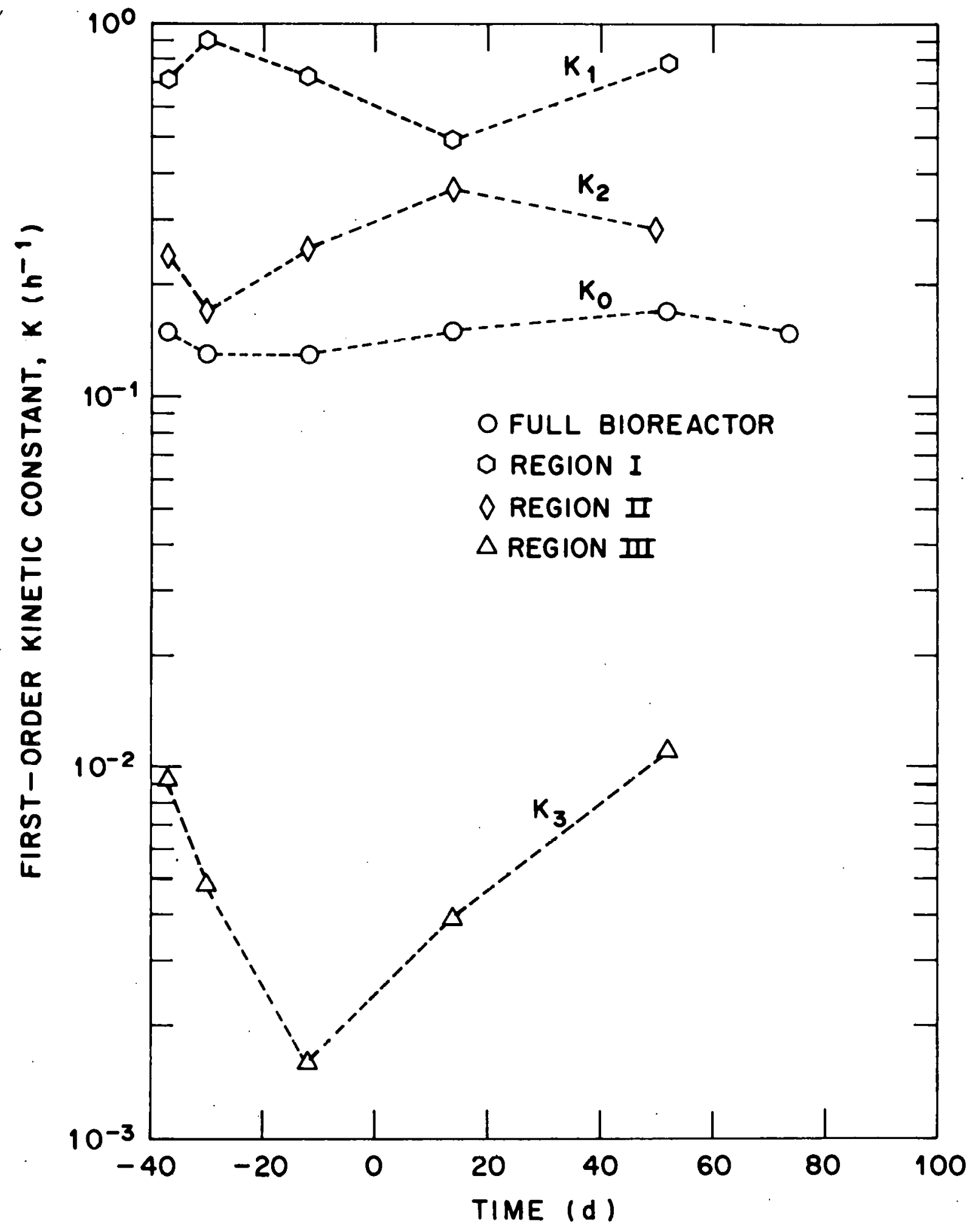

Figure 6.22. F.] ohal and regional first-order rate constants for control bioreactor during toxicity experiment No. 3. The constants were calculated from the soluble chemical oxygen demand profiles. 
ORNL DWG 81-60

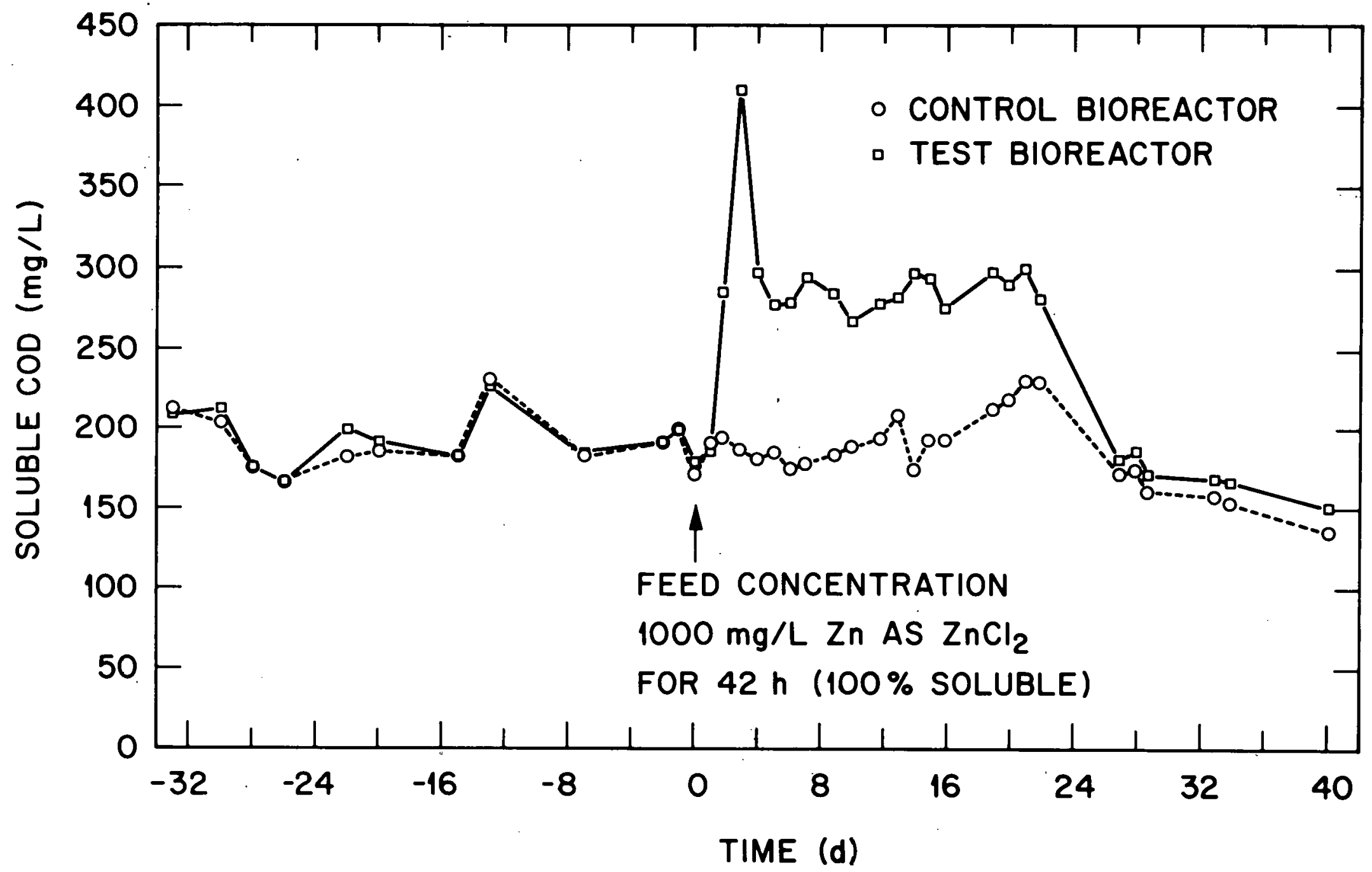

Figure 6.23. Soluble chemical oxygen demand in bioreactor effluent during toxicity experiment No. 1. (Influent COD $=3000 \mathrm{mg} / \mathrm{L}$ ). 
ORNL DWG $81-56$

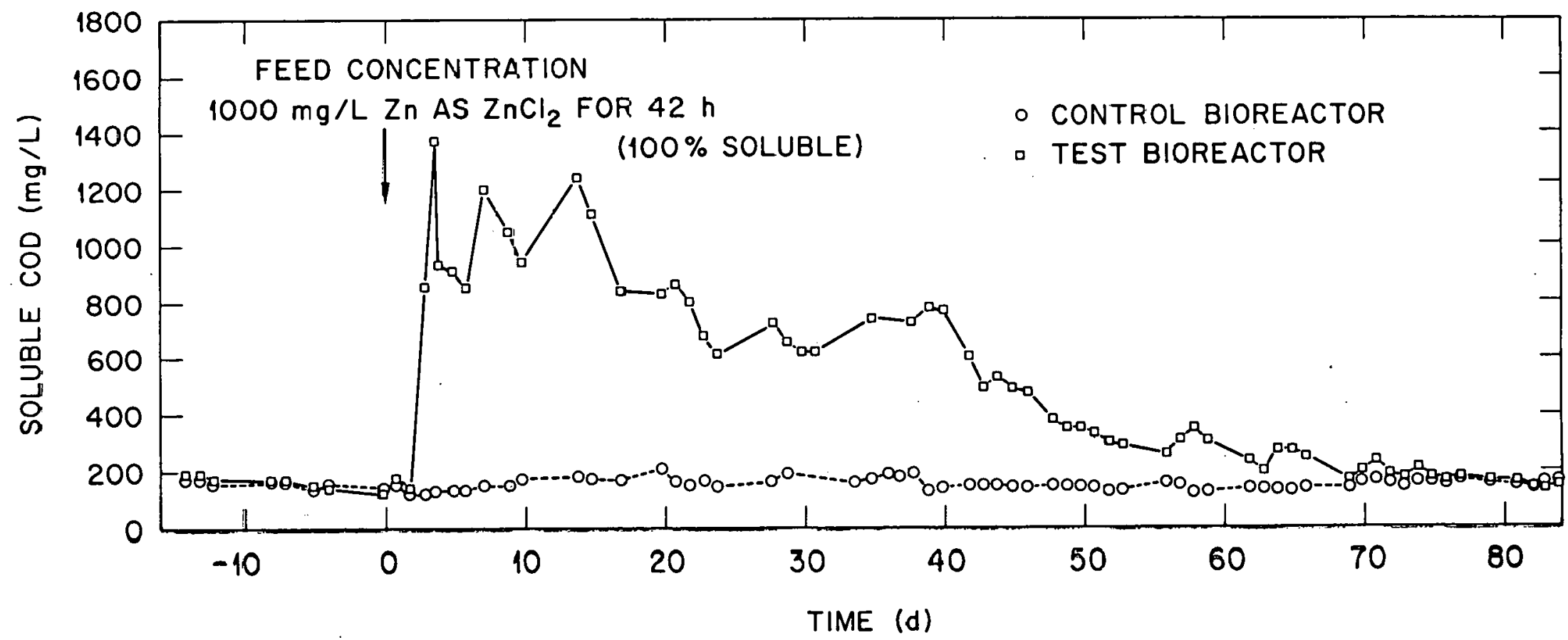

Figure 6.24. Soluble chemical oxygen demand in test $(\mathrm{T}-1)$ and control biorecctor effluents during toxicity experiment No. 2 . (Influent $\mathrm{COD}=3000 \mathrm{mg} / \mathrm{L})$. 
ORNL DWG 81-61

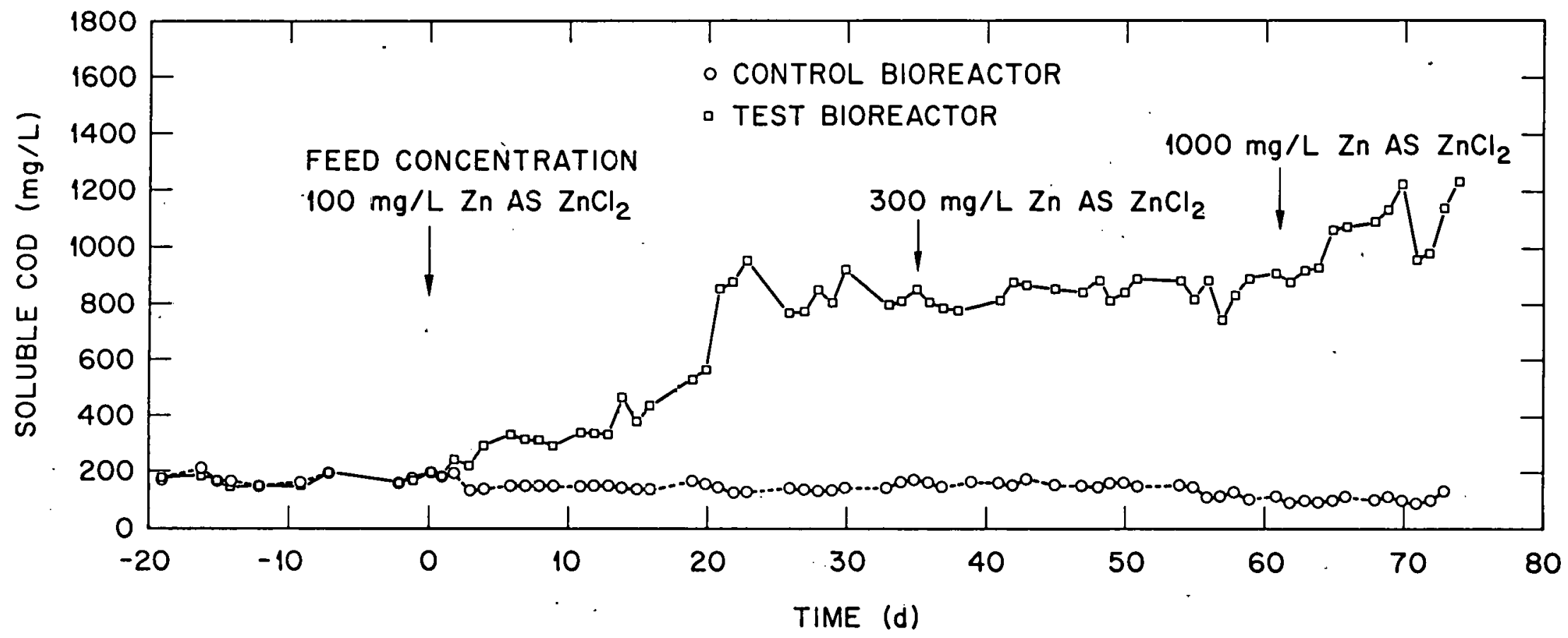

Figure 6.25. Soluble chemical oxygen demand in test $(\mathrm{T}-2)$ and control bioreactor effluerts during toxicity experiment No. 3 . (Influent $\operatorname{COD}=3000 \mathrm{mg} / \mathrm{L})$. 
experiments. In general, there was a measurable gradual increase (in proportion to the concentration of soluble zinc) in the soluble COD, probably related with increase in blological activity in the upper regions and the dispersion characteristics of the vessel. If these two phenomena did not occur, particularly under shock conditions, then the increase in soluble COD in the effluent should be very sudden because the unremoved $C O D$ was moving upward as a slug. Dispersion is considered to be beneficial because it tends to reduce the toxic potential of a toxic waste.

The soluble COD profiles for the three experiments are shown in Figures 6.26 to 6.28 . The general pattern is an upward shifting for inhibition and a downward shifting for recovery, and the rate of shifting could be considered as the rate of inhibition and the rate of recovery respectively. The profiles for the test bioreactor are compared with the average profile for the control bioreactor. These average profiles were obtained from the COD profiles for the control bioreactor during the time the particular toxicity experiment was being performed. The soluble COD profiles for the control bioreactor during the toxicity experiments are shown in Figures 6.29 to 6.31 .

A comparison between Figures 6.26 and 6.27 (both under shock-1oad conditions) indicates that an increase in the soluble fraction of zinc resulted in a higher degree of inhibition in the upper regtons and consequent1y more time would be needed for full recovery. The response pattern for shock and step-test conditions are somewhat similar in shape, but they differed in the rate of shifting or rate of inhibition. 
ORNL DWG 81-68

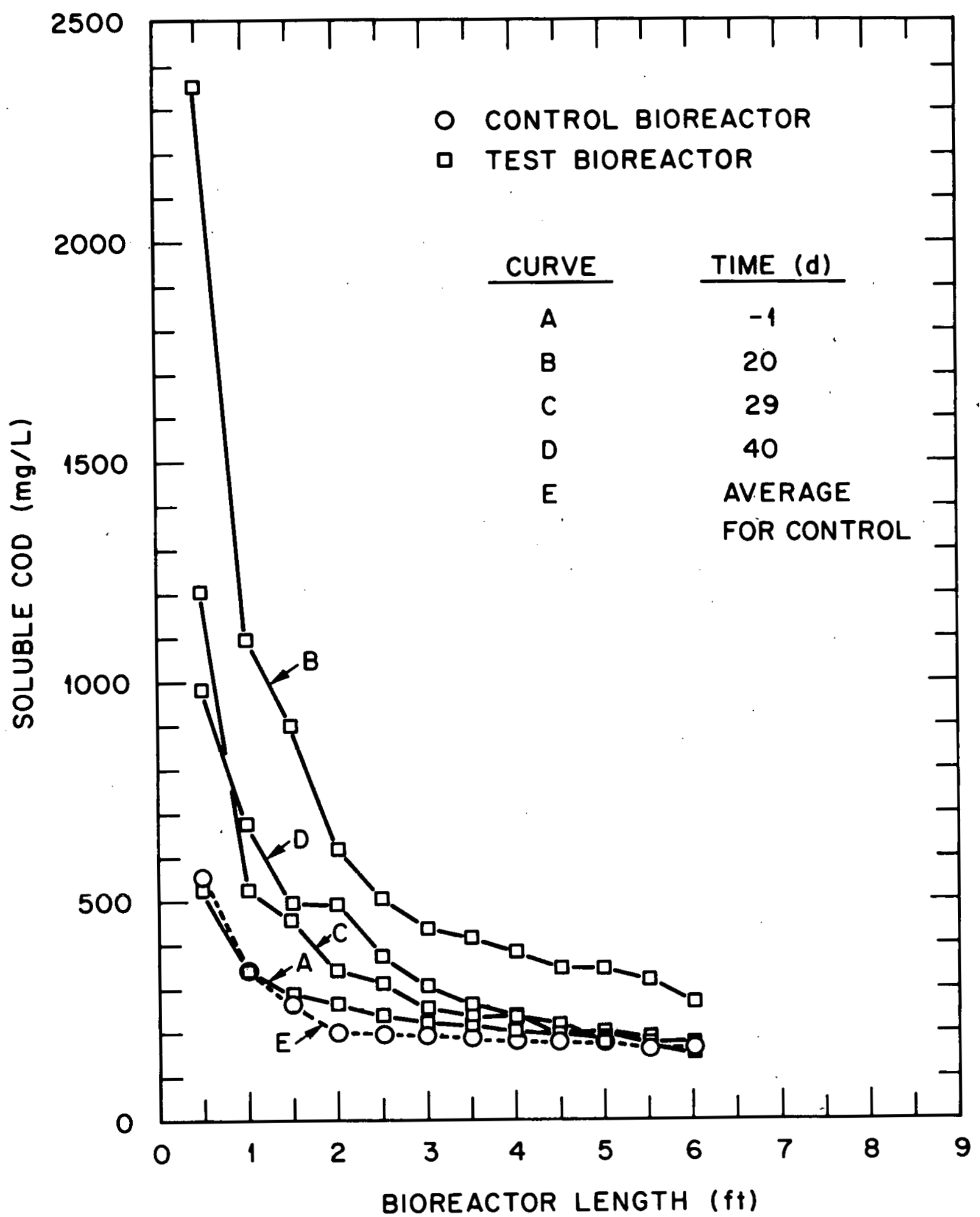

Figure 6.26. Soluble chemical oxygen demand profiles for test bioreactor (T-1) during toxicity experiment No. 1 . Also shown is the average profile for control bioreactor. (Influent $\operatorname{COD}=3000 \mathrm{mg} / \mathrm{L}$ ). .. 
ORNL DWG 81-67

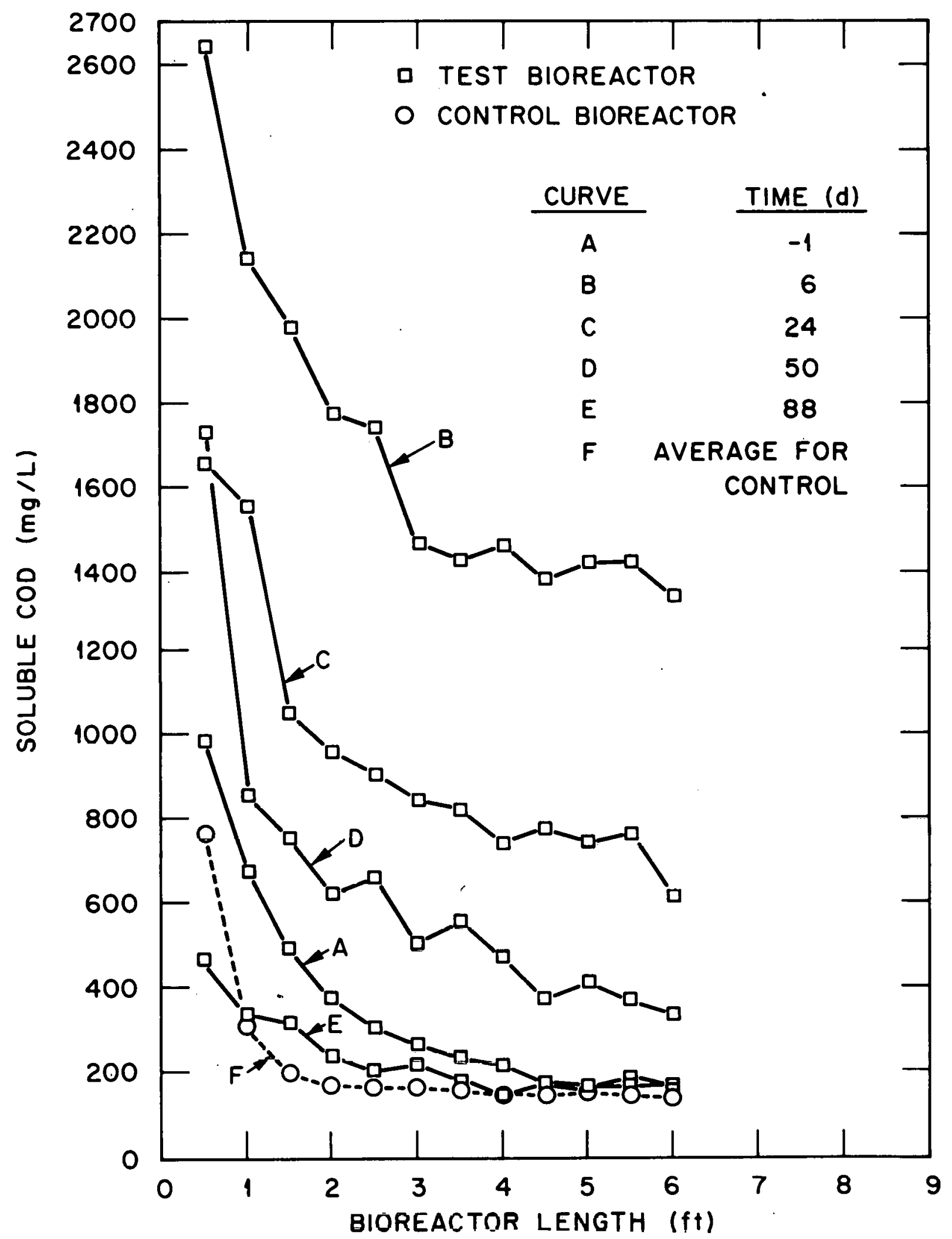

Figure 6.27. Soluble chemical oxygen demand profiles for test bioreactor (T-1) during tnxicity experiment No. 2. Also shown is the average profile for control bioreactor. (Influent COD $=3000 \mathrm{mg} / \mathrm{L}$ ). 
ORNL DWG 81-74

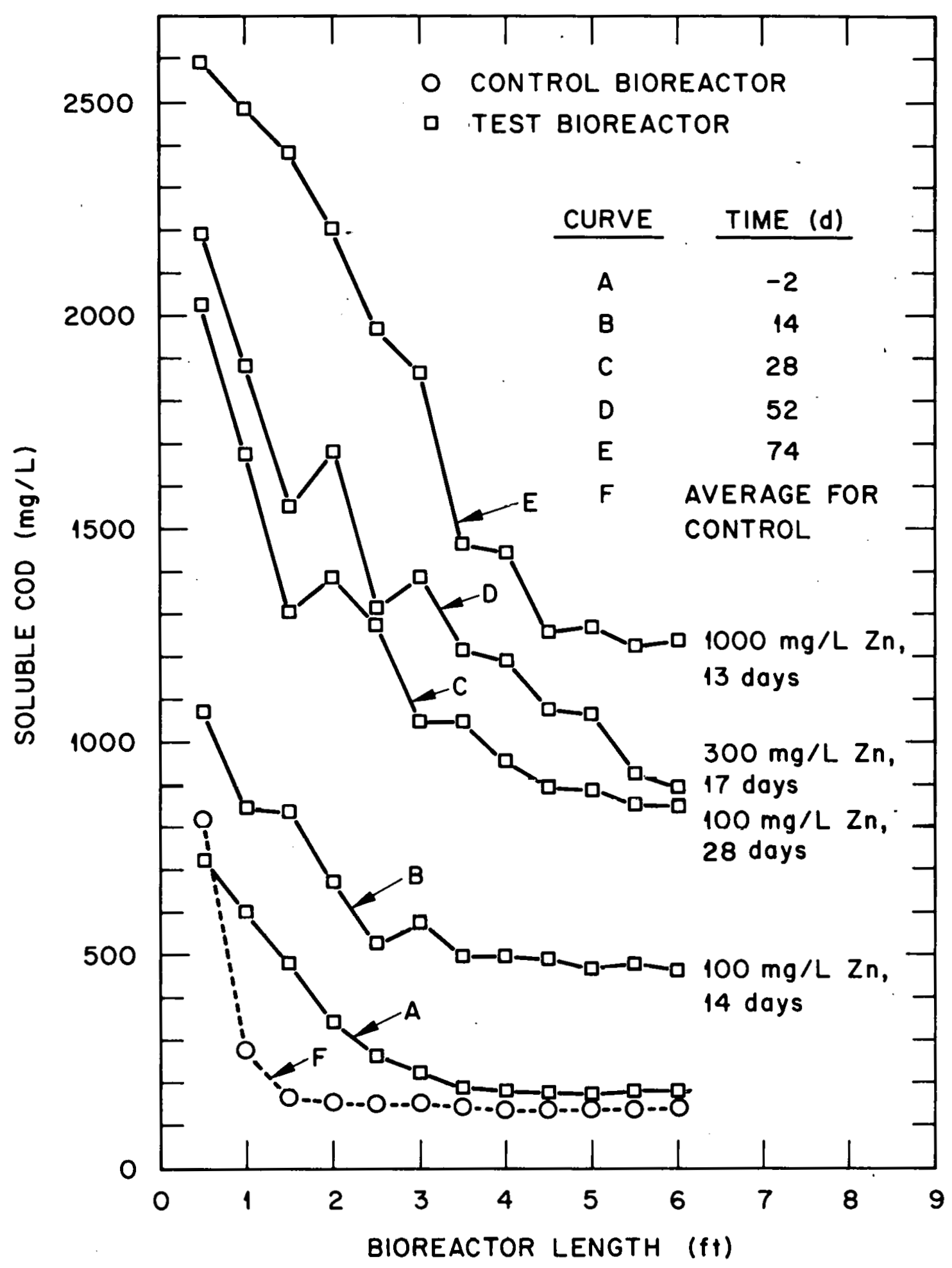

Figure 6.28. Soluble chemical oxygen demand profiles for test bioreactor during toxicity experiment No. 3. Also shown are the concentrations of zinc in the feed, and the time when the profile was done relative to the time when the particular concentration was first introduced in the feed. (Influent $\mathrm{COD}=3000 \mathrm{mg} / \mathrm{L}$ ). 
ORNL DWG 80-1755

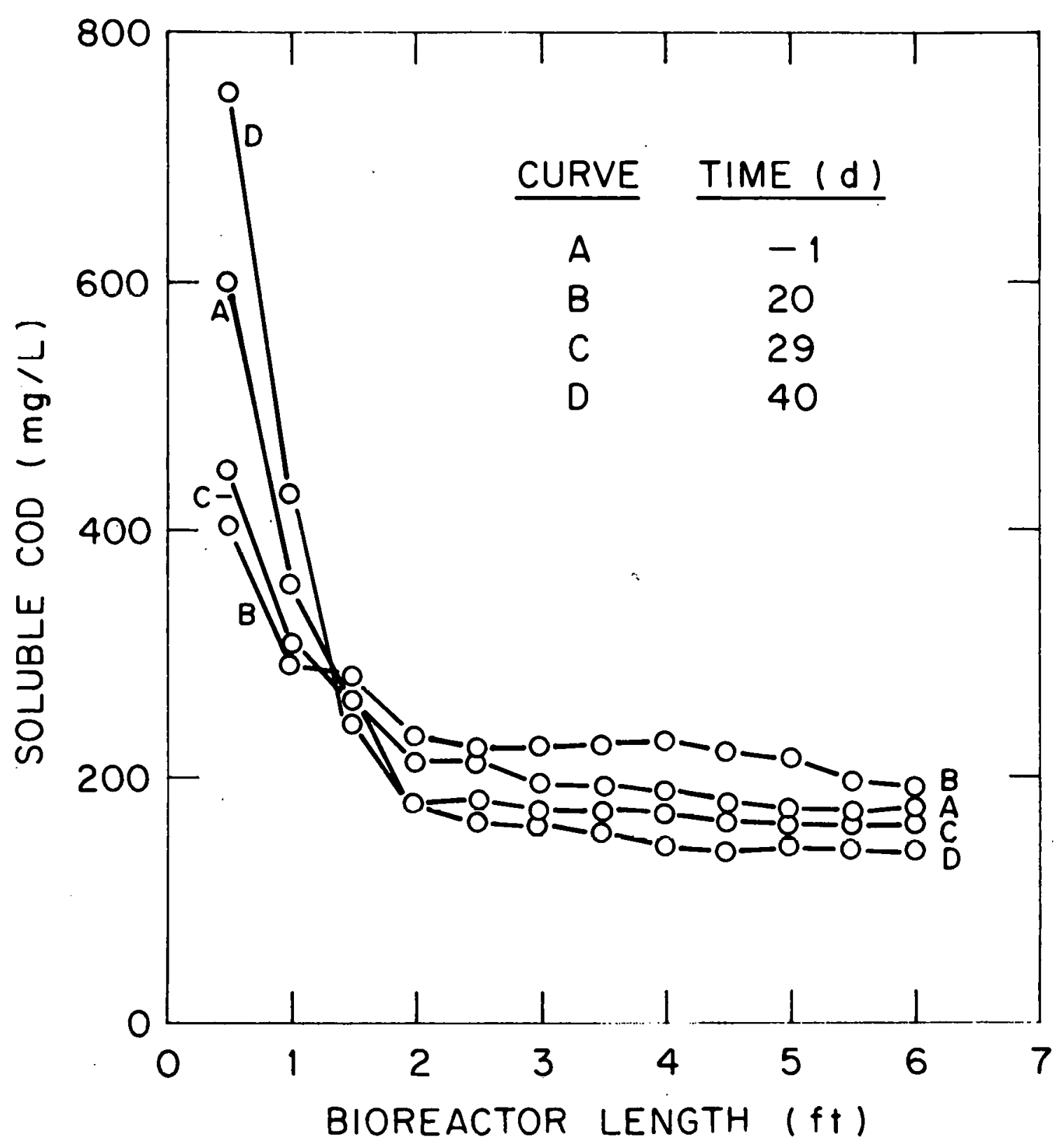

Figure 6.29. Soluble chemical oxygen demand profiles for control bioreactor during toxicity experiment No. 1. (Influent COD = $3000 \mathrm{mg} / \mathrm{L}$ ). 
ORNL DWG $80-1764$

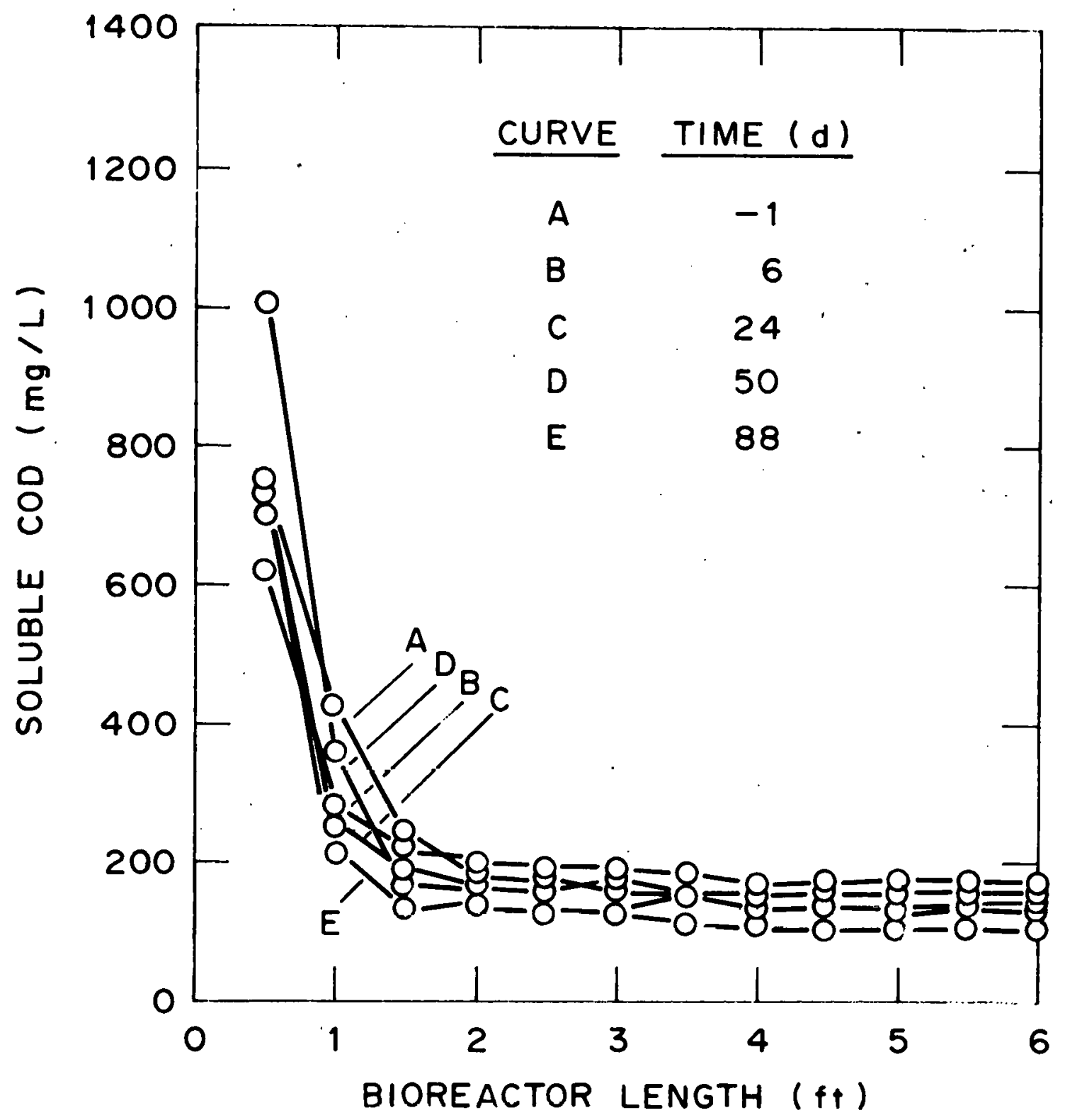

Figure 6.30. Soluble chemical oxygen demand for control bioreactor during toxicity experiment No. 2. (Influent COD $=3000 \mathrm{mg} / \mathrm{L}$ ). 


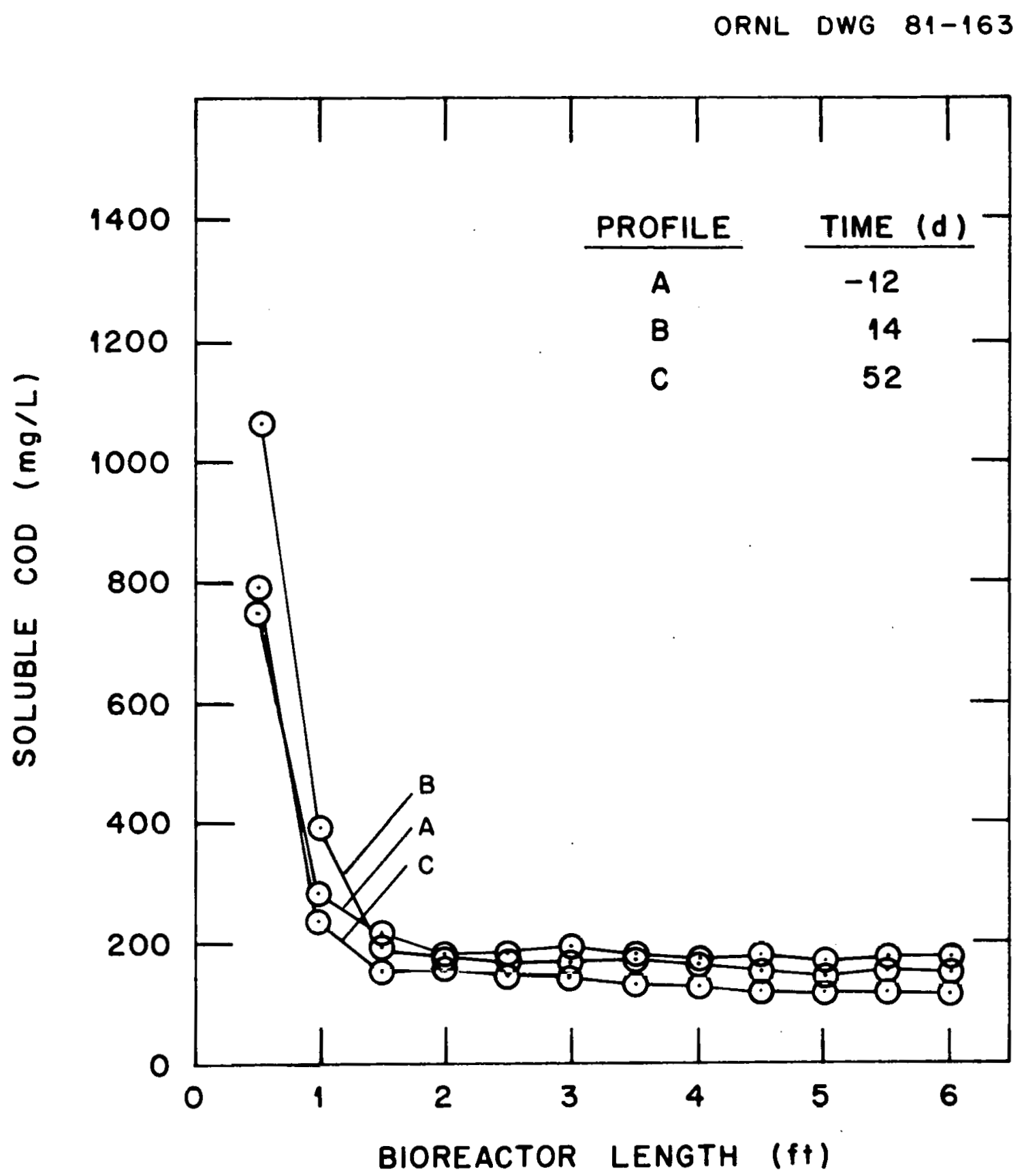

Figure 6.31. Soluble chemical oxygen demand profiles for control bioreactor during toxicity experiment No. 3. (Infiluent $\operatorname{COD}=3000 \mathrm{mg} / \mathrm{L}$ ). 
Due to time constraints the toxicity experiment under step-test conditions was not completed to recovery. It is expected however that it might follow the same trend as the one shown in Figure 6.27. This observation is based on a comparison between curve $B$ in Figure 6.27 and curve $E$ in Figure 6.28 .

\subsubsection{Gas Production and Composition}

As shown in Figures $6.32,6.33$, and 6.34 there is a decrease in the gas production rate as response from inhibition. This parameter by itself may not be good indicator of inhibitory conditions when there are large variations in the organic loading. The scattered nature of these figures is due mainly to the physical phenomena of bubble production and released in the packed bed. The gas production is not uniform but in random pulses. These phenomena added to variations in organic loading rates will probably cause wide variations in the gas production rate under field conditions (especially if the gas production rate is measured in $\mathrm{L} / \mathrm{h}$ for example).

The methane and carbon dioxide percent patterns as response from Inhibition are shown in Figures $6.35,6.36$, and 6.37 . The effects from toxicity are only noticeable in toxicity experiment No. 3 where the heavy metal was fed continuously.

The relative percentages of carbon dioxide and methane (about 30 and $70 \%$ in this study respectively) depend on the rate of production of each gas and in their solubility in the liquid phase. The solubility of carbon dioxide is several orders of magnitude higher than the solubility of methane. 62 Futhermore, under normal operating conditions, the ratio of 
ORNL DWG 81-57

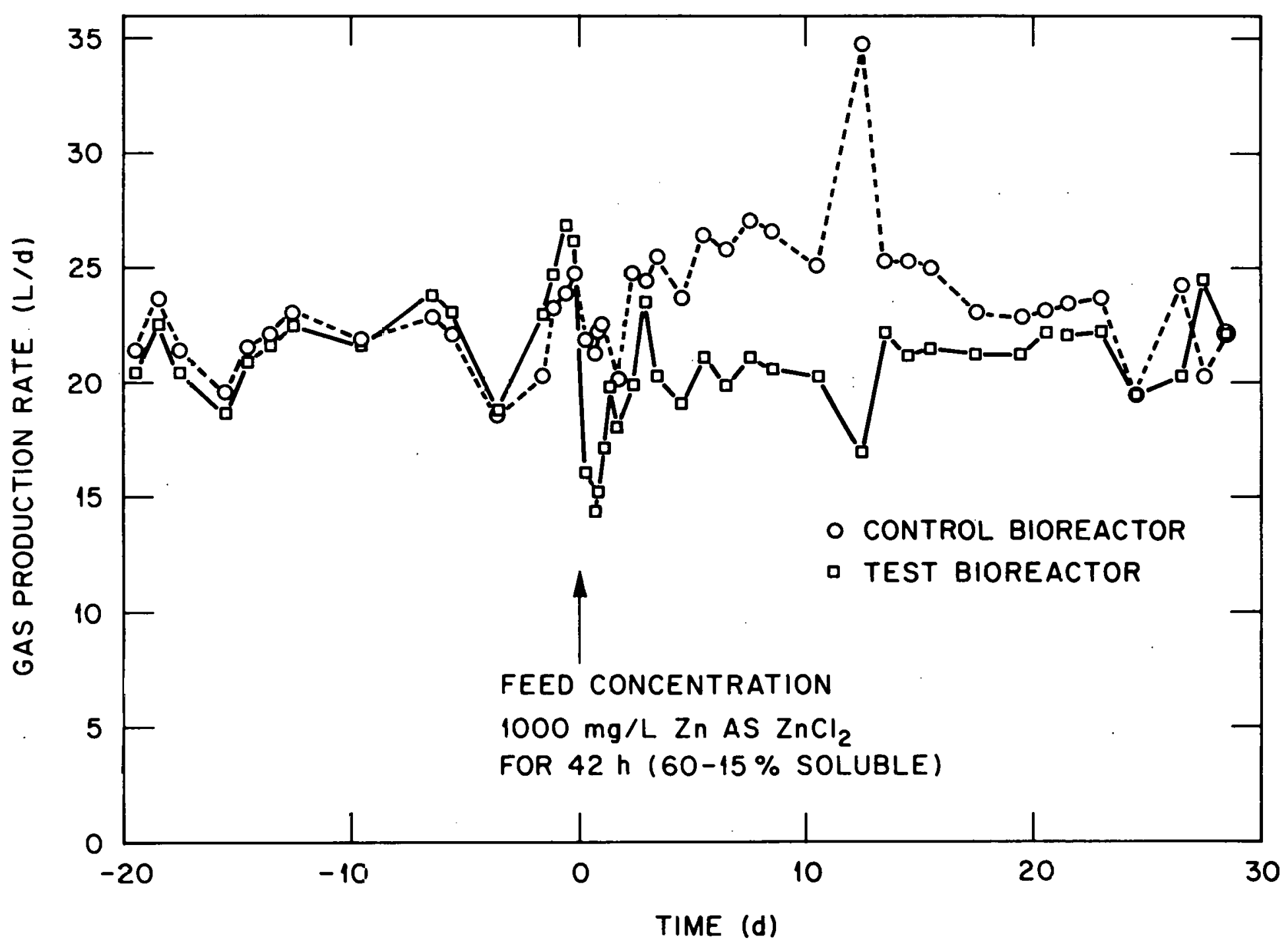

Figure 5.32. Gas production rate for control and test (T-1) bioreactors during toxicity experiment No. 1 . 


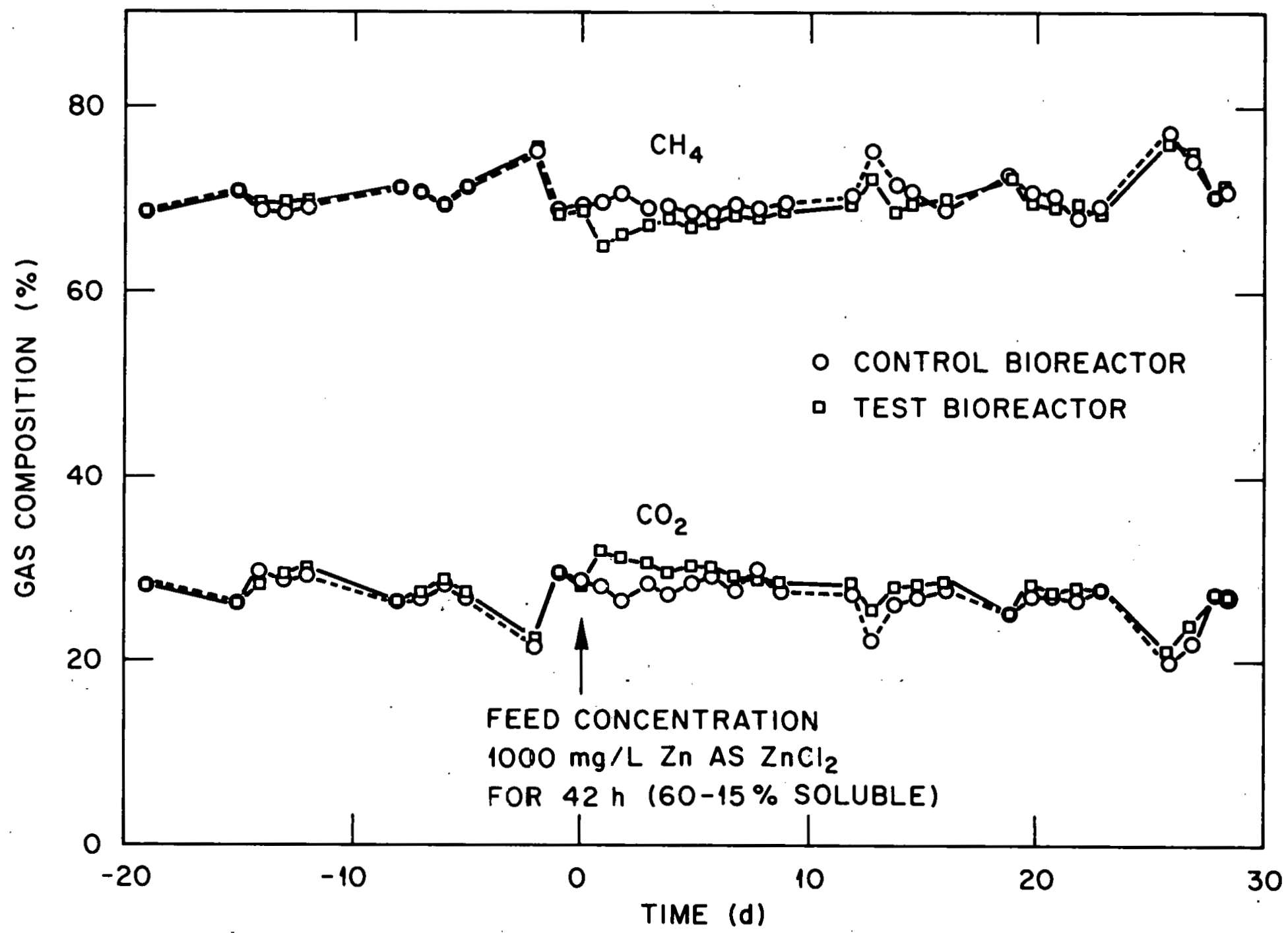

Figure 6.33. Methane and carbon dioxide percentages in the of $f-$ gas of control and test $(\mathrm{T}-1)$ bioreactors during toxicity experiment No. 1 . 
ORNL DWG $81-59$

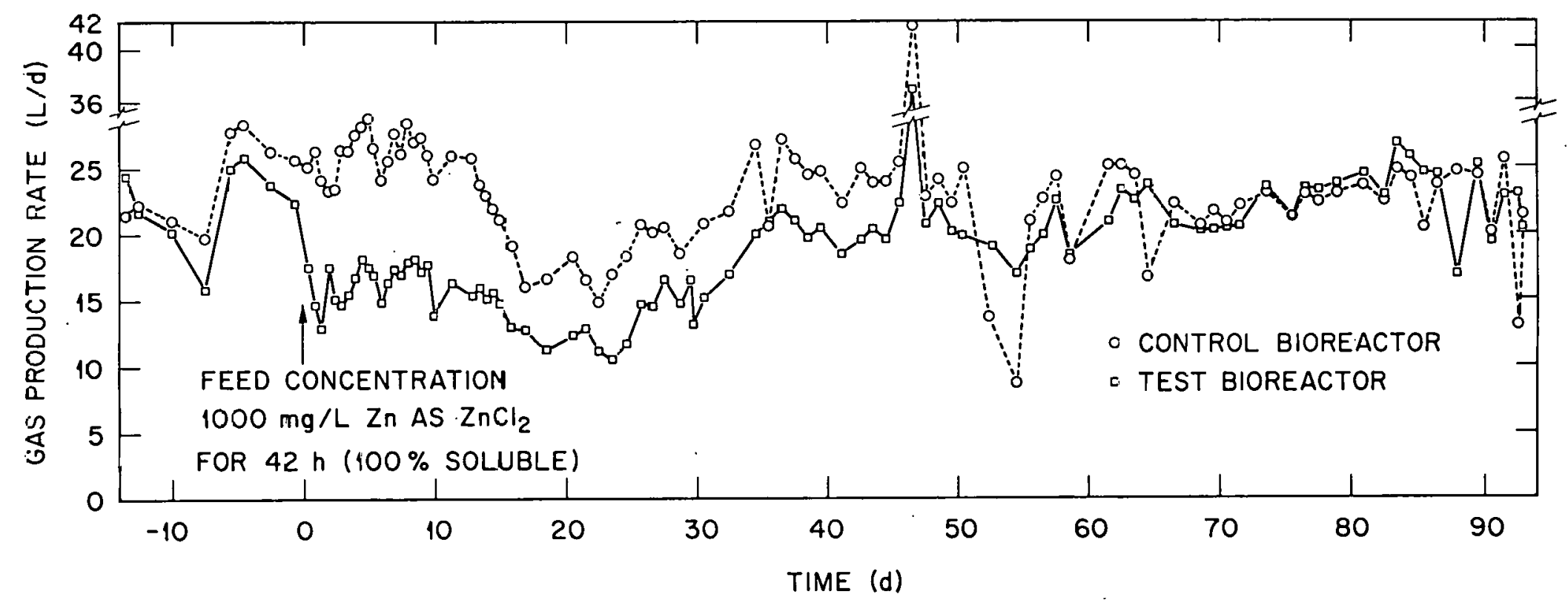

Figure 6.34. Gas production rate for control and test (T-1) bioreactors during toxicity experiment No. 2 . 
ORNL DWG 81-75

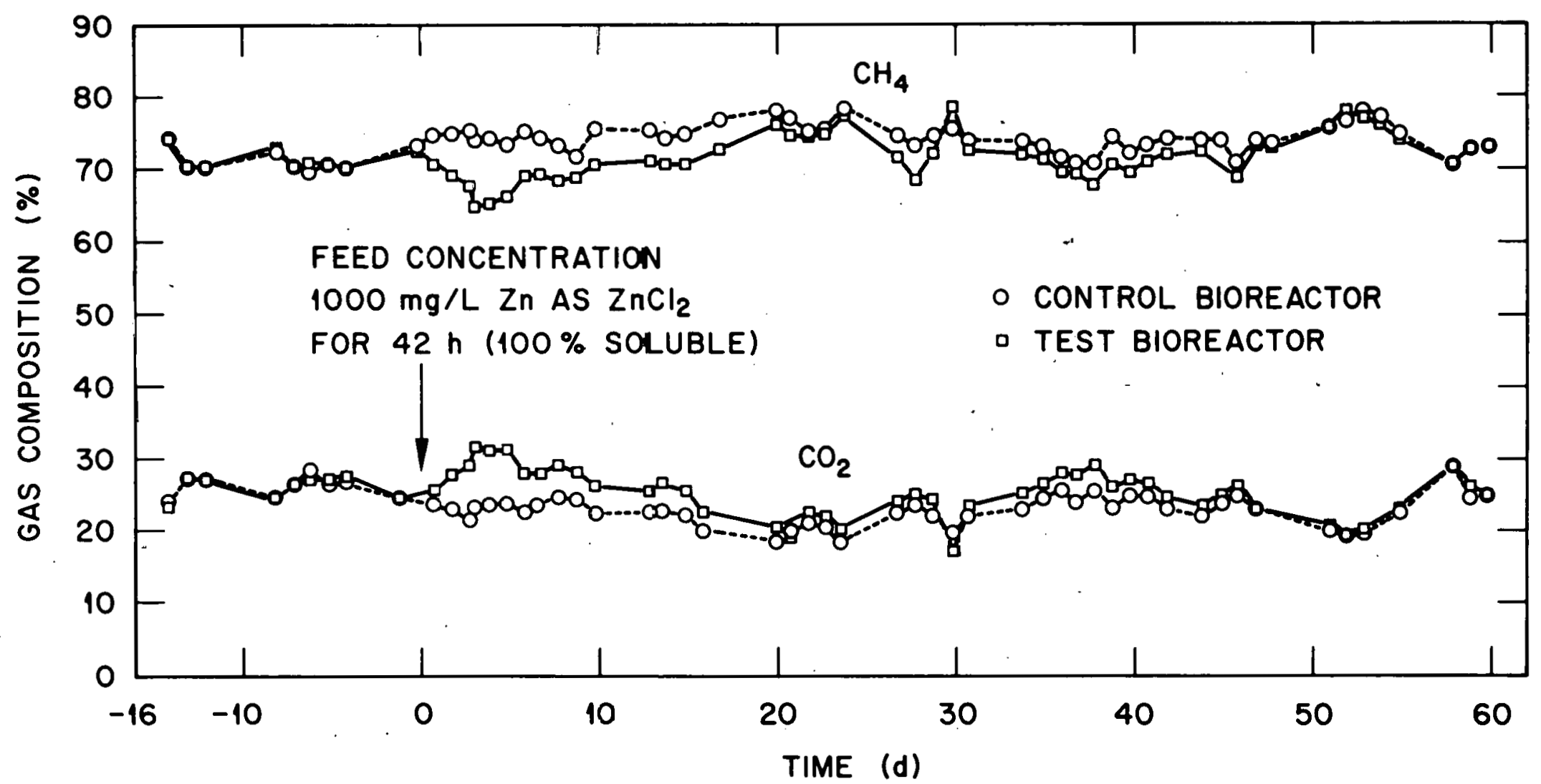

Figure 6.35. Methane and carbon dioxide percentages in the of $f-$ gas of control and test $(\mathrm{T}-1)$ bioreactors during toxicity experiment No. 2 . 
ORNL DWG 81-55

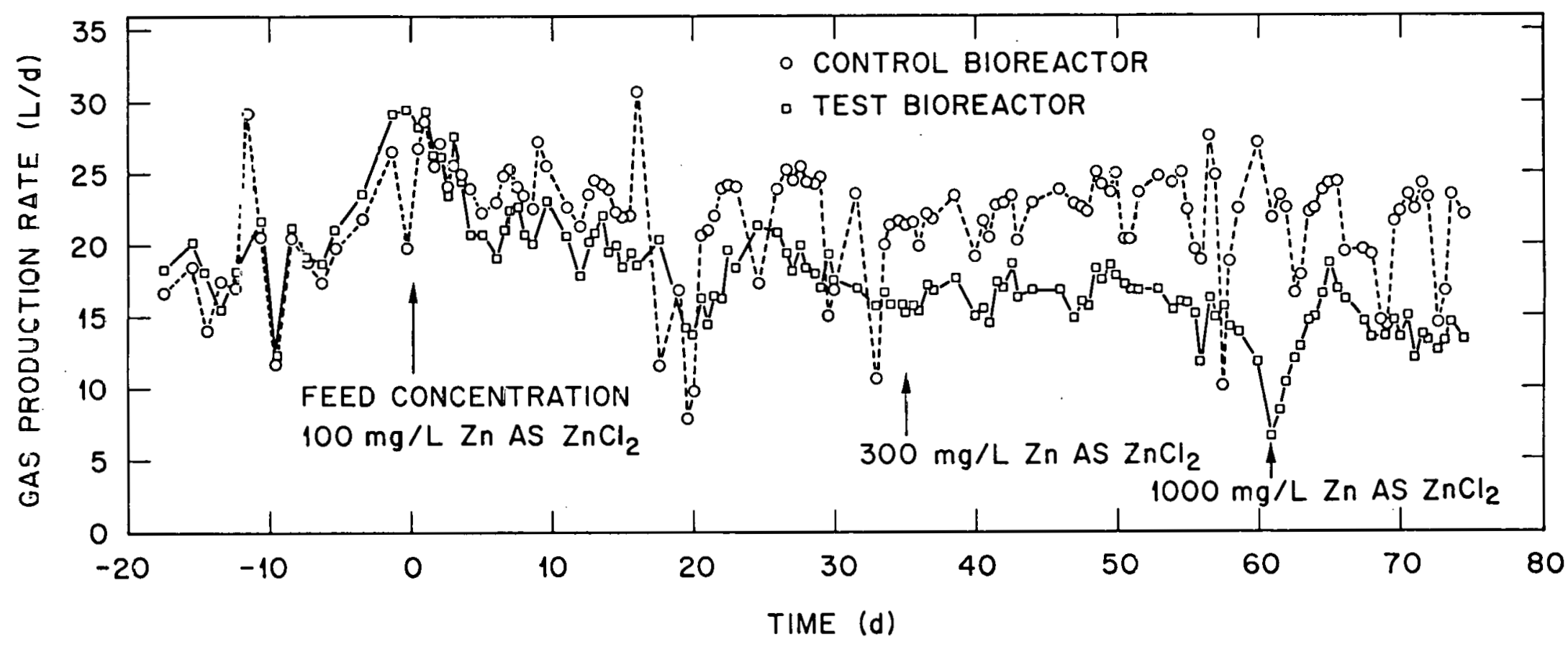

Figure 6.36. Gas production rate for control and test ( $\mathrm{T}-2)$ bioreactors during toxicity experiment No. 3 . 
ORNL DWG 81-64

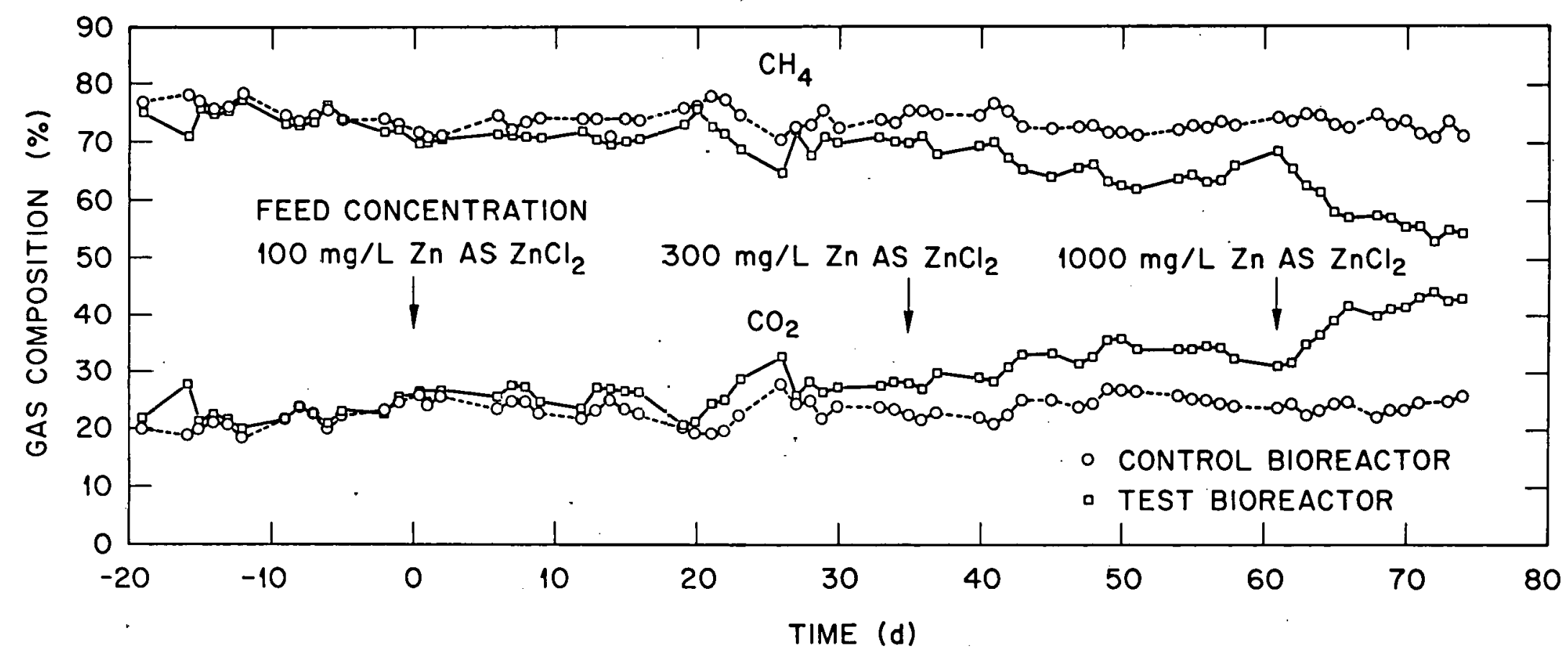

Figure 6.37. Methane and carbon dioxide percentages in the offgas of control and test ( $\mathrm{T}-2)$ bioreactors during toxicity experiment No. 3. 
carbon dioxide to methane varies with the character of the substrate undergoing decomposition. 63

Under normal operations conditions some of the carbon dioxide produced dissolves in the water maintaining an alkalinity level high enough to prevent a decrease in $\mathrm{pH}$ when the volatile acids are being produced. The alkalinity of the system (whose major contributor is the carbonate system) under the existing near-neutral $\mathrm{pH}$ conditions is given primarily by the bicarbonate ion. 64 This alkalinity serves as potential buffer when unbalanced conditions appear and the concentration of volatile acids begin to increase. When the acids are neutralized, carbon dioxide is produced. This production of carbon dioxide coupled with a decrease in the production of methane contribute to an increase in its percentage in the off-gas.

The change in gas composition during toxicity experiments under shock conditions were not noticeable to a great extent as in continuousfeeding of the heavy metal. This phenomena probably happened because of the relatively short time involved during the toxicity induction phase and the dilution phenomena in the gas chamber on top of the packed section where the gas samples were taken. This response is also modified by the shifting of biological activity to upper regions resulting in a decrease in reactor response as determined from the etfiluent. Whiti the heavy metal was fed continuously, the inhibitory phase was gradual and much longer times were involved. Shifting of biological activity to upper regions was observed, but it was expected that a point would eventualiy be reached where toxicity was gning to be uniformly distributed along the entire vessel. 
In summary, to observe a change in gas composition would require a continuous gas production with different composition for some time. For example, a sudden complete cessation in the gas production would result in no change in the composition of the gas in the gas chamber under the experimental conditions of this study.

\subsubsection{Acetic and Propionic Acid Profiles}

Acetic and propionic acids were found to be good indicators of inhibitor or toxicity to this system. As shown in Figures 6.38 to 6.43 , the acids were produced in the lower or active regions; however, since they were not used to the same extent (as in steady-state operation) they kept moving upward and reached the upper or inactive regions. Since these regions do not have enough bacterial population (methane formers), these acids. were not removed to a great extent. This state will exist for some time because of the long generation times for these microorganisms. Their capacity to use the acids and produre the necessary biomass will depend on the potential of the heavy metal to reach these regions. This potential depends on the metal removal capacity of the lower regions.

Based on these acid profiles and the soluble COD profiles shown before, it is concluded that the kinetic constant describes the biological activity of the methane formers. This observation could be anticipated since it is being considered that waste stabilization (soluble COD removal) occurs mainly with the production of methane (methanogenesis). In the operating mode the bioreactor is divided in two regions, one that produces the acids and the other that produces the methane. Since the 
ORNL DWG 81-72

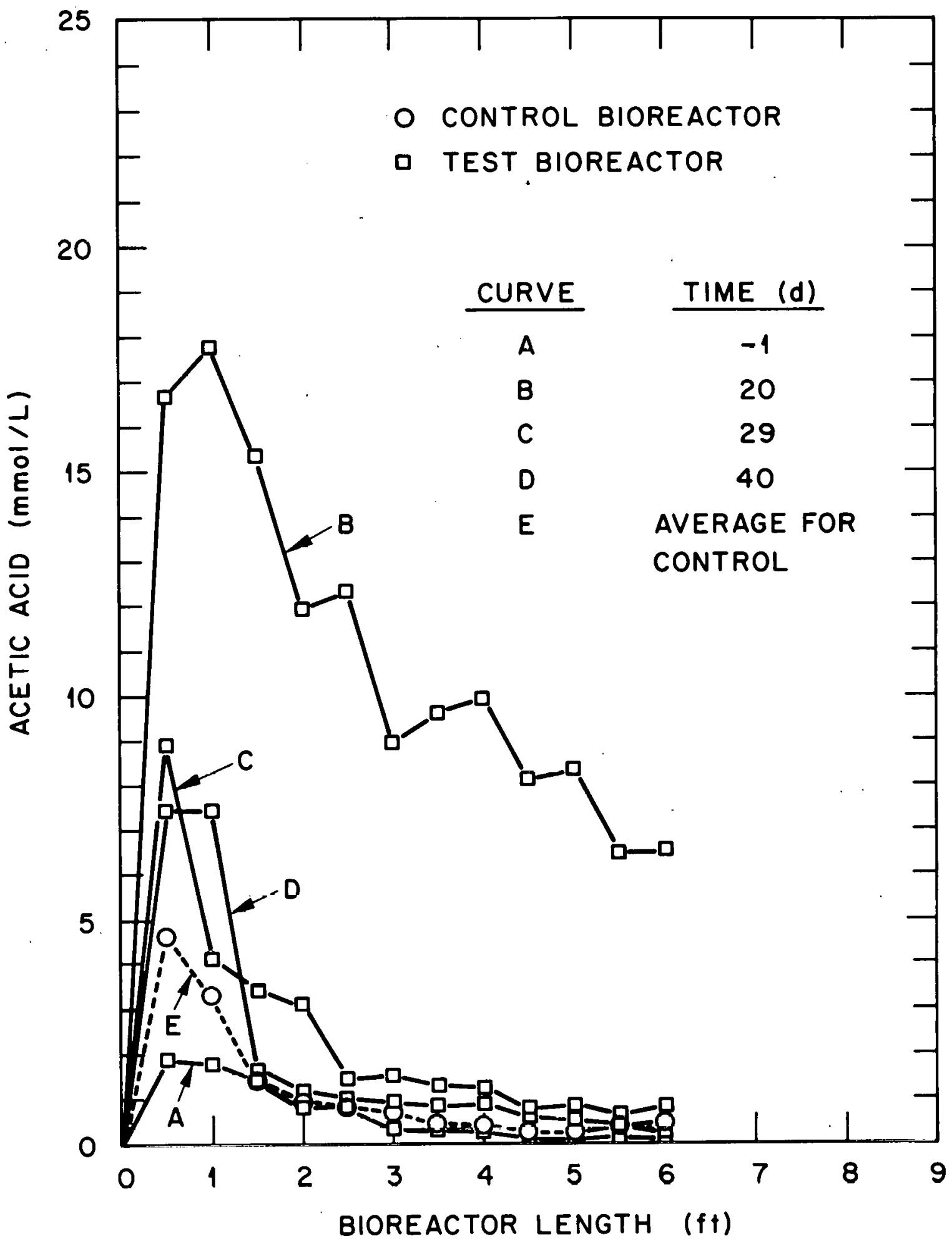

Figure 6.38. Acetic acid profiles for test bioreactor during toxicity experiment No. 1 . 
ORNL OWG 81-71

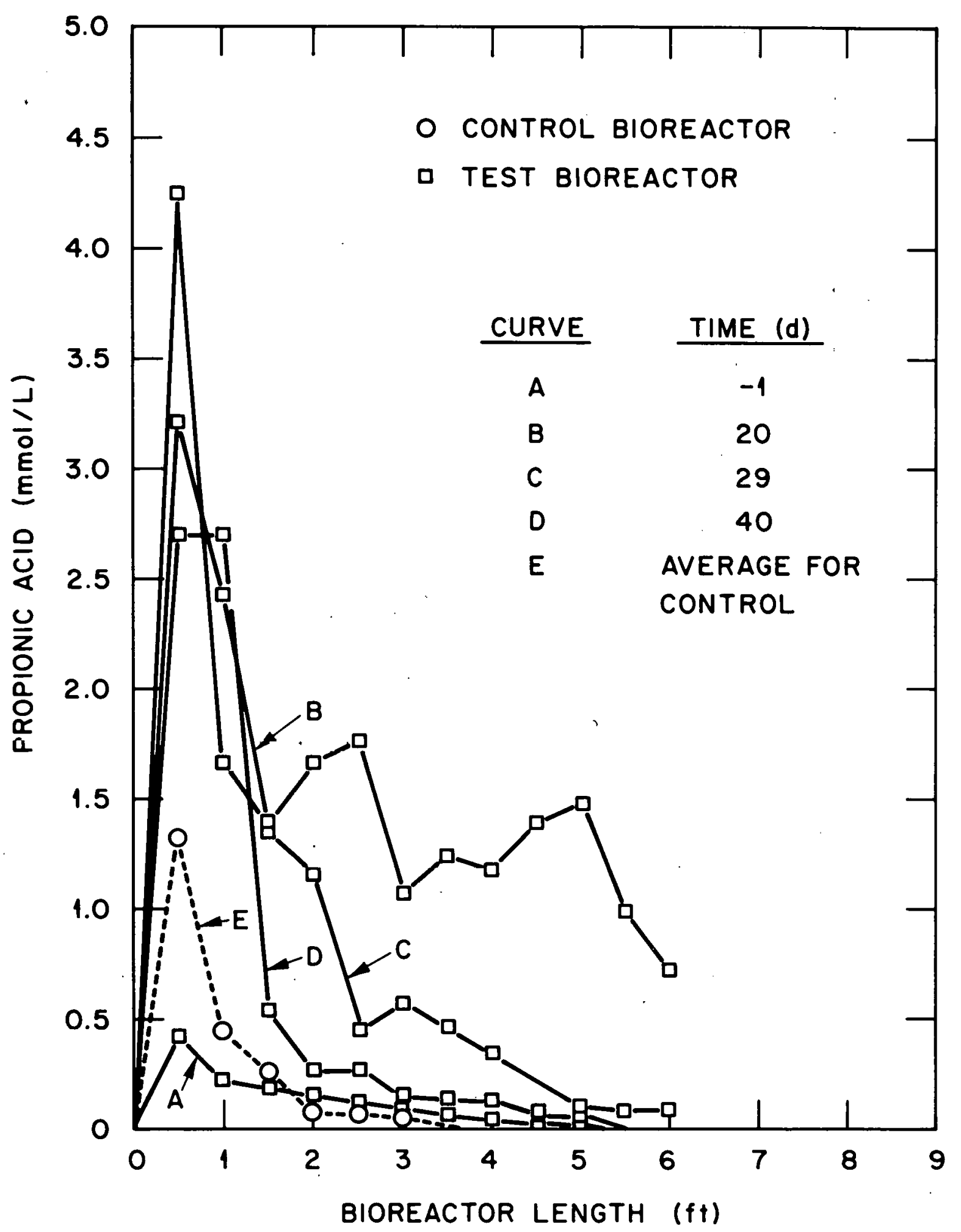

Figure 6.39. Propionic acid profiles for test bioreactors (T-1) during toxicity experiment No. 1. 
ORNL DWG 81-70

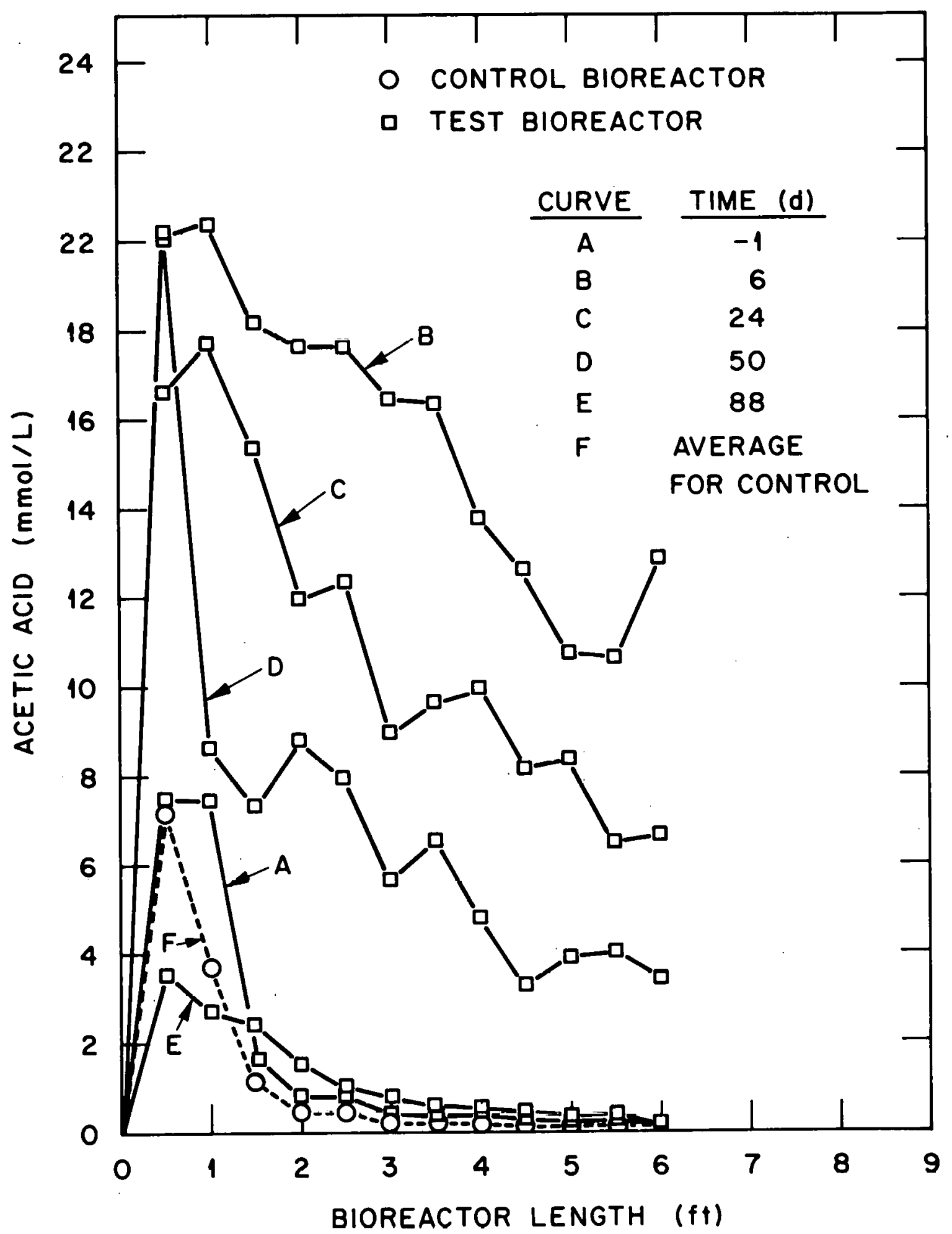

Figure 6.40. Acetic acid profiles for test (T-1) bioreactor during toxlelty experiulent No. 2. 
ORNL DWG 81-69

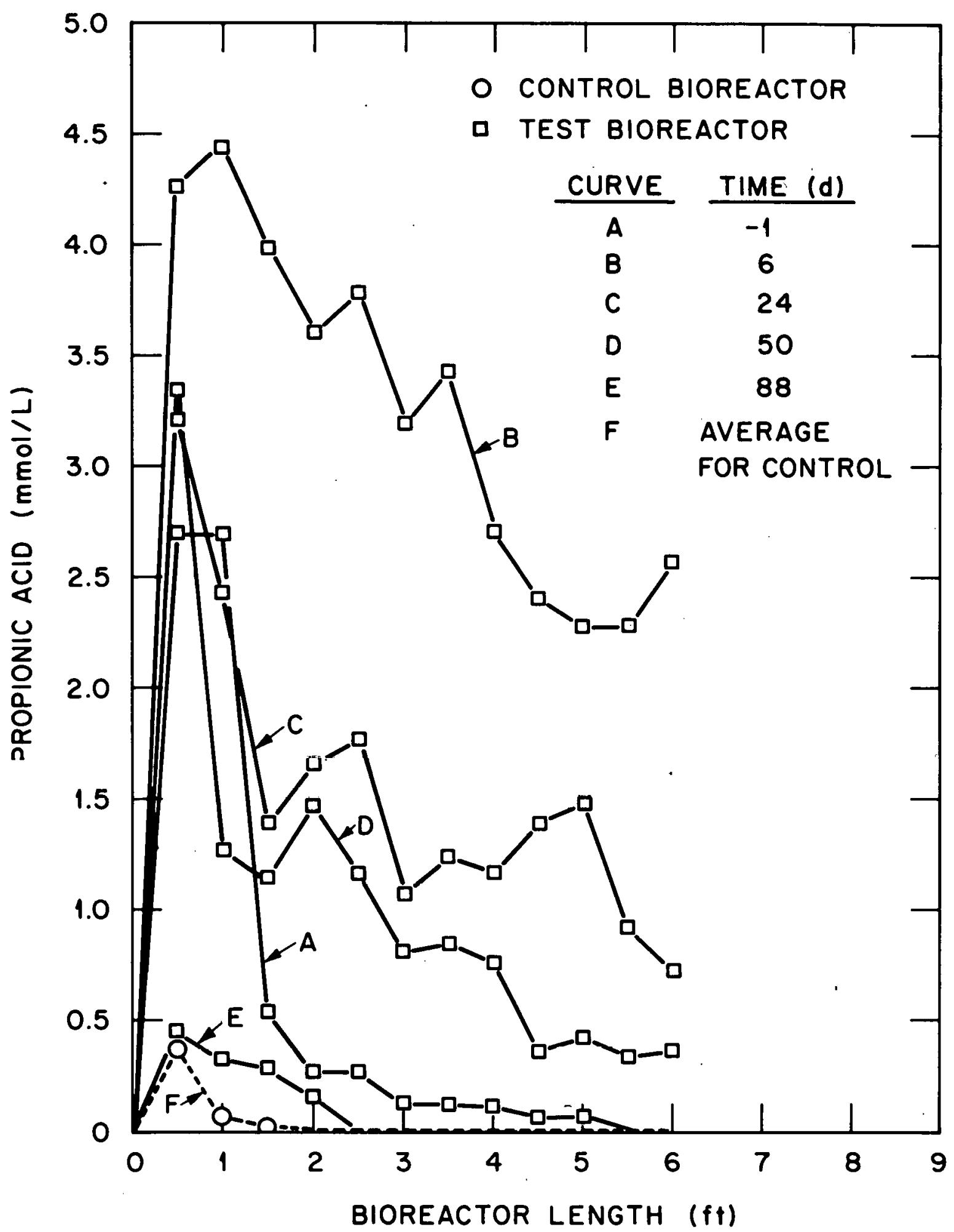

Figure 6.41. Propionic acid profiles for test bioreactor (T-1) during toxicity experiment No. 2 . 
ORNL DWG 81-76

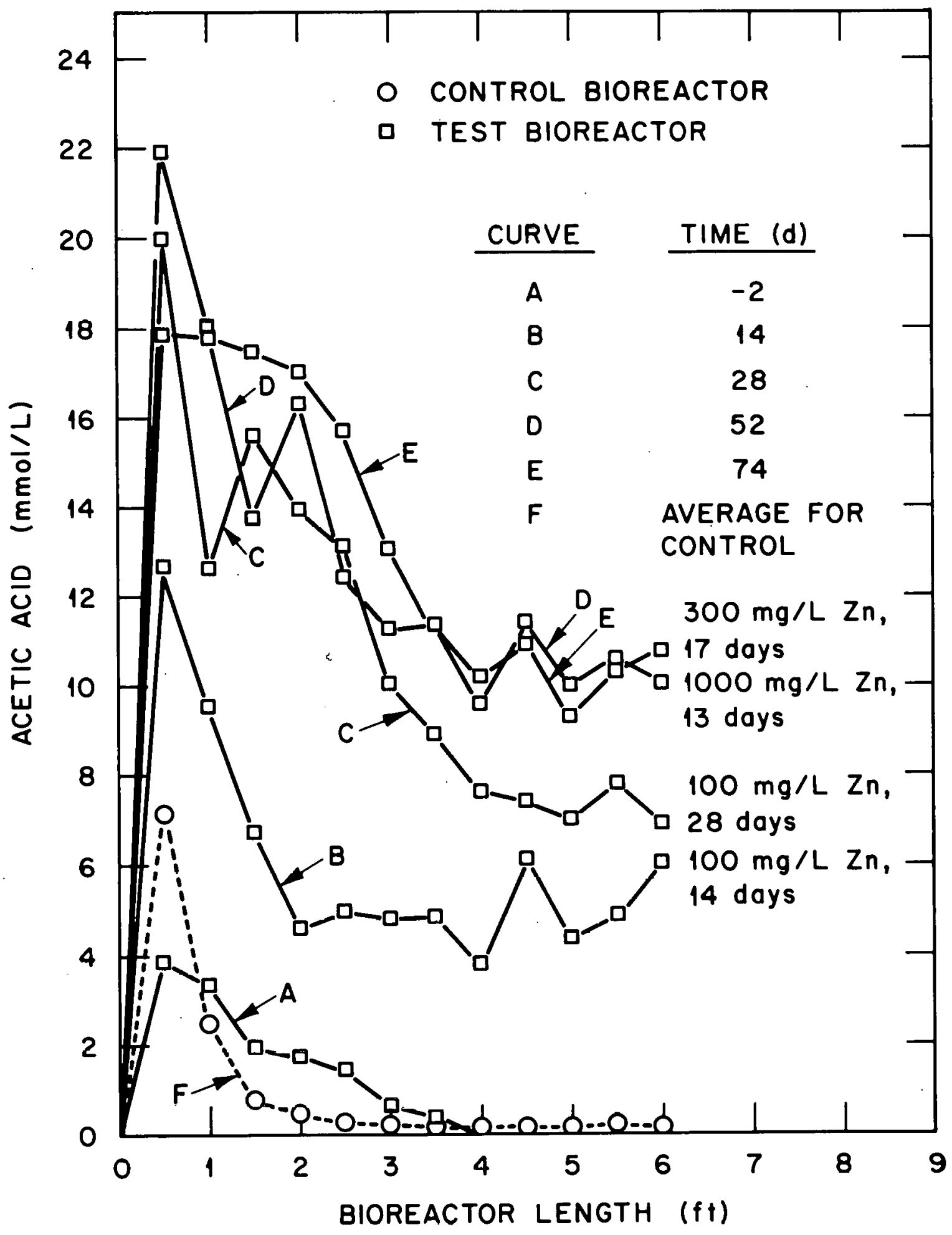

Figure 6.42. Acetis acid profiles for test bioreactor during toxicity experiment No. 3. Also shown are the concentrations of zinc in the feed and the time when the profile was done relative to the time when the particular concentration was first introduced in the feed. 
ORNL DWG $81-73$

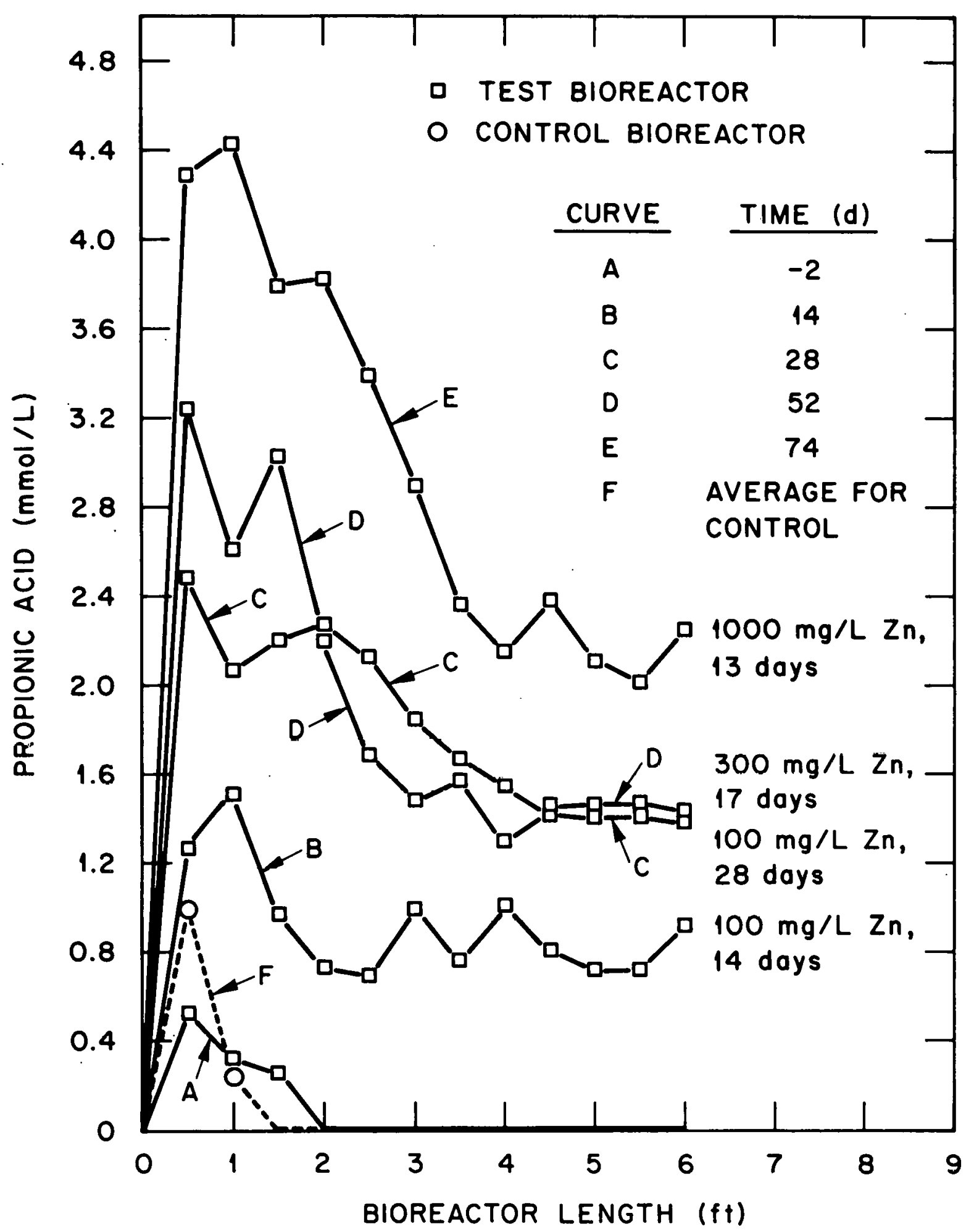

Figure 6.43. Propionic acid profiles for test bioreactor during toxicity experiment No. 2. Also shown are the concentrations of zinc in the feed and the time when the profile was done relative to the time when the particular concentration was first introduced in the feed. 
acids increased in concentration, it is concluded that inhibition was induced mainly to the methane formers. The same degree of inhibition to the acid formers should result in a decrease in acid production (acetogenesis), resulting in lower acid concentrations.

The best way to monitor the performance of an ANFLOW bioreactor would be to determine and physically define the active region. The rate of increase in total volatile acids concentration in the active region should be one of the variables to monitor and the one indicator for the need for control action. Since the process is a series reaction, this increased rate can be caused by an increased rate of production of volatile acids by the acid-producing bacteria (response to an increase in organic loading) or a decreased rate of acid consumption by the methane bacteria (inhibition). As shown in Figures 6.44 to 6.52 , the control bioreactor has its own volatile acid transients, especially in the active region, but they did not result in a decrease in bioreactor performance because this transient was dampered by the upper regions. This observation suggests that probably the heavy metal was present when the acids reached the upper regions of the dosed bioreactor, and this factor reduced their potential to dampen the inhibition caused to the active regions. Experience in the operation of ANFLOW bioreactors under field conditions could also be useful in the assessment of the presence and cause of unbalanced conditions, mainly, increase in acetogenesis or decrease in methanogenesis.

\section{$6.3 .4 \mathrm{pH}$ and Alkalinity}

The alkalinity in an ANFLOW bioreactor serves as a buffer preventing rapid changes in $\mathrm{pH}$. Bioreactor stability is therefore enhanced by 
ORNL DWG 80-1756

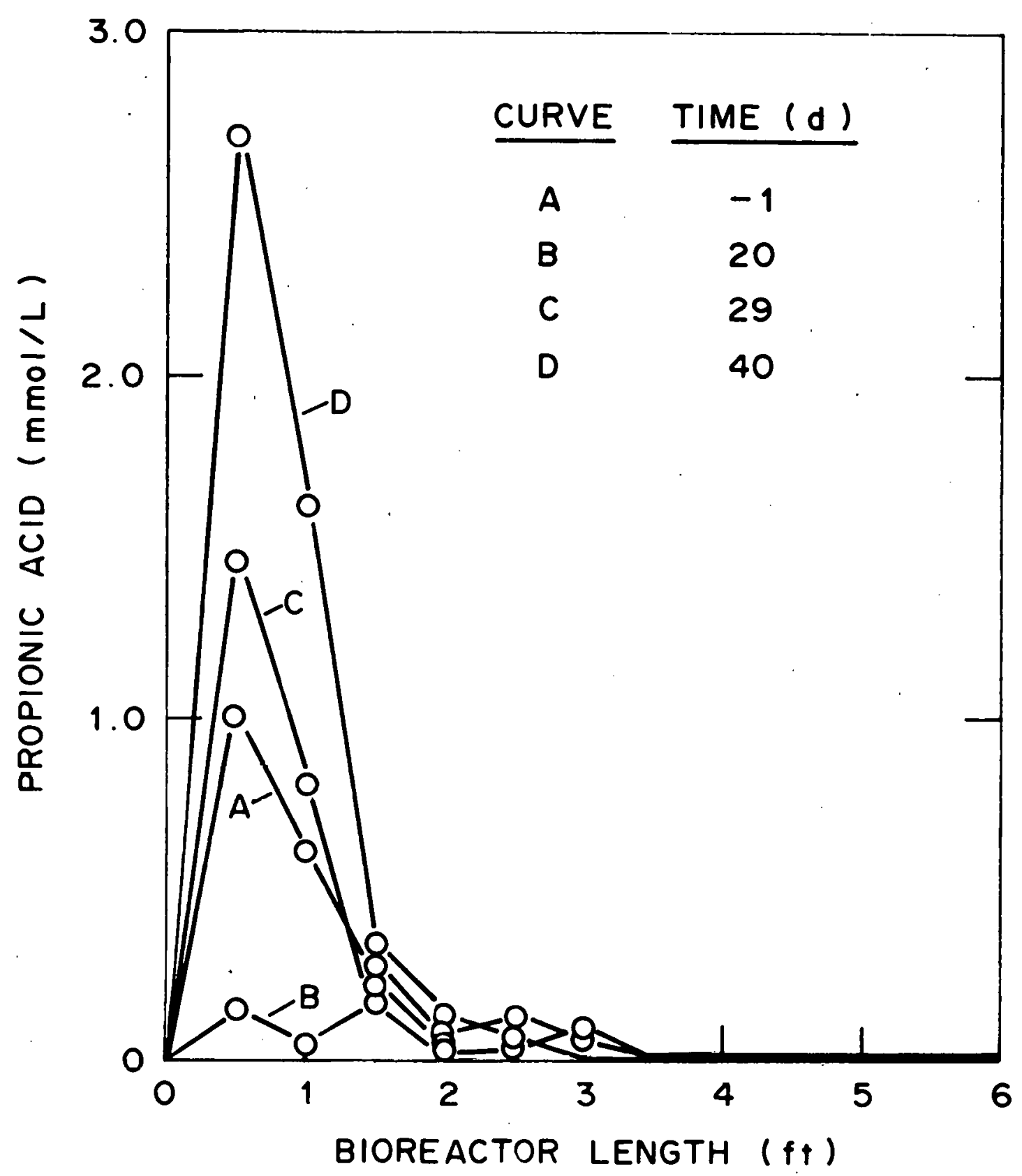

Figure 6.44. Propionic acid profiles for control bioreactor during toxicity experiment No. 1. 
ORNL DWG 80-1760

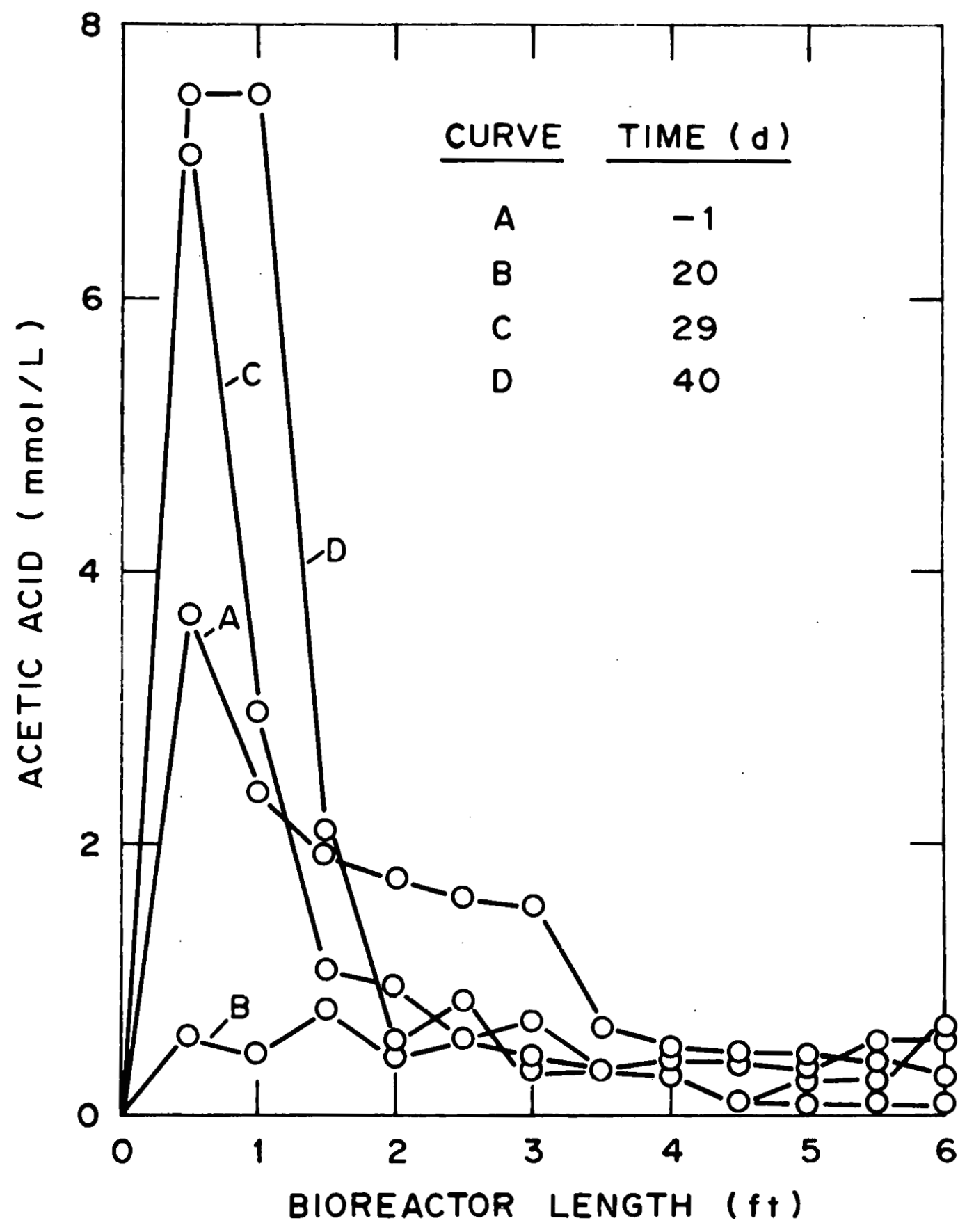

Figure 6.45. Acetic acid profiles for control bioreactor during toxicity experiment No. 1 . 
ORNL DWG 80-1757

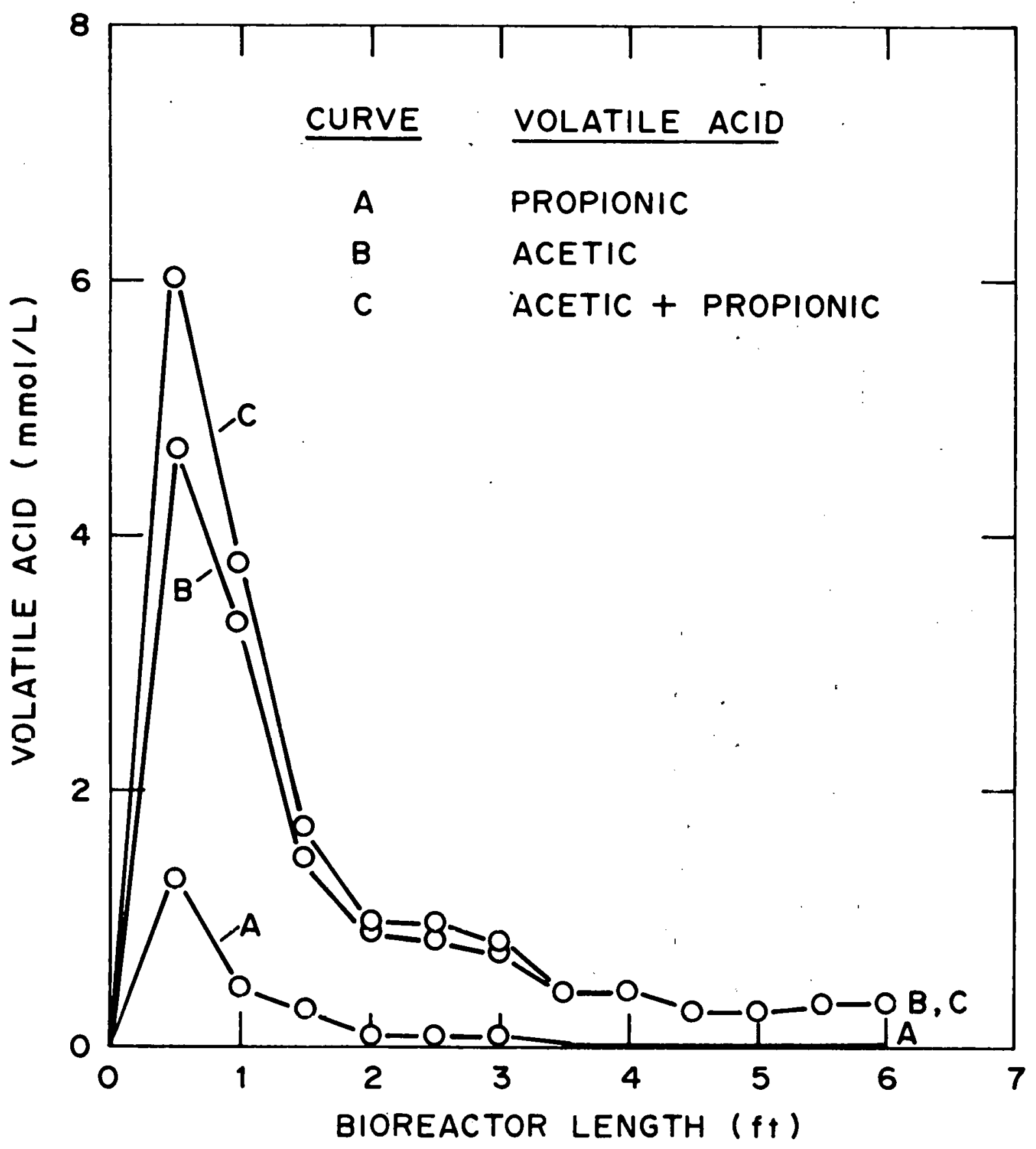

Figure 6.46. Average volatile acid profiles for control bioreactor during toxicity experiment No. 1. 
ORNL DWG 80-1758

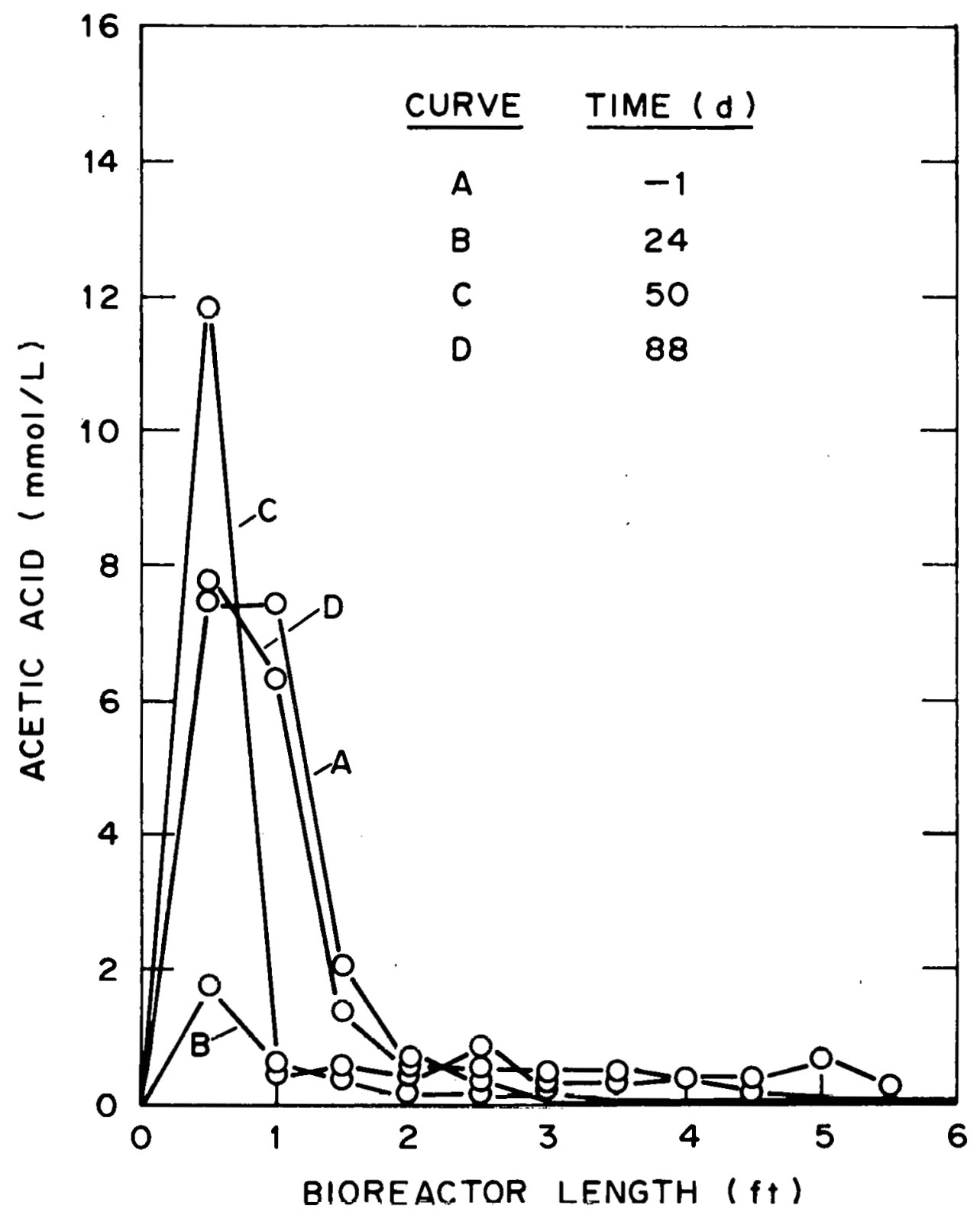

Figure 6.47. Acetic acid profiles for control bioreactor during toxicity experiment No. 2. 
ORNL DWG 80-1759

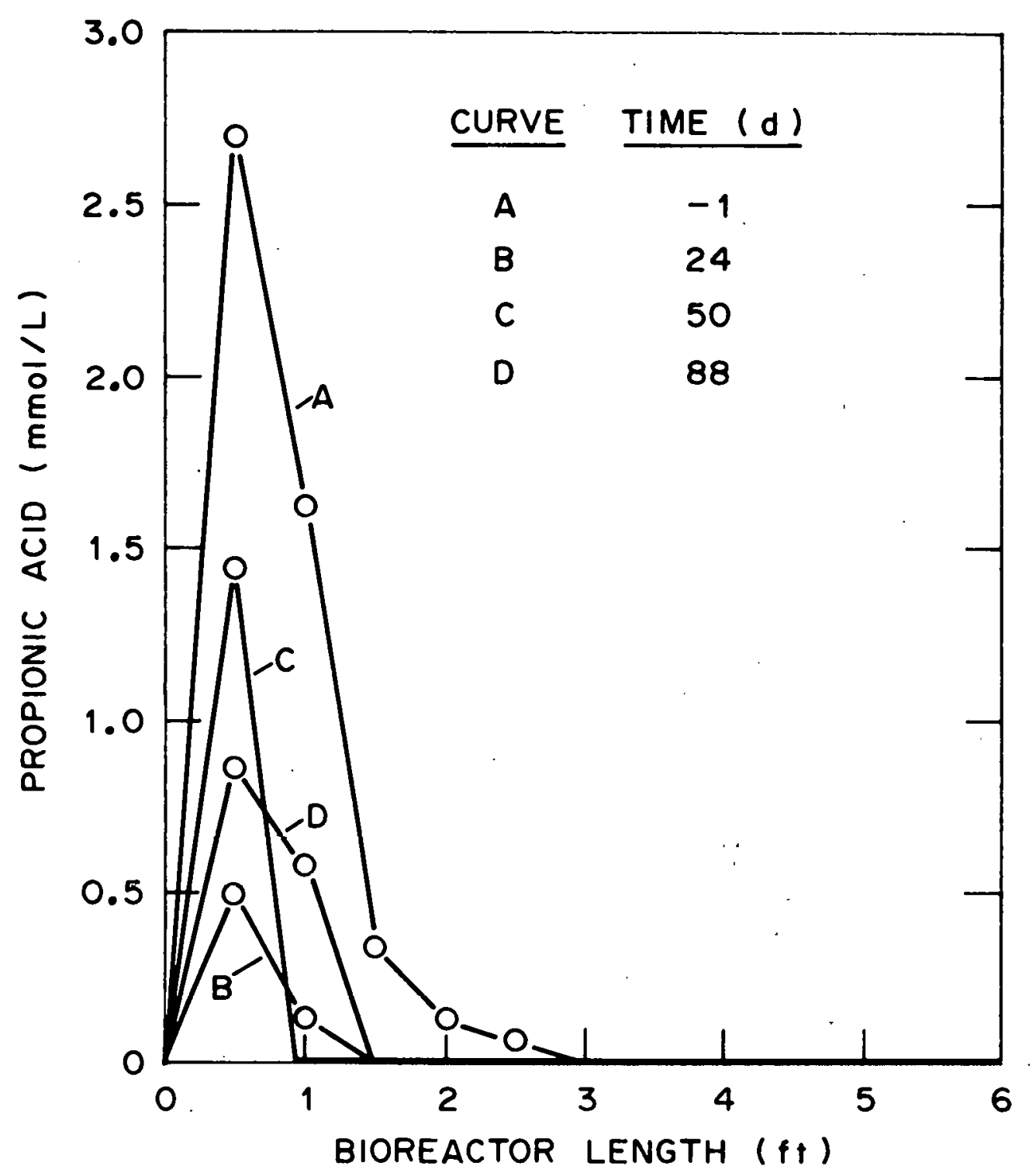

Figure 6.48. Propionic acid profiles for control bioreactor during toxicity experiment No. 2 . 
ORNL DWG $80-1761$

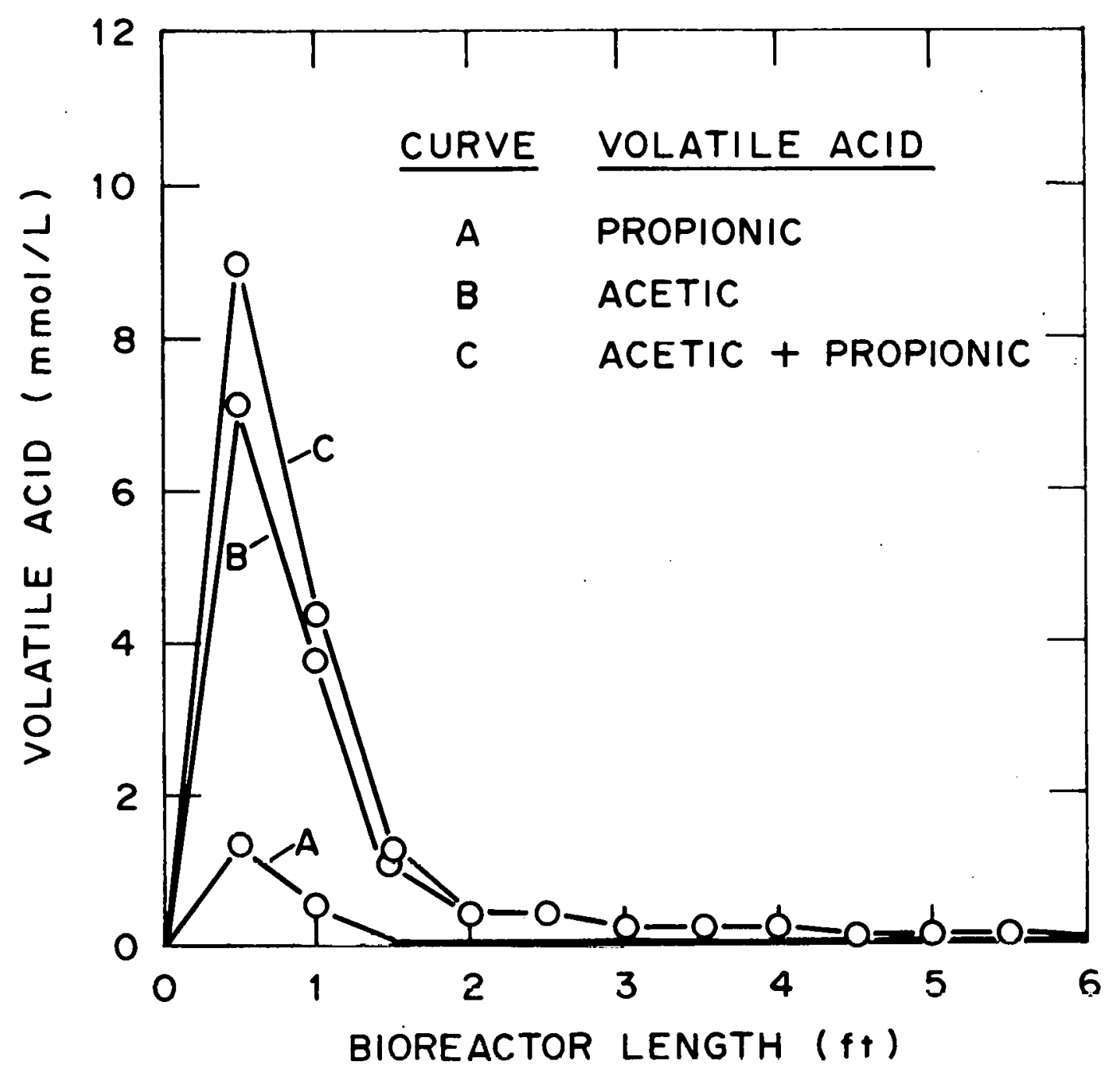

Figure 6.49. Average volatile acid profiles for control bioreactor during toxicity experiment No. 2 . 


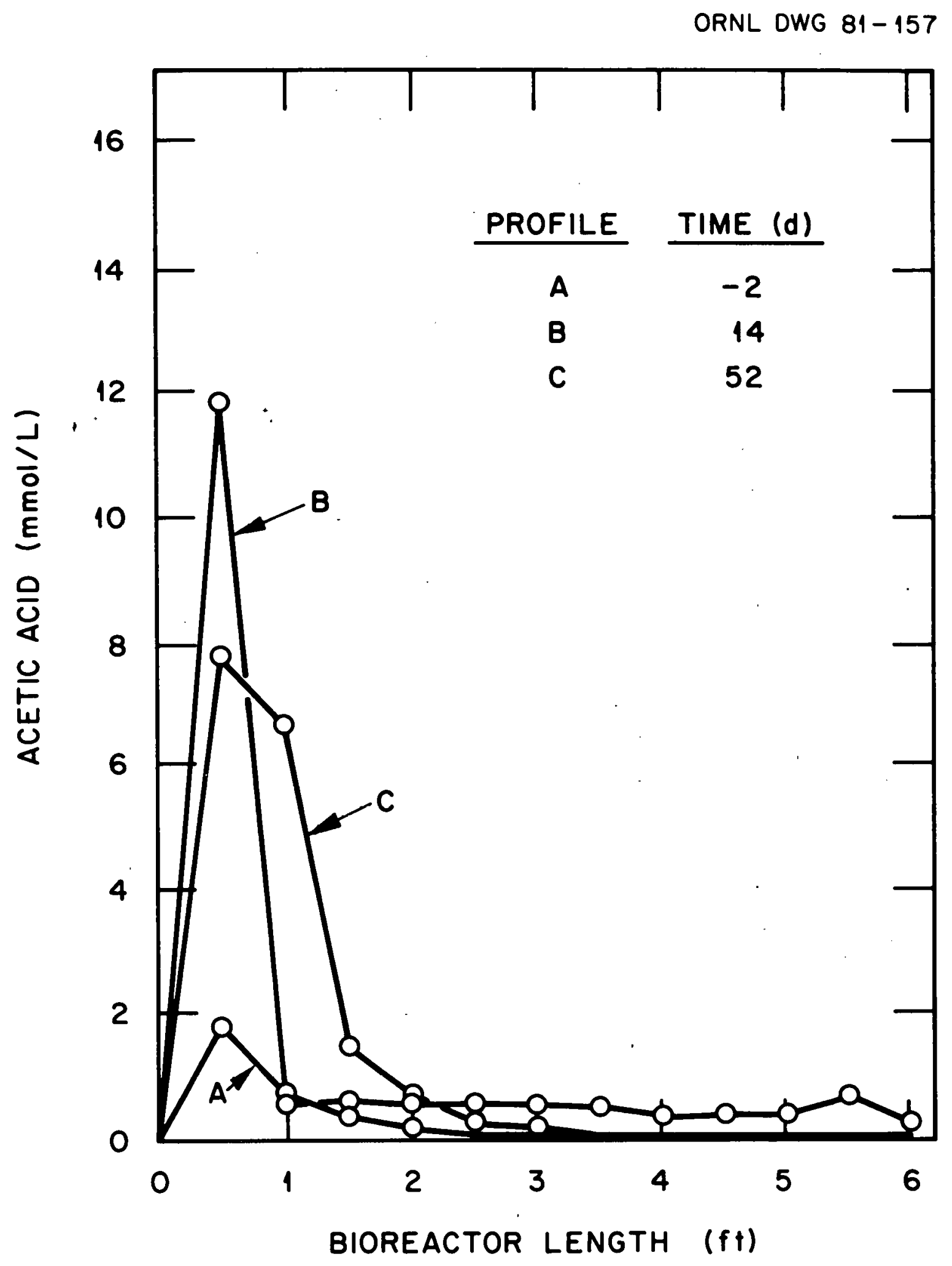

Figure 6.50. Acetic acid profiles for control bioreactors during toxicity experiment No. 2 . 
ORNL OWG $81-156$

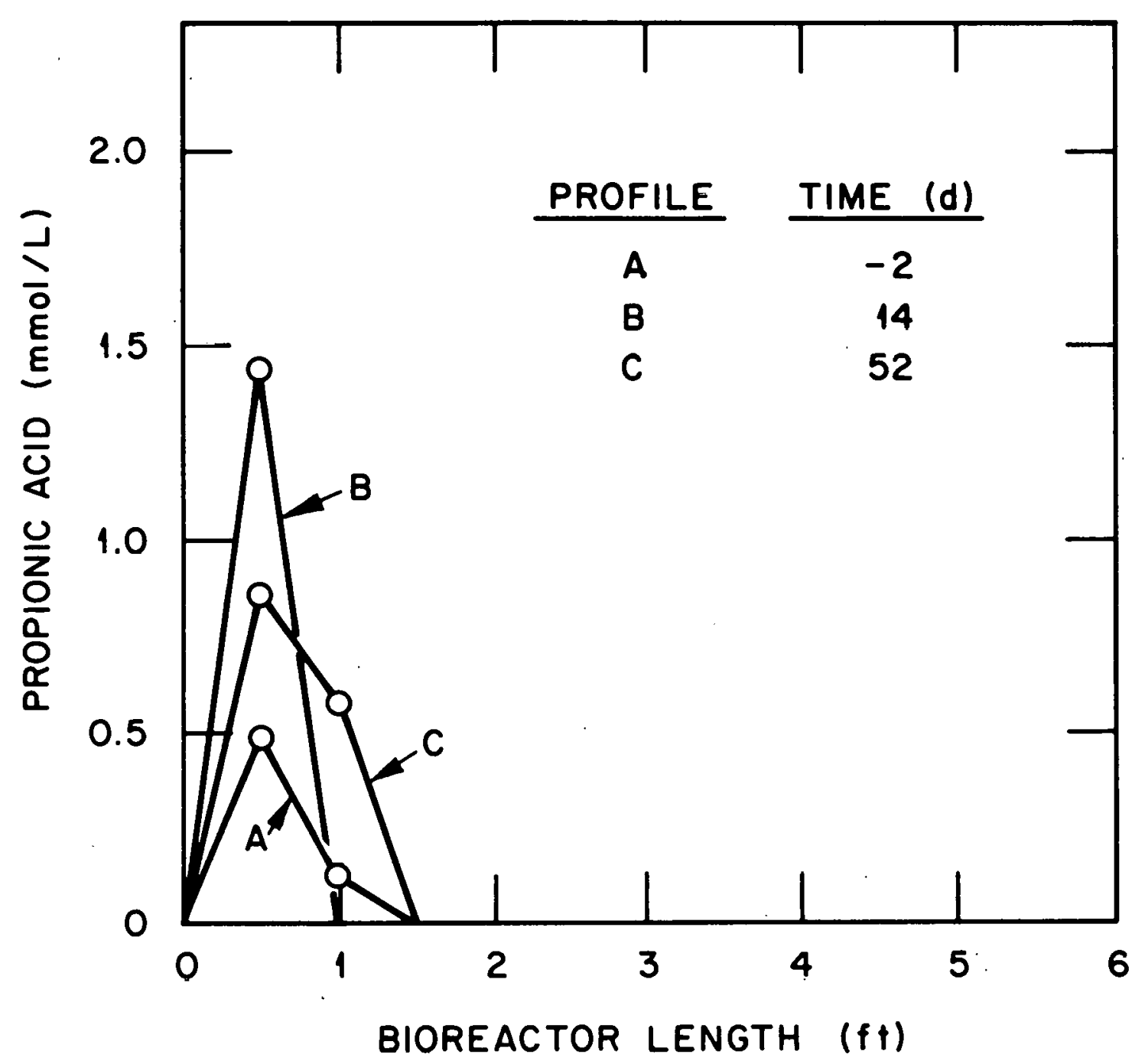

Figure 6.51. Propionic acid profiles for control bioreactor during toxicity experiment No. 3. 
ORNL DWG $81-158$

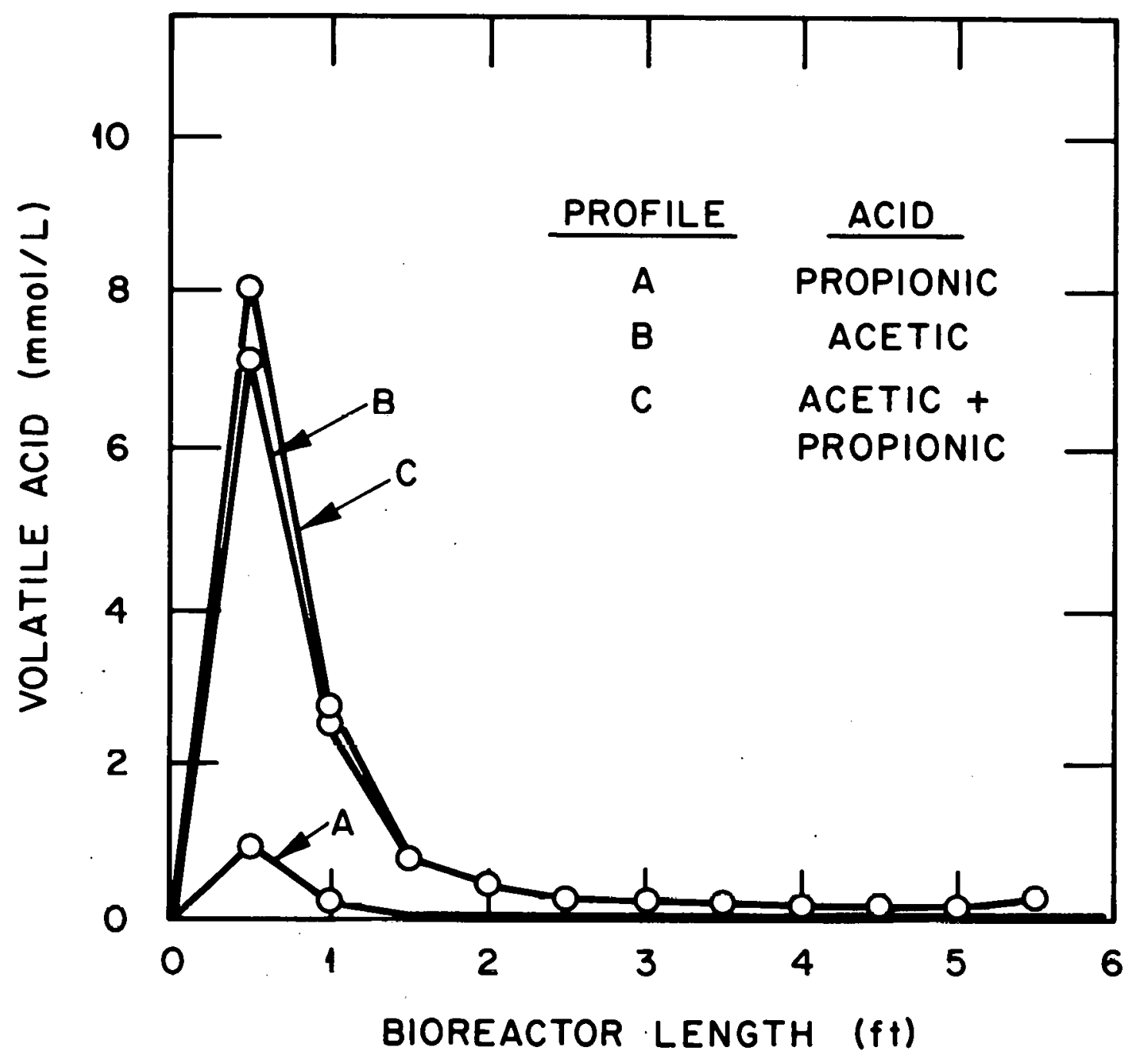

Figure 6.52. Average volatile acid profiles for control bioreactor during toxicity experiment No. 3. 
a high alkalinity concentration. Under normal operating conditions, the major buffering system is the carbon dioxide-bicarbonate system with the ammonium ion as the major cation. However, when the concentration of volatile acids is high, a substantial portion of the alkalinity as measured is caused by the volatile acids since the analysis for alkalinity is conducted by titrating with a strong acid to $\mathrm{pH}$ of 4.5 to 4.0 . The pK of acetic and propionic acids is about 4.5-5,65-66 therefore a portion of the titrant is used to neutralize the volatile acid salts.

It is considered that bicarbonate alkalinity would be a better indicator of bioreactor conditions rather than the total alkalinity since bicarbonate alkalinity is more related to the biochemical changes associated with anaerobic waste treatment. The bicarbonate ion is the major chemical species of the carbonate system. Carbon dioxide, the source of bicarbonate, is one of the by-products of methanogenesis. A separate analysis as proposed by Banta and Pomeroy67 could be useful. The alkalinity also depends on the kind of incoming waste. High protein wastes would have higher alkalinities because of the production of ammonia from proteine.

The $\mathrm{pH}$ is another indicator of possible problems within the reactorvessel. It is influenced by other operational variables, and although it is easy to be measured, it is not a sensitive indicator since it is a logarithmic function. For a system with adequate buffering capacity, it does not decrease significantly until the system is seriously affected. In a system such as ANFLOW, the alkalinity and $\mathrm{pH}$ are functions that would depend on the location within the bioreactor. 
Enough alkalinity was added during all toxicity experiments to help buffer the system. Based on $\mathrm{pH}$ and alkalinity measurements performed in the bloreactor effluents, the systems were well buffered (see Tables A. 8, B. 9 , and (. 8).

\subsection{Bioreactor Performance for Soluble Zinc Removal}

The removal of zinc was investigated during toxicity experiment No. 3 when the heavy metal was being fed continuously. As shown in Figure 6.53, the removal efficienctes for soluble zinc were more than $95 \%$ when the influent concentration was $100 \mathrm{mg} / \mathrm{L}$, about $90 \%$ for $300 \mathrm{mg} / \mathrm{L}$, and about $85 \%$ for $1000 \mathrm{mg} / \mathrm{L}$. This trend Indicates that the sorption capacity of the system was decreasing. Some analyses of total zinc concentration in the effluent were performed. It was found that the fraction of suspended zinc increased from about 10 to $20 \%$ at a zinc concentration In the feed of 100 and $300 \mathrm{mg} / \mathrm{L}$ to about 30 to $40 \%$ at $1000 \mathrm{mg} / \mathrm{L}$. These phenomena could be explained by an increase in biosolids sloughing from the fixed-films or by an increase in precipitated (carbonate or sulfide) zinc associated with a decrease in the sorption capacity of the column or both. Unfortunately, no data are available to support these or any other phenomena.

The soluble zinc concentrations in the bioreactor effluent during shock-load conditions are indicated in Figure 6.54. As can be seen, the curve begins with a gradual increase in concentration from background levels. This concentration level is believed to be the result of dispersion, as well as sorption of the heavy metal by the biomasses. The concentration of zinc in the effluent kept increasing until a maximum 
ORNL DWG $81-63$

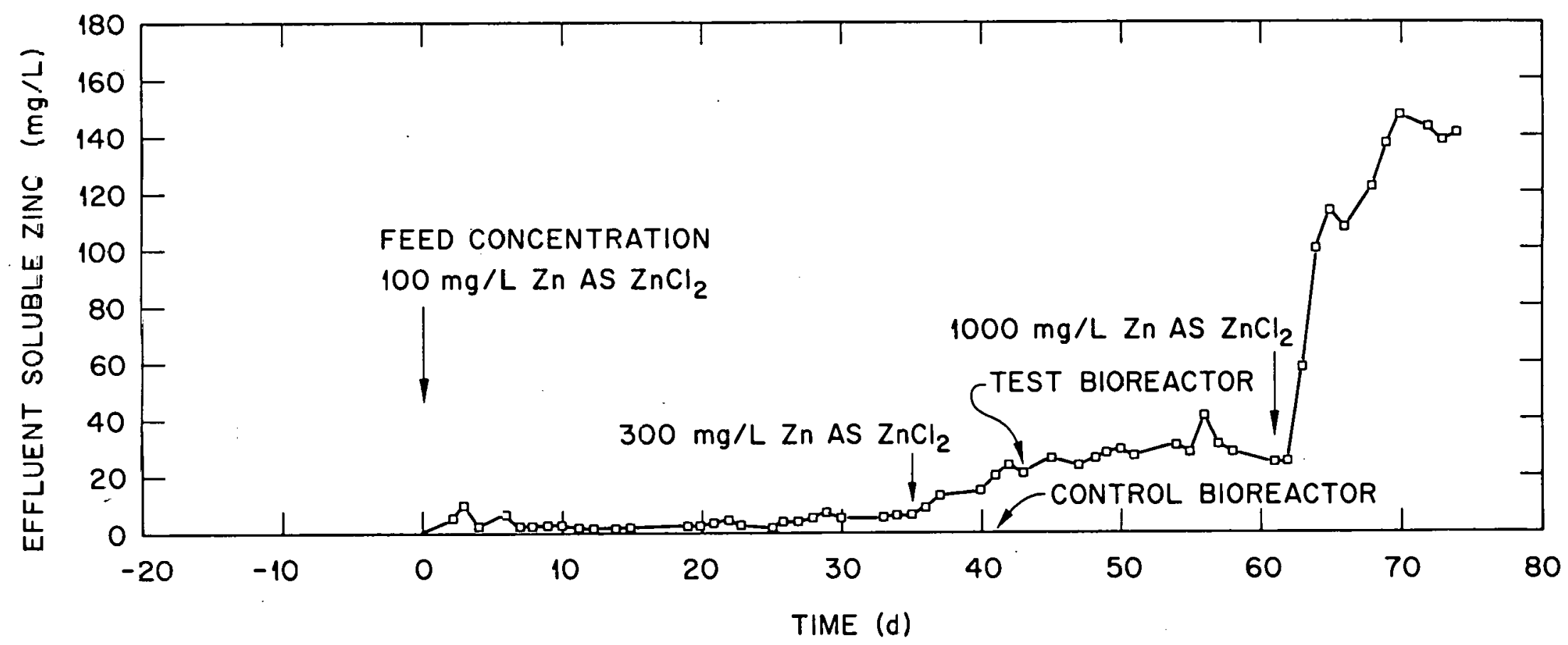

Figure 6.53. Soluble zinc concentration in test (T-2) and control bioreactor effluents during toxicity experiment No. 3. 
ORNL DWG 80-1753

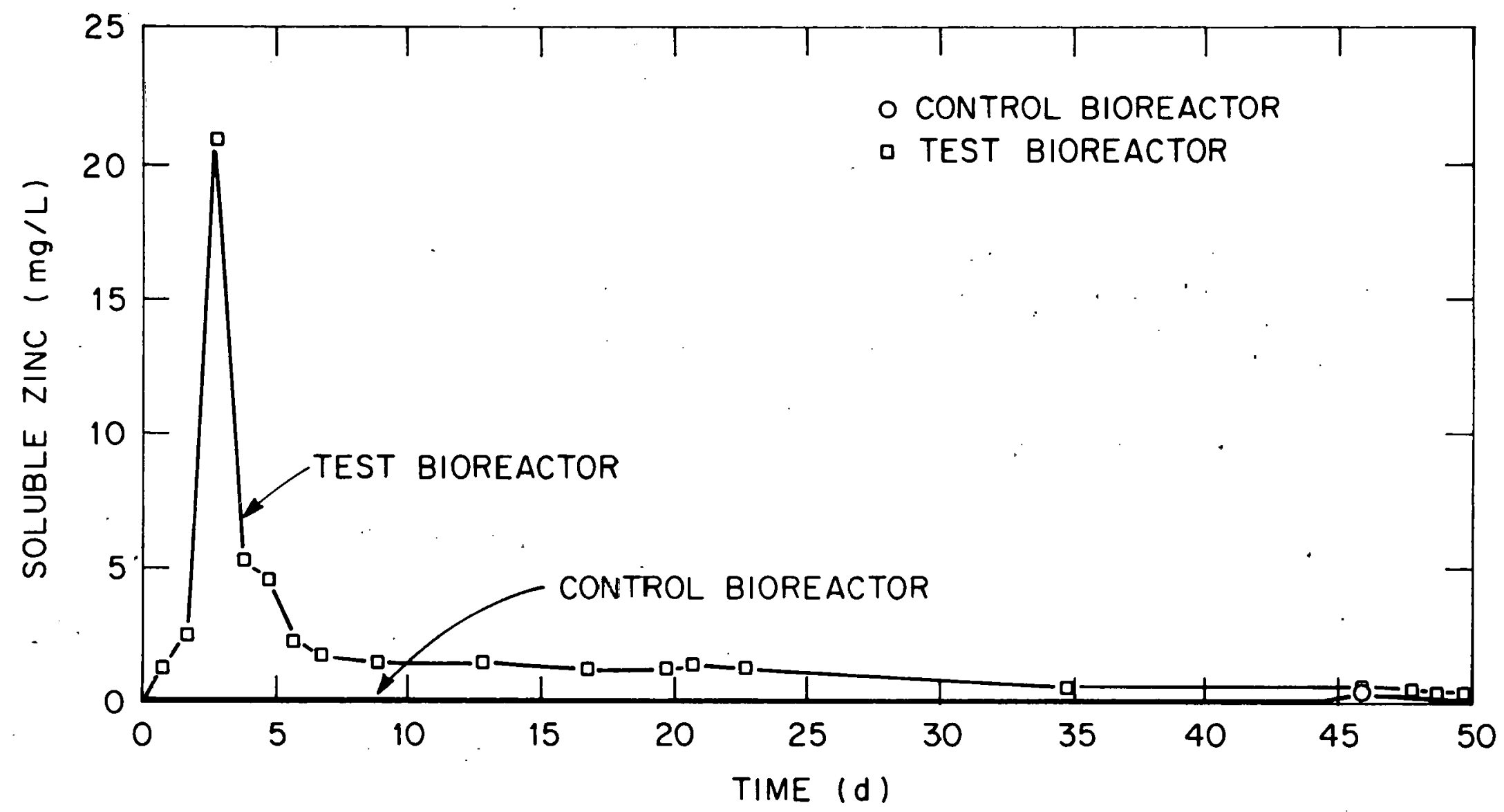

Figure 6.54. Soluble zinc in test $(T-1)$ bioreactor effluent during toxicity experiment No. 2 . 
was reached. After the shock load was stopped and feeding without zinc was resumed, wash out of the metal began to occur. Thereafter, the concentration of zinc began to decrease. It was not determined if this wash out was from the voids only or if it also included desorption from the fixed-films or biosolids.

\subsection{Sorption Factors and Distribution of Zinc Under Step-Feeding Conditions}

It was found that depending on the influent concentration and sorption factors the efficiency for soluble zinc removal in the active region (Region I) decreased from about 80 to $85 \%$ to about 20 to $30 \%$. As shown in Figure 6.55 and supported by Figure 6.56 , the upward shifting in the soluble zinc profiles, mainly in the lower regions of the bioreactor, could be caused by a decrease of the sorption capacity or the number of binding sites available in these regions. After these regions began to saturate, the upper regions received the increase in metal concentration and the sorption factors began to increase too.

As shown in Figures 6.55 and 6.56 , soluble zinc profiles and sorption factor profiles follow the same pattern as the soluble COD profiles. It seems reasonable to conclude that inhibition seems to be associated with the amount of heavy metal sorbed by the biosolids.

An attempt was made to determine if there was any relation between the sorption factor and the soluble zinc concentration at that location. Because of its flexibility, the Freundlich equation is the most widely used equation for complex systems that involve sorption phenomena. The equation as applied to this study can be expressed as 
ORNL DWG 80-1762

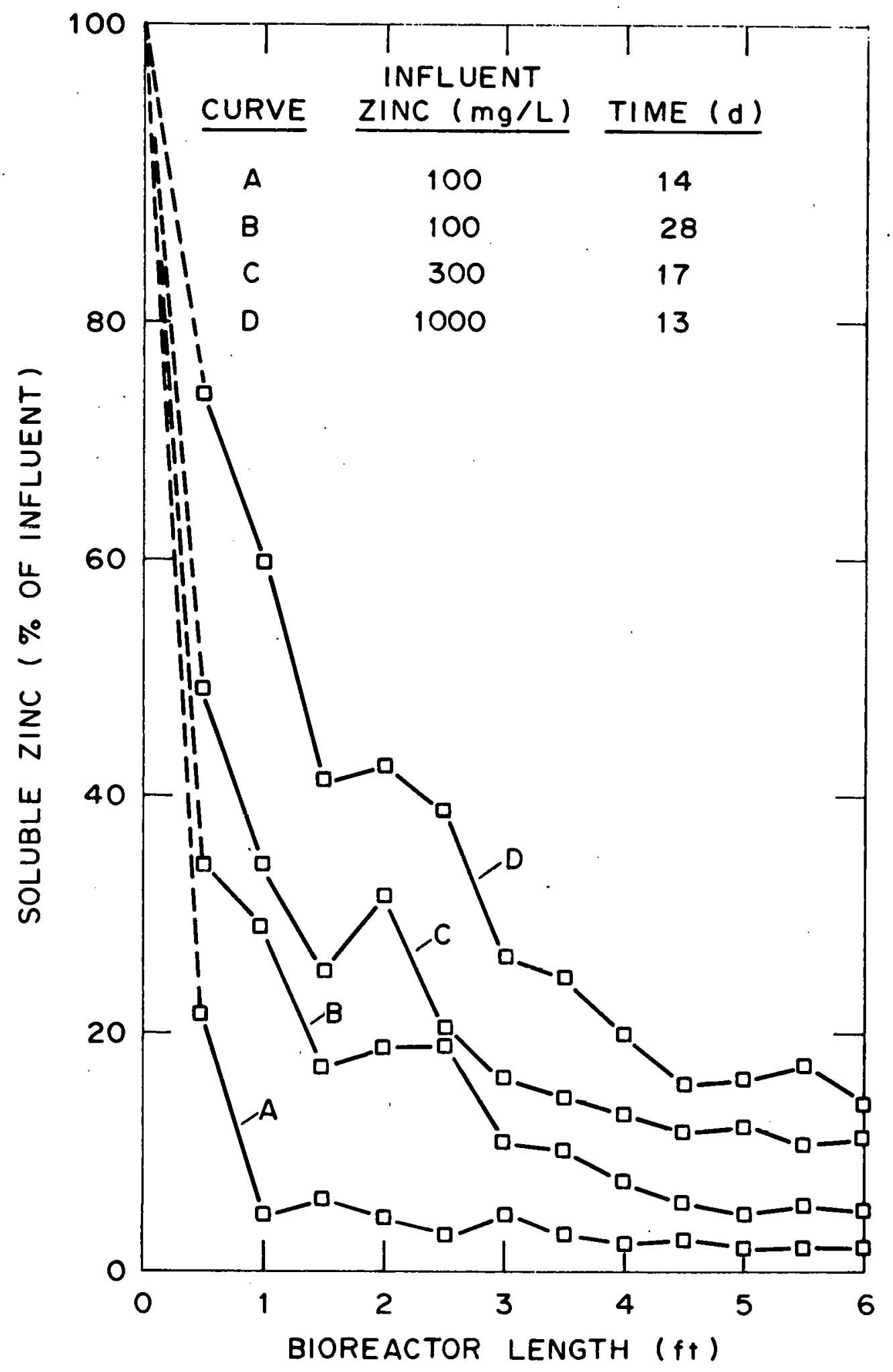

Figure 6.55. Soluble zinc profiles for test (T-2) bioreactor during toxicity experiment No. 3. Times given refer to the time when the profile was done relative to the time when the particular concentration was first introduced in the feed. 
ORNL DWG 80-1614

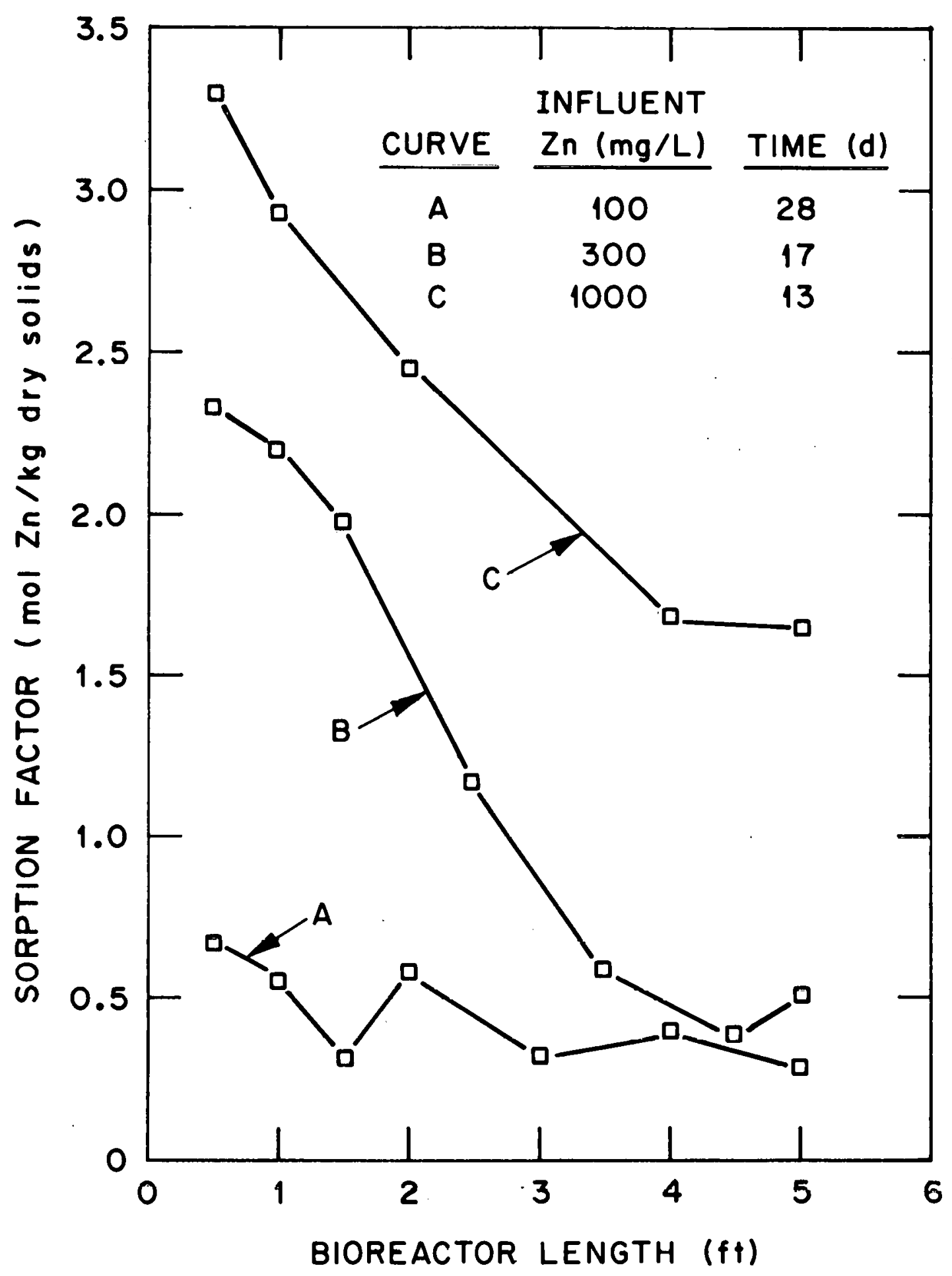

Figure 6.56. Sorption factor profiles for test (T-2) bioreactor during toxicity experiment No. 3. Times given refer to the time when the profile was done relative to the time when the particular concentration was first introduced. 


$$
\mathrm{SF}_{\mathrm{T}}=\mathrm{K}_{\mathrm{F}} \mathrm{C}^{1 / \mathrm{n}}
$$

where $\mathrm{K}_{\mathrm{F}}$ and $1 / \mathrm{n}$ are constants, $\mathrm{SF}_{\mathrm{T}}$ is the sorption factor in moles of zinc per $\mathrm{kg}$ of dry solids, and $\mathrm{C}$ is the concentration of soluble zinc in moles per $\mathrm{m}^{3}$. This equation can be linearized to become

$$
\ln \mathrm{SF}_{\mathrm{T}}=1 / \mathrm{n} \ln \mathrm{C}+\ln \mathrm{K}_{\mathrm{F}}
$$

The parameter ln $\mathrm{K}_{\mathrm{F}}$ could be considered as an indicator of sorption capacity and $1 / n$ of sorption intensity. $K_{F}$ and $1 / n$ are obtained from the intercept and slope of the straight line that results when the logarithm of the sorption factor is plotted against the logarithm of the soluble zinc concentration (see Figure 6.57).

From a least-squares fit of the sorption factors data, the following equation was obtained:

$$
\text { In } \mathrm{SF}_{\mathrm{T}}=0.5090 \text { in } \mathrm{C}-0.0383
$$

with a regression coefficient ( $r$ ) of 0.8955 . In its exponential form the equation is

$$
\mathrm{SF}_{\mathrm{T}}=0.9624 \mathrm{C}^{0.5090}
$$

These two equations are illustrated in Figures 6.57 and 6.58 .

As shown in Table 6.3 , it was found that over $90 \%$ of the heavy metal was organically bound in the solids sampled from the ANFLOW bioreactor. This finding supports other observed phenomena assoclated with inhibition or toxicity. The analyses were performed when the zinc concentration in the influent was 100 and $300 \mathrm{mg} / \mathrm{L}$. Not enough solids were collected, probably because of previous sampling, when zinc was being fed at a concentration of $1000 \mathrm{mg} / \mathrm{L}$. Previous sampling was performed on every other sample port to avoid not having enough solids to perform the 
ORNL DWG $80-1613$

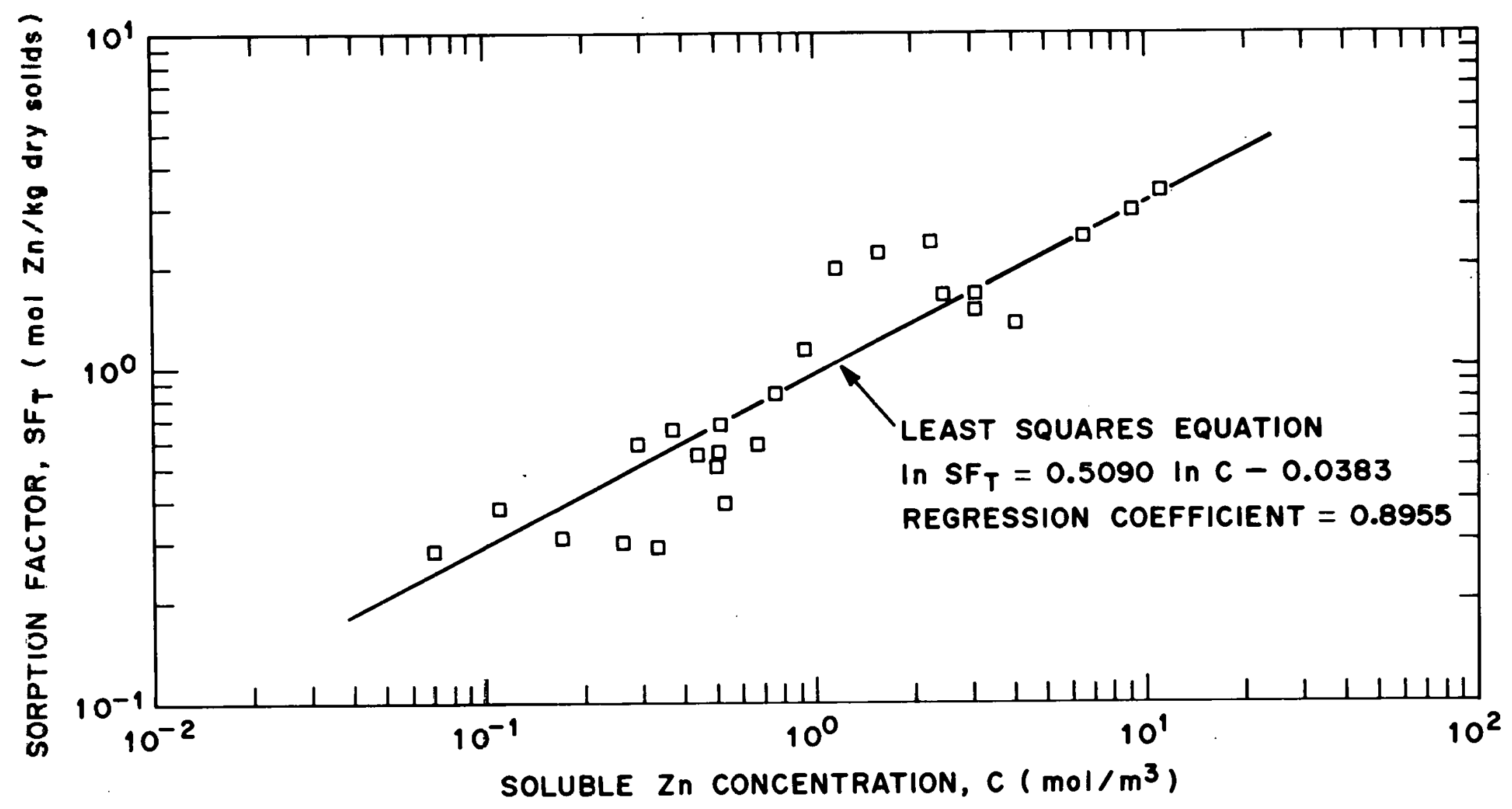

Figure 6.57. Freundlich-type relationship between the sorption factor and the soluble zinc concentration when plotted in log-log paper. 
ORNL DWG 80-1612

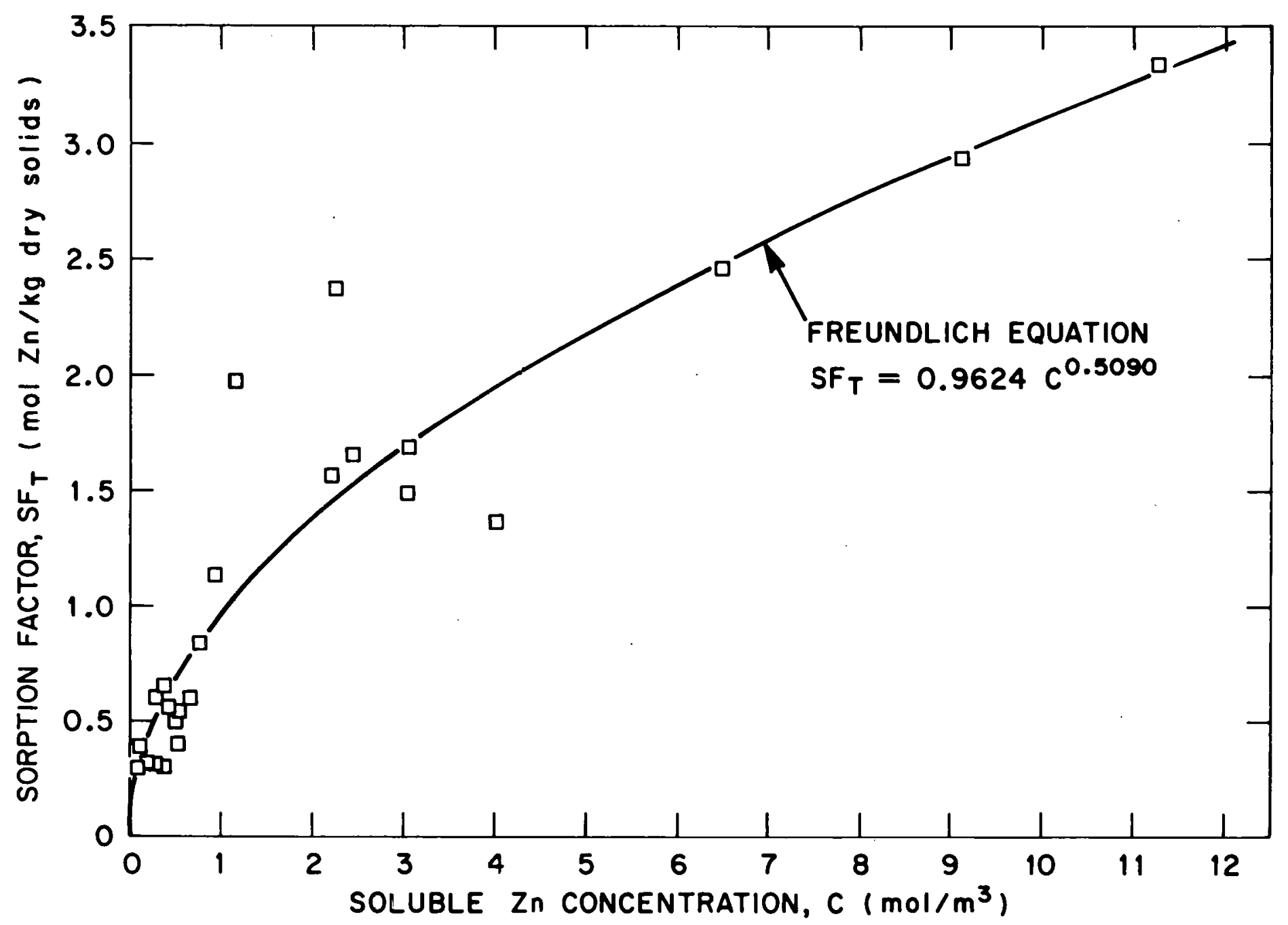

Figure 6.58. Freundlici equation describing the relationship between the soluble zinc concentration and the amount of zinc sorbed by the solids in an ANFLOW bioceactor. The solids would include fixedfilms as well as suspended nasses. 
Table 6.3. Distribution of Zinc in ANFLOW Bioreactor Solids During Toxicity Experiment No. 3

\begin{tabular}{|c|c|c|c|c|c|c|}
\hline \multirow{3}{*}{$\begin{array}{l}\text { Influent } \\
\text { In (mg/L) }\end{array}$} & \multirow{3}{*}{$\begin{array}{l}\text { Soluble Zinc } \\
\text { in Sample } \\
(\mathrm{mg} / \mathrm{L})\end{array}$} & \multirow{2}{*}{\multicolumn{3}{|c|}{ Sorption Factors }} & \multirow[b]{3}{*}{$\left(\mathrm{SF}_{\mathrm{o}}+\mathrm{SF}_{\mathrm{p}}\right)$} & \multirow{3}{*}{$\begin{array}{c}\% \\
\text { Recovery }^{a}\end{array}$} \\
\hline & & & & & & \\
\hline & & $\mathrm{SF}_{\mathrm{T}}$ & $\mathrm{SF}_{\mathrm{O}}$ & $\overline{\mathrm{SF}}$ & & \\
\hline 300 & 199 & 98.0 & 92 & 6.4 & 98.4 & 101.4 \\
\hline 300 & 262 & 89 & 82 & 5 & 87.0 & 97.8 \\
\hline 300 & 147.3 & 154.7 & 152 & 3.2 & 155.2 & 100.3 \\
\hline 100 & 21.8 & 19.2 & 22.1 & 1.3 & 23.4 & 121.9 \\
\hline 100 & 33.2 & 36.3 & 36 & 4.3 & 40.3 & 111.0 \\
\hline 100 & 49.9 & 54.2 & 43.1 & 2.5 & 45.6 & 84.1 \\
\hline 100 & 34.3 & 43.5 & 40.7 & 1.2 & 41.9 & 95.9 \\
\hline 100 & 29 & 36.2 & 28.3 & 0.8 & 29.1 & 80.4 \\
\hline 100 & 17 & 19.6 & 23.4 & 0.8 & 24.2 & 123.5 \\
\hline 100 & 18.7 & 38.3 & 37.7 & 0.5 & 38.2 & 99.7 \\
\hline 100 & 7.5 & 25.0 & 27.7 & .8 & 28.5 & 114.0 \\
\hline 100 & 4.9 & 18.2 & 21.4 & 0.5 & 21.9 & 120.3 \\
\hline
\end{tabular}

$\mathrm{a} \%$ recovery $=\frac{\mathrm{SF}_{\mathrm{O}}+\mathrm{SF}_{\mathrm{p}}}{\mathrm{SF_{ \textrm {T } }}} \times 100$ 
characterization of the heavy metal. Most of the solids were located on the lower regions of the bioreactor, mainly the first four sample ports. It is suspected that solids sampling probably enhanced the inhibitory state of the bioreactor by decreasing the amount of biosolids in the system. This would result in a decrease of its sorption capacity for heavy-metal removal in addition to decrease bioreactor performance for the removal of soluble COD.

\subsection{Overview of the Recovery Phenomena}

Recovery or resumption of normal operating conditions, global and reglonally, is a very important aspect of the overall phenomena of toxicity. The basic components of the phenomena of toxicity from heavy metals in ANFLOW bioreactors and the benefits that could result by investigating them are summarized in Table 6.4 .

The aspect of inducing toxicity has been studied to some extent and the basic benefit from it is that the toxicity potential of a heavy metal is reduced by precipitation from solution. This control measure reduces the interaction between the heavy metal and biomasses. The response from heavy-metal-induced toxicity was the basic objective of this work. The recovery aspect will be surveyed briefly, and research in this area as well as in acclimation is suggested. Research in the area of acclimation would be somewhat similar to toxicity experiment No. 3, where the concentration of the heavy metal is increased gradually, but it would involve much lower concentrations (6-10 mg/L) and smaller increments in heavy-metal concentration. 
Table 6.4. Basic Aspects of the Phenomena of Toxicity and the Engineering Significance of Their Study

\begin{tabular}{ll}
\hline $\begin{array}{c}\text { Basic Aspect } \\
\text { of Toxicity Phenomena }\end{array}$ & \multicolumn{1}{c}{$\begin{array}{c}\text { Engineering Significance of } \\
\text { Studying Basic Aspect }\end{array}$} \\
\hline Induction of Toxicity & $\begin{array}{l}\text { Development of control measures, for } \\
\text { example, precipitation of } \\
\text { heavy metals. }\end{array}$ \\
Response & $\begin{array}{l}\text { Proper identification of the pre- } \\
\text { sence of toxic conditions during } \\
\text { operation and the need for immediate } \\
\text { control actions }\end{array}$ \\
Recovery & $\begin{array}{l}\text { Development of routine procedures to } \\
\text { minimize the recovery time and } \\
\text { establishment of normal operating } \\
\text { conditions. } \\
\text { Development of procedures to enhance } \\
\text { system resistance and have broader } \\
\text { applications. }\end{array}$ \\
\hline
\end{tabular}


The discussion that will follow is only speculative in nature and is not based on actual data as evidence of its existance. Instead, it is mainly a rationalization that could serve as one explanation to the response data presented in previous sections.

During normal operation, bioreactor performance in the treatment of organic wastes probably depends on fixed-films and to some degree on suspended solids. It is not known with certainty the contribution of each phase nor whether this contribution depends on location. Under field conditions these suspended solids may come in the waste or are generated within the vessel by sloughing mechanisms. These mechanisms are probably caused by factors such as film growth, flow of liquid, bubble growth and generation, and upward movement of the produced bubbles. Depending on factors such as particle size, fluid velocity, and the tortuous path they need to follow within the packed bed they either settle down and are trapped in the voids, are removed by impaction or any other mechanisms, or are washed out of the system by the flowing liquid or by the gas bubbles as in flotation. For the most part its considered in this work that ANFLOW bioreactors depend on fixedfilms.

One of the advantages of this system, of particular significance under inhibitory conditions, is that since its performance depends on fixed-films, the biosolids remain in the system probably resulting in a decrease in the recovery time. One disadvantage, caused by the reactor type (i.e., packed vs mixed vessel), is the dilution phenomena during shock-loads. A packed bed probably has some degree of dispersion or 
dilution potential, but it is smaller than in mixed reactors. The safety factor involved in such situations depends on the size of the shock-load relative to the volume of the vessel and the degree of deve1opment or sophistication of the control actions in each system. Once inhibition is induced in a mixed reactor, the suspended soilds are washed out further decreasing the cell residence time or number of viable cells. This situation is reduced by full recycle. In any event, recovery times may be long, and seeding may be required.

The treatment process in the anaerobic fixed-films of an ANFLOW bioreactor could be described in a very simple manner using the simple biofilm model shown in Figure 6.59. This model is an extension of the biofilm model proposed by Atkinson $68-70$ as applied to an anaerobic fixedfilm. It is assumed that methanogensis or fermentation of the volatile acids is the rate-limiting step in the removal of soluble CoD. 71 The performance per unit volume of fixed film is considered to depend on the number of viable methane formers per cubic centimeter (viable cell density) and the growth rate associated with them. This cell density may not be uniforin throughout the film, but for simplicity it is assumed to be uniform. An increasing degree of inhibition, as reflected by the performance of the system to remove soluble COD, is the result of decreasing the number of viable cells in the film. The concentration of volatile acids within the film is the balance between production, utilization, and net diffusion rates. During inhibitory conditions, the rate of utilization decreases more than the rate of production, and buildup of acids occurs. These acids diffuse out of the film and enter the bulk solution. In the upper regions of the system where the biological 
ORNL DWG 80-1602

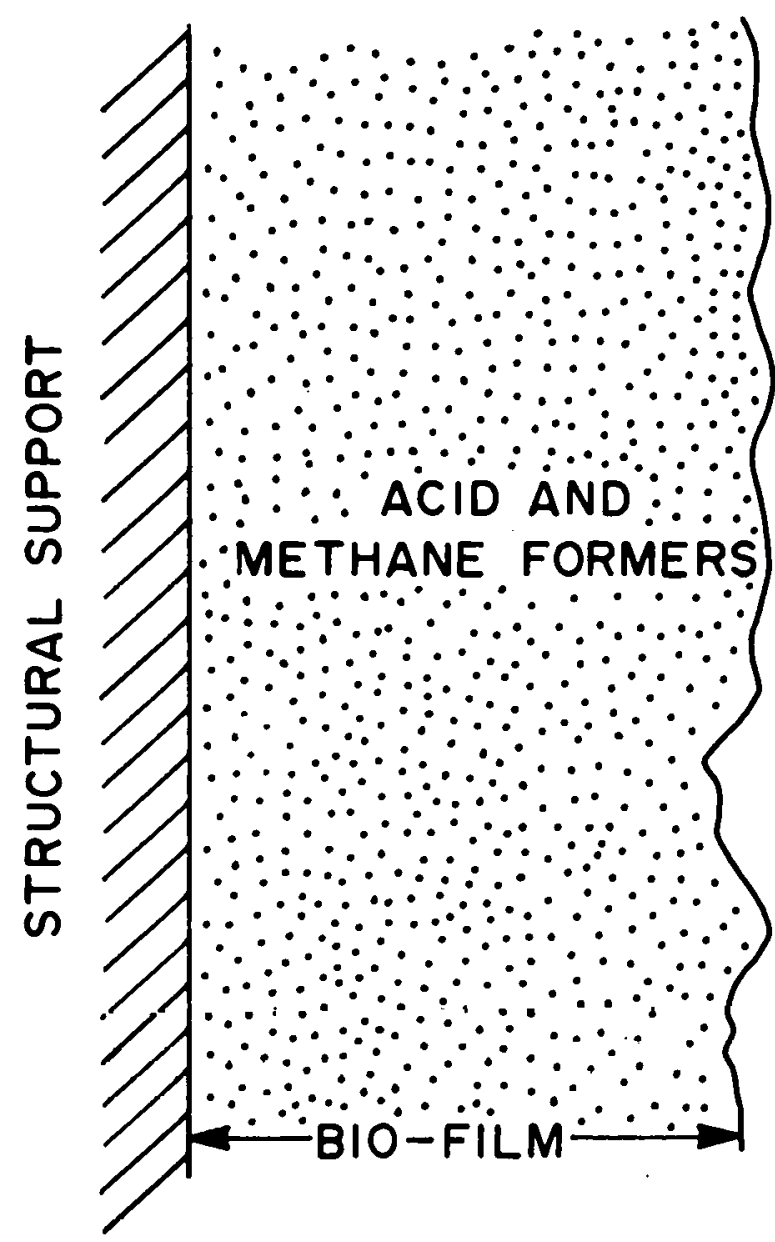

\section{BULK SOLUTION}

Figure 6.59. Simple model for a fixed-f1lm in an ANFLOW bioreactor. The film is formed by a heterogeneous mixture of acid and methane formers. 
activity is much lower, these acids diffuse into the film providing enough food for increasing the biological activities. The rate of increase is controlled by the presence of the heavy metal.

System recovery by a regeneration phenomena could be explained by supposing that a fixed-film that has been inhibited to a certain extent is allowed to recover. The regeneration mechanism proposed from this study is that the cell layers closer to the structural support are inhibited to a lesser extent than the upper layers of the film. These layers can grow and repopulate, increasing the thickness of the fixed film. As in normal operation, sloughing will occur but in this case inhibition would probably enhance the sloughing process by weakening the upper layer of the film. Cell death, lysis, and digestion by other bacteria (acid formers for example) are considered as the most probable sloughing-enhancing factors.

The time required to regenerate a fixed-film to the viable cell densities present during normal operation depends on the generation time and the initial density of the microorganisms involved. The generation time can be modified by environmental factors such as nutrients, pH, temperature, substrate, and absence of toxic materials. For example, an increase in volatile acids to very high concentrations may induce some inhibition on the methane formers and even on the acid formers.61 Relatively long recovery times are expected to be required in anderobic treatment simply because of the long generation times of the methane bacteria. 


\section{SUMMARY AND CONCLUSIONS}

Oak Ridge National Laboratory has developed an energy-conserving wastewater treatment system based on an anaerobic, upflow (ANFLOW) bioreactor. Since many applications of the ANFLOW process could involve the treatment of wastewaters containing heavy metals, the potentially toxic effects of these metals on the biological processes occurring in ANFLOW columns (primarily acetogenesis and methanogenesis) were investigated.

An experimental program was developed where zinc (as zinc chloride) in pulse inputs of $1000 \mathrm{mg} / \mathrm{t}$ and step inputs ranging from 100 to 1000 $\mathrm{mg} / \mathrm{L}$ were added to synthetic wastewaters being treated in ANFLOW columns with $0.057-\mathrm{m}^{3}$ volumes. The global and regional kinetic aspects of the toxicity phenomena were described with a mathematical model based on plugflow with axial dispersion and first-order kinetics for soluble COD removal. Bioreactor response to toxicity was determined hy monitoring operational parameters such as gas production and composition, acetic and propionic acid concentration profiles, soluble COD profiles, effluent soluble COD, $\mathrm{pH}$, and alkalinity. Metal sorption, removal and distribution were investigated under step-input conditions.

Several conclusions related with the phenomena of toxicity from heavy metals in ANFLOW bioreactors can be drawn from this research project :

1. The inhibitory effects of $\mathrm{Zn}$ on soluble substrate removal were found to be associated with the sorption of the heavy metal by the 
biosolids. Sorption (and consequently high metal-removal efficiencies) initially occurred in the lower sections of the column moving upward as the sorption capacity of these regions was beginning to decrease. This saturation trend resulted in a decrease in heavy-metal removal efficiencies. Consequently, a much larger reactor volume was needed to obtain the removal efficiencies previously obtalned in the lower regions. It was found that the sorption phenomena could be described by a Freundlich equation. This equation relates the amount of heavy metal (in moles of zinc per kilogram of dry solids) with the concentration of soluble metal (in moles of zinc per cubic meter) surrounding the solids. It was also found that most of the heavy metal present in the solids sampled from the ANFLOW bioreactor was organically bound or associated with biomasses. It is expected that under field conditions this distribution might be different.

Precipitation of heavy metals by formation of sulfide. is considered to play a major role when the metals are introduced under stepwise conditions. At $\mathrm{pH}$ values of 8 and above, most of the reduced sulfur exist in solution as $\mathrm{HS}^{-}$and $\mathrm{S}^{=}$ions. At $\mathrm{pH}^{-}$levels below 8 , the equilibrium shifts toward the formation of un-ionized $\mathrm{H}_{2} \mathrm{~S}$ and is about 80 percent complete at $\mathrm{pH} 7.66$ When the concentration of a heavy metal is increased gradually, the precipitation effectiveness of the hydrogen sulfide system is enhanced. This happens because the $\mathrm{H}_{2} \mathrm{~S}$ can supply sulfide ions continuously. Under shock conditions, only the sulfide ion will be able to protect the system.

2. 'The methane formers were the main group of bactcria inhibited by zinc. This finding was anticipated since the methane-forming bacteria 
are generally considered to be more susceptible to heavy metals than the acid-forming bacteria. An increase in volatile acid concentrations (acetic and propionic acids) was the local response after inhibiting these bacteria. Although acetic and propionic acids were used to determine the inhibitory effects of heavy metals on methanogenesis, a determination of total volatile acid concentration by steam distillation or chromatographic separation could be used as a criteria in the control of ANFLOW bioreactors. Inhibition, on a global scale, was reflected as an upward shifting in the concentration profiles for these two acids. It is belleved that the shifting in the soluble COD profiles was primarily. caused by the increase in volatile acid concentrations. Inhibition to the acid-forming bacteria is expected to result in a shifting of the maxima or peak of the volatile actds profile to upper regions in the reactor in addition to the upward/downward shifting in volatile acids concentration profiles. By the time the toxicant starts causing inhibition to the acid-forming bacteria the system has received extensive damage.

Gas production and composition were other variables used to monitor methanogenes1s. In general, it was found that inhibition from zinc was reflected as a decrease in gas production rate and a decrease in methane percent. The general characteristics of the response (magnitude and pattern) was found to be associated with the way inhibition was induced, either shock or stepwise, and the degree of inhibition. Since methane production rates are representative of methanogenesis it is proposed that a more sensitive parameter to monitor this stage will be the methane production rate (i.e. gas production rate $x$ methane percent). 
Based on the previous research findings it is concluded that a sound approach for operating and controlling an ANFLOW bioreactor will consist of determining the active region and monitoring methanogenesis with three basic parameters:

a. rate of methane production from whole vessel,

b. rate of change in volatile acids concentrations in active region, and

c. bicarbonate alkalinity in active region.

The first two parameters combined w111 be used as indicators of process stability and to establish the need for early control actions. The bicarbonate alkalinity shall be kept at a high enough level to help buffer any increase in volatile acid concentration resulting from inhibition to the methane bacteria. This technique will help prevent any synergistic effects between the toxicity of heavy metals and a decrease in $\mathrm{pH}$.

3. The plugflow with axial dispersion model with first-order kinetics was found to be useful in characterizing toxicity data. The kinetic parameter, a lump constant, reflected the inhibitory effects of heavy metals on the global and regional kinetics as determined from soluble COD removal data.

It was found that the biological activity progressively moved upward to upper regions of the reactor. It is believed that their relative rates of increase in biological activity depended on the concentration of the heavy metal. Its potential to Induce inhibition being dependent on the sorption capacity of lower regions.

It was observed that there is a characteristic response pattern as a result of inhibition in this system under shock-load and continuous-feed 
conditions. Each response pattern could be described by a function of the form:

$$
K(t)=K_{S s} / I_{\cdot} F_{\cdot},
$$

where the inhibition function (I.F.) characterizes the response and the conditions under which toxicity was induced.

4. System recovery was observed when feeding of wastewaters without zinc was resumed. It is postulated that this phenomena could be based on a regeneration process that involved sloughing of layers of biofilms, or other biosolids involved in zinc sorption, followed by continued growth of lower layers of biofilms not involved in heavy-metal sorption. Recovery times are considered to depend, among other things, on the long generation times of the methane-forming bacteria.

\section{RECOMMENDATIONS FOR FUTURE STUDY}

The research program of this project was designed to emphasize the development of methods, models, and definitions of mechanisms rather than to conduct a survey of varying effects among several metals. Future studies on ANFLOW bioreactors should be oriented toward the research areas of toxicity and development of design principles which may incorporate the phenomena of toxicity. Several projects recommended for future studies on these research areas are the following:

\section{In the Area of Toxicity}

a. study the toxicity phenomena under field conditions;

b. develop a technique for continuously monitoring the production of methane; 
c. explore ways of minimizing the recovery time of an ANFLOW system that has been toxified;

d. determine the general form of the inhibition function and the parameters that define it;

e. use the mixed-tanks-in-series model as an approach to the regional aspects of the toxicity phenomena;

f. study the toxic effects of other insulting agents.

\section{In the Area of Design}

Study the feasibility of using the plug flow with dispersion model with first-order kinetics, or any other rate expression, as part of the design criteria for ANFLOW bioreactors. A similar approach has been proposed by Thirumurthi 72 in the design of waste stabilization ponds. The following research projects would provide significant information:

a. application of the kinetic model to describe total COD or BOD removal in large-scale processes;

b. determination of the effects of temperature, loading rates, kind of waste and other factors on the global rate constant(s) (a reglonal approach may be very useful);

c. development of simpler techniques for determining accurately the reactor dispersion number and average residence time (these techniques should simplify the gathering and management of data);

d. determination of the effects of scaling-up on the reactor dispersion number and average residence time. 


\section{0}

\section{THIS PAGE \\ WAS INTENTIONALLY \\ LEFT BLANK}


9. APPENDIXES 
APPENDIX A: DATA FOR TOXICITY EXPERIMENT NO. 1

Toxicity experiment No. 1 was a shock-load (slug) of $1000 \mathrm{mg} / \mathrm{L}$ zinc as $\mathrm{ZnCl}_{2}$ for $42 \mathrm{~h}$; variable soluble fraction. The shockload began with $60 \%$ soluble zinc and ended with $15 \%$ soluble zinc. Time zero is taken as the time when the experiment began. 
Table A.1. Effluent Soluble Chemical Oxygen Demand for Control and Test Bioreactors During Toxicity Experiment No. 1

\begin{tabular}{|c|c|c|}
\hline \multirow[b]{2}{*}{ Time (days) } & \multicolumn{2}{|c|}{ Soluble COD (mg/L) } \\
\hline & Control Bioreactor & Test Bioreactor \\
\hline-33 & 213 & 210 \\
\hline-30 & 204 & 213 \\
\hline-28 & 175 & 175 \\
\hline-26 & 167 & 166 \\
\hline-22 & 182 & 200 \\
\hline-20 & 186 & 192 \\
\hline-15 & 183 & 183 \\
\hline-13 & 231 & 227 \\
\hline-7 & 1.83 & 185 \\
\hline-2 & 192 & 192 \\
\hline-1 & 200 & 200 \\
\hline 0 & 172 & 180 \\
\hline 0.771 & 198 & 193 \\
\hline 1.0 & 192 & 187 \\
\hline 1.729 & 195 & 285 \\
\hline 2.815 & 187 & 410 \\
\hline 3.875 & 182 & 288 \\
\hline 4.56 & 182 & 273 \\
\hline 5.0 & 185 & 278 \\
\hline 5.75 & 174 & 278 \\
\hline 6.0 & 175 & 279 \\
\hline 7.0 & 179 & 295 \\
\hline 8.729 & 183 & 285 \\
\hline 9.875 & 189 & .268 \\
\hline 11.75 & 194 & 279 \\
\hline 12.771 & 209 & 283 \\
\hline 13.771 & 175 & $298^{\circ}$ \\
\hline 14.75 & 194 & 294 \\
\hline 15.77 & 194 & 276 \\
\hline 18.75 & 213 & 298 \\
\hline 19.75 & 219 & 291 \\
\hline 20.75 & 211 & 300 \\
\hline 21.75 & 211 & 281 \\
\hline 26.75 & 173 & 182 \\
\hline 27.75 & 175 & 187 \\
\hline 28.625 & 162 & 173 \\
\hline 32.75 & 159 & 170 \\
\hline 33.75 & 155 & 168 \\
\hline 40 & 132 & 1.52 \\
\hline
\end{tabular}


Table A.2. Soluble Chemical Oxyger. Demand Profiles for Control and Test Bioreactors During Tcxicity Experiment No. $1^{\text {a }}$

\begin{tabular}{|c|c|c|c|c|c|c|c|c|c|c|c|c|c|}
\hline \multirow{2}{*}{$\begin{array}{c}\text { Time } \\
\text { (days) }\end{array}$} & \multirow[b]{2}{*}{ Bioreactor } & \multicolumn{12}{|c|}{$\begin{array}{l}\text { Bioreactor Length } \\
\left(\mathrm{cm} \times 3.281 \times 10^{-2}\right)\end{array}$} \\
\hline & & 0.5 & 1.0 & 1.5 & 2.0 & 2.5 & 3.0 & 3.5 & 4.0 & 4.5 & 5.0 & 5.5 & 6.0 \\
\hline \multirow{2}{*}{-1} & Control & 600 & 355 & 262 & 213 & 213 & 192 & 190 & 185 & 177 & 170 & 168 & 172 \\
\hline & Test & 528 & 348 & 287 & 268 & 236 & 220 & 212 & 202 & 196 & 187 & 183 & 176 \\
\hline \multirow{2}{*}{20} & Control & 403 & 290 & 281 & 232 & 222 & 223 & 225 & 227 & 219 & 211 & 194 & 190 \\
\hline & Test & 2352 & 1097 & 900 & 616 & 505 & 435 & 417 & 380 & 345 & 340 & 320 & 267 \\
\hline \multirow{2}{*}{29} & Control & 447 & 308 & 260 & 178 & 182 & 178 & 170 & 170 & 162 & 162 & 162 & 162 \\
\hline & Test & 1203 & 528 & 457 & 340 & 314 & 254 & 232 & 236 & 184 & 186 & 178 & 173 \\
\hline \multirow{2}{*}{40} & Control & 752 & 429 & 244 & 178 & 165 & 162 & 153 & 140 & 136 & 141 & 138 & 137 \\
\hline & Test & 985 & 675 & 492 & 492 & 372 & 305 & 267 & 236 & 219 & 175 & 162 & 152 \\
\hline \multicolumn{2}{|c|}{ Control average } & 551 & 346 & 262 & 200 & 196 & 189 & 185 & 181 & 174 & 171 & 166 & 165 \\
\hline \multicolumn{2}{|l|}{ S.D. } & 159 & 62 & 15 & 27 & 27 & 26 & 31 & 36 & 35 & 29 & 23 & 22 \\
\hline
\end{tabular}

${ }^{a} \mathrm{COD}$ concentrations in $\mathrm{mg} / \mathrm{L}$. 
Table A.3. Acetic Acid Profiles for Control and Test Bioreactors During Toxicity Experiment No. $1^{a}$

\begin{tabular}{|c|c|c|c|c|c|c|c|c|c|c|c|c|c|}
\hline \multirow{2}{*}{$\begin{array}{l}\text { Time } \\
\text { (days) }\end{array}$} & \multirow[b]{2}{*}{ Bioreactor } & \multicolumn{11}{|c|}{$\begin{array}{l}\text { Bioreactor Length } \\
\left(\mathrm{cm} \times 3.281 \times 10^{-2}\right)\end{array}$} & \multirow[b]{2}{*}{$\overline{6.0}$} \\
\hline & & 0.5 & 1.0 & 1.5 & 2.0 & 2.5 & 3.0 & 3.5 & 4.0 & 4.5 & 5.0 & 5.5 & \\
\hline \multirow{2}{*}{-1} & Control & 220 & 142 & 114 & 103 & 96 & 91 & 38 & 30 & 25 & 25 & 23 & 16 \\
\hline & Test & 114 & 108 & 90 & 70 & 58 & 54 & 51 & 51 & 37 & 30 & 26 & 15 \\
\hline \multirow{2}{*}{20} & Control & 35 & 26 & 47 & 26 & 33 & 25 & 20 & 25 & 24 & 19 & 31 & 34 \\
\hline & Test & 1000 & 1066 & 920 & 720 & 740 & 540 & 580 & 595 & 490 & 501 & 389 & 394 \\
\hline \multirow{2}{*}{29} & Control & 423 & 178 & 63 & 57 & 32 & 41 & 18 & 20 & 6 & 17 & 16 & 37 \\
\hline & Test & 537 & 249 & 207 & 186 & 85 & 961 & 80 & 77 & 45 & 50 & 396 & 50 \\
\hline \multirow{2}{*}{40} & Control & 450 & 450 & 125 & 30 & 50 & 20 & 20 & 20 & 10 & 5 & 5 & 5 \\
\hline & Test & 450 & 450 & 100 & 50 & 50 & 20 & 20 & 20 & 10 & 10 & 10 & 10 \\
\hline Control & Average & 282 & 199 & 87 & 54 & 53 & 44 & 24 & 24 & 16 & 17 & 19 & 23 \\
\hline S. D. & & 194 & 179 & 38 & 35 & 30 & 32 & 9 & 5 & 10 & 8 & 11 & 15 \\
\hline
\end{tabular}

a Acetic Acid concentrations are in $\mathrm{mg} / \mathrm{L}$. 
Table A.4. Propionic Acid Prcfiles for Control and Test Bioreactors During During Toxicity Experiment No. $1^{a}$

\begin{tabular}{|c|c|c|c|c|c|c|c|c|c|c|c|c|c|}
\hline \multirow{2}{*}{$\begin{array}{c}\text { Time } \\
\text { (days) } \\
\end{array}$} & \multirow[b]{2}{*}{ Bioreactor } & \multicolumn{12}{|c|}{$\begin{array}{l}\text { Bioreactor length } \\
\left(\mathrm{cm} \times 3.281 \times 10^{-2}\right)\end{array}$} \\
\hline & & 0.5 & 1.0 & 1.5 & 2.0 & 2.5 & 3.0 & 3.5 & 4.0 & 4.5 & 5.0 & 5.5 & 6.0 \\
\hline \multirow{2}{*}{-1} & Control & 75 & 45 & 20 & 7 & 10 & 5 & 0 & 0 & 0 & 0 & 0 & 0 \\
\hline & Test & 31 & 16 & 14 & 11 & 9 & 8 & 6 & 4 & 4 & 4 & 0 & 0 \\
\hline \multirow{2}{*}{20} & Control & 11 & 4 & 14 & 2 & 4 & 7 & 0 & 0 & 0 & 0 & 0 & 0 \\
\hline & Test & 238 & 180 & 103 & 123 & 131 & 79 & 92 & 87 & 103 & 110 & 68 & 53 \\
\hline \multirow{2}{*}{29} & Control & 108 & 60 & 16 & 4 & 1 & 1 & 0 & 0 & 0 & 0 & 0 & 0 \\
\hline & Test & 313 & 122 & 100 & 85 & 30 & 42 & 34 & 26 & 6 & 7 & 6 & 7 \\
\hline \multirow{2}{*}{40} & Control & 200 & 120 & 25 & 10 & 5 & 0 & 0 & 0 & 0 & 0 & 0 & 0 \\
\hline & Test & 200 & 200 & 40 & 20 & 20 & 10 & 10 & 10 & 5 & 5 & 0 & .0 \\
\hline Control & 1 Average & 99 & 57 & 19 & 6 & 5 & 3 & 0 & 0 & 0 & 0 & 0 & 0 \\
\hline S. D. & & 79 & 48 & 5 & 4 & 4 & 3 & 0 & 0 & 0 & 0 & 0 & 0 \\
\hline
\end{tabular}

a Propionic acid concentrations are in $\mathrm{mg} / \mathrm{L}$, a value of zero is used to indicate a nondetectable concentration. 
Table A.5. Cummulative Gas Production, in Liters, for Control and Test Bioreactors During Toxicity Experiment No. 1

\begin{tabular}{|c|c|c|}
\hline \multirow[b]{2}{*}{ Time (days) } & \multicolumn{2}{|c|}{ Bioreactor } \\
\hline & Control & Test \\
\hline-33.042 & 0 & 0 \\
\hline-30.042 & 55.85 & 54.72 \\
\hline-29.042 & 71.81 & 69.85 \\
\hline-28.042 & 95.01 & 91.44 \\
\hline-27.042 & 116.00 & 113.27 \\
\hline-26.042 & 137.64 & 134.93 \\
\hline-23.042 & 195.96 & 189.23 \\
\hline-22.042 & 215.48 & 209.53 \\
\hline-21.042 & 237.50 & 230.77 \\
\hline-20.042 & 259.04 & 251.2 \\
\hline-19.042 & 282.75 & 273.80 \\
\hline-16.230 & 343.25 & 330.61 \\
\hline-15.042 & 366.56 & 352.83 \\
\hline-14.125 & 386.34 & 372.09 \\
\hline-13.042 & 410.34 & 395.55 \\
\hline-12.084 & 432.41 & 417.08 \\
\hline-7.082 & 541.52 & 525.43 \\
\hline-6.042 & 565.31 & 550.19 \\
\hline-5.125 & 585.57 & 571.44 \\
\hline-2.042 & 642.76 & 629.04 \\
\hline-1.208 & 659.66 & 648.11 \\
\hline-1.111 & 661.81 & 650.52 \\
\hline-0.974 & 665.15 & 653.50 \\
\hline-0.253 & 682.32 & 672.89 \\
\hline-0.163 & 684.55 & 675.25 \\
\hline 0.045 & 689.33 & 679.35 \\
\hline 0.722 & 704.13 & 690.25 \\
\hline 0.821 & 706.24 & 691.68 \\
\hline 0.911 & 708.27 & 693.05 \\
\hline 0.996 & 710.15 & 694.39 \\
\hline 1.038 & 711.09 & 695.11 \\
\hline 1.716 & 725.08 & 708.55 \\
\hline 1.823 & 727.23 & 710.48 \\
\hline 1.942 & 729.69 & 712.55 \\
\hline 2.007 & 731.18 & 713.68 \\
\hline 2.038 & 731.91 & 714.22 \\
\hline 2.792 & 750.60 & 729.24 \\
\hline 2.99 & 755.5 & 733.94 \\
\hline 3.913 & 779.24 & 752.7 \\
\hline 5.028 & 805.68 & 773.99 \\
\hline 6.052 & 832.75 & 795.6 \\
\hline 7.042 & 858.43 & 815.37 \\
\hline 8.048 & 885.61 & 836.56 \\
\hline
\end{tabular}


Table A.5. (Cont1nued)

\begin{tabular}{crr}
\hline & & Bioreactor \\
\cline { 2 - 3 } Time (days) & Control & Test \\
\hline 9.052 & 912.33 & 857.24 \\
12.035 & 987.42 & 917.80 \\
13.052 & 1022.85 & 935.01 \\
14.050 & 1048.16 & 957.16 \\
15.039 & 1073.26 & 978.70 \\
16.047 & 1098.27 & 1000.11 \\
19.050 & 1167.57 & 1063.89 \\
20.030 & 1190.09 & 1084.71 \\
21.028 & 1213.26 & 1106.87 \\
22.035 & 1236.9 & 1129.07 \\
23.038 & 1260.60 & 1151.37 \\
26.042 & 1319.93 & 1210.38 \\
27.042 & 1344.22 & 1231.74 \\
28.051 & 1365.82 & 1256.41 \\
29.045 & 1387.98 & 1278.54 \\
33.042 & 1492.13 & 1373.23 \\
& & \\
\hline
\end{tabular}


Table A.6. Gas Production Rate, in Liters per Day, for Control and Test Bioreactors During Toxicity Experiment No. $1^{\text {a }}$

\begin{tabular}{|c|c|c|c|}
\hline \multirow[b]{2}{*}{$\Delta t$ (days) } & \multirow[b]{2}{*}{$t_{1 / 2 \text { (days) }}$} & \multicolumn{2}{|c|}{ Bioreactor } \\
\hline & & Control & Test \\
\hline 3 & -31.542 & 18.62 & 18.24 \\
\hline 1 & -29.542 & 15.96 & 15.13 \\
\hline 1 & $-28 \cdot 542$ & 23.2 & 21.59 \\
\hline 1 & -27.542 & 20.99 & 21.83 \\
\hline 1 & -26.542 & 21.64 & 21.66 \\
\hline 3 & -22.542 & 19.44 & 18.10 \\
\hline 1 & -21.542 & 19.52 & 20.3 \\
\hline 1 & -20.542 & 22.02 & 21.24 \\
\hline 1 & -19.542 & 21.54 & 20.43 \\
\hline 1 & -18.542 & 23.71 & 22.60 \\
\hline 2.812 & -17.636 & 21.51 & 20.20 \\
\hline 1.188 & -15.636 & 19.62 & 18.70 \\
\hline 0.917 & -14.584 & 21.57 & 21.00 \\
\hline 1.083 & -13.584 & 22.16 & 21.66 \\
\hline .958 & -12.563 & 23.04 & 22.47 \\
\hline 5.002 & -9.583 & 21.81 & 21.66 \\
\hline 1.040 & -6.562 & 22.88 & 23.81 \\
\hline .917 & -5.584 & 22.09 & 23.17 \\
\hline 3.083 & -3.584 & 18.55 & 18.68 \\
\hline 0.834 & -1.625 & 20.26 & 22.98 \\
\hline 0.084 & -1.250 & 23.21 & 24.64 \\
\hline 0.097 & -1.160 & 22.16 & 24.85 \\
\hline 0.137 & -1.043 & 24.38 & 21.75 \\
\hline 0.781 & -0.614 & 23.81 & 26.89 \\
\hline 0.090 & -0.208 & 24.78 & 26.22 \\
\hline 0.208 & -0.059 & 22.98 & 19.71 \\
\hline 0.677 & 0.384 & 21.86 & 16.10 \\
\hline 0.099 & 0.772 & 21.31 & 14.44 \\
\hline 0.090 & 0.866 & 22.22 & 15.22 \\
\hline 0.085 & 0.954 & 22.12 & 15.76 \\
\hline 0.042 & 1.017 & 22.38 & 17.14 \\
\hline 0.678 & 1.377 & 20.63 & 19.82 \\
\hline 0.107 & 1.770 & 20.09 & 18.04 \\
\hline 0.119 & 1.883 & 20.67 & 17.39 \\
\hline 0.065 & 1.975 & 22.92 & 17.38 \\
\hline 0.031 & 2.023 & 23.55 & 17.42 \\
\hline 0.754 & 2.415 & 24.79 & 19.92 \\
\hline 0.2 & 2.892 & 24.5 & 23.5 \\
\hline .923 & 3.452 & 25.75 & 20.33 \\
\hline 1.115 & 4.471 & 23.71 & 19.09 \\
\hline 1.024 & 5.540 & 26.44 & 21.10 \\
\hline 0.990 & 6.547 & 25.94 & 19.97 \\
\hline 1.006 & 7.545 & 27.02 & 21.06 \\
\hline
\end{tabular}


Table A.6. (Continued)

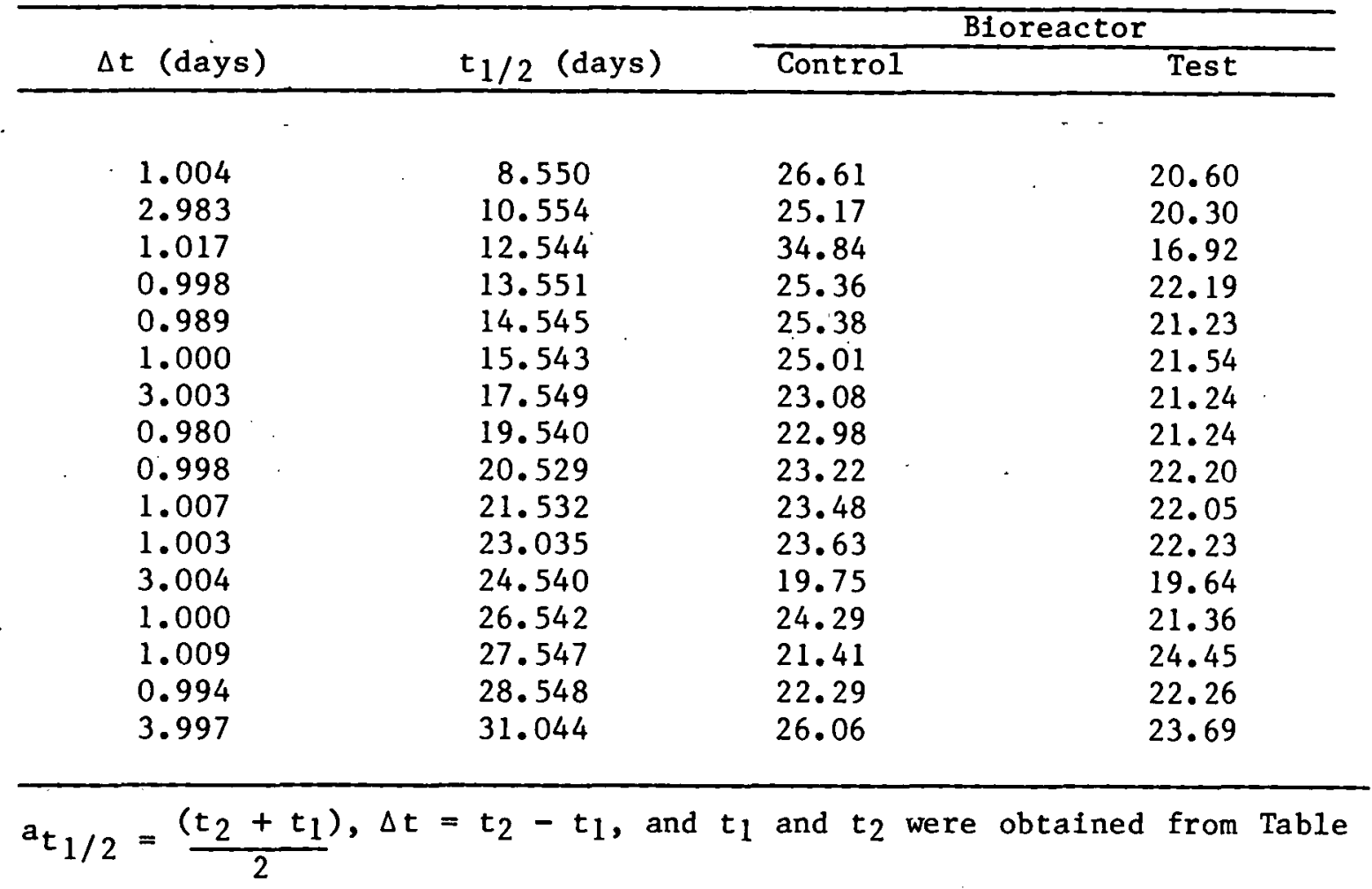

A. 5 . 
Table A.7. Gas Composition for Control and Test Bioreactors During Toxicity Experiment No. 1

\begin{tabular}{|c|c|c|c|c|c|c|}
\hline \multirow[b]{2}{*}{$\Delta t$ (days) } & \multicolumn{3}{|c|}{ Control Bioreactor } & \multicolumn{3}{|c|}{ Test Bioreactor } \\
\hline & $\%$ air & $\% \mathrm{CH}_{4}$ & $\% \mathrm{CO}_{2}$ & $\%$ air & $\% \mathrm{CH}_{4}$ & $\% \mathrm{CO}_{2}$ \\
\hline-29.125 & 2.0 & 74.3 & 23.7 & 2.4 & 74.2 & 23.4 \\
\hline-28.135 & 2.2 & 71.3 & 26.5 & 2.2 & 70.1 & 27.7 \\
\hline-26.125 & 1.6 & 71.1 & 27.2 & 1.6 & 71.4 & 26.9 \\
\hline-22.125 & 2.5 & 70.7 & 26.8 & 3.4 & 69.7 & 26.9 \\
\hline-20.146 & 3.8 & 68.9 & 27.3 & 3.4 & 69.4 & 27.2 \\
\hline-19.125 & 3.1 & 68.5 & 28.4 & 3.0 & 68.9 & 28.1 \\
\hline-15.104 & 3.1 & 70.7 & 26.2 & 3.2 & 70.6 & 26.2 \\
\hline-14.021 & 1.9 & 68.6 & 29.5 & 2.3 & 69.4 & 28.3 \\
\hline-13.094 & 2.6 & 68.6 & 28.8 & 1.4 & 69.6 & 29.0 \\
\hline-12.115 & 1.6 & 69.3 & 29.1 & 1.9 & 69.2 & 29.9 \\
\hline-8.063 & 2.3 & 71.3 & 26.4 & 2.5 & 71.0 & 26.5 \\
\hline-7.104 & 2.3 & 70.9 & 26.8 & 2.0 & 70.9 & 27.1 \\
\hline-6.042 & 2.0 & 69.5 & 28.5 & 2.1 & 69.4 & 28.5 \\
\hline-5.021 & 1.8 & 71.3 & 26.9 & 2.0 & 71.0 & 27.0 \\
\hline-2.0 & 3.4 & 75.0 & 21.6 & 2.5 & 75.2 & 22.3 \\
\hline-1.0 & 1.7 & 68.4 & 29.8 & 1.7 & 68.6 & 29.7 \\
\hline 0 & 1.9 & 69.5 & 28.6 & 2.4 & 69.2 & 28.4 \\
\hline 0.833 & 2.2 & 69.6 & 28.2 & 3.0 & 65.0 & 32 \\
\hline 1.750 & 2.3 & 70.9 & 26.8 & 2.5 & 66.3 & 31.3 \\
\hline 1.917 & 2.3 & 71.2 & 26.5 & 2.8 & 66.6 & 30.6 \\
\hline 2.979 & 2.3 & 69.2 & 28.5 & 2.2 & 67.2 & 30.6 \\
\hline 3.792 & 3.2 & 69.4 & 27.4 & 2.9 & 67.6 & 29.6 \\
\hline 4.792 & 2.9 & 68.6 & 28.5 & 2.5 & 67.0 & 30.5 \\
\hline 5.0 & 2.4 & 67.5 & 30.1 & 3.3 & 65.7 & 31.0 \\
\hline 5.729 & 2.1 & 68.7 & 29.2 & 2.5 & 67.5 & 30.0 \\
\hline 6.75 & 2.6 & 69.5 & 27.9 & 2.2 & 68.5 & 29.3 \\
\hline 7.0 & 1.6 & 70.9 & 27.5 & 2.6 & 68.0 & 29.4 \\
\hline 7.75 & 2.1 & 69.0 & 29.9 & 2.5 & 68.1 & 29.4 \\
\hline $8.0^{\circ}$ & 1.8 & 69.7 & 28.5 & 1.8 & 69.1 & 29.1 \\
\hline 8.75 & 2.6 & 69.8 & 27.6 & 3.2 & 68.5 & 28.3 \\
\hline 9.0 & 2.9 & 69.0 & 28.1 & 1.8 & 69.1 & 29.1 \\
\hline 11.895 & 2.4 & 70.3 & 27.3 & 2.4 & 69.5 & 28.1 \\
\hline 12.813 & 2.3 & 75.3 & 22.4 & 2.4 & 72.1 & 25.5 \\
\hline 13.0 & 1.7 & 75.2 & 23.1 & 2.6 & 70.8 & 26.6 \\
\hline 13.771 & 2.1 & 71.6 & 26.4 & 3.1 & 68.8 & 28.1 \\
\hline 14.75 & 2.0 & 71.0 & 27.0 & 2.0 & 69.7 & 28.3 \\
\hline 15.75 & 3.2 & 69.5 & 27.3 & 2.2 & 69.5 & 28.4 \\
\hline 16.0 & 3.0 & 69.2 & 27.8 & 1.9 & 69.8 & 28.3 \\
\hline 18.792 & 2.4 & 72.4 & 25.2 & 2.2 & 72.4 & 25.4 \\
\hline 19.75 & 2.1 & 70.8 & 27.1 & 2.1 & 69.7 & 28.2 \\
\hline 20.75 & 3.0 & 70.2 & 26.8 & 3.5 & 69.4 & 27.1 \\
\hline 21.792 & 4.8 & 68.4 & 26.8 & 2.7 & 69.4 & 27.9 \\
\hline 22.75 & 3.1 & 69.2 & 27.7 & 3.0 & 68.8 & 28.1 \\
\hline
\end{tabular}


Table A.7. (Cont1nued)

\begin{tabular}{|c|c|c|c|c|c|c|}
\hline \multirow[b]{2}{*}{$\Delta t$ (days) } & \multicolumn{3}{|c|}{ Control Bioreactor } & \multicolumn{3}{|c|}{ Test Bioreactor } \\
\hline & $\%$ air & $\% \mathrm{CH}_{4}$ & $\% \mathrm{CO}_{2}$ & $\overline{\%}$ a1r & $\% \mathrm{CH}_{4}$ & $\% \mathrm{CO}_{2}$ \\
\hline $\begin{array}{l}25.792 \\
26.000 \\
26.813 \\
27.792 \\
28.333\end{array}$ & $\begin{array}{l}2.6 \\
2.8 \\
1.5 \\
2.1 \\
1.9\end{array}$ & $\begin{array}{l}77.4 \\
76.5 \\
74.3 \\
70.5 \\
70.9\end{array}$ & $\begin{array}{l}20.0 \\
20.7 \\
24.2 \\
27.4 \\
27.2\end{array}$ & $\begin{array}{l}2.6 \\
2.8 \\
1.7 \\
2.3 \\
1.6\end{array}$ & $\begin{array}{l}76.2 \\
76.1 \\
74.5 \\
70.4 \\
71.1\end{array}$ & $\begin{array}{l}21.2 \\
21.1 \\
23.8 \\
27: 3 \\
27.3\end{array}$ \\
\hline
\end{tabular}


Table A.8. Effluent $\mathrm{pH}$ and Alkalinity for Control and Test Bioreactors During Toxicity Experiment No. 1

\begin{tabular}{|c|c|c|c|c|c|c|}
\hline \multirow[b]{2}{*}{ Time (da } & \multirow[b]{2}{*}{$\frac{\text { Control }}{\mathrm{pH}}$} & \multirow[b]{2}{*}{$\frac{\text { Test }}{\mathrm{pH}}$} & \multicolumn{2}{|c|}{ Control } & \multicolumn{2}{|c|}{ Test } \\
\hline & & & $\begin{array}{c}\text { Alkalinity } \\
\text { (mg/L as) } \\
\mathrm{CaCO}_{3}\end{array}$ & $\begin{array}{l}\text { Alkalinity } \\
\text { (meq/L) }\end{array}$ & $\begin{array}{c}\text { Alkalinity } \\
\text { (mg/L as) } \\
\mathrm{CaCO}_{3}\end{array}$ & $\begin{array}{l}\text { Alkalinity } \\
(\mathrm{meq} / \mathrm{L})\end{array}$ \\
\hline-30.031 & 7.13 & 7.12 & - & - & - & - \\
\hline-26.250 & 7.11 & 7.15 & - & - & - & - \\
\hline-22.042 & 7.31 & 7.28 & - & - & - & - \\
\hline-21.042 & 7.32 & 7.26 & - & - & - & - \\
\hline-20.083 & 7.27 & 7.27 & - & - & - & - \\
\hline-14.000 & 7.45 & 7.35 & - & - & - & - \\
\hline-13.042 & 7.37 & 7.37 & - & - & - & - \\
\hline-12.052 & 7.26 & 7.34 & - & - & - & - \\
\hline-7.042 & 7.19 & - & - & - & - & - \\
\hline-6.271 & 7.33 & - & - & - & - & - \\
\hline-5.083 & 7.35 & - & - & - & - & - \\
\hline-1.167 & 7.09 & 7.27 & 3018 & 60.4 & 2982 & 59.6 \\
\hline-0.188 & 7.34 & 7.27 & - & - & - & - \\
\hline 0.979 & 7.21 & 7.12 & 2941 & 58.8 & 2851 & 57.0 \\
\hline 1.938 & 7.27 & 7.08 & 2940 & 58.8 & 2420 & 48.4 \\
\hline 2.792 & 7.20 & 7.17 & 2965 & 59.3 & 2500 & 50.0 \\
\hline 3.781 & 7.17 & 7.09 & 2940 & 58.8 & 2520 & 50.4 \\
\hline 4.729 & 7.31 & 7.2 & 2920 & 58.4 & 2580 & 51.6 \\
\hline 5.75 & 7.32 & 7.33 & 2950 & 59.0 & 2650 & 53.0 \\
\hline 6.74 & 7.29 & 7.13 & 2940 & 58.8 & 2750 & 55.0 \\
\hline 7.76 & 7.39 & 7.34 & 2920 & 58.4 & 2740 & 54.8 \\
\hline 8.729 & 7.38 & 7.36 & 3033 & 60.7 & 2805 & 56.1 \\
\hline 11.75 & 7.25 & 7.22 & 2850 & 57.0 & 2750 & 55.0 \\
\hline 12.833 & 7.50 & 7.22 & 3122 & 62.4 & 2841 & 56.8 \\
\hline 13.781 & 7.37 & 7.39 & 3123 & 62.5 & 2920 & 58.4 \\
\hline 14.760 & 7.33 & 7.33 & 3150 & 63.0 & 2900 & 58.0 \\
\hline 16.037 & 7.46 & 7.56 & 3080 & 61.6 & 3050 & 61.0 \\
\hline 18.740 & 7.37 & 7.36 & 3070 & 61.4 & 3000 & 60.0 \\
\hline 19.75 & 7.48 & 7.32 & 3011 & 60.2 & 2906 & 58.1 \\
\hline 20.823 & 7.26 & 7.32 & 3036 & 60.7 & 2970 & 59.4 \\
\hline 21.923 & 7.34 & 7.44 & 3030 & 60.6 & 3000 & 60.0 \\
\hline 22.778 & 7.47 & 7.44 & 2970 & 59.4 & 2970 & 59.4 \\
\hline 25.948 & 7.67 & 7.62 & 2950 & 59.0 & 2944 & 58.9 \\
\hline 27.865 & 7.72 & 7.39 & 3020 & 60.4 & 2970 & 59.4 \\
\hline 28.990 & 7.34 & 7.34 & 3006 & 60.1 & 2995 & 59.9 \\
\hline
\end{tabular}


Table A.9. Global First-Order Rate Constants ${ }^{a}$ for Control and Test Bioreactor During Toxicity Experiment No. 1

\begin{tabular}{|c|c|c|c|c|c|c|}
\hline \multirow[b]{2}{*}{ Time (days) } & \multicolumn{3}{|c|}{ Control Bioreactor $b$} & \multicolumn{3}{|c|}{ Test Bioreactor ${ }^{c}$} \\
\hline & $f_{o}$ & $k_{0} \bar{t}_{0}$ & $\mathrm{~K}_{\mathrm{o}}$ & $f_{o}$ & $k_{o} \bar{t}_{0}$ & $\mathrm{~K}_{\mathrm{o}}$ \\
\hline-33 & 0.071 & 5.39 & 0.12 & 0.070 & 5.43 & 0.12 \\
\hline-30 & 0.068 & 5.53 & 0.12 & 0.071 & 5.39 & 0.12 \\
\hline-28 & 0.058 & 6.06 & 0.14 & 0.058 & 6.06 & 0.14 \\
\hline-26 & 0.056 & 6.18 & 0.13 & 0.055 & 6.24 & 0.14 \\
\hline $\begin{array}{l}-22 \\
-20\end{array}$ & $\begin{array}{l}0.061 \\
0.062\end{array}$ & $\begin{array}{l}5.88 \\
5.83\end{array}$ & $\begin{array}{l}0.13 \\
0.13\end{array}$ & $\begin{array}{l}0.067 \\
0.064\end{array}$ & $\begin{array}{l}5.57 \\
5.72\end{array}$ & $\begin{array}{l}0.13 \\
0.13\end{array}$ \\
\hline-15 & 0.061 & 5.88 & 0.13 & 0.061 & 5.88 & 0.13 \\
\hline-13 & 0.077 & 5.13 & 0.11 & 0.076 & 5.17 & 0.12 \\
\hline-7 & 0.061 & 5.88 & 0.13 & 0.062 & 5.83 & 0.13 \\
\hline-2 & 0.064 & 5.72 & 0.12 & 0.064 & 5.72 & 0.13 \\
\hline-1 & 0.067 & 5.57 & 0.12 & 0.067 & 5.57 & 0.13 \\
\hline 0 & 0.057 & 6.11 & 0.13 & 0.060 & 5.94 & 0.14 \\
\hline-0.771 & 0.066 & 5.62 & 0.12 & 0.064 & 5.72 & 0.13 \\
\hline 1.0 & 0.064 & 5.72 & 0.12 & 0.062 & 5.83 & 0.13 \\
\hline 1.729 & 0.065 & 5.67 & 0.12 & 0.095 & 4.49 & 0.10 \\
\hline 2.815 & 0.062 & 5.83 & 0.13 & 0.137 & 3.48 & 0.08 \\
\hline 3.875 & 0.061 & 5.88 & 0.13 & 0.096 & 4.46 & 0.10 \\
\hline 4.56 & 0.061 & 5.88 & 0.13 & 0.091 & 4.62 & 0.11 \\
\hline 5.0 & 0.062 & 5.83 & 0.13 & 0.093 & 4.55 & 0.10 \\
\hline 5.75 & 0.058 & 6.06 & 0.14 & 0.093 & 4.55 & 0.10 \\
\hline 6.0 & 0.058 & 6.06 & 0.14 & 0.093 & 4.55 & 0.10 \\
\hline 7.0 & 0.060 & 5.94 & 0.13 & 0.098 & 4.40 & 0.10 \\
\hline 8.729 & 0.061 & 5.88 & 0.13 & 0.095 & 4.49 & 0.10 \\
\hline 9.875 & 0.063 & 5.78 & 0.12 & 0.089 & 4.68 & 0.11 \\
\hline 11.75 & 0.065 & 5.67 & 0.12 & 0.093 & 4.55 & 0.10 \\
\hline 12.771 & 0.070 & 5.43 & 0.12 & 0.094 & 4.52 & 0.10 \\
\hline 13.771 & 0.058 & 6.06 & 0.13 & 0.099 & 4.37 & 0.10 \\
\hline 14.75 & 0.065 & 5.67 & 0.12 & 0.098 & 4.40 & 0.10 \\
\hline $\begin{array}{l}15.77 \\
18.75\end{array}$ & $\begin{array}{l}0.065 \\
0.071\end{array}$ & $\begin{array}{l}5.67 \\
5.39\end{array}$ & $\begin{array}{l}0.12 \\
0.12\end{array}$ & $\begin{array}{l}0.092 \\
0.099\end{array}$ & $\begin{array}{l}4.59 \\
4.37\end{array}$ & $\begin{array}{l}0.10 \\
0.10\end{array}$ \\
\hline 19.75 & 0.073 & 5.30 & 0.11 & 0.097 & 4.43 & 0.10 \\
\hline 20.75 & 0.070 & 5.43 & 0.12 & 0.100 & 4.34 & 0.10 \\
\hline 21.75 & 0.070 & 5.43 & 0.12 & 0.094 & 4.52 & 0.10 \\
\hline 26.75 & 0.058 & 6.06 & 0.14 & 0.061 & 5.88 & 0.13 \\
\hline 27.75 & 0.058 & 6.06 & 0.14 & 0.062 & 5.83 & 0.13 \\
\hline 28.625 & 0.054 & 6.30 & 0.14 & 0.058 & 6.06 & 0.14 \\
\hline 32.75 & 0.053 & 6.37 & 0.14 & 0.057 & 6.11 & 0.14 \\
\hline 33.75 & 0.052 & 6.43 & 0.14 & 0.056 & 6.18 & 0.14 \\
\hline 40 & 0.044 & 7.03 & 0.15 & 0.051 & 6.50 & 0.15 \\
\hline
\end{tabular}

acalculated from effluent soluble chemical oxygen demand (see Table A. 1).

$b \bar{t}_{o}$ for control bioreactors $=46.6 \mathrm{~h}$.

$\bar{c}_{\mathrm{t}_{0}}$ for test bioreactors $=43.8 \mathrm{~h}$. 
Table A.10 Global and Local First-Order Rate Constantsa for Control and Test Bioreactors During Toxicity Experiment No. 1.

\begin{tabular}{|c|c|c|c|c|c|c|c|c|c|c|c|c|c|}
\hline $\begin{array}{l}\text { Tine } \\
\text { (days) }\end{array}$ & Bioreactor & $\mathrm{f}_{\mathrm{o}}$ & $k_{0} \bar{t}_{0}$ & $k_{0}\left(h^{-1}\right)$ & $\mathrm{f}_{1}$ & $\mathrm{~K}_{1} \overline{\mathrm{t}}_{1}$ & $\mathrm{~K}_{1}\left(\mathrm{~h}^{-1}\right)$ & $\mathrm{f}_{2}$ & $\mathrm{k}_{2} \overline{\mathrm{t}}_{2}$ & $K_{2}(h r l)$ & $\mathrm{f}_{3}$ & $\mathrm{f}_{3} \mathrm{t}_{3}$ & $\mathrm{~K}_{3}\left(\mathrm{~h}^{-1}\right)$ \\
\hline \multirow{2}{*}{-1} & Control & 0.057 & 6.11 & 0.13 & 0.200 & 3.70 & 0.95 & 0.355 & 1.65 & 0.14 & 0.808 & 0.23 & 0.0074 \\
\hline & Test & 0.059 & 6.00 & 0.14 & 0.176 & 4.29 & 1.16 & 0.507 & 0.92 & 0.084 & 0.657 & 0.50 & 0.017 \\
\hline \multirow{2}{*}{20} & Control & 0.063 & 5.78 & 0.12 & 0.134 & 5.74 & 1.47 & 0.576 & 0.71 & 0.061 & 0.819 & 0.21 & 0.0067 \\
\hline & Test & 0.089 & 4.68 & 0.11 & 0.748 & 0.27 & 0.073 & 0.262 & 2.45 & 0.22 & 0.433 & 1.20 & 0.041 \\
\hline \multirow{2}{*}{29} & Control & 0.054 & 6.30 & 0.14 & 0.149 & 5.14 & 1.32 & 0.398 & 1.39 & 0.12 & 0.910 & 0.10 & 0.0032 \\
\hline & Test & 0.058 & 6.06 & 0.14 & 0.401 & 1.45 & 0.39 & 0.283 & 2.23 & 0.20 & 0.509 & 0.90 & 0.031 \\
\hline \multirow{2}{*}{40} & Control & 0.046 & 6.87 & C. 15 & 0.251 & 2.81 & 0.72 & 0.237 & 2.75 & 0.24 & 0.770 & 0.29 & 0.0093 \\
\hline & Test & 0.051 & 6.50 & C.15 & 0.328 & 1.97 & 0.53 & 0.499 & 0.95 & 0.086 & 0.309 & 1.94 & 0.066 \\
\hline
\end{tabular}

Ealculated from soluble chemical oxygen demanc profiles (see Table A.2). 
APPENDIX B: DATA FOR TOXICITY EXPERIMENT NO. 2

Toxicity experiment No. 2 was a shock-load (slug) of $1000 \mathrm{mg} / \mathrm{L} \mathrm{zinc}$ as $\mathrm{ZnCl}_{2}$ for $42 \mathrm{~h} ; 100 \%$ soluble zinc. Time zero is taken as the time when the experiment began. 
Table B.1. Effluent Soluble Chemical Oxygen Demand ${ }^{a}$ for Control and Test Bioreactors During Toxicity Exper1ment No. 2

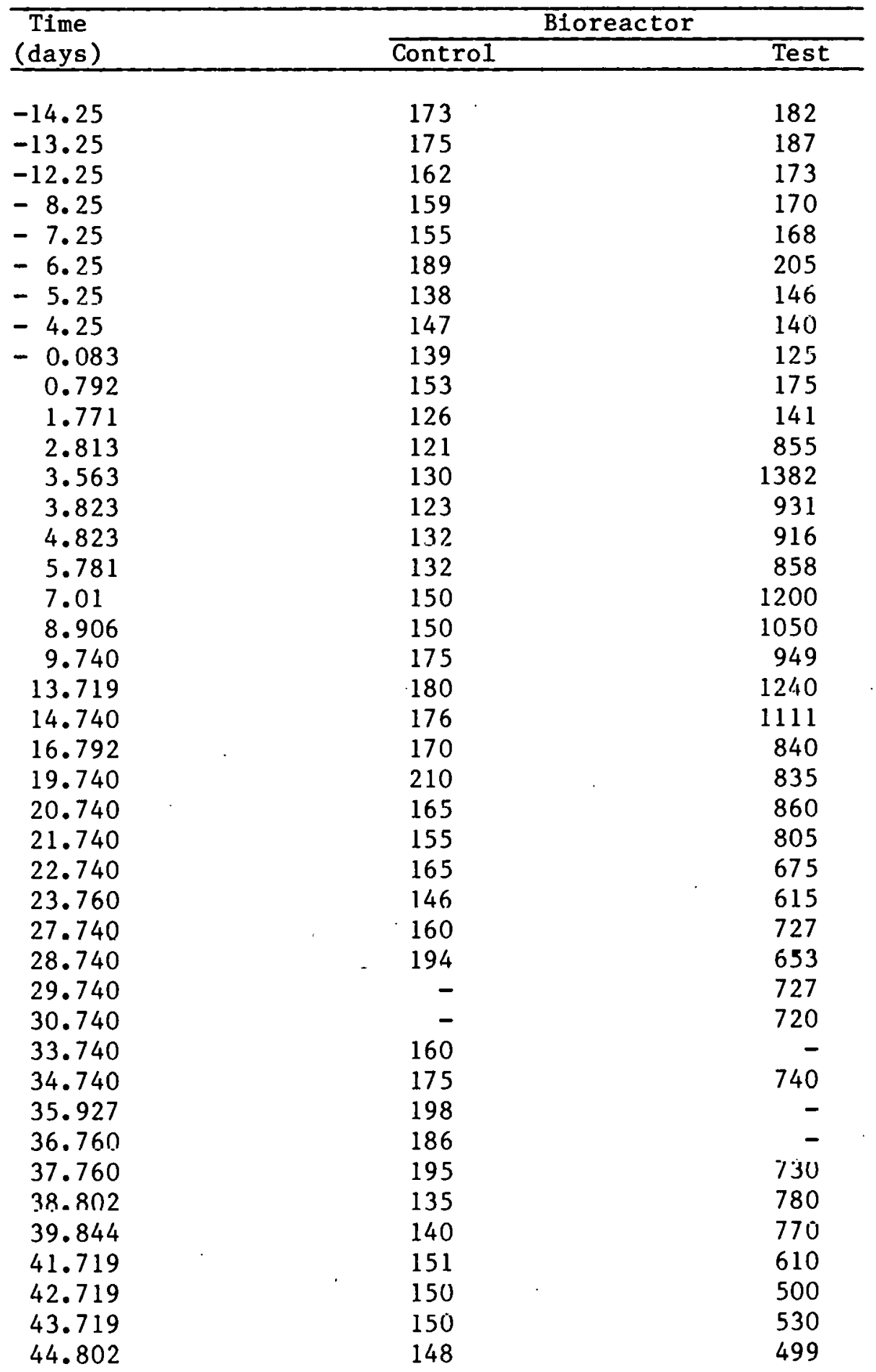


Table B.1. (Continued)

\begin{tabular}{|c|c|c|c|}
\hline \multirow{2}{*}{$\begin{array}{c}\text { Time } \\
\text { (days) } \\
\end{array}$} & \multicolumn{3}{|c|}{ Bioreactor } \\
\hline & Control & & Test \\
\hline 45.875 & 148 & & 481 \\
\hline 47.740 & 152 & & 382 \\
\hline 48.740 & 150 & & 353 \\
\hline 49.771 & 150 & & 353 \\
\hline 50.750 & 142 & & 338 \\
\hline 51.771 & 138 & & 303 \\
\hline 52.750 & 137 & & 299 \\
\hline 55.823 & 161 & & 265 \\
\hline 56.792 & 157 & & 311 \\
\hline 57.792 & 129 & & 351 \\
\hline 58.792 & 130 & & 306 \\
\hline 61.771 & 143 & & 243 \\
\hline 62.792 & 138 & & 204 \\
\hline 63.792 & 136 & & 280 \\
\hline 64.792 & 134 & & 277 \\
\hline 65.792 & 141 & & 253 \\
\hline 68.854 & 147 & & 179 \\
\hline 69.792 & 169 & & 208 \\
\hline 70.792 & 172 & & 240 \\
\hline 71.792 & 163 & & 198 \\
\hline 72.792 & 150 & & 184 \\
\hline 73.792 & 165 & & 213 \\
\hline 74.771 & 161 & & 185 \\
\hline 75.771 & 154 & & 164 \\
\hline 76.750 & 176 & & 180 \\
\hline 78.917 & 159 & & 169 \\
\hline 80.792 & 152 & & 163 \\
\hline 81.979 & 144 & & 144 \\
\hline 82.750 & 162 & & 144 \\
\hline 83.750 & 167 & . & 151 \\
\hline 84.750 & 152 & & 157 \\
\hline 87.771 & 154 & & 175 \\
\hline 88.750 & 149 & & 170 \\
\hline 89.771 & 113 & & 134 \\
\hline 90.750 & 117 & & 109 \\
\hline 91.771 & 133 & & 123 \\
\hline
\end{tabular}

avalues given in $\mathrm{mg} / \mathrm{L}$. 
Table B.2 Soluble Chemical Oxygen Demand Profiles for Control and Test Bioreactors During Toxicity Experiment No. $2^{a}$

\begin{tabular}{|c|c|c|c|c|c|c|c|c|c|c|c|c|c|}
\hline \multirow{2}{*}{$\begin{array}{c}\text { Time } \\
\text { (days) }\end{array}$} & & \multicolumn{12}{|c|}{ Bioreactor Length $\left(\mathrm{cm} \times 3.281 \times 10^{-2}\right)$} \\
\hline & & 0.5 & 1.0 & 1.5 & 2.0 & 2.5 & 3.0 & 3.5 & 4.0 & 4.5 & 5.0 & 5.5 & 6.0 \\
\hline \multirow{2}{*}{-1} & Cor.trol & 752 & 429 & 244 & 178 & 165 & 162 & 153 & 140 & 136 & 141 & 138 & 137 \\
\hline & Test & 985 . & 675 & 492 & 372 & 305 & 267 & 236 & 219 & 175 & 162 & 155 & 152 \\
\hline \multirow{2}{*}{6} & Control & 620 & 2810 & 225 & 195 & 192 & 192 & 185 & 170 & 175 & 178 & 174 & 170 \\
\hline & Test & 2650 & 214! & 1980 & 1772 & 1740 & 1464 & 1428 & 1460 & 1380 & 1420 & 1420 & 1340 \\
\hline \multirow{2}{*}{24} & Control & 746 & 258 & 198 & 175 & 167 & 178 & 159 & 152 & 160 & 160 & 166 & 167 \\
\hline & Test & 1658 & 155.5 & 1048 & 960 & 907 & 845 & 826 & 744 & 773 & 747 & 764 & 615 \\
\hline \multirow{2}{*}{50} & Contro & 1009 & 361 & 173 & 160 & 156 & 153 & 155 & 149 & 148 & 138 & 145 & 142 \\
\hline & Test & 1730 & 856 & 752 & 620 & 658 & 505 & 556 & 476 & 374 & 414 & 370 & 338 \\
\hline \multirow{2}{*}{88} & Control & 705 & $2 \vdots 7$ & 133 & 143 & 135 & 133 & 113 & 113 & 107 & 107 & 102 & 105 \\
\hline & Test & 463 & 334 & 318 & 237 & 207 & 218 & 170 & 148 & 170 & 157 & 185 & 151 \\
\hline \multicolumn{2}{|c|}{ Control Ave. } & 766 & 3199 & 195 & 169 & 163 & 164 & 153 & 145 & 145 & 145 & 145 & 144 \\
\hline \multicolumn{2}{|c|}{ S. D. } & 146 & 35 & 44 & 19 & 21 & 23 & 26 & 21 & 26 & 27 & 28 & 26 \\
\hline
\end{tabular}

${ }^{a}$ COD concentrations in $\mathrm{mg} / \mathrm{L}$. 
Table B. 3 Cummulative Gas Production, in Liters, for Control and Test Bioreactors During Toxicfty Experiment No. 2

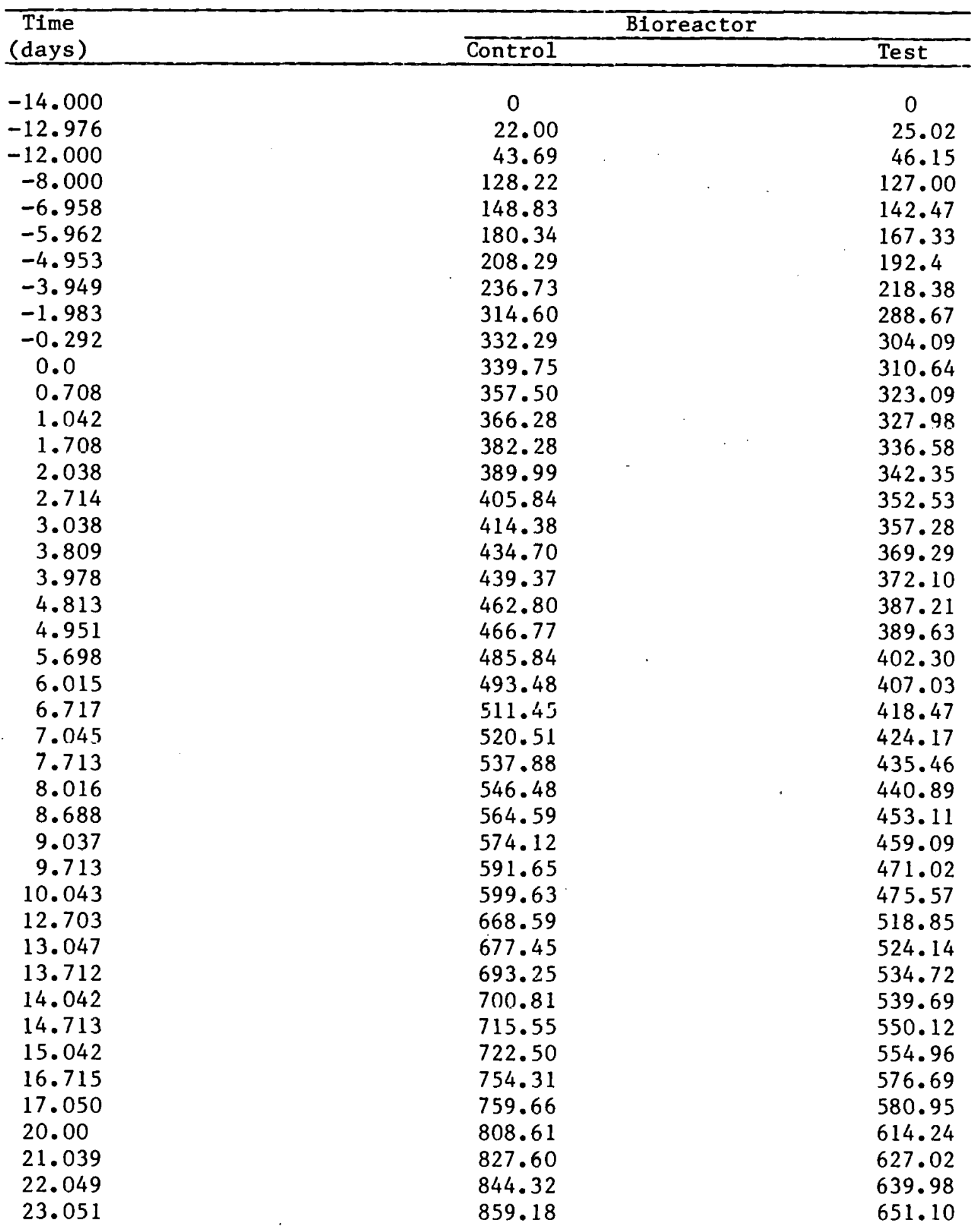


Table B.3 (continued)

\begin{tabular}{|c|c|c|}
\hline \multirow{2}{*}{$\begin{array}{c}\text { Time } \\
\text { (days) }\end{array}$} & \multicolumn{2}{|c|}{ Bioreactor } \\
\hline & Control & Test \\
\hline 24.035 & 875.83 & 661.34 \\
\hline 25.222 & 897.56 & 675.12 \\
\hline 26.708 & 917.87 & 689.58 \\
\hline 27.042 & 934.70 & 701.71 \\
\hline 28.049 & 955.27 & 718.28 \\
\hline 29.044 & 973.70 & 732.97 \\
\hline 30.038 & 991.03 & 745.97 \\
\hline 31.052 & 1012.06 & 761.22 \\
\hline 34.046 & 1077.00 & 811.87 \\
\hline 35.042 & 1103.50 & 831.67 \\
\hline 36.042 & 1124.03 & 852.49 \\
\hline 37.051 & 1151.40 & 874.51 \\
\hline 38.042 & 1176.81 & 895.32 \\
\hline 39.003 & 1200.34 & 914.16 \\
\hline 40.104 & 1227.54 & 936.66 \\
\hline 42.052 & 1271.16 & 972.51 \\
\hline 43.048 & 1296.02 & 991.96 \\
\hline 44.038 & 1319.66 & 1012.12 \\
\hline 45.045 & 1343.77 & 1031.80 \\
\hline 45.868 & 1364.73 & 1050.17 \\
\hline 47.045 & 1413.72 & 1093.57 \\
\hline 48.050 & 1437.71 & 1114.41 \\
\hline 49.042 & 1461.58 & 1136.44 \\
\hline 50.042 & 1483.90 & 1156.61 \\
\hline 50.717 & 1498.77 & 1176.45 \\
\hline 54.042 & 1544.21 & 1239.90 \\
\hline 55.046 & 1552.93 & 1256.97 \\
\hline 56.038 & 1573.64 & 1275.62 \\
\hline 57.046 & 1596.53 & 1295.63 \\
\hline 58.044 & 1620.74 & 1318.11 \\
\hline 61.047 & 1675.13 & 1373.57 \\
\hline 62.047 & 1700.20 & 1394.39 \\
\hline 63.042 & 1725.22 & 1417.61 \\
\hline 64.038 & 1749.56 & 1440.07 \\
\hline 65.042 & 1765.28 & 1463.80 \\
\hline 68.042 & 1831.98 & 1526.05 \\
\hline 69,046 & 1852.69 & 1546.35 \\
\hline 70.044 & $18 / 4.34$ & 1566.62 \\
\hline 71.047 & 1895.21 & 1587.12 \\
\hline 72.042 & 1917.22 & 1608.18 \\
\hline 75.049 & 1986.63 & 1679.27 \\
\hline 76.044 & 2007.86 & 1700.51 \\
\hline 77.052 & 2030.96 & 1724.13 \\
\hline 78.042 & 2053.14 & 1747.05 \\
\hline
\end{tabular}


Table B.3 (continued)

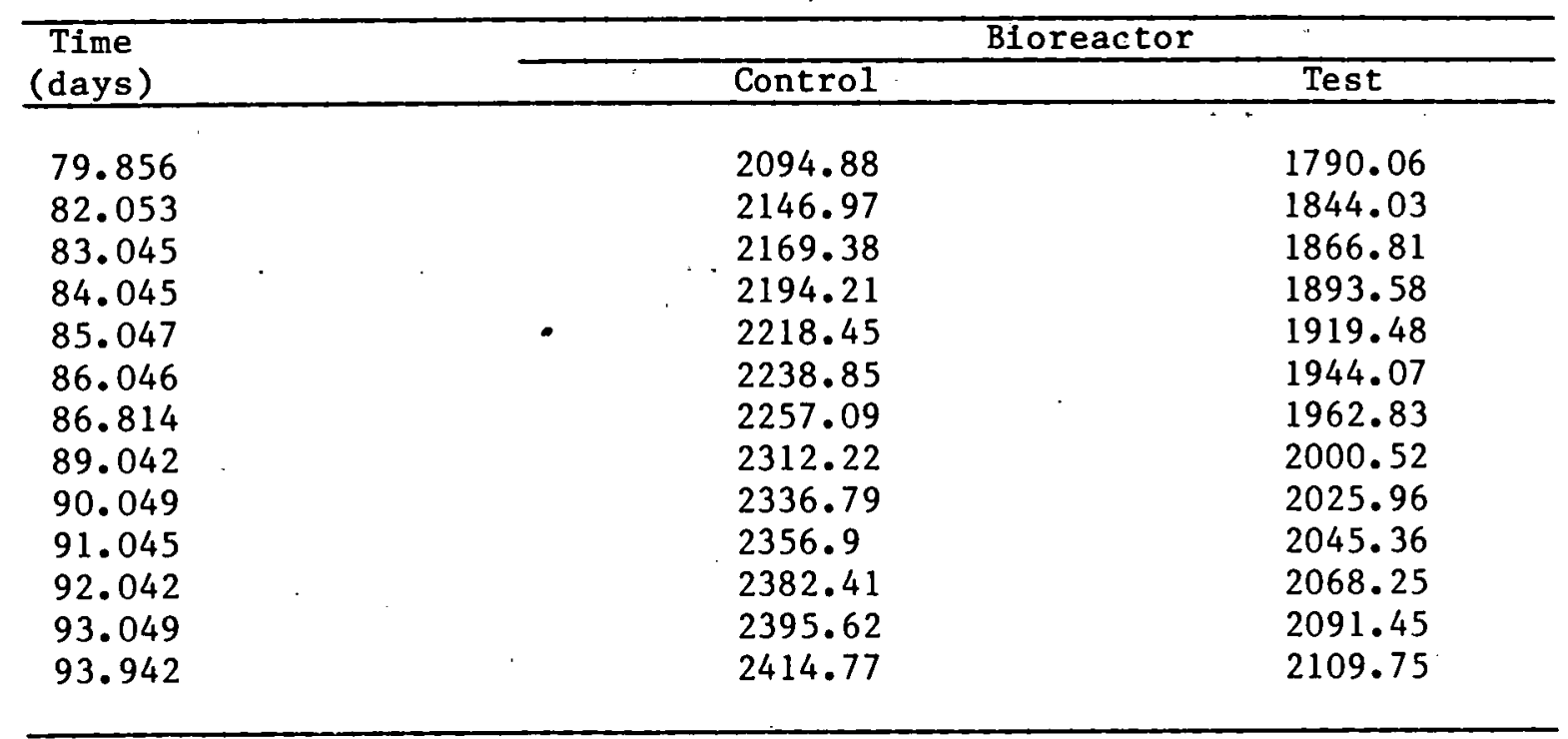


Table B.4. Gas Production Rate (Liters Per Day) for the Control and Test Bioreactors During Toxictty Experiment No. 2

\begin{tabular}{|c|c|c|c|}
\hline \multirow[b]{2}{*}{$\Delta t{(\text { days })^{a}}$} & \multirow[b]{2}{*}{$t_{1 / 2}$ (days) $^{b}$} & \multicolumn{2}{|c|}{ Bioreactor } \\
\hline & & Control & Test \\
\hline 1.024 & -13.488 & 21.48 & 24.43 \\
\hline .976 & -12.488 & 22.22 & 21.65 \\
\hline 4.000 & -10.000 & 21.13 & 20.21 \\
\hline 1.042 & -7.479 & 19.78 & 14.85 \\
\hline 1.009 & -5.458 & 27.70 & 25.07 \\
\hline 1.004 & -4.451 & 28.33 & 25.88 \\
\hline 2.966 & -2.466 & 26.25 & 23.71 \\
\hline .691 & -.638 & 25.60 & 22.32 \\
\hline .292 & -.146 & 25.55 & 22.43 \\
\hline .708 & .354 & 25.07 & 17.58 \\
\hline .334 & .875 & 26.29 & 14.64 \\
\hline .666 & 1.375 & 24.02 & 12.91 \\
\hline .330 & 1.873 & 23.36 & 17.48 \\
\hline .676 & 2.376 & 23.45 & 15.06 \\
\hline .324 & 2.876 & 26.36 & 14.66 \\
\hline .771 & 3.424 & 26.36 & 15.58 \\
\hline .169 & 3.894 & 27.63 & 16.63 \\
\hline .835 & 4.396 & 28.06 & 18.10 \\
\hline .138 & 4.882 & 28.77 & 17.54 \\
\hline .747 & 5.325 & 25.53 & 16.96 \\
\hline .317 & 5.857 & 24.10 & 14.92 \\
\hline .702 & 6.366 & 25.56 & 16.30 \\
\hline .328 & 6.881 & 27.62 & 17.38 \\
\hline .668 & 7.379 & 26.00 & 16.90 \\
\hline .303 & 7.865 & 28.38 & 17.92 \\
\hline .672 & 8.352 & 26.95 & 18.18 \\
\hline .349 & 8.863 & 27.31 & 17.13 \\
\hline .676 & 9.375 & 25.93 & 17.65 \\
\hline .330 & 9.878 & 24.18 & 13.79 \\
\hline 2.660 & 11.373 & 25.92 & 16.27 \\
\hline .344 & 12.875 & 25.76 & 15.38 \\
\hline 0.665 & 13.380 & 23.76 & 15.91 \\
\hline 0.330 & 13.877 & 22.91 & 15.06 \\
\hline 0.671 & 14.378 & 21.97 & 15.54 \\
\hline 0.329 & 14.878 & 21.12 & 14.71 \\
\hline 1.673 & 15.879 & 19.01 & 12.99 \\
\hline 0.335 & 16.883 & 15.97 & 12.72 \\
\hline 2.950 & 18.525 & 16.59 & 11.28 \\
\hline 1.039 & 20.520 & 18.28 & 12.30 \\
\hline 1.010 & 21.544 & 16.55 & 12.83 \\
\hline 1.002 & 22.550 & 14.83 & 11.10 \\
\hline 0.984 & 23.543 & 16.92 & 10.41 \\
\hline 1.187 & 24.629 & 18.31 & 11.61 \\
\hline
\end{tabular}


Table B.4. (Continued)

\begin{tabular}{|c|c|c|c|}
\hline \multirow[b]{2}{*}{$\Delta t$ (days) } & \multirow[b]{2}{*}{$t_{1 / 2}$ (days) } & \multicolumn{2}{|c|}{ Bioreactor } \\
\hline & & Control & Test \\
\hline 0.994 & 29.541 & 17.43 & 13.08 \\
\hline 1.014 & 30.545 & 20.74 & 15.04 \\
\hline 2.994 & 32.549 & 21.69 & 16.92 \\
\hline 0.996 & 34.544 & 26.61 & 19.88 \\
\hline 1.000 & 35.342 & 20.53 & 20.82 \\
\hline 1.009 & 36.547 & 27.13 & 21.82 \\
\hline 0.991 & 37.547 & 25.64 & 20.99 \\
\hline 0.961 & 38.523 & 24.48 & 19.90 \\
\hline 1.010 & 39.554 & 24.70 & 20.44 \\
\hline 1.948 & 41.078 & 22.39 & 18.40 \\
\hline 0.996 & 42.550 & 24.96 & 19.53 \\
\hline 0.990 & 43.543 & 23.88 & 20.36 \\
\hline 1.007 & 44.542 & 23.94 & 19.54 \\
\hline 0.823 & 45.457 & 25.47 & 22.32 \\
\hline 1.177 & 46.457 & 41.62 & 36.87 \\
\hline 1.005 & 47.548 & 23.87 & 20.74 \\
\hline 0.992 & 48.546 & 24.06 & 22.21 \\
\hline 1.000 & 49.542 & 22.32 & 20.17 \\
\hline 1.000 & 50.380 & 24.910 & 19.84 \\
\hline 3.325 & 52.379 & 13.67 & 19.08 \\
\hline 1.004 & 54.544 & 8.68 & 17.00 \\
\hline 0.992 & 55.542 & 20.87 & 18.80 \\
\hline 1.008 & 56.542 & 22.61 & 19.85 \\
\hline 0.998 & 57.545 & 24.26 & 22.52 \\
\hline 3.003 & 59.546 & 18.11 & 18.47 \\
\hline 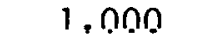 & 61.547 & 25.07 & $20.8 \overline{2}$ \\
\hline 0.995 & 62.545 & 25.15 & 23.34 \\
\hline 0.996 & 63.540 & 24.44 & 22.55 \\
\hline 1.004 & 64.540 & 15.65 & 23.63 \\
\hline 3.000 & 66.542 & 22.23 & 20.75 \\
\hline 1.004 & 68.544 & 20.63 & 20.22 \\
\hline 0.998 & 69.545 & 21.69 & 20.31 \\
\hline 1.003 & 70.546 & 20.81 & 20.44 \\
\hline 0.995 & 71.545 & 22.12 & 21.47 \\
\hline 3.007 & 73.546 & 23.08 & 23.54 \\
\hline 0.995 & 75.547 & 21.34 & 21.35 \\
\hline 1.008 & 76.548 & 22.92 & 23.43 \\
\hline 0.990 & 77.547 & 22.40 & 23.23 \\
\hline 1.814 & 78.949 & 23.01 & 23.71 \\
\hline 2.197 & 80.955 & 23.71 & 24.56 \\
\hline 0.992 & 82.549 & 22.59 & 22.96 \\
\hline 1.000 & 83.545 & 24.83 & 26.77 \\
\hline 1.002 & 84.546 & 24.19 & 25.85 \\
\hline 0.999 & 85.547 & 20.42 & 24.61 \\
\hline
\end{tabular}


Table B.4. (Continued)

\begin{tabular}{lclc}
\hline$\Delta t$ (days) & $t_{1 / 2}$ (days) & \multicolumn{2}{c}{ Bioreactor } \\
\cline { 4 - 4 } 0.768 & 86.430 & 23.75 & Test \\
2.228 & 87.928 & 24.74 & 24.43 \\
1.007 & 89.546 & 24.40 & 16.92 \\
0.996 & 90.547 & 20.19 & 25.26 \\
0.997 & 91.544 & 25.59 & 19.48 \\
1.007 & 92.546 & 13.12 & 22.96 \\
0.893 & 93.496 & 21.44 & 23.04 \\
& & & 20.49 \\
\hline
\end{tabular}

$a_{\Delta t}=t_{2}-t_{1} ; t_{1}$ and $t_{2}$ wcre obtalned from Table B. 3.

$b_{t_{1 / 2}}=\left(t_{2}+t_{1}\right) / 2$. 
Table B.5. Gas Composition for Control and Test Bioreactors During Toxicity Experiment No. 2

\begin{tabular}{|c|c|c|c|c|c|c|}
\hline \multirow[b]{2}{*}{ Time (days) } & \multicolumn{3}{|c|}{ Control Bioreactor } & \multicolumn{3}{|c|}{ Test Bloreactor } \\
\hline & $\%$ Air & $\% \mathrm{CH}_{4}$ & $\% \mathrm{CO}_{2}$ & $\%$ Air & $\% \mathrm{CH}_{4}$ & $\% \mathrm{CO}_{2}$ \\
\hline-14.177 & 1.5 & 74.3 & 24.2 & 1.7 & 74.5 & 23.8 \\
\hline-13.198 & 2.1 & 70.5 & 27.4 & 2.3 & 70.4 & 27.3 \\
\hline-12.167 & 1.9 & 70.7 & 27.4 & 1.6 & 71.1 & 27.3 \\
\hline-8.108 & 2.4 & 72.9 & 24.7 & 2.8 & 72.2 & 25.0 \\
\hline-7.972 & 2.4 & 71.8 & 25.8 & 2.5 & 72.0 & 25.5 \\
\hline-7.260 & 3.1 & 70.5 & 26.4 & 2.9 & 70.7 & 26.4 \\
\hline-6.260 & 2.3 & 69.7 & 28.1 & 2.2 & 70.7 & 27.1 \\
\hline-5.257 & 3.1 & 70.6 & 26.3 & 2.6 & 70.6 & 26.8 \\
\hline-4.219 & 2.9 & 70.4 & 26.7 & 2.4 & 70.3 & 27.3 \\
\hline-1.250 & 2.0 & 73.2 & 24.8 & 2.4 & 72.7 & 24.9 \\
\hline-0.243 & 1.7 & 74.3 & 24.0 & 1.7 & 73.8 & 23.0 \\
\hline 0.75 & 1.7 & 74.7 & 23.6 & 2.5 & 71.8 & 25.7 \\
\hline 1.729 & 1.8 & 74.9 & 23.3 & 3.0 & 69.2 & 27.8 \\
\hline 2.740 & 3.0 & 75.4 & 21.6 & 3.0 & 67.9 & 29.1 \\
\hline 3.010 & 2.5 & 74.1 & 23.4 & 3.4 & 65.0 & 31.6 \\
\hline 3.844 & 2.0 & 74.2 & 23.8 & 3.4 & 65.4 & 31.2 \\
\hline 4.840 & 2.6 & 73.5 & 23.9 & 2.4 & 66.3 & 31.3 \\
\hline 5.750 & 2.1 & 75.3 & 22.6 & 2.7 & 69.2 & 28.1 \\
\hline 6.736 & 1.9 & 74.3 & 23.8 & 2.8 & 69.1 & 28.1 \\
\hline 7.740 & 2.0 & 73.4 & 24.6 & 2.4 & 68.5 & 29.1 \\
\hline 8.733 & 3.7 & 71.9 & 24.4 & 3.0 & 68.8 & 28.3 \\
\hline 9.760 & 1.9 & 75.5 & 22.6 & 2.8 & 70.9 & 26.3 \\
\hline 12.813 & 1.8 & 75.4 & 22.8 & 2.6 & 71.1 & 26.3 \\
\hline 13.740 & 2.8 & 74,3 & 23.9 & 2.5 & 70.8 & 26.7 \\
\hline 14.771 & 2.8 & 74.9 & 22.3 & 3.3 & 70.9 & 25.8 \\
\hline 16.750 & 3.0 & 76.9 & 20.1 & 4.5 & 72.9 & 22.6 \\
\hline 19.927 & 3.1 & 78.2 & 18.7 & 3.2 & 76.2 & 20.6 \\
\hline 20.750 & 3.0 & 77.0 & 20.0 & 3.6 & 74.7 & 19.1 \\
\hline 21.740 & 3.2 & 75.4 & 21.3 & 2.9 & 74.9 & 22.5 \\
\hline 22.760 & 3.6 & 75.7 & 20.7 & 3.1 & 74.5 & 22.4 \\
\hline 23.771 & 2.9 & 78.3 & 18.8 & 2.1 & 77.4 & 20.5 \\
\hline 26.730 & 2.5 & 74.8 & 22.7 & 4.0 & 71.8 & 24.2 \\
\hline 27.760 & 2.8 & 73.5 & 23.7 & 6.0 & 68.8 & 25.2 \\
\hline 28.771 & 2.8 & 74.8 & 22.4 & 3.2 & 72.4 & 24.5 \\
\hline 29.729 & 4.2 & 75.9 & 20.0 & 3.9 & 78.7 & 17.4 \\
\hline 30.740 & 3.6 & 74.0 & 22.4 & 3.5 & 72.7 & 23.8 \\
\hline 33.740 & 2.6 & 74.2 & 23.3 & 2.1 & 72.4 & 25.5 \\
\hline 34.826 & 2.1 & 73.3 & 24.6 & 1.8 & 71.6 & 26.6 \\
\hline 35.948 & 2.5 & 71.6 & 25.8 & 2.5 & 69.5 & 28.0 \\
\hline 36.760 & 5.0 & 71.0 & 24.0 & 2.8 & 69.4 & 27.8 \\
\hline 37.760 & 3.4 & 71.0 & 25.7 & 2.7 & 68.0 & 29.3 \\
\hline 38.736 & 1.9 & 74.6 & 23.5 & 3.3 & 70.6 & 26.2 \\
\hline 39.740 & 2.7 & 72.2 & 25.0 & 2.7 & 69.9 & 27.4 \\
\hline
\end{tabular}


Table B.5. (Continued)

\begin{tabular}{|c|c|c|c|c|c|c|}
\hline \multirow[b]{2}{*}{ Time (days) } & \multicolumn{3}{|c|}{ Control Bioreactor } & \multicolumn{3}{|c|}{ Test Bioreactor } \\
\hline & $\%$ Air & $\% \mathrm{CH}_{4}$ & $\% \mathrm{CO}_{2}$ & $\%$ Air & $\% \mathrm{CH}_{4}$ & $\% \mathrm{CO}_{2}$ \\
\hline 40.740 & 1.6 & 73.5 & 24.9 & 2.2 & 71.1 & 26.7 \\
\hline 41.781 & 2.7 & 74.3 & 23.0 & 3.2 & 72.0 & 24.9 \\
\hline 43.750 & 3.8 & 74.0 & 22.2 & 3.9 & 72.4 & 23.7 \\
\hline 44.781 & 2.0 & 74.1 & 23.9 & 1.1 & 73.9 & 25.0 \\
\hline 45.771 & 4.0 & 71.0 & 25.0 & 4.8 & 68.9 & 26.3 \\
\hline 46.792 & 2.4 & 74.0 & 23.6 & 2.9 & 73.3 & 23.8 \\
\hline 47.813 & 3.5 & 73.8 & 22.7 & 2.9 & 73.3 & 23.8 \\
\hline 50.969 & 3.8 & 75.9 & 20.2 & 3.3 & 75.8 & 20.9 \\
\hline 51.804 & 3.8 & 76.7 & 19.5 & 2.7 & 78.0 & 19.3 \\
\hline 52.802 & 2.5 & 78.0 & 19.5 & 2.5 & 77.1 & 20.4 \\
\hline 53.896 & 2.7 & 77.3 & 19.9 & 2.1 & 76.7 & 21.2 \\
\hline 54.813 & 2.5 & 74.9 & 22.5 & 2.9 & 74.1 & 23.0 \\
\hline 57.804 & 1.4 & 70.6 & 28.0 & 1.4 & 70.6 & 28.0 \\
\hline 58.750 & 2.3 & 72.8 & 24.9 & 1.2 & 72.6 & 26.2 \\
\hline 59.823 & 1.7 & 73.1 & 25.2 & 1.7 & 73.2 & 25.1 \\
\hline 60.760 & 2.6 & 75.4 & 22.0 & 2.5 & 74.2 & 23.3 \\
\hline 61.781 & 3.1 & 72.8 & 24.1 & 2.0 & 73.9 & 24.1 \\
\hline 63.896 & - & - & - & 2.3 & 73.6 & 24.1 \\
\hline 64.781 & 2.8 & 73.5 & 23.7 & 2.4 & 72.3 & 25.3 \\
\hline 65.750 & 1.7 & 75.5 & 22.8 & 1.6 & 74.7 & 23.7 \\
\hline 66.802 & 2.3 & 75.8 & 22.0 & 2.7 & 74.9 & 22.4 \\
\hline 67.792 & 1.8 & 75.0 & 23.2 & 1.7 & 75.1 & 2.3 .3 \\
\hline 70.792 & 2.8 & 75.0 & 22.3 & 3.2 & 74.6 & 22.1 \\
\hline 71.771 & 2.2 & 76.6 & 21.1 & 2.2 & 76.7 & 21.1 \\
\hline 72.802 & 1.8 & 75.6 & 22.7 & 2.0 & 75.1 & 22.9 \\
\hline 73.792 & 1.8 & 72.9 & 25.3 & 1.8 & 72.7 & 25.5 \\
\hline 75.896 & 1.9 & 72.7 & 25.4 & 1.8 & 72.3 & 25.8 \\
\hline 77.792 & 3.2 & 72.7 & 24.1 & 1.5 & 74.1 & 24.4 \\
\hline 78.885 & 2.4 & 73.0 & 24.7 & 1.4 & 73.3 & 25.3 \\
\hline 79.781 & 0.9 & 71.8 & 27.2 & 1.8 & 71.0 & 27.1 \\
\hline 80.771 & 1.0 & 71.9 & 27.1 & 2.8 & 70.0 & 27.2 \\
\hline 81.927 & 2.1 & 71.2 & 26.7 & 3.2 & 70.9 & 25.9 \\
\hline 84.823 & 1.6 & 72.2 & 26.2 & 2.8 & 69.7 & 27.5 \\
\hline 85.875 & 1.3 & 73.0 & 25.6 & 1.6 & 72.2 & 26.2 \\
\hline 86.804 & 1.8 & 72.8 & 25.4 & 1.4 & 72.6 & 26.0 \\
\hline 87.804 & 1.6 & 73.6 & 24.8 & 2.0 & 72.4 & 25.6 \\
\hline 88.833 & 2.5 & 73.2 & 24.3 & 2.0 & 74.3 & 23.6 \\
\hline 91.792 & 1.5 & 74.5 & 24.0 & 1.5 & 74.0 & 24.5 \\
\hline
\end{tabular}


Table B.6. Acetic Acid Profiles for Control and Test Bioreactors During Toxicity Experiment No. $2^{\mathrm{a}}$

\begin{tabular}{|c|c|c|c|c|c|c|c|c|c|c|c|c|c|}
\hline \multirow[b]{2}{*}{ Time (days) } & \multirow[b]{2}{*}{ Bioreactor } & \multicolumn{12}{|c|}{$\begin{array}{l}\text { Bioreactor Length } \\
\left(\mathrm{cm} \times 3.281 \times 10^{-2}\right)\end{array}$} \\
\hline & & 0.5 & 1.0 & 1.5 & 2.0 & 2.5 & 3.0 & 3.5 & 4.0 & 4.5 & 5.0 & 5.5 & 6.0 \\
\hline \multirow{2}{*}{-1} & Control & 450 & 450 & 125 & 30 & 50 & 20 & 20 & 20 & 10 & 5 & 5 & 5 \\
\hline & Test & 450 & 450 & 100 & 50 & 50 & 20 & 20 & 20 & 10 & 10 & 10 & 10 \\
\hline \multirow{2}{*}{6} & Control & $\star$ & $\star$ & * & * & * & * & $\star$ & * & * & * & * & * \\
\hline & Test & 1202 & 1223 & 1092 & 1058 & 1058 & 989 & 982 & 824 & 762 & 646 & 639 & 769 \\
\hline \multirow{2}{*}{24} & Control & 107 & 37 & 22 & 7 & 10 & 11 & 2 & 0 & 0 & 0 & 0 & 0 \\
\hline & Test & 1000 & 1066 & 920 & 720 & 740 & 540 & 580 & 595 & 490 & 501 & 389 & 394 \\
\hline \multirow{2}{*}{50} & Control & 712 & 33 & 31 & 31 & 31 & 31 & 30 & 22 & 22 & 22 & 38 & 15 \\
\hline & Test & 1211 & 517 & $4 \div 2$ & 529 & 478 & 337 & 393 & 288 & 198 & 235 & 243 & 206 \\
\hline \multirow{2}{*}{88} & Control & 468 & 380 & 37 & 40 & 16 & 0 & 0 & 0 & 0 & 0 & 0 & 0 \\
\hline & Test & 215 & 162 & $1 \div 7$ & 91 & 58 & 52 & 32 & 25 & 18 & 14 & 14 & 0 \\
\hline \multicolumn{2}{|c|}{ Control Ave. } & 434 & 225 & $\bar{b} 6$ & 27 & 27 & 16 & 13 & 11 & 8 & 7 & 11 & 5 \\
\hline \multicolumn{2}{|l|}{ S. D. } & 249 & 221 & 49 & 14 & 18 & 13 & 14 & 12 & 10 & 10 & 18 & 7 \\
\hline
\end{tabular}

acetic acid concentration in $\mathrm{mg} / \mathrm{L}$; a value of zero is used to denote a nondetectable concentration. 
Table B.7. Propionic Acid Profiles for Control and Test Bioreactors During Toxicity Experiment No. $2^{\mathrm{a}}$

\begin{tabular}{|c|c|c|c|c|c|c|c|c|c|c|c|c|c|}
\hline \multirow[b]{2}{*}{ Time (days) } & \multirow[b]{2}{*}{ Bioreactor } & \multicolumn{12}{|c|}{$\begin{array}{l}\text { Bioreactor Length } \\
\left(\mathrm{cm} \times 3.281 \times 10^{-2}\right)\end{array}$} \\
\hline & & 0.5 & 1.0 & 1.5 & 2.0 & 2.5 & 3.0 & 3.5 & 4.0 & 4.5 & 5.0 & 5.5 & 6.0 \\
\hline \multirow{2}{*}{-1} & Control & 200 & 120 & 25 & 10 & 5 & 0 & 0 & 0 & 0 & 0 & 0 & 0 \\
\hline & Test & 200 & 200 & 40 & 20 & 20 & 10 & 10 & 10 & 5 & 5 & 0 & 0 \\
\hline \multirow{2}{*}{6} & Control & $\star$ & * & $\star$ & $\star$ & * & * & * & $\star$ & $\star$ & * & $\star$ & * \\
\hline & Test & 316 & 329 & 289 & 267 & 280 & 236 & 254 & 200 & 178 & 169 & 169 & 191 \\
\hline \multirow{2}{*}{24} & Control & 36 & 10 & 0 & 0 & 0 & 0 & 0 & 0 & 0 & 0 & 0 & 0 \\
\hline & Test & 238 & 180 & 103 & 123 & 131 & 79 & 92 & 87 & 103 & 110 & 68 & 53 \\
\hline \multirow{2}{*}{50} & Control & 107 & 0 & 0 & 0 & 0 & 0 & 0 & 0 & 0 & 0 & 0 & 4 \\
\hline & Test & 248 & 94 & 85 & 109 & 86 & 60 & 63 & 56 & 27 & 31 & 25 & 27 \\
\hline \multirow{2}{*}{88} & Control & 64 & 43 & 0 & 0 & 0 & 0 & 0 & 0 & 0 & 0 & 0 & 0 \\
\hline & Test & 32 & 24 & 21 & 12 & 0 & 0 & 0 & 0 & 0 & 0 & 0 & 0 \\
\hline \multicolumn{2}{|c|}{ Control Ave. } & 102 & 43 & 6 & 3 & 1 & 0 & 0 & 0 & 0 & 0 & 0 & 1 \\
\hline S.D. & & 72 & 54 & 13 & 5 & 3 & 0 & 0 & 0 & 0 & 0 & 0 & 2 \\
\hline
\end{tabular}

apropionic acid concentrations in $\mathrm{mg} / \mathrm{L}$; a value of zero is used to denote nondetectable concentrations. 
Table B.8. Effluent $\mathrm{pH}$ and Alkalinity for Control and Test Bioreactors During Toxicity Experiment No. 2

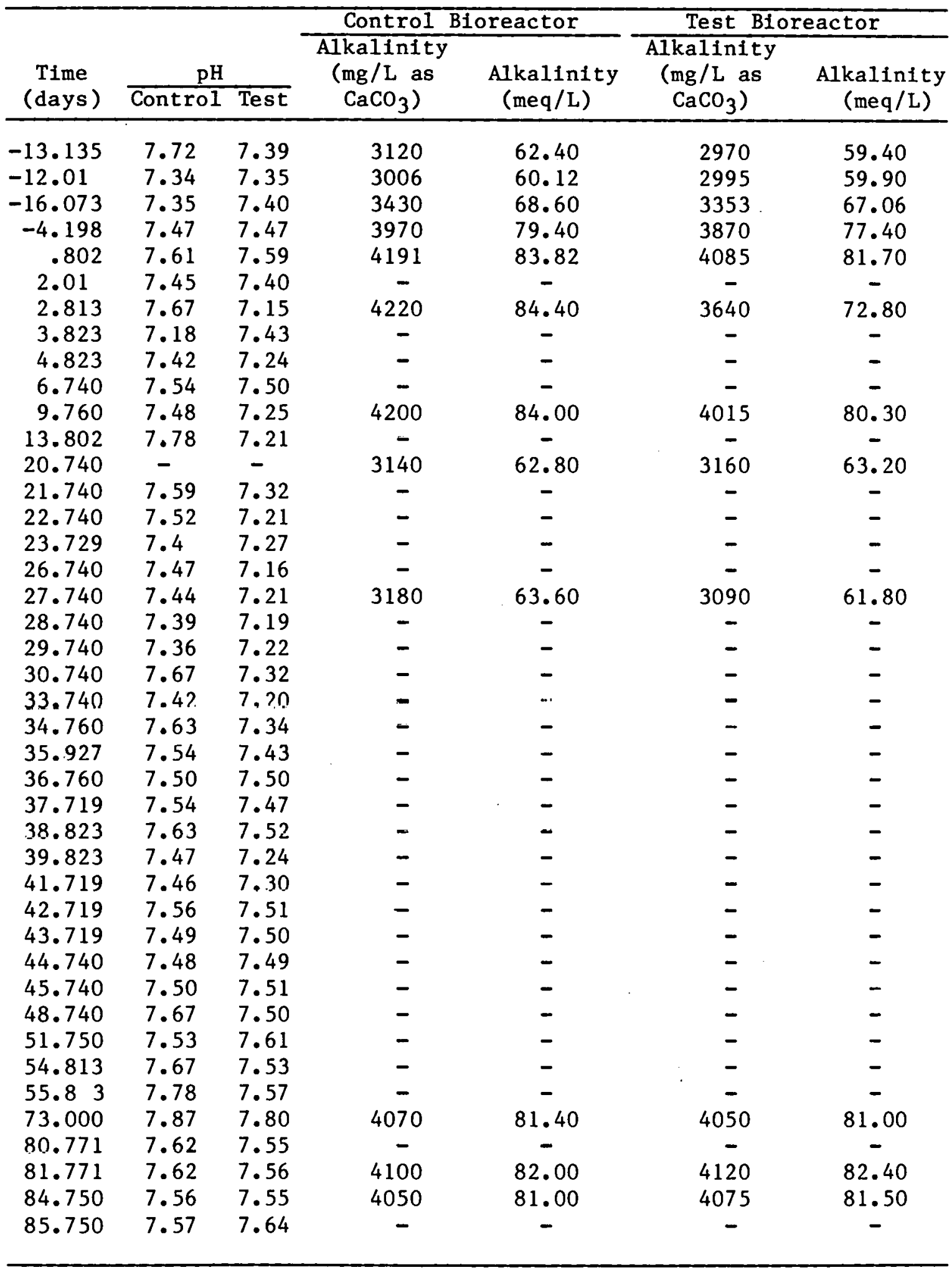


Table B.9. Global First-Order Rate Constants ${ }^{a}$ for Control and Test Bioreactors During Toxicity Experiment No. 2

\begin{tabular}{|c|c|c|c|c|c|c|}
\hline \multirow[b]{2}{*}{ Time (days) } & \multicolumn{3}{|c|}{ Control Bioreactor } & \multicolumn{3}{|c|}{ Test Bioreactor } \\
\hline & $f_{o}$ & $k_{0} \bar{t}_{0}$ & $k_{0}\left(h^{-1}\right)$ & $f_{0}$ & $\mathrm{~K}_{0} \bar{t}_{0}$ & $K_{0}\left(h^{-1}\right)$ \\
\hline$-14 \cdot 25$ & 0.058 & 6.06 & 0.13 & 0.061 & 5.88 & 0.13 \\
\hline-13.25 & 0.058 & 6.06 & 0.13 & 0.062 & 5.83 & 0.13 \\
\hline$-12 \cdot 25$ & 0.054 & 6.30 & 0.14 & 0.058 & 6.06 & 0.14 \\
\hline-8.25 & 0.053 & 6.37 & 0.14 & 0.057 & 6.11 & 0.14 \\
\hline-7.25 & 0.052 & 6.43 & 0.14 & 0.056 & 6.18 & 0.14 \\
\hline-6.25 & 0.063 & 5.78 & 0.12 & 0.068 & 5.53 & 0.13 \\
\hline-5.25 & 0.046 & 6.87 & 0.15 & 0.049 & 6.64 & 0.15 \\
\hline-4.25 & 0.049 & 6.64 & 0.14 & 0.047 & 6.79 & 0.16 \\
\hline-0.083 & 0.046 & 6.87 & 0.15 & 0.042 & 7.21 & 0.16 \\
\hline 0.792 & 0.051 & 6.50 & 0.14 & 0.058 & 6.06 & 0.14 \\
\hline 1.771 & 0.042 & 7.21 & 0.15 & 0.047 & 7.69 & 0.16 \\
\hline 3.563 & 0.043 & 7.12 & 0.15 & 0.461 & 0.98 & 0.022 \\
\hline 3.823 & 0.041 & 7.30 & 0.16 & 0.310 & 1.66 & 0.038 \\
\hline 4.823 & 0.044 & 7.03 & 0.15 & 0.305 & 1.69 & 0.039 \\
\hline 5.781 & 0.044 & 7.03 & 0.15 & 0.286 & 1.81 & 0.041 \\
\hline 7.01 & 0.050 & 6.57 & 0.14 & 0.400 & 1.21 & 0.028 \\
\hline 8.906 & 0.050 & 6.57 & 0.14 & 0.350 & 1.44 & 0.033 \\
\hline 9.740 & 0.058 & 6.06 & 0.13 & 0.316 & 1.62 & 0.037 \\
\hline 13.719 & 0.060 & 5.94 & 0.13 & 0.413 & 1.16 & 0.026 \\
\hline 14.740 & 0.059 & 6.00 & 0.13 & 0.370 & 1.34 & 0.031 \\
\hline 16.792 & 0.057 & 6.11 & 0.13 & 0.280 & 1.85 & 0.042 \\
\hline 19.740 & 0.070 & 5.43 & 0.12 & 0.278 & 1.87 & 0.043 \\
\hline 20.740 & 0.055 & 6.24 & 0.13 & 0.287 & 1.81 & 0.041 \\
\hline 21.740 & 0.052 & 6.43 & 0.14 & 0.268 & 1.94 & 0.044 \\
\hline 22.740 & 0.055 & 6.24 & 0.13 & 0.225 & 2.30 & 0.053 \\
\hline 23.760 & 0.049 & 6.64 & 0.14 & 0.205 & 2.51 & 0.057 \\
\hline 27.740 & 0.053 & 6.37 & 0.14 & 0.242 & 2.15 & 0.049 \\
\hline 28.740 & 0.065 & 5.67 & 0.12 & 0.218 & 2.37 & 0.054 \\
\hline 29.740 & - & - & - & 0.242 & 2.15 & 0.049 \\
\hline 30.740 & - & - & - & 0.240 & 2.17 & 0.050 \\
\hline 33.740 & 0.053 & 6.37 & 0.14 & - & - & - \\
\hline 34.740 & 0.058 & 6.06 & 0.13 & 0.247 & 2.11 & 0.048 \\
\hline 35.927 & 0.066 & 5.62 & 0.12 & - & - & - \\
\hline 36.760 & 0.062 & 5.83 & 0.13 & - & - & - \\
\hline 37.760 & 0.065 & 5.67 & 0.12 & 0.243 & 2.14 & 0.049 \\
\hline 38.802 & 0.045 & 6.95 & 0.15 & 0.260 & 2.00 & 0.046 \\
\hline 39.844 & 0.047 & 6.79 & 0.15 & 0.257 & 2.03 & 0.046 \\
\hline 41.719 & 0.050 & 6.57 & 0.14 & 0.203 & 2.53 & 0.058 \\
\hline 42.719 & 0.050 & 6.57 & 0.14 & 0.167 & 2.98 & 0.068 \\
\hline 43.719 & 0.050 & 6.57 & 0.14 & 0.177 & 2.84 & 0.065 \\
\hline 44.802 & 0.049 & 6.64 & 0.14 & 0.166 & 3.00 & 0.068 \\
\hline 45.875 & 0.049 & 6.64 & 0.14 & 0.150 & 3.25 & 0.074 \\
\hline
\end{tabular}


Table B.9. (Continued)

\begin{tabular}{|c|c|c|c|c|c|c|}
\hline \multirow[b]{2}{*}{ Time (days) } & \multicolumn{3}{|c|}{ Control Bioreactor } & \multicolumn{3}{|c|}{ Test Bioreactor } \\
\hline & $f_{0}$ & $K_{0} \bar{t}_{0}$ & $K_{0}\left(h^{-1}\right)$ & $f_{o}$ & $\mathrm{~K}_{0} \mathrm{t}_{\mathrm{o}}^{-}$ & $k_{0}\left(h^{-1}\right)$ \\
\hline 47.740 & 0.051 & 6.50 & 0.14 & 0.127 & 3.68 & 0.084 \\
\hline 48.740 & 0.050 & 6.57 & 0.14 & 0.118 & 3.88 & 0.089 \\
\hline 49.771 & 0.050 & 6.57 & 0.14 & 0.118 & 3.88 & 0.089 \\
\hline 50.750 & 0.047 & 6.79 & 0.15 & 0.113 & 4.00 & 0.091 \\
\hline 51.771 & 0.046 & 6.87 & 0.15 & 0.101 & 4.31 & 0.10 \\
\hline 52.750 & 0.046 & 6.87 & 0.15 & 0.100 & 4.34 & 0.10 \\
\hline 55.823 & 0.054 & 6.30 & 0.14 & 0.088 & 4.72 & 0.10 \\
\hline 56.792 & 0.052 & 6.43 & 0.14 & 0.104 & 4.23 & 0.10 \\
\hline 57.792 & 0.043 & 7.12 & 0.15 & 0.117 & 3.90 & 0.09 \\
\hline 58.792 & 0.043 & 7.12 & 0.15 & 0.102 & 4.28 & 0.10 \\
\hline 61.771 & 0.048 & 6.72 & 0.14 & 0.081 & 4.97 & 0.11 \\
\hline 62.792 & 0.046 & 6.87 & 0.15 & 0.068 & 5.53 & 0.13 \\
\hline 63.792 & 0.045 & 6.95 & 0.15 & 0.093 & 4.55 & 0.10 \\
\hline 64.792 & 0.045 & 6.95 & 0.15 & 0.092 & 4.59 & 0.10 \\
\hline 65.792 & 0.047 & 6.79 & 0.15 & 0.084 & 4.86 & 0.11 \\
\hline 68.854 & 0.049 & 6.64 & 0.14 & 0.060 & 5.94 & 0.14 \\
\hline 69.792 & 0.056 & 6.18 & 0.13 & 0.069 & 5.48 & 0.13 \\
\hline 70.792 & 0.057 & 6.11 & 0.13 & 0.080 & 5.01 & 0.11 \\
\hline 71.792 & 0.054 & 6.30 & 0.14 & 0.066 & 5.62 & 0.13 \\
\hline 72.792 & 0.050 & 6.57 & 0.14 & 0.061 & 5.88 & 0.13 \\
\hline 73.792 & 0.055 & 6.24 & 0.13 & 0.071 & 5.39 & 0.12 \\
\hline 74.771 & 0.054 & 6.30 & 0.14 & 0.062 & 5.83 & 0.13 \\
\hline 75.771 & 0.051 & 6.50 & 0.14 & 0.055 & 6.24 & 0.14 \\
\hline 76.750 & 0.059 & 6.00 & 0.13 & 0.060 & 5.94 & 0,14 \\
\hline 70.917 & 0.053 & 6.37 & 0.14 & 0.056 & 6.18 & 0.14 \\
\hline 80.792 & 0.051 & 6.50 & 0.14 & 0.054 & 6.30 & 0.14 \\
\hline 81.979 & 0.048 & 6.72 & 0.14 & 0.048 & 6.72 & 0.15 \\
\hline 82.750 & 0.054 & 6.30 & 0.14 & 0.048 & 6.72 & 0.15 \\
\hline 83.750 & 0.056 & 6.18 & 0.13 & 0.050 & 6.57 & 0.15 \\
\hline 84.750 & 0.051 & 6.50 & 0.14 & 0.052 & 6.43 & 0.15 \\
\hline 87.771 & 0.051 & 6.50 & 0.14 & 0.058 & 6.06 & 0.14 \\
\hline 88.750 & 0.050 & 6.57 & 0.14 & 0.057 & 6.11 & 0.14 \\
\hline 89.771 & 0.038 & 7.58 & 0.16 & 0.045 & 6.95 & 0.16 \\
\hline 90.750 & 0.039 & 7.49 & 0.16 & 0.036 & 7.79 & 0.18 \\
\hline 91.771 & 0.044 & 7.03 & 0.15 & 0.041 & 7.30 & 0.17 \\
\hline
\end{tabular}

${ }^{a}$ Calculated from effluent soluble chemical oxygen demand (see Table B.1).

$b_{t_{0}}$ for control bioreactor $=46.6$ hours.

$\vec{c}_{\mathrm{t}}$ for test bioreactor $=43.8$ hours. 
Table B. 10. Effluent Dissolved Zinc Concentrations ${ }^{a}$ for Contro1 and Test Bioreactors During Toxicity Experiment No. 2

\begin{tabular}{|c|c|c|}
\hline \multirow[b]{2}{*}{ Time (days) } & \multicolumn{2}{|c|}{ Bioreactor } \\
\hline & Control & Test \\
\hline 0.802 & $<0.05$ & 1.38 \\
\hline 1.771 & $<0.05$ & 2.5 \\
\hline 2.813 & $<0.05$ & 20.82 \\
\hline 3.823 & $<0.05$ & 5.26 \\
\hline 4.823 & $<0.05$ & 4.57 \\
\hline 5.781 & $<0.05$ & 2.30 \\
\hline 6.740 & $<0.05$ & 1.8 \\
\hline 8.740 & $<0.05$ & 1.34 \\
\hline 9.760 & 0.06 & 1.48 \\
\hline 12.719 & $<0.05$ & 1.5 \\
\hline 16.740 & $<0.05$ & 1.3 \\
\hline 19.740 & 0.14 & 1.3 \\
\hline 20.740 & $<0.05$ & 1.5 \\
\hline 22.740 & $<0.05$ & 1.3 \\
\hline 34.760 & 0.08 & 0.64 \\
\hline 37.990 & 0.45 & - \\
\hline 45.875 & 0.5 & 0.75 \\
\hline 47.740 & 0.2 & 0.5 \\
\hline 48.740 & 0.16 & 0.38 \\
\hline 49.750 & 0.1 & 0.3 \\
\hline 50.771 & 0.09 & - \\
\hline 54.823 & 0.14 & 0.2 \\
\hline 55.792 & 0.1 & 0.2 \\
\hline 56.750 & 0.2 & 0.3 \\
\hline 57.750 & $<0.05$ & 0.1 \\
\hline 58.750 & 0.1 & 0.1 \\
\hline 61.771 & $<0.05$ & 0.23 \\
\hline 62.792 & $<0.05$ & $<0.05$ \\
\hline 63.792 & 0.1 & 0.1 \\
\hline 64.792 & 0.2 & 0.5 \\
\hline 65.792 & 0.1 & 0.2 \\
\hline 68.854 & $<0.05$ & 0.27 \\
\hline 69.792 & $<0.05$ & 0.09 \\
\hline 70.792 & $<0.05$ & 0.08 \\
\hline 71.792 & $<0.05$ & 0.11 \\
\hline 72.792 & 0.07 & 0.13 \\
\hline 75.792 & $<0.05$ & 0.1 \\
\hline 76.771 & $<0.05$ & 0.09 \\
\hline 77.771 & $<0.05$ & 0.12 \\
\hline 78.750 & $<0.05$ & 0.13 \\
\hline 80.917 & $<0.05$ & 0.17 \\
\hline 82.792 & $<0.05$ & 0.12 \\
\hline 83.958 & $<0.05$ & 0.28 \\
\hline
\end{tabular}


Table B. 10. (Continued)

\begin{tabular}{|c|c|c|}
\hline \multirow[b]{2}{*}{ Time (days) } & \multicolumn{2}{|c|}{ Bloreactor } \\
\hline & Control & Test \\
\hline 84.750 & $<0.05$ & 0.17 \\
\hline 85.750 & $<0.05$ & 0.15 \\
\hline 86.750 & 0.06 & 0.14 \\
\hline 89.771 & 0.05 & 0.11 \\
\hline 90.750 & $<0.05$ & 0.14 \\
\hline 91.771 & 0.21 & 0.20 \\
\hline 92.750 & 0.23 & 0.30 \\
\hline
\end{tabular}

aZinc concentrations in $\mathrm{mg} / \mathrm{L}$. 
Table B.11. Overa11 and Regional First-Order Rate Constants ${ }^{a}$ for Control and Test Bioreactors During Toxicity Experiment No. 2

\begin{tabular}{|c|c|c|c|c|c|c|c|c|c|c|c|c|c|}
\hline $\begin{array}{c}\text { Tim:e } \\
\text { (days) }\end{array}$ & Bioreactor & $f_{0}$ & $k_{0} \bar{t}_{0}$ & $\mathrm{~K}_{\mathrm{O}}$ & $\mathrm{f}_{1}$ & $\mathrm{k}_{1} \bar{t}_{1}$ & $\mathrm{~K}_{1}$ & $\mathrm{f}_{2}$ & $\mathrm{~K}_{2} \overline{\mathrm{t}}_{2}$ & $\mathrm{~K}_{2}$ & $\mathrm{f}_{3}$ & $\mathrm{~K}_{3} \bar{t}_{3}$ & $\mathrm{~K}_{3}$ \\
\hline \multirow{2}{*}{-1} & Control & 0.046 & 6.87 & 0.15 & 0.251 & 2.81 & 0.72 & 0.237 & 2.75 & 0.24 & 0.770 & 0.29 & 0.0093 \\
\hline & Test & 0.051 & 6.50 & 1.15 & 0.328 & 1.97 & 0.53 & 0.378 & 1.51 & 0.14 & 0.409 & 1.23 & 0.042 \\
\hline \multirow{2}{*}{5} & Control & 0.057 & 6.11 & 0.13 & 0.207 & 3.56 & 0.91 & 0.315 & 1.94 & 0.17 & 0.872 & 0.15 & 0.0048 \\
\hline & Test & 0.447 & 1.03 & 0.024 & 0.883 & 0.13 & 0.035 & 0.669 & 0.48 & 0.044 & 0.756 & 0.31 & 0.011 \\
\hline \multirow{2}{*}{24} & Control & 0.056 & 5.18 & 0.13 & 0.249 & 2.86 & 0.73 & 0.224 & 2.93 & 0.25 & 0.954 & 0.05 & 0.0016 \\
\hline & Test & 0.205 & 2.51 & 0.057 & 0.553 & 0.79 & 0.21 & 0.579 & 0.70 & 0.064 & 0.641 & 0.52 & 0.0018 \\
\hline \multirow{2}{*}{50} & Control & 0.47 & 6.79 & 0.15 & 0.336 & 1.90 & 0.49 & 0.159 & 4.17 & 0.36 & 0.888 & 0.12 & 0.0039 \\
\hline & Test & 0.113 & 4.00 & 0.091 & 0.577 & 0.72 & 0.19 & 0.358 & 1.63 & 0.15 & 0.545 & 0.75 & 0.026 \\
\hline \multirow{2}{*}{88} & Control & 0.035 & 7.90 & 0.17 & 0.235 & 3.06 & 0.78 & 0.203 & 3.26 & 0.28 & 0.734 & 0.35 & 0.011 \\
\hline & Test & 0.050 & 6.57 & 0.15 & 0.154 & 4.96 & 1.34 & 0.512 & 0.90 & 0.082 & 0.637 & 0.53 & 0.018 \\
\hline
\end{tabular}

${ }^{a}$ Calculated from the soluble chemical oxygen demand profiles (see Table B.2). 
APPENDIX C: DATA FOR TOXICITY EXPERIMENT NO. 3

Toxicity experiment No. 3 was a step increase in feed zinc concentration as follows:

$100 \mathrm{mg} / \mathrm{L}$ zinc, $100 \%$ soluble for $35 \mathrm{~d}$

$300 \mathrm{mg} / \mathrm{L}$ zinc, $100 \%$ soluble for $26 \mathrm{~d}$

$1000 \mathrm{mg} / \mathrm{L}$ zinc; $100 \%$ soluble for $13 \mathrm{~d}$

Time zero is taken as the time when the experiment. began with an influent zinc concentration of $100 \mathrm{mg} / \mathrm{L}$. 
Table C.1. Effluent Soluble Chemical Oxygen Demand for Control and Test Bioreactors During Toxicity Experiment No. 3

\begin{tabular}{|c|c|c|}
\hline Time (d) & $\begin{array}{c}\text { Control Bioreactor } \\
\text { COD (mg/L) }\end{array}$ & $\begin{array}{c}\text { Test Bioreactor } \\
\text { CoD (mg/L) }\end{array}$ \\
\hline-20.125 & 172 & 172 \\
\hline-19.125 & 170 & 175 \\
\hline-16.177 & 210 & 190 \\
\hline-15.177 & 165 & 160 \\
\hline-14.177 & 165 & 150 \\
\hline-12.156 & 146 & 146 \\
\hline-9.177 & 160 & 155 \\
\hline-7.177 & 194 & 194 \\
\hline-2.177 & 160 & 160 \\
\hline-1.177 & 175 & 170 \\
\hline 0.010 & 198 & 198 \\
\hline 0.844 & 186 & 186 \\
\hline 1.844 & 195 & 243 \\
\hline 2.885 & 135 & 223 \\
\hline 3.927 & 140 & 290 \\
\hline 5.802 & 151 & 331 \\
\hline 6.802 & 150 & 315 \\
\hline 7.802 & 150 & 315 \\
\hline 8.885 & 148 & 292 \\
\hline 9.958 & 148 & 340 \\
\hline 11.802 & 152 & 332 \\
\hline 12.802 & 150 & 335 \\
\hline 13.833 & 142 & 463 \\
\hline 14.854 & 138 & 379 \\
\hline 15.833 & 137 & 436 \\
\hline 18.906 & 161 & 526 \\
\hline 19.875 & 157 & 561 \\
\hline 20.833 & 145 & 854 \\
\hline 21.833 & 129 & 879 \\
\hline 22.833 & 130 & 958 \\
\hline 25.854 & 143 & 767 \\
\hline 26.875 & 138 & 773 \\
\hline 27.875 & 136 & 848 \\
\hline 28.875 & 134 & 803 \\
\hline 29.875 & 141 & 922 \\
\hline 32.938 & 147 & 793 \\
\hline $33.8 / 3$ & 169 & 810 \\
\hline 34.875 & 172 & 850 \\
\hline 35.875 & 163 & 802 \\
\hline 36.875 & 150 & 785 \\
\hline 39.875 & 165 & 776 \\
\hline 40.854 & 161 & 818 \\
\hline 41.854 & 154 & 879 \\
\hline
\end{tabular}


Table C.1. (Continued)

\begin{tabular}{lcc}
\hline Time (d) & $\begin{array}{r}\text { Control Bioreactor } \\
\text { COD (mg/L) }\end{array}$ & $\begin{array}{r}\text { Test } \\
\text { CoD (mg/L) }\end{array}$ \\
\hline 42.833 & 176 & 868 \\
45.000 & 159 & 855 \\
46.985 & 152 & 843 \\
48.063 & 144 & 881 \\
48.833 & 162 & 815 \\
49.833 & 167 & 840 \\
50.833 & 152 & 893 \\
53.854 & 154 & 884. \\
54.833 & 149 & 820 \\
55.854 & 113 & 887 \\
56.833 & 117 & 744 \\
57.854 & 133 & 835 \\
58.958 & 105 & 893 \\
60.844 & 117 & 912 \\
61.844 & 95 & 880 \\
62.854 & 100 & 920 \\
63.833 & 92 & 930 \\
64.833 & 100 & 1060 \\
65.958 & 114 & 1078 \\
67.792 & 103 & 1094 \\
68.833 & 111 & 1132 \\
69.844 & 100 & 1229 \\
70.854 & 91 & 960 \\
71.833 & 102 & 983 \\
72.917 & 107 & 1139 \\
73.958 & 132 & 1233 \\
\hline & & \\
\hline
\end{tabular}


Table C.2. Soluble Chemical Dxygen Demand, a Profiles for Control and Test Bioreactor During Toxicity Experiment No. 3

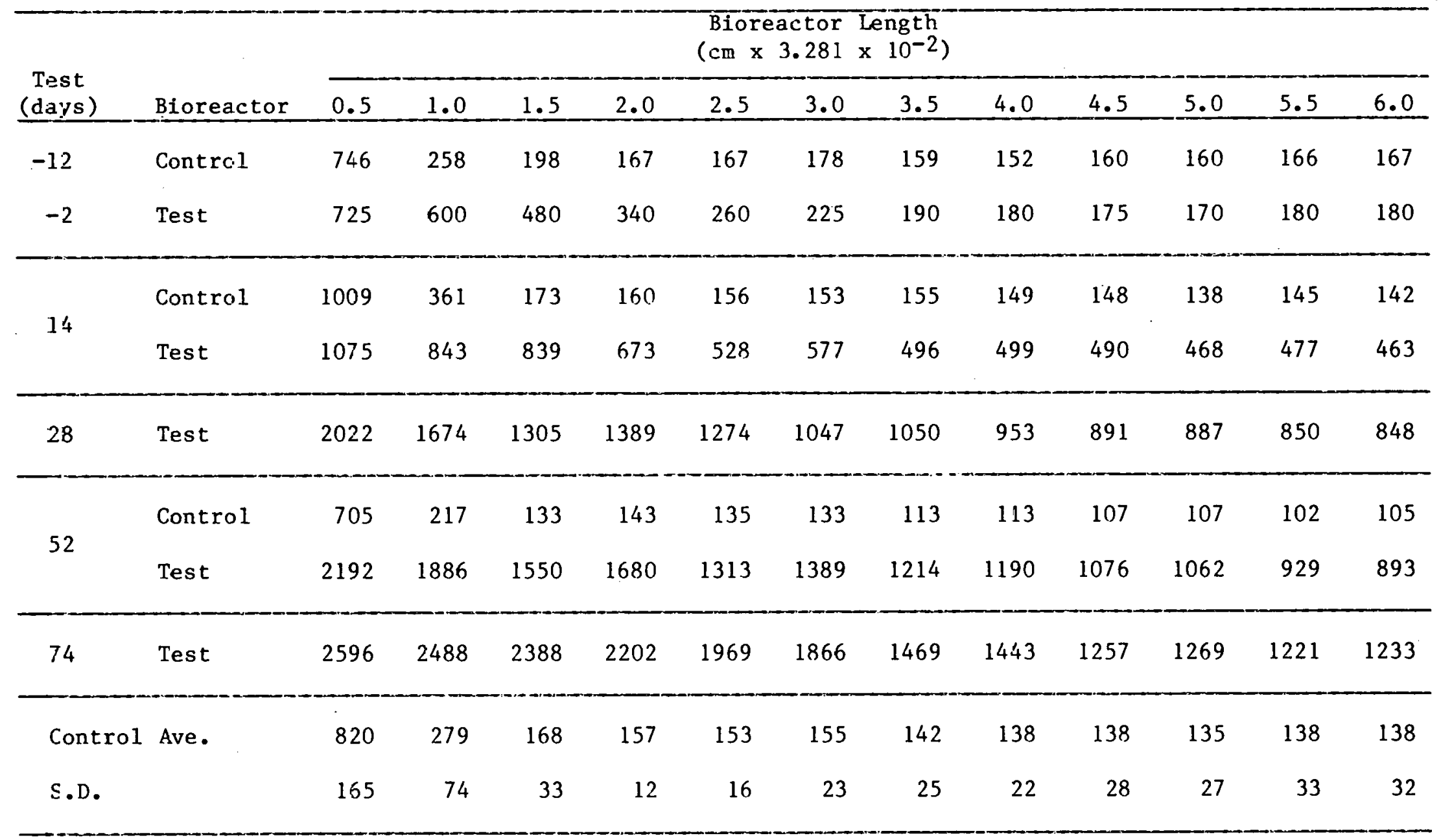

$\mathrm{a}_{\mathrm{COD}}$ concentrations are in $\mathrm{mg} / \mathrm{L}$. 
Table C.3. Cummulative Gas Production (Liters) for Control and Test Bioreactors During Toxicity Experiment No. 3

\begin{tabular}{|c|c|c|}
\hline Time (days) & Test Bioreactor & Control Bioreactor \\
\hline-18.972 & 0 & 0 \\
\hline-15.970 & 55.11 & 50.09 \\
\hline-15.050 & 73.75 & 67.05 \\
\hline-13.967 & 93.38 & 82.23 \\
\hline-12.985 & 108.62 & 99.49 \\
\hline-12.008 & 126.40 & 116.21 \\
\hline-11.194 & 151.85 & 140.01 \\
\hline-10.208 & 173.40 & 160.32 \\
\hline-8.981 & 188.51 & 174.77 \\
\hline-7.978 & 209.80 & 195.38 \\
\hline-6.945 & 229.61 & 214.81 \\
\hline-5.878 & 249.57 & 233.48 \\
\hline-4.983 & 268.38 & 251.21 \\
\hline-1.928 & 340.24 & 317.97 \\
\hline-0.875 & 370.94 & 345.95 \\
\hline 0.042 & 397.93 & 364.15 \\
\hline 0.826 & 420.05 & 385.10 \\
\hline 1.134 & 429.08 & 393.85 \\
\hline 1.792 & 446.36 & 410.62 \\
\hline 2.125 & 455.02 & 419.26 \\
\hline 2.896 & 473.15 & 437.90 \\
\hline 3.087 & 478.42 & 442.79 \\
\hline 3.917 & 498.74 & 463.52 \\
\hline 4.188 & 505.18 & 469.99 \\
\hline 5.795 & 538.30 & 505.80 \\
\hline 6.135 & 544.78 & 513.61 \\
\hline 6.795 & 558.71 & 529.99 \\
\hline 7.131 & 566.24 & 538.47 \\
\hline 7.797 & 581.30 & 554.50 \\
\hline 8.121 & 588.00 & 562.11 \\
\hline 8.837 & 602.34 & 578.29 \\
\hline 9.128 & 608.95 & 586.22 \\
\hline 9.951 & 627.92 & 607.18 \\
\hline 11.810 & 666.24 & 649.37 \\
\hline 12.128 & 671.94 & 656.17 \\
\hline 12.802 & 685.56 & 672.00 \\
\hline 13.135 & 692.51 & 680.16 \\
\hline 13.808 & 707.41 & 696.48 \\
\hline 14.125 & 713.60 & 704.03 \\
\hline 14.796 & 727.01 & 719.03 \\
\hline 15.129 & 733.14 & 726.35 \\
\hline 15.801 & 746.18 & 741.22 \\
\hline 16.128 & 752.26 & 751.26 \\
\hline 18.794 & 806.67 & 781.05 \\
\hline
\end{tabular}


Table C.3. (Continued)

\begin{tabular}{|c|c|c|}
\hline Time (days) & Test Bioreactor & Control Bioreactor \\
\hline 19.125 & 810.33 & 786.66 \\
\hline 19.801 & 819.99 & 792.11 \\
\hline 20.129 & 824.52 & 795.38 \\
\hline 20.795 & 835.38 & 809.17 \\
\hline 21.122 & 840.13 & 816.09 \\
\hline 21.794 & 851.37 & 830.95 \\
\hline 22.129 & 856.84 & 838.98 \\
\hline 22.792 & 869.87 & 855.07 \\
\hline 23.128 & 876.07 & 863.19 \\
\hline 25.795 & 933.43 & 909.55 \\
\hline 26.130 & 940.43 & 917.58 \\
\hline 26.795 & 953.40 & 934.45 \\
\hline 27.130 & 959.53 & 942.65 \\
\hline 27.797 & 972.89 & 959.66 \\
\hline 28.125 & 978.97 & 967.67 \\
\hline 28.795 & 991.09 & 983.89 \\
\hline 29.122 & 996.65 & 992.01 \\
\hline 29.796 & 1009.77 & 1002.16 \\
\hline 30.125 & 1015.57 & 1007.73 \\
\hline 32.796 & 1060.99 & 1070.89 \\
\hline 33.125 & 1066.19 & 1074.43 \\
\hline 33.795 & 1077.37 & 1087.94 \\
\hline 34.129 & 1082.66 & 1095.14 \\
\hline 34.795 & 1093.28 & 1109.65 \\
\hline 35.128 & 1098.38 & 1116.79 \\
\hline 35.796 & 1108.87 & 1130.93 \\
\hline 36.130 & 1114.03 & 1137.66 \\
\hline 36.794 & 1125.47 & 11.52 .41 \\
\hline 37.125 & 1131.09 & 1159.67 \\
\hline 39.794 & 1178.52 & 1222.53 \\
\hline 40.133 & 1183.65 & 1229.08 \\
\hline 40.792 & 1193.93 & 1243.38 \\
\hline 41.128 & 1198.89 & 1250.31 \\
\hline 41.797 & 1210.61 & 1265.65 \\
\hline 42.135 & 1216.40 & 1273.41 \\
\hline 42.792 & 1228.69 & 1288.81 \\
\hline 43.125 & 1234.15 & 1295.59 \\
\hline 44.939 & 1264.77 & 1337.33 \\
\hline 46.801 & 1296.27 & 1381.71 \\
\hline 47.137 & 1301.27 & 1389.42 \\
\hline 47.795 & 1311.81 & 1404.37 \\
\hline 48.128 & 1317.07 & 1411.83 \\
\hline 48.795 & 1329.31 & 1428.61 \\
\hline 49.128 & 1335.17 & 1436.66 \\
\hline 49.797 & 1347.66 & 1452.56 \\
\hline
\end{tabular}


Table C.3. (Continued)

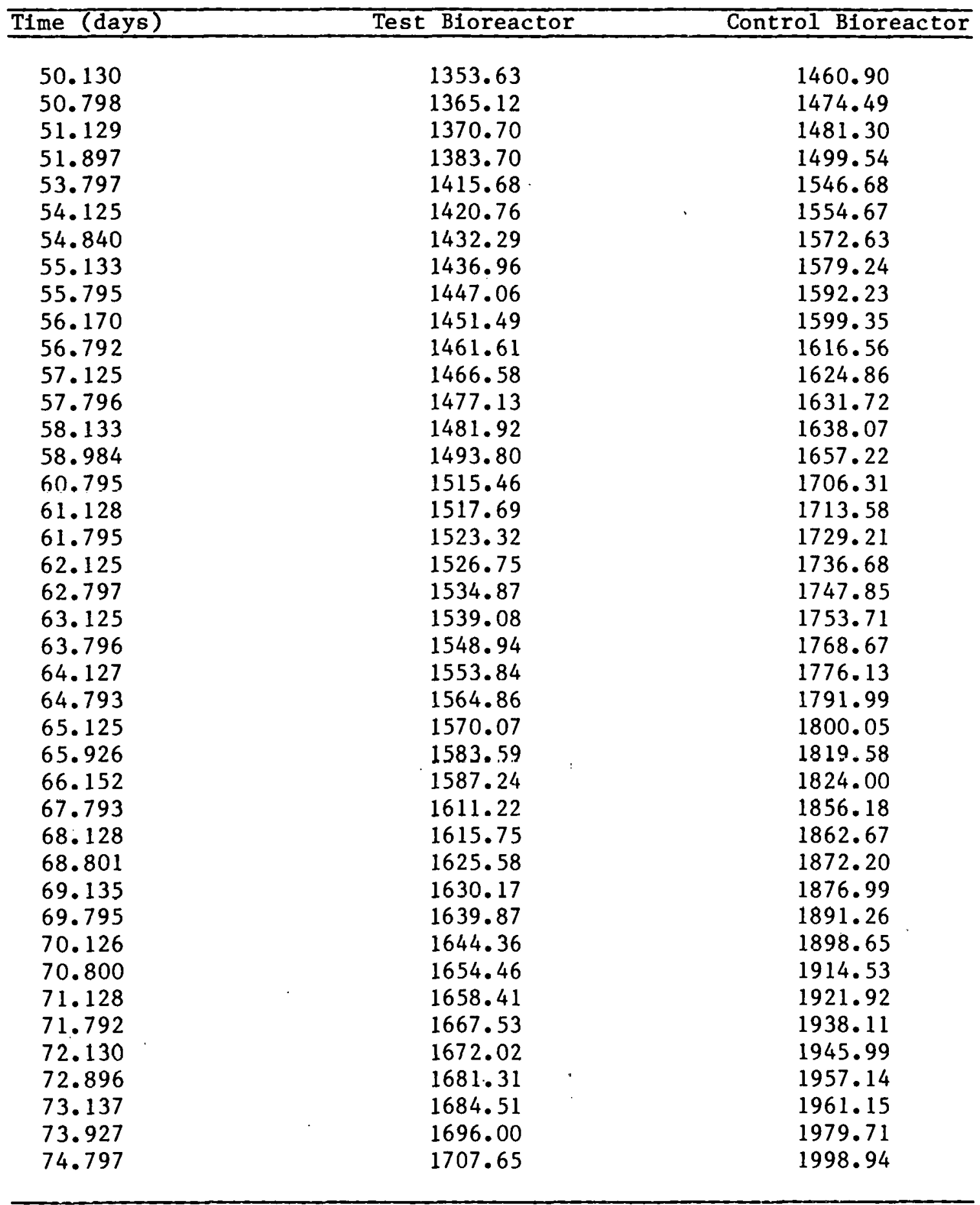


Table C.4. Total Gas Production Rates (Liters per Day) for Control and Test Bioreactors During Toxicity Experiment No. 3

\begin{tabular}{|c|c|c|c|}
\hline$\Delta t(\text { days })^{\mathrm{a}}$ & $t_{1 / 2}$ (days) $^{b}$ & Control Bioreactor & Test Bioreactor \\
\hline 3.0020 & $-17 \cdot 4710$ & 16.69 & 18.36 \\
\hline 0.9200 & -15.5100 & 18.43 & 20.26 \\
\hline 1.0830 & -47.5087 & 14.02 & 18.13 \\
\hline 0.9820 & -13.4785 & 17.58 & 15.52 \\
\hline 0.9770 & -12.4965 & 17.11 & 18.20 \\
\hline 0.8140 & -11.6010 & 29.24 & 31.27 \\
\hline 0.9860 & -10.7010 & 20.60 & 21.86 \\
\hline 1.2270 & -9.5945 & 11.78 & 12.31 \\
\hline 1.0030 & -8.4795 & 20.55 & 21.23 \\
\hline 1.0330 & -7.4615 & 18.81 & 19.18 \\
\hline 1.0670 & -6.4115 & 17.50 & 18.71 \\
\hline 0.8950 & -5.4305 & 19.81 & 21.02 \\
\hline 3.0550 & -3.4555 & 21.85 & 23.52 \\
\hline 1.0530 & -1.4015 & 26.57 & 29.15 \\
\hline 0.9170 & -0.4165 & 19.85 & 29.43 \\
\hline 0.7840 & 0.4340 & 26.72 & 28.21 \\
\hline 0.3080 & 0.9802 & 28.41 & 29.32 \\
\hline 0.6580 & 1.4630 & 25.49 & 26.26 \\
\hline 0.3330 & 1.9612 & 27.03 & 26.01 \\
\hline 0.7710 & 2.5105 & 24.18 & 23.51 \\
\hline 0.1910 & 2.9915 & 25.60 & 27.59 \\
\hline 0.8300 & 3.5020 & 24.98 & 24.48 \\
\hline 0.2710 & 4.0525 & 23.87 & 23.76 \\
\hline 1.6070 & 4.9915 & 22.28 & 20.61 \\
\hline 0.3400 & 5.9650 & 22.97 & 19.06 \\
\hline 0.6600 & 6.4680 & 24.82 & 21.11 \\
\hline 0.3360 & 6.9630 & 25.24 & 22.41 \\
\hline 0.6660 & 7.4640 & 24.07 & 22.61 \\
\hline 0.3240 & 7.9590 & 23.49 & 20.68 \\
\hline 0.7160 & 8.4790 & 22.60 & 20.03 \\
\hline 0.2910 & 8.9825 & 27.25 & 22.71 \\
\hline 0.8230 & 9.5395 & 25.47 & 23.05 \\
\hline 1.8590 & 10.8805 & 22.70 & 20.61 \\
\hline 0.3180 & 11.9640 & 21.38 & 17.92 \\
\hline 0.6740 & 12.4650 & 23.49 & 20.21 \\
\hline 0.3330 & 12.9685 & 24.50 & 20.87 \\
\hline 0.6730 & 13.4715 & 24.25 & 22.14 \\
\hline 0.3170 & 13.9930 & 23.82 & 19.53 \\
\hline 0.6710 & 14.4605 & 22.35 & 19.99 \\
\hline 0.3330 & 14.9625 & 21.98 & 18.41 \\
\hline 0.6720 & 15.4650 & 22.13 & 19.40 \\
\hline 0.3270 & 15.9645 & 30.70 & 18.59 \\
\hline 2.6660 & 17.4610 & 11.17 & 20.41 \\
\hline 0.3310 & 18.9595 & 16.95 & 11.06 \\
\hline
\end{tabular}


Table C.4. (Continued)

\begin{tabular}{|c|c|c|c|c|}
\hline$\overline{\Delta t \text { (days) }}$ & $t_{1 / 2}$ (days) & Control Bioreactor & Test & Bioreactor \\
\hline 0.6760 & $19.4630^{\circ}$ & 8.06 & & 14.29 \\
\hline 0.3280 & 19.9650 & 9.97 & & 13.81 \\
\hline 0.6660 & 20.4623 & 20.71 & & 16.31 \\
\hline 0.3270 & 20.9585 & 21.16 & & 14.53 \\
\hline 0.6720 & 21.4580 & 22.11 & & 16.73 \\
\hline 0.3350 & 21.9615 & 23.97 & & 16.33 \\
\hline 0.6630 & 22.4605 & 24.27 & & 19.65 \\
\hline 0.3360 & 22.9600 & 24.17 & & 18.45 \\
\hline 2.6670 & 24.4615 & 17.38 & & 21.51 \\
\hline 0.3350 & 25.9625 & 23.97 & & 20.90 \\
\hline 0.6650 & 26.4625 & 25.37 & & 19.53 \\
\hline 0.3350 & 26.9625 & 24.48 & & 18.30 \\
\hline 0.6670 & 27.4635 & 25.50 & & 20.03 \\
\hline 0.3280 & 27.9610 & 24.42 & & 18.54 \\
\hline 0.6700 & 28.4600 & 24.21 & & 18.09 \\
\hline 0.3270 & 28.9585 & 24.83 & & 17.00 \\
\hline 0.6740 & 29.4590 & 15.06 & & 19.47 \\
\hline 0.3290 & 29.9605 & 16.93 & . & 17.63 \\
\hline 2.6710 & 31.4605 & 23.65 & & 17.00 \\
\hline 0.3290 & 32.9605 & 10.76 & & 15.81 \\
\hline 0.6700 & 33.4600 & 20.16 & & 16.69 \\
\hline 0.3340 & 33.9620 & 21.56 & & 15.84 \\
\hline 0.6660 & 34.4620 & 21.79 & & 15.95 \\
\hline 0.3330 & 34.9615 & 21.44 & & 15.32 \\
\hline 0.6680 & 35.4620 & 21.17 & & 15.70 \\
\hline 0.3340 & 35.9630 & 20.15 & & 1.5 .45 \\
\hline 0.6640 & 36.4620 & 22.21 & & 17.23 \\
\hline 0.3310 & 36.9595 & 21.93 & & 16.98 \\
\hline 2.6690 & 38.4595 & 23.55 & & 17.77 \\
\hline 0.3390 & 39.9635 & 19.32 & & 15.13 \\
\hline 0.6590 & 40.4625 & 21.70 & & 15.60 \\
\hline 0.3360 & 40.9600 & 20.63 & & 14.70 \\
\hline 0.6690 & 41.4625 & 22.93 & & 17.52 \\
\hline 0.3380 & 41.9660 & 22.96 & & 17.13 \\
\hline 0.6570 & 42.4635 & 23.44 & & 18.71 \\
\hline 0.3330 & 42.9585 & 20.36 & & 16.40 \\
\hline 1.8140 & 44.0320 & 23.01 & & 16.88 \\
\hline 1.8620 & 45.8700 & 23.83 & & 16.92 \\
\hline 0.3360 & 46.9690 & 22.95 & & 14.88 \\
\hline 0.6580 & 47.4660 & 22.72 & & 16.02 \\
\hline 0.3330 & 47.9615 & 22.40 & & 15.80 \\
\hline 0.6670 & 48.4615 & 25.16 & & 18.35 \\
\hline 0.3330 & 48.9615 & 24.17 & & 17.60 \\
\hline 0.6690 & 49.4625 & 23.77 & & 18.67 \\
\hline 0.3330 & 49.9635 & 25.05 & & 17.93 \\
\hline
\end{tabular}


Table C.4. (Continued)

\begin{tabular}{|c|c|c|c|}
\hline$\overline{\Delta t \text { (days) }}$ & $t_{1 / 2}$ (days) & Control Bioreactor & Test Bioreactor \\
\hline 0.6680 & 50.4640 & 20.34 & 17.20 \\
\hline 0.3310 & 50.9635 & 20.57 & 16.86 \\
\hline 0.7680 & 51.5130 & 23.75 & 16.93 \\
\hline 1.9000 & 52.8470 & 24.81 & 16.83 \\
\hline 0.3280 & 53.9610 & 24.36 & 15.49 \\
\hline 0.7150 & 54.4825 & 25.12 & 16.13 \\
\hline 0.2930 & 54.9865 & 22.56 & 15.94 \\
\hline 0.6620 & 55.4640 & 19.62 & 15.26 \\
\hline 0.3750 & 55.9825 & 18.99 & 11.81 \\
\hline 0.6220 & 56.4810 & 27.67 & 16.27 \\
\hline 0.3330 & 56.9585 & 24.92 & 14.92 \\
\hline 0.6710 & 57.4605 & 10.22 & 15.72 \\
\hline 0.3370 & 57.9645 & 18.84 & 14.21 \\
\hline 0.8510 & 58.5585 & 22.50 & 13.96 \\
\hline 1.8110 & 59.8895 & 27.11 & 11.96 \\
\hline 0.3330 & 60.9615 & 21.83 & 6.70 \\
\hline 0.6670 & 61.4615 & 23.43 & 8.44 \\
\hline 0.3300 & 61.9600 & 22.64 & 10.39 \\
\hline 0.6720 & 62.4610 & 16.62 & 12.08 \\
\hline 0.3280 & 62.9610 & 17.87 & 12.84 \\
\hline 0.6710 & 63.4605 & 22.30 & 14.69 \\
\hline 0.3310 & 63.9615 & 22.54 & 14.80 \\
\hline 0.6660 & 64.4600 & 23.81 & 16.55 \\
\hline 0.3320 & 64.9590 & 24.28 & 18.70 \\
\hline 0.8010 & 65.5255 & 24.38 & 16.88 \\
\hline 0.2260 & 66.0390 & 19.56 & 16.15 \\
\hline 1.6410 & 67.3415 & 19.61 & 14.61 \\
\hline 0.3350 & 67.9605 & 19.37 & 13.52 \\
\hline 0.6730 & 68.4645 & 14.61 & 14.61 \\
\hline 0.3340 & 68.9680 & 14.34 & 13.74 \\
\hline 0.6600 & 69.4650 & 21.62 & 14.70 \\
\hline 0.3310 & 69.9605 & 22.33 & 13.56 \\
\hline 0.6740 & 70.4630 & 23.56 & 14.99 \\
\hline 0.3280 & 70.9640 & 22.53 & 12.04 \\
\hline 0.6640 & 71.4600 & 24.38 & 13.73 \\
\hline 0.3380 & 71.9610 & 23.31 & 13.28 \\
\hline 0.7660 & 72.5130 & 14.56 & 12.13 \\
\hline 0.2410 & 73.0165 & 16.64 & 13.28 \\
\hline 0.7900 & 73.5320 & 23.49 & 14.54 \\
\hline $0.870 n$ & 74.3620 & 22.10 & 13.39 \\
\hline
\end{tabular}

$a_{\Delta t}=t_{2}-t_{1} ; t_{1}$ and $t_{2}$ were obtained from Table c.3.

$b_{t_{1 / 2}}=\left(t_{2}+t_{1}\right) / 2$. 
Table C.5. Gas Percentages in of $f$-Gas for Control and Test Bioreactors During Toxicity Experiment No. 3

\begin{tabular}{|c|c|c|c|c|c|c|}
\hline \multirow{2}{*}{ Time (days) } & \multicolumn{3}{|c|}{ Control Bioreactor } & \multicolumn{3}{|c|}{ Test Bioreactor } \\
\hline & $\%$ Air & $\% \mathrm{CH}_{4}$ & $\% \mathrm{CO}_{2}$ & $\%$ Air & $\% \mathrm{CH}_{4}$ & $\% \mathrm{CO}_{2}$ \\
\hline-19.146 & 3.0 & 76.9 & 20.1 & 3.1 & 75.2 & 21.7 \\
\hline-15.979 & 3.1 & 78.2 & 18.7 & 1.4 & 71.0 & 27.6 \\
\hline-15.146 & 3.0 & 77.0 & 20.0 & 2.8 & 75.9 & 21.3 \\
\hline-14.167 & 3.2 & 75.4 & 21.3 & 2.6 & 74.9 & 22.4 \\
\hline-13.135 & 3.6 & 75.7 & 20.7 & 3.1 & 75.1 & 21.8 \\
\hline-12.042 & 2.9 & 78.3 & 18.8 & 2.7 & 77.2 & 20.1 \\
\hline-9.167 & 2.5 & 74.8 & 22.7 & 3.7 & 73.4 & 22.9 \\
\hline-8.146 & 2.8 & 73.5 & 23.7 & 2.9 & 73.1 & 24.0 \\
\hline-7.125 & 2.8 & 74.8 & 22.7 & 3.7 & 73.4 & 22.9 \\
\hline-6.146 & 4.2 & 75.9 & 20.0 & 2.7 & 76.1 & 21.2 \\
\hline-5.156 & 3.6 & 74.0 & 22.4 & 2.4 & 74.6 & 23.0 \\
\hline-2.156 & 2.6 & 74.2 & 23.3 & 4.4 & 72.8 & 22.8 \\
\hline-1.063 & 2.1 & 73.3 & 24.6 & 2.4 & 72.3 & 25.3 \\
\hline 0.042 & 2.5 & 71.6 & 25.8 & 3.9 & 69.9 & 26.2 \\
\hline 0.885 & 5.0 & 71.0 & 24.0 & 5.4 & 69.9 & 24.7 \\
\hline 1.875 & 3.4 & 71.0 & 25.7 & 3.0 & 70.5 & 26.5 \\
\hline 5.844 & 1.9 & 74.6 & 23.5 & 2.4 & 71.3 & 26.3 \\
\hline 6.844 & 2.7 & 72.2 & 25.0 & 1.0 & 71.2 & 27.8 \\
\hline 7.854 & 1.6 & 73.5 & 24.9 & 1.6 & 71.0 & 27.4 \\
\hline 8.885 & 2.7 & 74.3 & 23.0 & 4.1 & 70.9 & 25.0 \\
\hline 11.854 & 3.8 & 74.0 & 22.0 & 3.7 & 71.9 & 24.0 \\
\hline 12.882 & 2.0 & 74.1 & 23.9 & 2.3 & 70.4 & 27.3 \\
\hline 13.879 & 4.0 & 71.0 & 25 & 3.1 & 69.6 & 27.3 \\
\hline 14.897 & 2.4 & 74.0 & 23.6 & 3.1 & 70.1 & 26.7 \\
\hline 15.948 & 3.5 & 73.8 & 22.7 & 2.6 & 70.6 & 26.8 \\
\hline 19.080 & 3.8 & 76.0 & 20.2 & 6.1 & 73.1 & 20.8 \\
\hline 19.923 & 3.8 & 76.7 & 19.5 & 2.8 & 75.7 & 21.5 \\
\hline 21.027 & 2.5 & 78.0 & 19.5 & 2.5 & 72.9 & 24.6 \\
\hline 21.987 & 2.7 & 77.4 & 19.9 & 3.1 & 71.5 & 25.4 \\
\hline 22.014 & 2.5 & 74.9 & 22.5 & 1.9 & 68.9 & 29.2 \\
\hline 25.909 & 1.4 & 70.6 & 28.0 & 2.1 & 65.0 & 32.9 \\
\hline 26.914 & 2.3 & 72.8 & 24.9 & 1.6 & 72.4 & 26.0 \\
\hline 27.978 & 1.7 & 73.1 & 25.2 & 3.7 & 67.8 & 28.5 \\
\hline 28.876 & 2.6 & 75.4 & 22.0 & 2.2 & 71.0 & 26.8 \\
\hline 29.919 & 3.1 & 72.8 & 24.1 & 2.4 & 70.0 & 27.6 \\
\hline 32.958 & 2.0 & 74.0 & 24.0 & 1.3 & 71.0 & 27.6 \\
\hline 33.899 & 2.8 & 73.5 & 23.7 & 1.4 & 70.2 & 28.4 \\
\hline 34.862 & 1.7 & 75.5 & 22.8 & 1.7 & 70.0 & 28.3 \\
\hline 35.907 & 2.3 & 75.7 & 22.0 & 1.8 & 71.1 & 27.1 \\
\hline 36.875 & 1.8 & 75.0 & 23.2 & 1.8 & 68.2 & 30.0 \\
\hline 39.902 & 2.8 & 75.0 & 22.2 & 1.4 & 69.5 & 29.1 \\
\hline 40.877 & 2.2 & 76.7 & 21.1 & 1.6 & 70.0 & 28.4 \\
\hline 41.936 & 1.8 & 75.5 & 22.7 & 1.4 & 67.4 & 31.2 \\
\hline
\end{tabular}


Table C.5. (Continued)

\begin{tabular}{|c|c|c|c|c|c|c|}
\hline \multirow[b]{2}{*}{ Time (days) } & \multicolumn{3}{|c|}{ Control Bioreactor } & \multicolumn{3}{|c|}{ Test Bioreactor } \\
\hline & $\%$ Air & $\% \mathrm{CH}_{4}$ & $\% \mathrm{CO}_{2}$ & $\%$ Air & $\% \mathrm{CH}_{4}$ & $\% \mathrm{CO}_{2}$ \\
\hline 42.894 & 1.8 & 72.9 & 25.3 & 1.1 & 65.5 & 33.4 \\
\hline 45.000 & 1.9 & 72.7 & 25.4 & 2.1 & 64.4 & 33.5 \\
\hline 46.969 & 3.2 & 72.7 & 24.1 & 2.8 & 65.6 & 31.6 \\
\hline 47.991 & 2.4 & 73.0 & 24.7 & 1.0 & 66.4 & 32.6 \\
\hline 48.882 & 0.9 & 71.9 & 27.2 & 1.2 & 63.5 & 35.3 \\
\hline 49.881 & 1.0 & 71.9 & 27.1 & 1.2 & 62.8 & 36.0 \\
\hline 51.004 & 2.1 & 71.3 & 26.7 & 3.7 & 62.2 & 34.1 \\
\hline 53.882 & 1.6 & 72.2 & 26.2 & 1.9 & 63.9 & 34.2 \\
\hline 54.967 & 1.3 & 73.1 & 25.6 & 1.3 & 64.5 & 34.2 \\
\hline 55.911 & 1.8 & 72.8 & 25.4 & 2.0 & 63.2 & 34.8 \\
\hline 56.908 & 1.6 & 73.6 & 24.8 & 2.1 & 63.5 & 34.4 \\
\hline 57.936 & 2.5 & 73.2 & 24.3 & 1.5 & 66.0 & 32.5 \\
\hline 60.898 & 1.5 & 74.5 & 24.0 & 0 & 68.6 & 31.4 \\
\hline 61.904 & 1.5 & 73.9 & 24.6 & 2.4 & 65.7 & 31.9 \\
\hline 62.880 & 2.1 & 75.0 & 22.9 & 2.2 & 62.8 & 35.0 \\
\hline 63.867 & 1.6 & 74.9 & 23.5 & 1.6 & 61.6 & 36.8 \\
\hline 64.864 & 2.0 & 73.2 & 24.8 & 2.4 & 58.2 & 39.4 \\
\hline 65.983 & 2.2 & 72.7 & 25.1 & 1.1 & 57.3 & 41.6 \\
\hline 67.889 & 2.5 & 75.0 & 22.5 & 2.4 & 57.5 & 40.1 \\
\hline 68.853 & 3.0 & 73.3 & 23.7 & 1.4 & 57.2 & 41.4 \\
\hline 69.869 & 2.4 & 73.8 & 23.8 & 2.6 & 55.9 & 41.6 \\
\hline 70.874 & 3.4 & 71.6 & 25.0 & 0.8 & 55.9 & 43.3 \\
\hline 71.861 & 2.5 & 71.0 & 26.5 & 2.5 & 53.1 & 44.4 \\
\hline 72.938 & 0.9 & 73.8 & 25.3 & 2.0 & 55.1 & 42.9 \\
\hline 73.982 & 1.8 & 72.1 & 26.1 & 2.0 & 54.8 & 43.2 \\
\hline
\end{tabular}


Table C.6. Acetic Acid Profiles ${ }^{a}$ for Control and Test Bioreactors During Toxicity Experiment No. 3

\begin{tabular}{|c|c|c|c|c|c|c|c|c|c|c|c|c|c|}
\hline \multirow{2}{*}{$\begin{array}{c}\text { Time } \\
\text { (days) }\end{array}$} & \multirow[b]{2}{*}{ Bioreactor } & \multicolumn{12}{|c|}{$\begin{array}{c}\text { Bioreactor Length } \\
\left(\mathrm{cm} \times 3.281 \times 10^{-2}\right)\end{array}$} \\
\hline & & 0.5 & 1.0 & 1.5 & 2.0 & 2.5 & 3.0 & 3.5 & 4.0 & 4.5 & 5.0 & 5.5 & 6.0 \\
\hline-12 & Control & 107 & 37 & 22 & 7 & 10 & 11 & 2 & 0 & 0 & 0 & 0 & 0 \\
\hline-2 & Test & 232 & 201 & 115 & 104 & 85 & $40^{\circ}$ & 20 & 0 & 0 & 0 & 0 & 0 \\
\hline \multirow{2}{*}{14} & Control & 712 & 33 & 31 & 31 & 31 & 31 & 30 & 22 & 22 & 22 & 38 & 15 \\
\hline & Test & 764 & 573 & 407 & 276 & 296 & 289 & $291^{\circ}$ & 228 & 369 & 263 & 293 & 362 \\
\hline 28 & Test & 1201 & 759 & 938 & 839 & 787 & 602 & 538 & 458 & 445 & 422 & 469 & 417 \\
\hline \multirow{2}{*}{52} & Control & 468 & 380 & 87 & 40 & 16 & 0 & 0 & 0 & 0 & 0 & 0 & 0 \\
\hline & Test & 1315 & 1083 & 826 & 981 & 748 & 678 & 681 & 574 & 686 & 661 & 631 & 601 \\
\hline 74 & Test & 1073 & 1070 & 1050 & 1022 & 943 & 786 & 667 & 616 & 657 & 559 & 619 & 646 \\
\hline \multicolumn{2}{|c|}{ Control Ave. } & 429 & 150 & 47 & 26 & 19 & 14 & 11 & 7 & 7 & 7 & 13 & 5 \\
\hline S.D. & & 304 & 199 & 35 & 17 & 11 & 16 & 17 & 13 & 13 & 13 & 22 & 9 \\
\hline
\end{tabular}

${ }^{a}$ Acetic acid concentrations in $\mathrm{mg} / \mathrm{L}$; a value of zero is used to denote a nondetectable concentration. 
Table C.7. Propionic Acid Profiles ${ }^{a}$ for Control and Test Bioreactors During Toxicity Experiment No. 3

\begin{tabular}{|c|c|c|c|c|c|c|c|c|c|c|c|c|c|}
\hline \multirow{2}{*}{$\begin{array}{c}\text { Time } \\
\text { (days) }\end{array}$} & \multirow[b]{2}{*}{ Bioreactor } & \multicolumn{12}{|c|}{$\begin{array}{l}\text { Bioreactor Length } \\
\left(\mathrm{cm} \times 3.281 \times 10^{-2}\right)\end{array}$} \\
\hline & & 0.5 & 1.0 & 1.5 & 2.0 & 2.5 & 3.0 & 3.5 & 4.0 & 4.5 & 5.0 & 5.5 & 6.0 \\
\hline-12 & Control & 36 & 10 & 1 & 0 & 0 & 0 & 0 & 0 & 0 & 0 & 0 & 0 \\
\hline-2 & Test & 39 & 24 & 19 & 0 & 0 & 0 & 0 & 0 & 0 & 0 & 0 & 0 \\
\hline \multirow{2}{*}{14} & Control & 107 & 0 & 0 & 0 & 0 & 0 & 0 & 0 & 0 & 0 & 0 & 0 \\
\hline & Test & 94 & 112 & 72 & 54 & 51 & 73 & 57 & 75 & 60 & 53 & 53 & 68 \\
\hline 28 & Test & 184 & 153 & 163 & 168 & 158 & 137 & 124 & 115 & 105 & 104 & 104 & 102 \\
\hline \multirow{2}{*}{52} & Control & 64 & 43 & 0 & 0 & 0 & 0 & 0 & 0 & 0 & 0 & 0 & 0 \\
\hline & Test & 240 & 193 & 232 & 163 & 125 & 110 & 116 & 96 & 107 & 109 & 109 & 106 \\
\hline 74 & Test & 318 & 328 & 281 & 284 & 251 & 214 & 175 & 159 & 176 & 156 & 150 & 167 \\
\hline \multicolumn{2}{|c|}{ Control Ave. } & 69 & 15 & 0.3 & 0 & 0 & 0 & 0 & 0 & 0 & 0 & 0 & 0 \\
\hline \multicolumn{2}{|c|}{ S. D. } & 36 & 23 & 0.6 & 0 & 0 & 0 & 0 & 0 & 0 & 0 & 0 & 0 \\
\hline
\end{tabular}

apropionic acid concentrations in $\mathrm{mg} / \mathrm{L}$; a value of zero is used to denote a nondetectable concentration. 
Table C.8. Effluent $\mathrm{pH}$ and Alkalinity for Control and Test Bioreactors During Toxicity Experiment No. 3

\begin{tabular}{|c|c|c|c|c|c|c|}
\hline \multirow[b]{2}{*}{ Time (days) } & \multicolumn{3}{|c|}{ Control Bioreactor } & \multicolumn{3}{|c|}{ Test Bioreactor } \\
\hline & $\mathrm{pH}$ & $\begin{array}{l}\text { Alkalinity } \\
\text { (meq/L) }\end{array}$ & $\begin{array}{c}\text { Alkalinity } \\
\text { (mg/L as) } \\
\mathrm{CaCO}_{3}\end{array}$ & $\mathrm{pH}$ & $\begin{array}{l}\text { Alkalinity } \\
\text { (meq/L) }\end{array}$ & $\begin{array}{c}\text { Alkalinity } \\
\text { (mg/L as) } \\
\mathrm{CaCO}_{3}\end{array}$ \\
\hline-15.177 & - & 62.8 & 3140 & - & 61.0 & 3050 \\
\hline$-14 \cdot 177$ & 7.59 & - & - & 7.26 & - & - \\
\hline-13.177 & 7.52 & - & - & 7.25 & - & - \\
\hline-12.177 & 7.40 & - & - & 7.20 & - & - \\
\hline-9.177 & 7.47 & - & - & 7.18 & - & - \\
\hline-8.177 & 7.44 & 63.6 & 3180 & 4.34 & 62.0 & 3100 \\
\hline-7.177 & 7.39 & - & - & 7.23 & - & - \\
\hline-6.177 & 7.36 & - & - & 7.22 & - & - \\
\hline-5.177 & 7.67 & - & - & 7.30 & - & - \\
\hline-2.177 & 7.42 & - & - & 7.34 & - & - \\
\hline-1.177 & 7.63 & - & - & 7.40 & - & - \\
\hline 0.010 & 7.54 & - & - & 7.39 & - & - \\
\hline 0.844 & 7.50 & - & - & 7.36 & - & - \\
\hline 1.802 & 7.54 & - & - & 7.42 & - & - \\
\hline 2.885 & 7.63 & - & - & 7.43 & - & - \\
\hline 3.875 & 7.47 & - & - & 7.26 & - & - \\
\hline 5.802 & 7.46 & - & - & 7.26 & - & - \\
\hline 6.802 & 7.56 & - & - & 7.35 & - & - \\
\hline 7.802 & 7.49 & - & - & 7.40 & - & - \\
\hline 8.823 & 7.48 & - & - & 7.45 & - & - \\
\hline 9.823 & 7.50 & - & - & 7.36 & - & - \\
\hline 12.823 & 7.67 & - & - & 7.45 & - & $=$ \\
\hline 18.917 & 7.67 & - & - & 7.50 & - & - \\
\hline 19.885 & 7.78 & - & - & 7.53 & - & - \\
\hline 33.875 & 7.87 & 81.4 & 4070 & 7.53 & 75.0 & 3750 \\
\hline 40.854 & 7.87 & 82.4 & 4120 & 7.36 & 72.2 & 3610 \\
\hline 41.854 & 7.62 & 82.0 & 4100 & 7.46 & 72.3 & 3610 \\
\hline 42.833 & 7.62 & 81 & - & 7.44 & - & - \\
\hline 48.833 & 7.65 & - & - & 7.32 & 69.8 & 3490 \\
\hline 49.833 & 7.56 & 80 & 4000 & 7.33 & $=$ & - \\
\hline 53.854 & 7.64 & - & - & 7.17 & 67.2 & 3360 \\
\hline 55.854 & 7.64 & - & - & - & - & - \\
\hline 56.833 & - & - & - & - & 64.8 & 3240 \\
\hline 60.844 & 7.61 & - & - & 7.33 & - & - \\
\hline 61.833 & 7.60 & - & - & 7.40 & 65.6 & 3280 \\
\hline 62.854 & 7.63 & 78 & 3900 & 7.62 & 67.8 & 3390 \\
\hline 63.833 & 7.58 & 79 & 3950 & 7.23 & 65.2 & 3260 \\
\hline 64.833 & 7.56 & 80.2 & 4010 & 7.10 & 62.4 & 3120 \\
\hline 65.958 & 7.7 & 80 & 4000 & 7.074 & 59 & 2950 \\
\hline 67.813 & 7.69 & 80 & 4000 & 7.11 & 58 & 2900 \\
\hline
\end{tabular}


Table C. 8. (Continued)

\begin{tabular}{ccccccc}
\hline & & Control Bioreactor & & \multicolumn{2}{c}{ Test Bioreactor } \\
\cline { 2 - 7 } Time (days) & $\mathrm{pH}$ & $\begin{array}{c}\text { Alkalinity } \\
(\mathrm{meq} / \mathrm{L})\end{array}$ & $\begin{array}{c}\text { Alkalinity } \\
(\mathrm{mg} / \mathrm{L} \text { as }) \\
\mathrm{CaCO}_{3}\end{array}$ & $\mathrm{pH}$ & $\begin{array}{c}\text { Alkalinity } \\
(\mathrm{meq} / \mathrm{L})\end{array}$ & $\begin{array}{c}\text { Alkalinity } \\
(\mathrm{mg} / \mathrm{L} \text { as } \\
\mathrm{CaCO}_{3}\end{array}$ \\
\hline 68.833 & 7.64 & 76 & 3800 & 7.05 & 57.6 & 2880 \\
69.884 & 7.60 & 76 & 3800 & 7.00 & 57 & 2850 \\
70.854 & - & - & - & 7.01 & 57.2 & 2860 \\
71.833 & - & - & - & 7.05 & 56 & - \\
72.917 & - & - & - & 7.00 & - & 2800 \\
\hline
\end{tabular}


Table C.9. Soluble Zinc Profiles for Test Bioreactor During Toxicity

Experiment No. $3^{a}$

\begin{tabular}{|c|c|c|c|c|c|c|c|c|c|c|c|c|c|c|}
\hline \multirow{2}{*}{$\begin{array}{c}\text { Influent } \\
\text { Zn } \\
(\mathrm{mg} / \mathrm{L})\end{array}$} & \multirow{2}{*}{$\begin{array}{l}\text { Time } \\
\text { (days) }\end{array}$} & \multirow{2}{*}{$\begin{array}{l}\text { Conc. } \\
\text { Units }\end{array}$} & \multicolumn{12}{|c|}{$\begin{array}{c}\text { Bioreactor Length } \\
\left(\mathrm{cm} \times 3.281 \times 10^{-2}\right)\end{array}$} \\
\hline & & & 0.5 & 1.0 & 1.5 & 2.0 & 2.5 & 3.0 & 3.5 & 4.0 & 4.5 & 5.0 & 5.5 & 6.0 \\
\hline \multirow{4}{*}{100} & \multirow{2}{*}{14} & $\mathrm{mg} / \mathrm{L}$ & 21.8 & 7.3 & 11.1 & 4.4 & 3.0 & 4.6 & 3.0 & 2.5 & 2.5 & 1.9 & 2.0 & 1.9 \\
\hline & & $\%$ & 21.8 & 7.3 & 11.1 & 4.4 & 3.0 & 4.6 & 3.0 & 2.5 & 2.5 & 1.9 & 2.0 & 1.9 \\
\hline & \multirow{2}{*}{23} & $\mathrm{mg} / \mathrm{L}$ & 34.3 & 29.0 & 17.0 & 13.7 & 18.7 & 10.8 & 10.3 & 7.5 & 5.9 & 4.9 & 5.5 & 5.1 \\
\hline & & $\%$ & 34.3 & 29.0 & 17.0 & 18.7 & 18.7 & 10.3 & 10.3 & 7.5 & 5.9 & $4.9^{\prime}$ & 5.5 & 5.1 \\
\hline \multirow{2}{*}{300} & \multirow{2}{*}{17} & $\mathrm{mg} / \mathrm{L}$ & 147.3 & 101.9 & 75.4 & 94.4 & 60.3 & 49.3 & 43.8 & 39.9 & 34.8 & 35.9 & 32.6 & 33.3 \\
\hline & & $\%$ & 49.1 & 34.0 & 25.1 & 31.5 & 20.3 & 16.4 & 14.6 & 13.3 & 11.6 & 12.0 & 10.9 & 11.1 \\
\hline \multirow{2}{*}{1000} & \multirow{2}{*}{13} & $\mathrm{mg} / \mathrm{L}$ & 736.1 & 596.4 & 413.0 & 424.5 & 387.6 & 262.9 & 246.3 & 200.0 & 158.2 & 160.0 & 172.0 & 141.0 \\
\hline & & $\%$ & 73.6 & 59.6 & 41.3 & 42.5 & 38.8 & 26.3 & 24.6 & 20.0 & 15.8 & 16.0 & 17.2 & 14.1 \\
\hline
\end{tabular}

a Time $=0$, at the beginning of the feeding of the particular zinc concentration (i.e., 100, 300, and $1000 \mathrm{mg} / \mathrm{L})$; concentration in \% relative to zinc concentration in feed. 
Table C.10. Effluent Dissolved Zinc for Control and Test Bioreactors During Toxicity Experiment No. $3^{a}$

\begin{tabular}{|c|c|c|}
\hline Time (days) & Control Bioreactor & Test Bioreactor \\
\hline$-19 \cdot 177$ & $<0.05$ & $<0.05$ \\
\hline-16.177 & 0.1 & $<0.05$ \\
\hline-15.177 & $<0.05$ & $<0.05$ \\
\hline-13.177 & $<0.05$ & $<0.05$ \\
\hline-0.156 & 0.1 & $<0.05$ \\
\hline 2.073 & 0.5 & 5.2 \\
\hline 2.906 & 0.1 & 9.9 \\
\hline 3.927 & $<0.05$ & 2.9 \\
\hline 5.896 & 0.2 & 6.5 \\
\hline 6.896 & $<0.05$ & 2.5 \\
\hline 7.833 & 0.1 & 2.4 \\
\hline 8.885 & 0.2 & 2.3 \\
\hline 9.958 & 0.5 & 2.8 \\
\hline 11.177 & 0.2 & 1.6 \\
\hline 12.177 & 0.2 & $1.6(2.4)$ \\
\hline 13.833 & 0.1 & 1.9 \\
\hline 14.854 & 0.1 & 1.8 \\
\hline 18.906 & 0.1 & 2.4 \\
\hline 19.875 & 0.1 & 2.2 \\
\hline 20.833 & 0.2 & 3.7 \\
\hline 21.833 & $<0.05$ & 4.1 \\
\hline 22.833 & 0.1 & $2.4(3.0)$ \\
\hline 25.854 & $<0.05$ & $4.0(5.1)$ \\
\hline 26.875 & $<0.05$ & 4.2 \\
\hline 27.875 & 0.1 & 5.1 \\
\hline 28.875 & 0.2 & 7.0 \\
\hline 29.87 .5 & 0.1 & 5.8 \\
\hline 32.958 & $<0.05$ & 5.9 \\
\hline 33.875 & $<0.05$ & 6.4 \\
\hline 34.875 & $<0.05$ & 6.8 \\
\hline 35.875 & $<0.05$ & 9.0 \\
\hline 36.875 & 0.1 & 13.4 \\
\hline 39.875 & $<0.05$ & 15.3 \\
\hline 40.854 & $<0.05$ & 20.2 \\
\hline 41.854 & $<0.05$ & 24.0 \\
\hline 42.833 & $<0.05$ & 21.3 \\
\hline 45.000 & $<0.05$ & 26.5 \\
\hline 46.875 & $<0.05$ & 24.8 \\
\hline 48.063 & $<0.05$ & 26.5 \\
\hline 48.833 & $<0.05$ & 28.3 \\
\hline 49.833 & $<0.05$ & $29.5(33.2)$ \\
\hline 50.833 & 0.1 & 27.4 \\
\hline 53.979 & 0.1 & 31.2 \\
\hline 33 & $<0.05$ & 28.8 \\
\hline
\end{tabular}


Table C.10. (Continued)

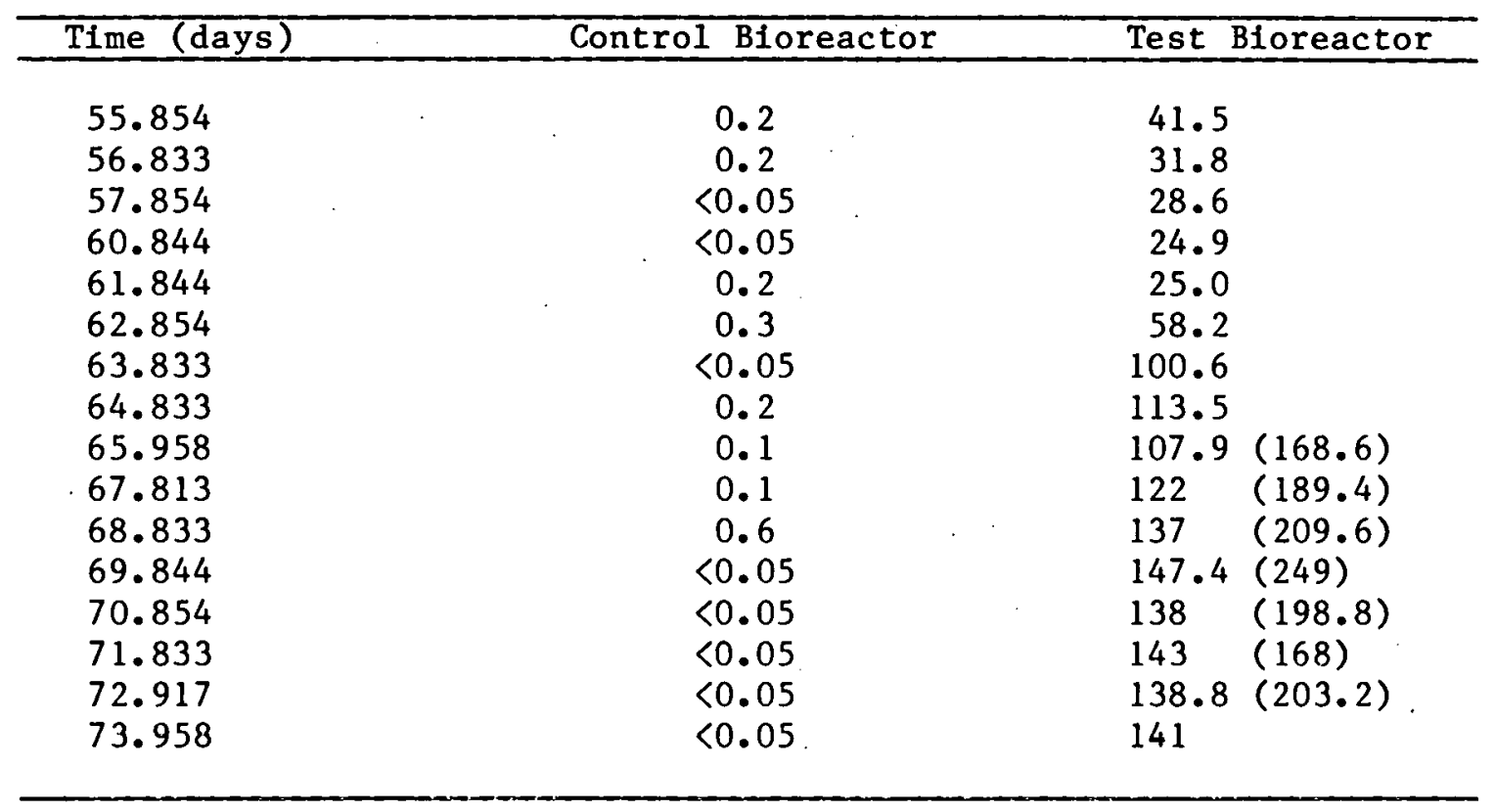

a Numbers in parenthesis represent the total zinc concentration for that sample; concentrations are in $\mathrm{mg} / \mathrm{L}$. 
Table C.11. First Order Rate Constants ${ }^{a}$ for Control and Test Bioreactors During Toxicity Experiment No. 3

\begin{tabular}{|c|c|c|c|c|c|c|}
\hline \multirow[b]{2}{*}{ Time (days) } & \multicolumn{3}{|c|}{ Control Reactorb } & \multicolumn{3}{|c|}{ Test Bioreactorc } \\
\hline & $f_{o}$ & $k_{o} \bar{t}_{o}$ & $K_{0}\left(h^{-1}\right)$ & $f_{o}$ & $\mathrm{~K}_{0} \bar{t}_{0}$ & $\mathrm{~K}_{0}\left(\mathrm{~h}^{-1}\right)$ \\
\hline-20.125 & 0.057 & 6.11 & 0.13 & 0.057 & 6.95 & 0.17 \\
\hline-19.125 & 0.057 & 6.11 & 0.13 & 0.058 & 6.88 & 0.17 \\
\hline-16.177 & 0.070 & 5.43 & 0.12 & 0.063 & 6.54 & 0.16 \\
\hline-15.177 & 0.055 & 6.24 & 0.13 & 0.053 & 7.25 & 0.18 \\
\hline-14.177 & 0.055 & 6.24 & 0.13 & 0.050 & 7.50 & 0.18 \\
\hline-12.156 & 0.049 & 6.64 & 0.14 & 0.049 & 7.59 & 0.19 \\
\hline-9.177 & 0.053 & 6.37 & 0.14 & 0.052 & 7.34 & 0.18 \\
\hline-7.177 & 0.065 & 5.67 & 0.12 & 0.065 & 6.42 & 0.16 \\
\hline-2.177 & 0.053 & 6.37 & 0.14 & 0.053 & 7.25 & 0.18 \\
\hline-1.177 & 0.058 & 6.06 & 0.13 & 0.057 & 6.95 & 0.17 \\
\hline 0.010 & 0.066 & 5.62 & 0.12 & 0.066 & 6.36 & 0.16 \\
\hline 0.844 & 0.062 & 5.83 & 0.13 & 0.062 & 6.61 & 0.16 \\
\hline 1.844 & 0.065 & 5.67 & 0.12 & 0.081 & 5.57 & 0.14 \\
\hline 2.885 & 0.045 & 6.95 & 0.15 & 0.074 & 5.91 & 0.14 \\
\hline 3.927 & 0.047 & 6.79 & 0.15 & 0.097 & 4.93 & 0.12 \\
\hline 5.802 & 0.050 & 6.57 & 0.14 & 0.110 & 4.51 & 0.11 \\
\hline 6.802 & 0.050 & 6.57 & 0.14 & 0.105 & 4.66 & 0.11 \\
\hline 7.802 & 0.050 & 6.57 & 0.14 & 0.105 & 4.66 & 0.11 \\
\hline 8.885 & 0.049 & 6.64 & 0.14 & 0.097 & 4.93 & 0.12 \\
\hline 9.958 & 0.049 & 6.64 & 0.14 & 0.113 & 4.42 & 0.11 \\
\hline 11.802 & 0.051 & 6.50 & 0.14 & 0.111 & 4.48 & 0.11 \\
\hline 12.802 & 0.050 & 6.57 & 0.14 & 0.112 & 4.45 & 0.11 \\
\hline 13.833 & 0.047 & 6.79 & 0.15 & 0.154 & 3.47 & 0.085 \\
\hline 14.854 & 0.046 & 6.87 & 0.15 & 0.126 & 4.07 & 0.10 \\
\hline 15.833 & 0.046 & 6.87 & 0.15 & 0.145 & 3.65 & 0.089 \\
\hline 18.906 & 0.054 & 6.30 & 0.14 & 0.175 & 3.12 & 0.076 \\
\hline 19.875 & 0.052 & 6.43 & 0.14 & 0.187 & 2.94 & 0.072 \\
\hline 20.833 & 0.048 & 6.72 & 0.14 & 0.285 & 1.93 & 0.047 \\
\hline 21.833 & 0.043 & 7.12 & 0.15 & 0.293 & 1.87 & 0.046 \\
\hline 22.833 & 0.043 & 7.12 & 0.15 & 0.319 & 1.69 & 0.041 \\
\hline 25.854 & 0.048 & 6.72 & 0.14 & 0.256 & 2.17 & 0.053 \\
\hline 26.875 & 0.046 & 6.87 & 0.15 & 0.258 & 2.15 & 0.053 \\
\hline 27.875 & 0.045 & 6.95 & 0.15 & 0.283 & 1.95 & 0.048 \\
\hline 28.875 & 0.045 & 6.95 & 0.15 & 0.268 & 2.07 & 0.051 \\
\hline 29.875 & 0.047 & 6.79 & 0.15 & 0.307 & 1.77 & 0.043 \\
\hline 32.938 & 0.049 & 6.64 & 0.14 & 0.264 & 2.10 & 0.051 \\
\hline 33.875 & 0.056 & 6.18 & 0.13 & 0.270 & 2.05 & 0.050 \\
\hline 34.875 & 0.057 & 6.11 & 0.13 & 0.283 & 1.95 & 0.048 \\
\hline 35.875 & 0.054 & 6.30 & 0.14 & 0.267 & 2.07 & 0.051 \\
\hline 36.875 & 0.050 & 6.57 & 0.14 & 0.262 & 2.12 & 0.052 \\
\hline 39.875 & 0.055 & 6.24 & 0.13 & 0.259 & 2.14 & 0.052 \\
\hline 40.854 & 0.054 & 6.30 & 0.14 & 0.273 & 2.02 & 0.049 \\
\hline
\end{tabular}


Table C.11. (Continued)

\begin{tabular}{|c|c|c|c|c|c|c|c|}
\hline \multirow[b]{2}{*}{ Time (days) } & \multicolumn{4}{|c|}{ Control Bioreactor } & \multicolumn{3}{|c|}{ Test Bioreactor } \\
\hline & $f_{0}$ & $k_{o} \bar{t}_{o}$ & $k_{0}$ & $\left(h^{-1}\right)$ & $\mathbf{f}_{\mathrm{o}}$ & $k_{0} \bar{t}_{0}$ & $\mathrm{~K}_{0}\left(\mathrm{~h}^{-1}\right)$ \\
\hline 41.854 & 0.051 & 6.50 & & 0.14 & 0.293 & 1.87 & 0.046 \\
\hline 42.833 & 0.059 & 6.00 & & 0.13 & 0.289 & 1.90 & 0.046 \\
\hline 45.000 & 0.053 & 6.37 & & 0.14 & 0.285 & 1.93 & 0.047 \\
\hline 46.875 & 0.051 & 6.50 & & 0.14 & 0.281 & 1.96 & 0.048 \\
\hline 48.063 & 0.048 & 6.72 & & 0.14 & 0.294 & 1.86 & 0.045 \\
\hline 48.833 & 0.054 & 6.30 & & 0.14 & 0.272 & 2.03 & 0.050 \\
\hline $49.833^{\circ}$ & 0.056 & 6.18 & & 0.13 & 0.280 & 1.97 & 0.048 \\
\hline 50.833 & 0.051 & 6.50 & & 0.14 & 0.298 & 1.84 & 0.045 \\
\hline 53.854 & 0.051 & 6.50 & & 0.14 & 0.295 & 1.86 & 0.045 \\
\hline 54.833 & 0.050 & 6.57 & & 0.14 & 0.273 & $\therefore \quad 2.02$ & 0.049 \\
\hline 55.854 & 0.038 & 7.58 & & 0.16 & 0.296 & 1.85 & 0.045 \\
\hline 56.833 & 0.039 & 7.49 & & 0.16 & 0.248 & 2.24 & 0.055 \\
\hline 57.854 & 0.044 & 7.03 & & 0.15 & 0.278 & 1.98 & 0.048 \\
\hline 58.958 & 0.035 & 7.90 & & 0.17 & 0.298 & 1.84 & 0.045 \\
\hline 60.844 & 0.039 & 7.49 & & 0.16 & 0.304 & 1.79 & 0.044 \\
\hline 61.844 & 0.032 & 8.26 & & 0.18 & 0.293 & 1.87 & 0.046. \\
\hline 62.854 & 0.033 & 8.13 & & 0.17 & 0.307 & 1.77 & 0.043 \\
\hline 63.833 & 0.031 & 8.38 & & 0.18 & 0.310 & 1.75 & 0.043 \\
\hline 64.833 & 0.033 & 8.13 & & 0.17 & 0.353 & 1.49 & 0.036 \\
\hline 65.958 & 0.038 & 7.58 & & 0.16 & 0.359 & 1.46 & 0.036 \\
\hline 67.792 & 0.034 & 8.02 & & 0.17 & 0.365 & 1.43 & 0.035 \\
\hline 68.833 & 0.037 & 7.69 & & 0.17 & 0.377 & 1.37 & 0.033 \\
\hline 69.844 & 0.033 & 8.13 & & 0.17 & 0.410 & 1.22 & 0.030 \\
\hline 70.8 .54 & 0.0 .30 & 8.52 & & 0.18 & 0.320 & 1.69 & 0.041 \\
\hline 71.833 & 0.034 & 8.02 & & 0.17 & 0.328 & 1.64 & 0.040 \\
\hline 72.917 & 0.036 & 7.79 & & 0.17 & 0.380 & 1.34 & 0.033 \\
\hline 73.958 & 0.044 & 7.03 & & 0.15 & 0.411 & 1.21 & 0.030 \\
\hline
\end{tabular}

acalculated from effluent soluble COD (see Table C.1).

$b_{t_{o}}$ for control bioreactor $=46.6 \cdot \mathrm{h}$.

$\bar{c}_{t_{0}}$ for test bioreactor $=40.9 \mathrm{~h}$. 
Table C. 12. Global and Local First Order Rate Constantsa for Control and Test Bioreactors During Toxicity Experiment No. 3

\begin{tabular}{|c|c|c|c|c|c|c|c|c|c|c|c|c|c|}
\hline $\begin{array}{c}\text { Time } \\
\text { (days) }\end{array}$ & Bioreactor & $\mathrm{f}_{0}$ & $k_{0} \bar{t}_{0}$ & $\left(\mathrm{~h}^{-\mathrm{l}}\right)$ & $\mathrm{E}_{1}$ & $\mathrm{~K}_{1} \overline{\mathrm{t}}_{1}$ & $\frac{\mathrm{k}_{1}}{\left(\mathrm{~h}^{-1}\right)}$ & $\mathrm{f}_{2}$ & $\mathrm{~K}_{2} \overline{\mathrm{t}}_{2}$ & $\left(\mathrm{k}_{2}=1\right)$ & f 3 & $k_{3} \bar{t}_{3}$ & $\left(\mathrm{~h}^{-1}\right)$ \\
\hline-37 & Control & 0.046 & 6.87 & 0.15 & 0.251 & 2.81 & 0.72 & 0.237 & 2.75 & 0.24 & 0.770 & 0.29 & 0.0093 \\
\hline-2 & Test & 0.060 & 6.74 & 0.17 & 0.242 & 3.00 & 0.88 & 0.469 & 1.08 & 0.11 & 0.529 & 0.82 & 0.030 \\
\hline-30 & Control & 0.57 & 6.11 & 0.13 & 0.207 & 3.56 & 0.91 & 0.315 & 1.94 & 0.17 & 0.872 & 0.15 & 0.0048 \\
\hline 14 & Test & 0.154 & 3.47 & 0.085 & 0.353 & 1.75 & 0.51 & 0.626 & 0.58 & 0.057 & 0.688 & 0.43 & 0.016 \\
\hline-12 & Control & 0.056 & 6.18 & 0.13 & 0.249 & 2.86 & 0.73 & 0.224 & 2.93 & 0.25 & 0.954 & 0.05 & 0.0016 \\
\hline 28 & Test & 0.233 & 1.95 & 0.048 & 0.674 & 0.48 & 0.14 & 0.687 & 0.45 & 0.044 & 0.611 & 0.60 & 0.022 \\
\hline 14 & Cont rol & 0.047 & 6.79 & 0.15 & 0.336 & 1.90 & 0.49 & 0.159 & 4.17 & 0.36 & 0.888 & 0.12 & 0.0039 \\
\hline 52 & Test & 0.298 & 1.84 & 0.045 & 0.731 & 0.37 & 0.11 & 0.766 & 0.30 & 0.029 & 0.532 & 0.81 & 0.030 \\
\hline 52 & Control & 0.035 & 7.90 & 0.17 & 0.235 & 3.06 & 0.78 & 0.203 & 3.26 & 0.28 & 0.734 & 0.35 & 0.011 \\
\hline 74 & Test & 0.411 & 1.21 & 0.030 & 0.865 & 0.16 & 0.047 & 0.348 & 0.18 & 0.018 & 0.560 & 0.73 & 0.027 \\
\hline
\end{tabular}

acalculated from the soluble chenical oxygen denand profiles.

bValues for $K_{0}, K_{1}, K_{2}$, and $K_{3}$ are expressed in $h^{-1}$. 
Table C.13. Sorption Factors Profile for Test Bioreactor During Toxicity Experiment No. 3 Using a Feed Zinc Concentration of $100 \mathrm{mg} / \mathrm{L}$

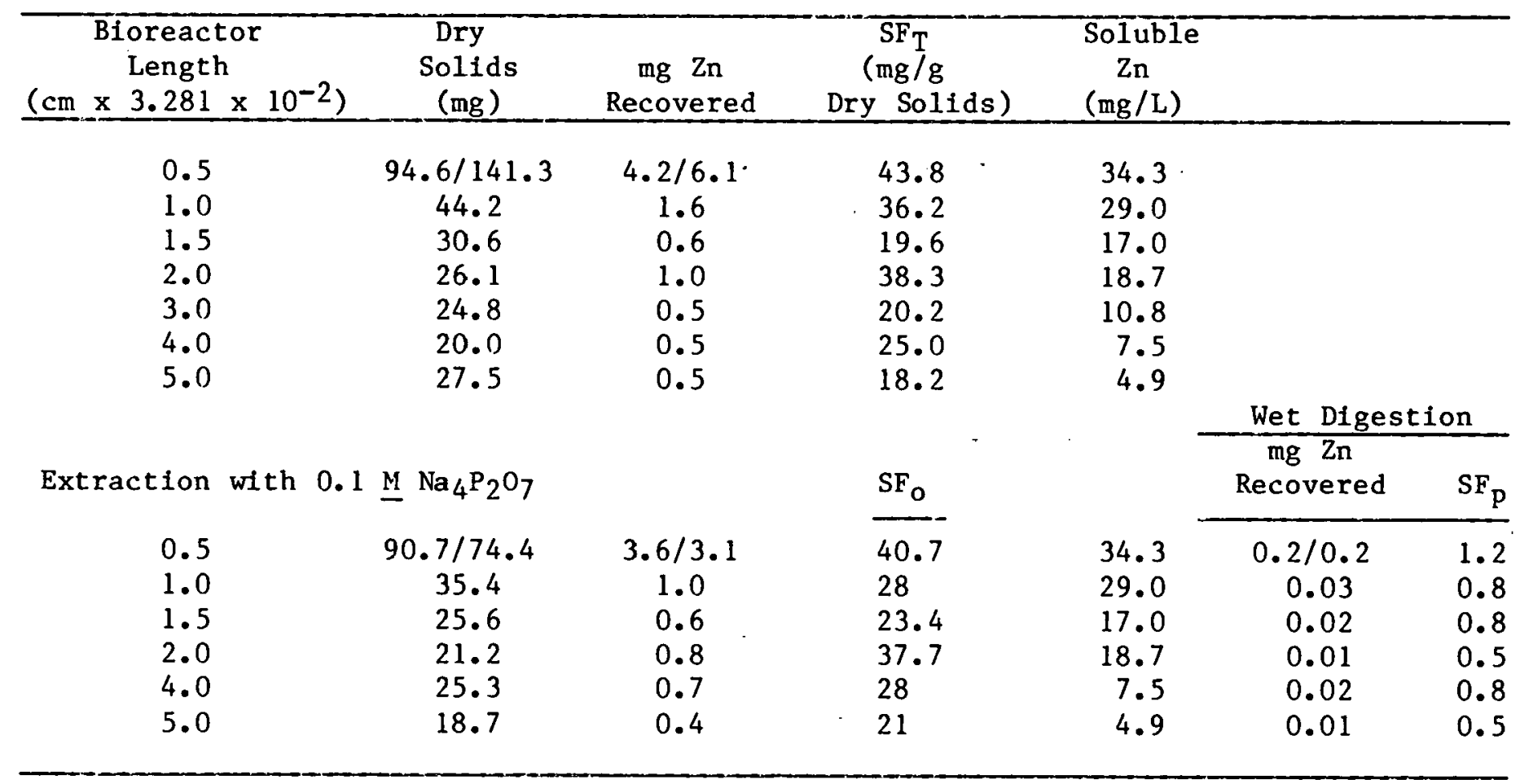


Table C.14. Sorption Factors Profile for Test Bioreactor During Toxicity Experiment No. 3 Using a Feed Zinc Concentration of $300 \mathrm{mg} / \mathrm{L}$

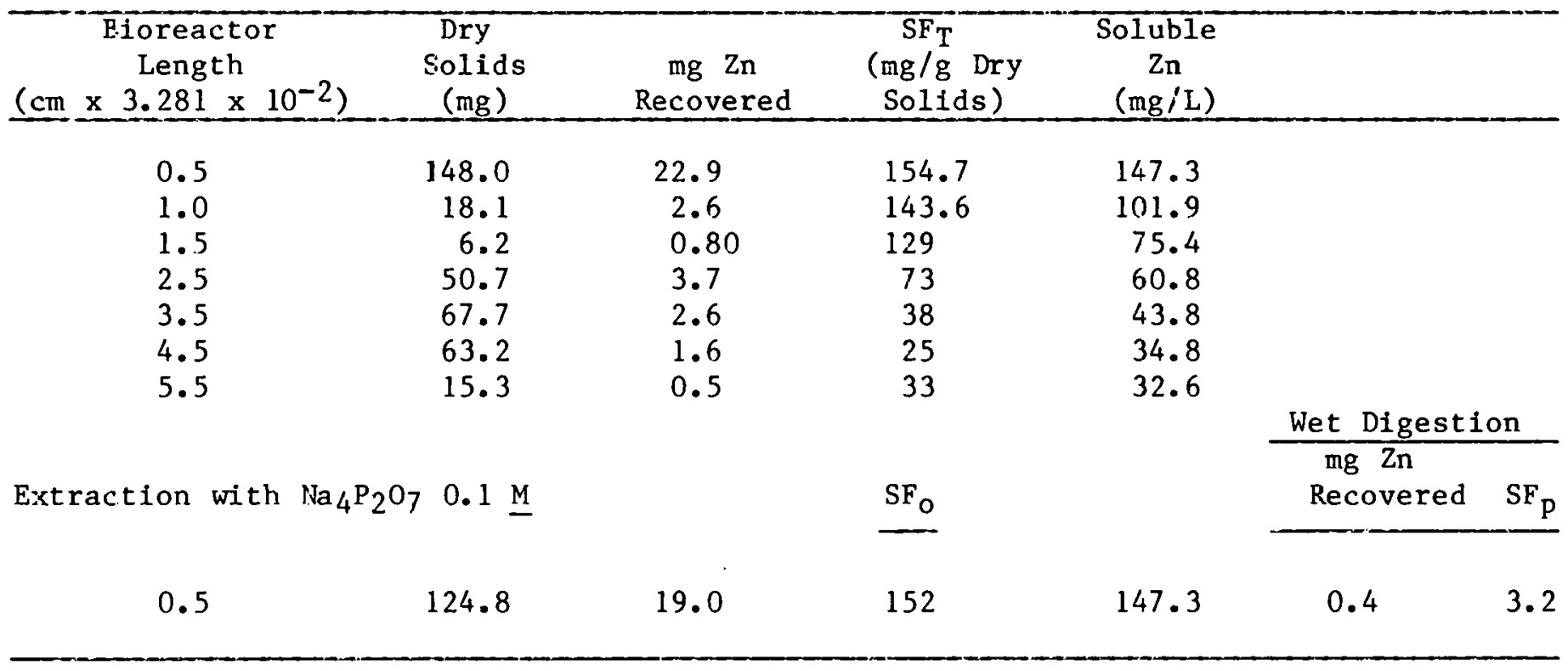


Table C.15. Sorption Factors Profile for Test Bioreactor During Toxicity Experiment No. 3 Using a

Feed Zinc Concentration of $1000 \mathrm{mg} / \mathrm{L}$

\begin{tabular}{ccccc}
$\begin{array}{c}\text { Bioreactor } \\
\text { Length } \\
\left(\mathrm{cm} \times 3.281 \times 10^{-2}\right)\end{array}$ & $\begin{array}{c}\text { Dry Solids } \\
(\mathrm{mg})\end{array}$ & $\begin{array}{c}\text { mg Zn } \\
\text { Recovered }\end{array}$ & $\begin{array}{c}\text { SF } \\
\text { Dry Zn/g Solids })\end{array}$ & $\begin{array}{c}\text { Soluble } \\
\text { zinc } \\
(\mathrm{mg} / \mathrm{L})\end{array}$ \\
\hline 0.5 & 142.1 & 31.0 & 218.2 & 736.4 \\
1.0 & 28.7 & 5.5 & 191.6 & 596.4 \\
2.0 & 10 & 1.6 & 160 & 424.5 \\
4.0 & 10 & 1.1 & 110 & 200.0 \\
5.0 & 13.0 & 1.4 & 108 & 160.0 \\
\hline
\end{tabular}




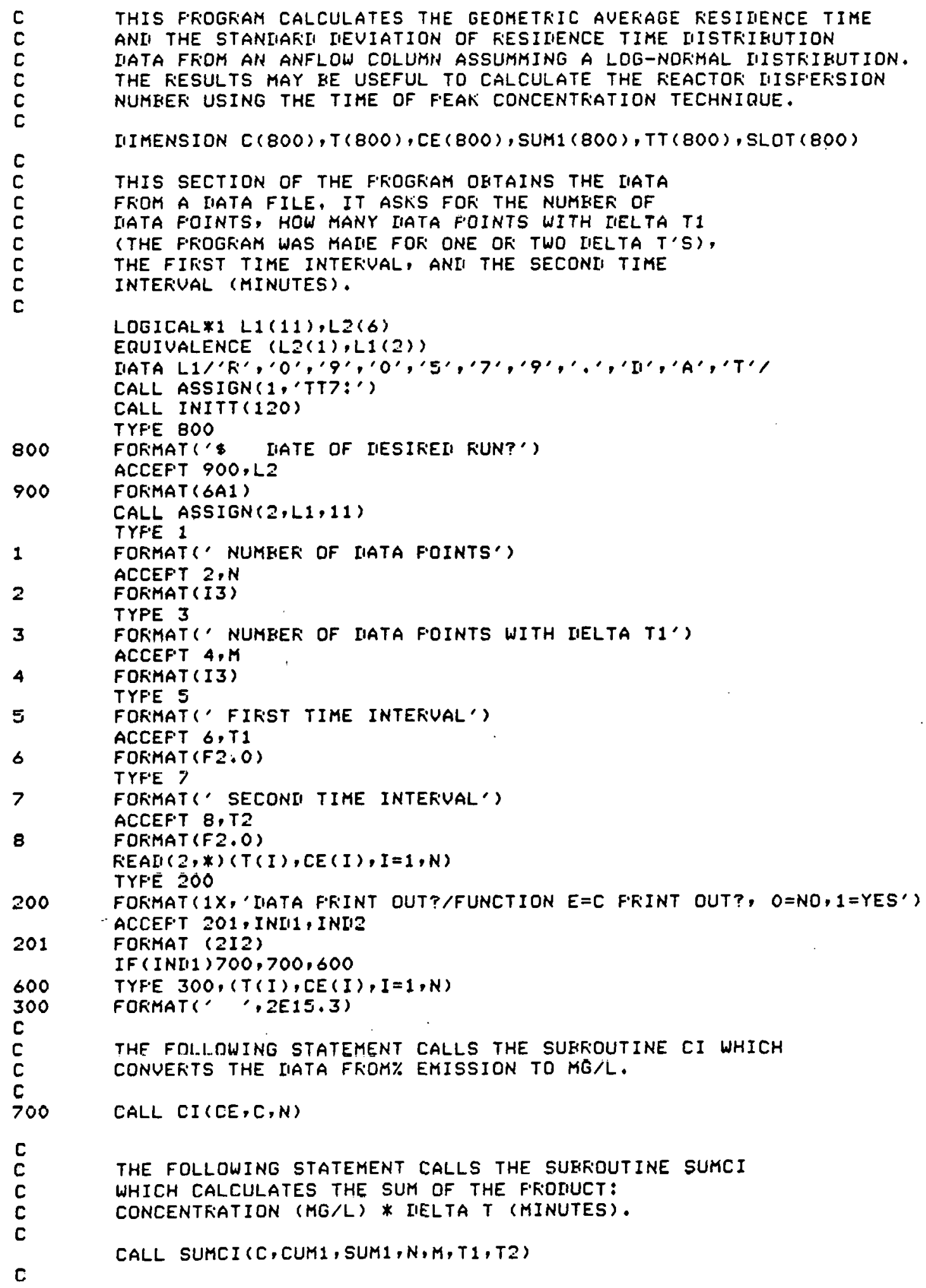




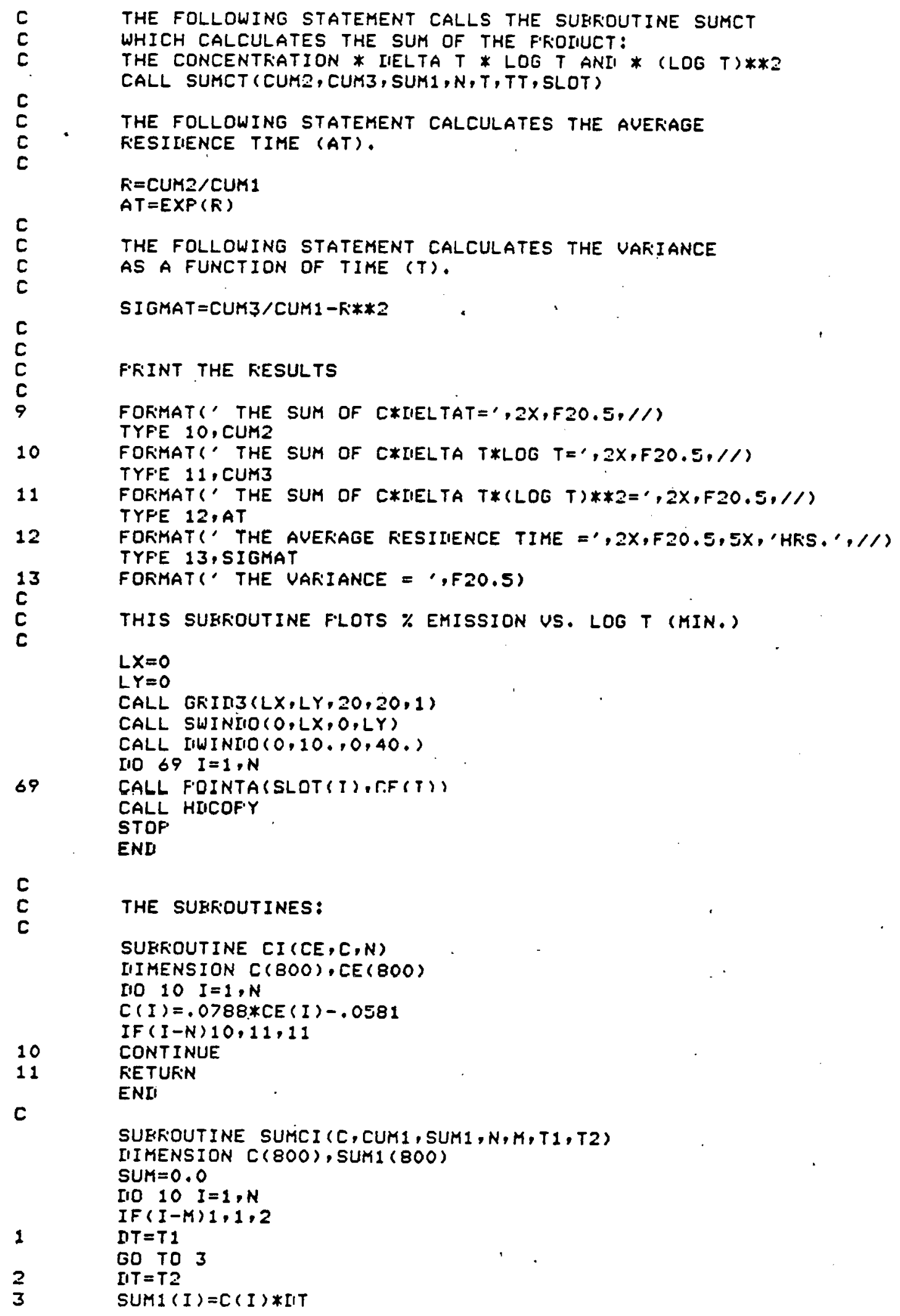




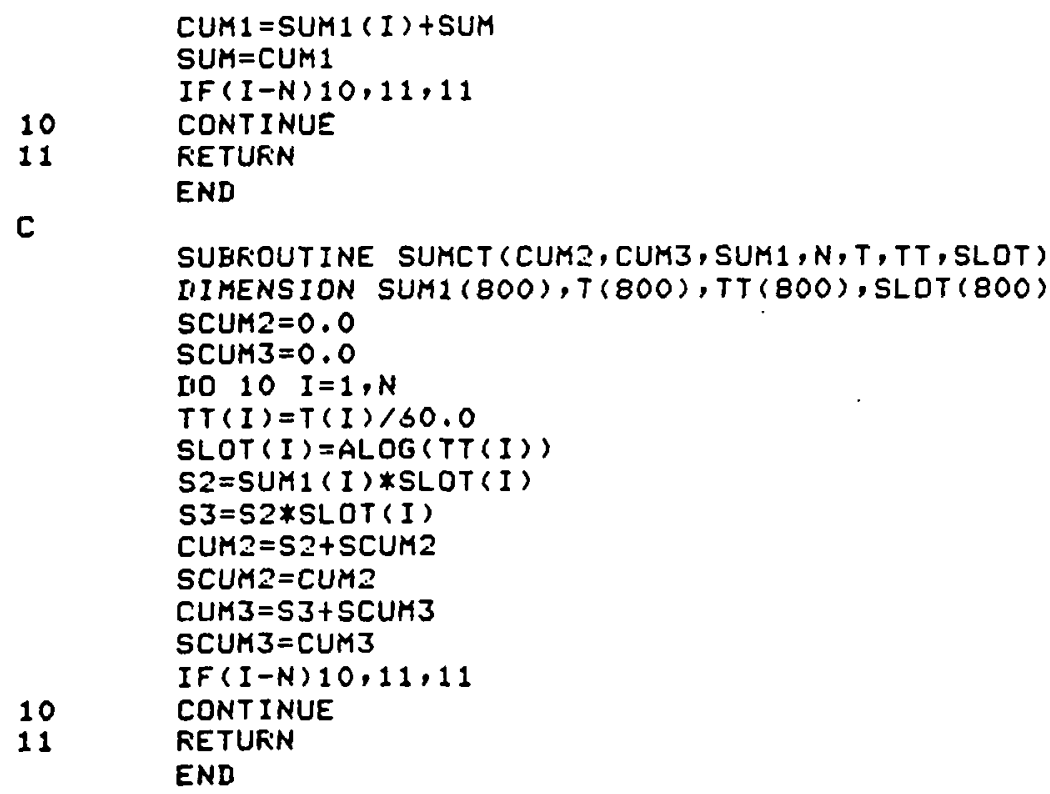

C

SUEKOUTINE SUMCT (CUM2, CUM3, SUM1,N,T,TT, SLOT) IIIMENSION SUM1 $(800), T(800)$, TT $(800)$, SLOT $(800)$ SCUM2 $=0.0$

11 RETUFIN

END 


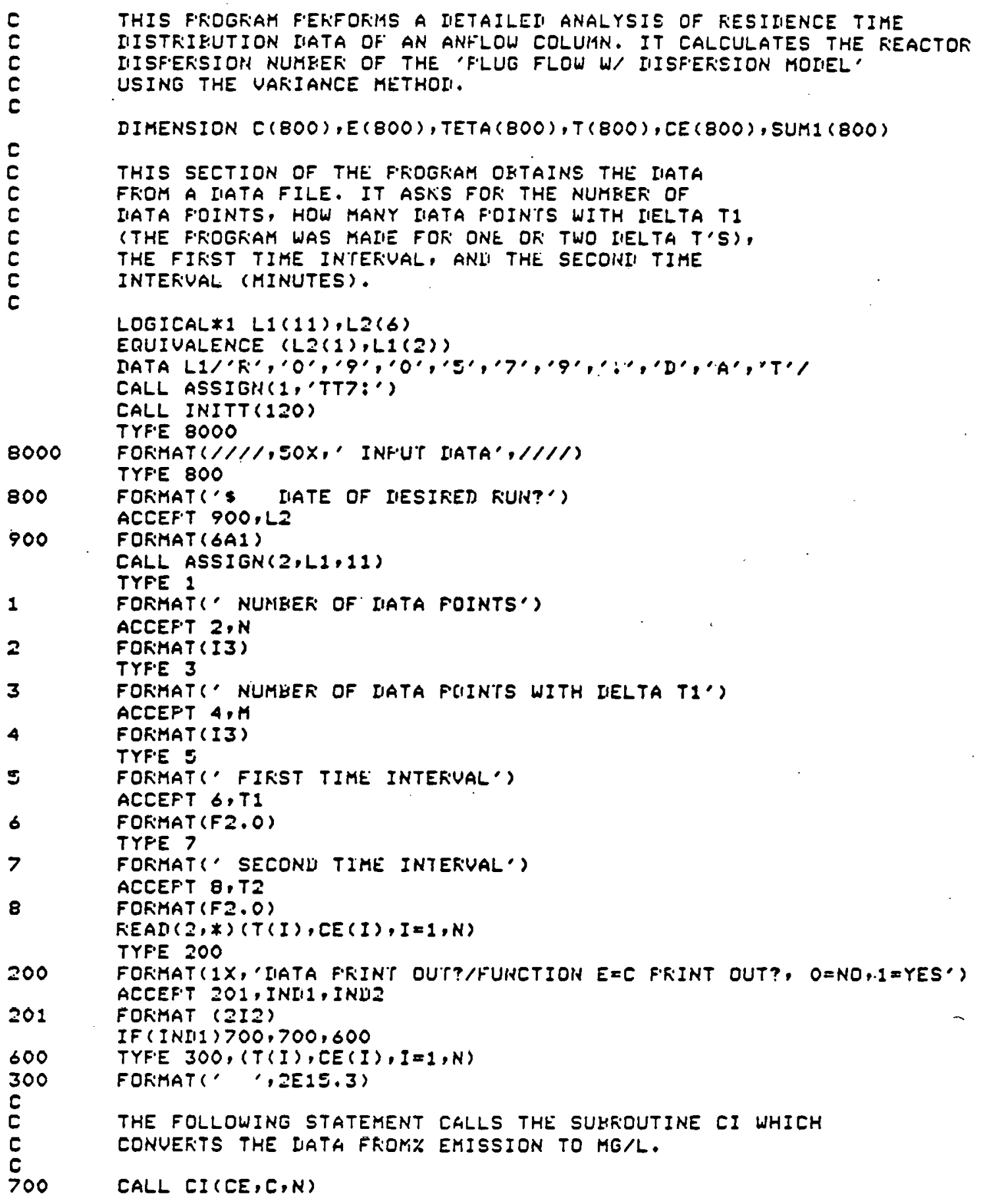


THE FOLLOWING 'STATEMENT CALLS THE SUEROUIINE. SUHCI WHICH CALCULATES THE SUH OF THE FROIUCT: CONCENTRATION (MG/L) * IIEI.TA T (MINUTES).

CALL SUMCI (C, CUM1, SUM1,N,M,T1,T2)

THE FOLLOWING STATEMENT CALLS THE SURKOUTINE SUMCT WHICH CALCULATES THE SUM OF THE FR̃OIUCT:

THE CONCENTRATION * IIELTA T* T ANI * T**I.

CALL SUMCT (CUMI, CUM 3, SUM1,N,T)

THE FOLLOWING STATEMENT CALCULATES THE AUERAGE RESIIIENCE TIME (AT).

$A T=C U M 2 / C U M 1$

THE FOLLOWING STATEMENT CALCULATES THE VARIIATCE AS A FUNETION OF TIME (T).

SIGMAT $=$ CUMZ/CUMI $-A T * * 2$

THE FOLLOWING STATEMENT CALCULATES THE VAFIANCE AS A FUNCTION OF THETA. THE FIEIUUCEI TIME.

\section{SIGMA $=$ SIGMAT/AT**?}

$S=S I G M A$

C
C
C

THE FOLOWING STATEMENT CALIS THE SUEROUTINE EC WHICH CALCULATES THE E=C FUNCTION ANLI THETA THE REDUCEI TIME.

CALL EC(C,N,CUN1, T,E,TETA,AT)

THE FOLLOWING STATEMENT CALLS THE SUKKOUTINE IFF WHICH CALCULATES THE IIISPERSION COEFFICIENT OF THE 'FLUG FLOW WITH IISFERSIDN MOIEL'.

CALL DFF (DF, S)

AT $=A T, B O .0$

F.RINT THE RESULTS

TYF'E 9000 FORMAT $(/ / / /$, SOX, ' KESULTS, $/ / / /)$ TYFE 9,CUM1 FORMAT' 'THE SUI4 OF C*[IEL.TAT =', IX,F2O.5,/1) TYFE 10, CUM? FORMATS" THE SUM DF $C *[I E I . T A T * T=\prime, 2 X, F 20.5,1 /$ ) TYF'E 11, CUM3 FOFMATS' THE SUI OF C*DELTA T*T**Z=', $2 X, F 20.3,1 / 1)$ TYFE 12,AT FORMAT'" THE AUERIAGE RESIIIENCE TIME $\left.=\prime, 2 X, F 20,5,5 X, ' H K S^{\prime}, / 1\right)$ TYF'E 13, SIGMAT, SIGMA

13 FORMATS' THE UARIANCE FOR E(T)=',2X,F20.5, 'ANLI FOR E=C =', $2 X$, $1 F 20.5, / /)$ 


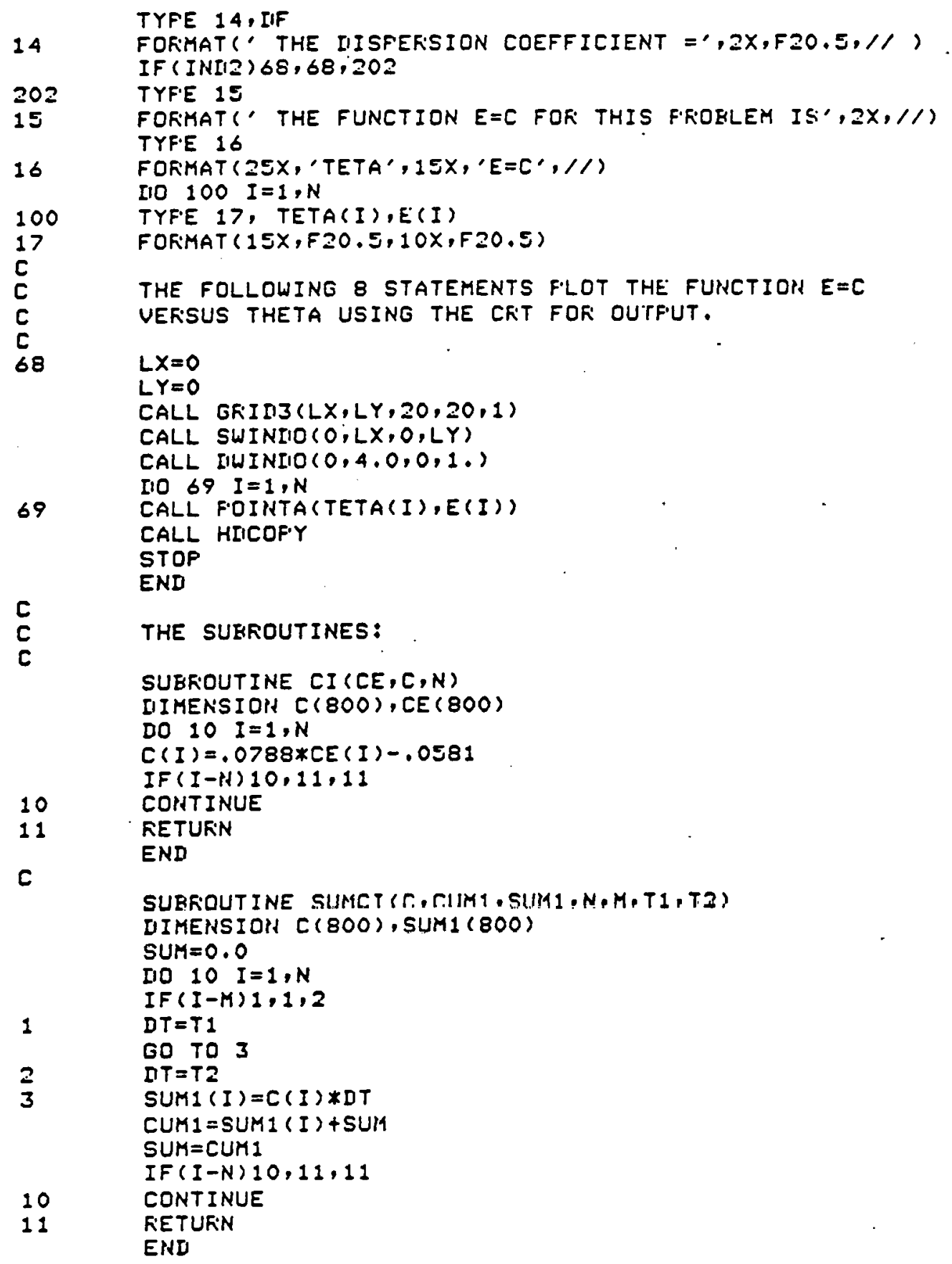


c

SUBROUT IHE SUIACT (CUM2, CUIY3, SUIA1, N,T)

IIIMENSION SUM1 $(800), T(800)$

SCUM $2=0.0$

SCUM3 $=0.0$

IIO $10 \quad I=1, \mathrm{~N}$

$S 2=\operatorname{SUM} I(I) * T(I)$

$S 3=S 2 * T(I)$

CUM $2=52+5$ CUM 2

SCUM2 = CUM2

CUM $3=53+5 C U M 3$

SCUM3 $=$ CUM3

IF $(I-N) 10,11,11$

10 CONTINUE

11 RETURN

END

C

SUEROUTINE EC(C,N,CUIA1,T,E, TETA,AT)

IIIMENSION $C(800), T(800), T E T A(800), E(800)$

[10 $10 \quad I=1, N$

$E T=C(I) /$ CUM 1

$E(I)=A T * E T$

TETART $=T(I) / A T$

$I F(I-N) 10,11,11$

10 CONTINUE

11 RETUR:N

ENI

c

SUBR:OUTINE IIFF (IIF, S)

IMF'LICIT IIOUELE F'RECISION (A-H,O-Z)

IIF $=S / 2$

3

IIF $=$ IIF +0.001

$B=\operatorname{IEXF}(-1 . / \mathrm{IIF})$

$F R=S-2 *([I F-(D F * * 2) *(1-B))$

IF (FF. GE.0.0)GO TO 3

IF (FR.LT,0,0)GO TO 4

4

IIF $=D F-1,0 E-5$

$B=\operatorname{DEXF}(-1.0 /$ IIF $)$

$F K^{\circ}=S-2.0 *(I F-(I F * * 2) *(1-E))$

IF(FR.LE.0.0) GO TO 4

IF (FR.GT.0.0)00 TO 5

5

$I \mathrm{IF}=\mathrm{IIF}+1,0 \mathrm{E}-7$

$\mathrm{B}=\mathrm{LIEXF}(-1.0 / \mathrm{UF})$

$F R=S-2,0 *(I I F-(I F * * 2) *(1-8))$

IF (FR. GT.0.0)GO TO 5

IF (FR.LE, 0.0)60 TO 6

6

REETURN

ERII 


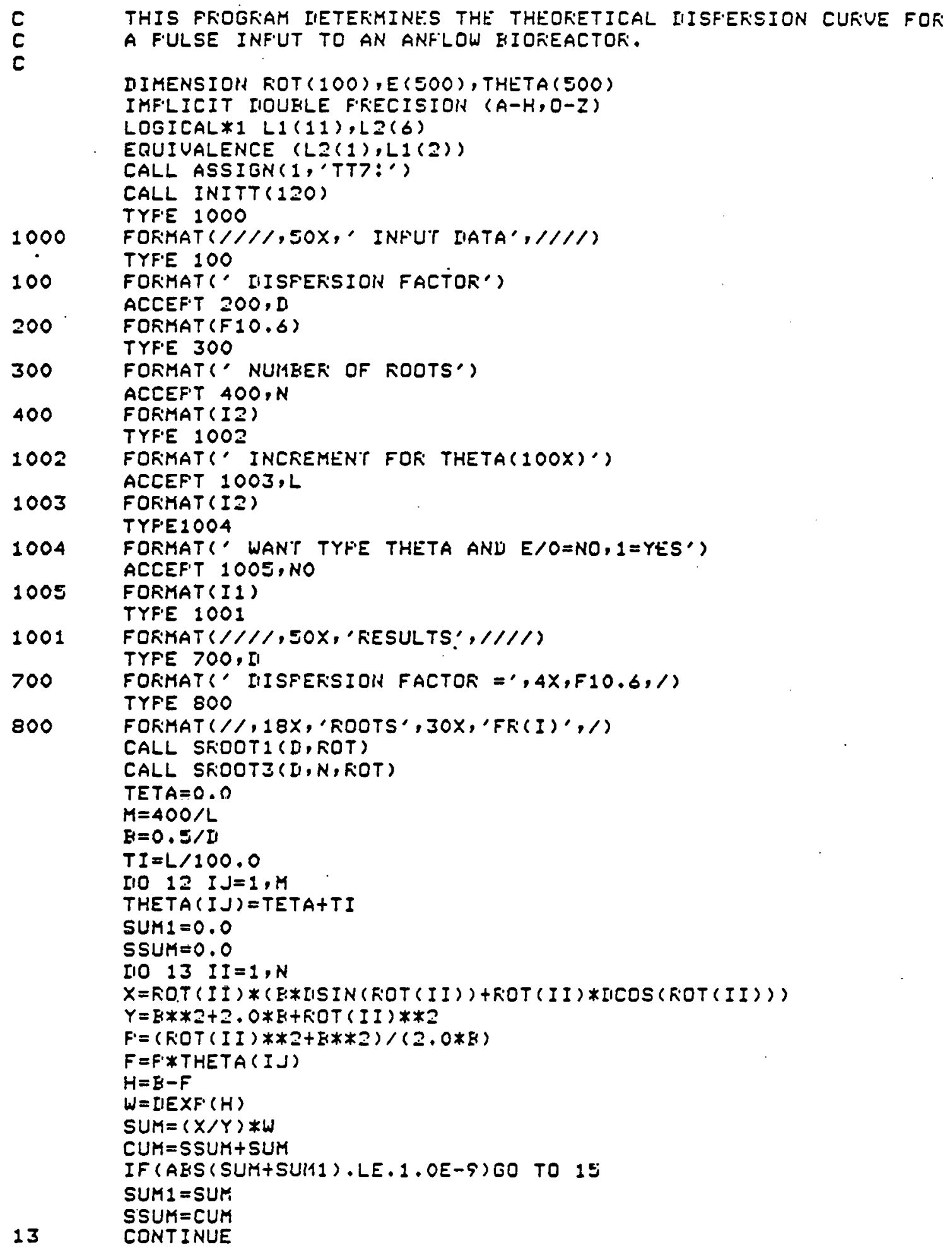




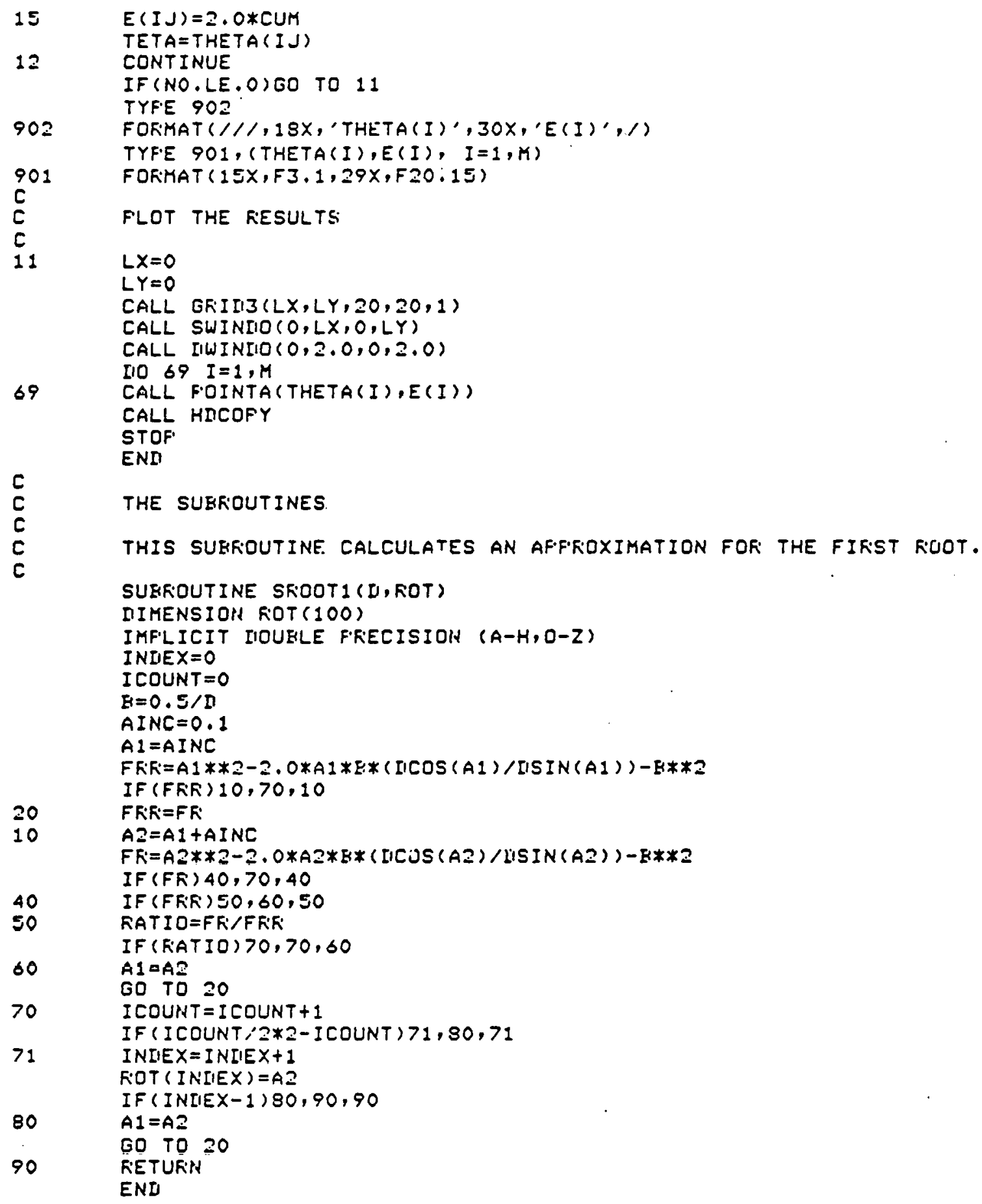




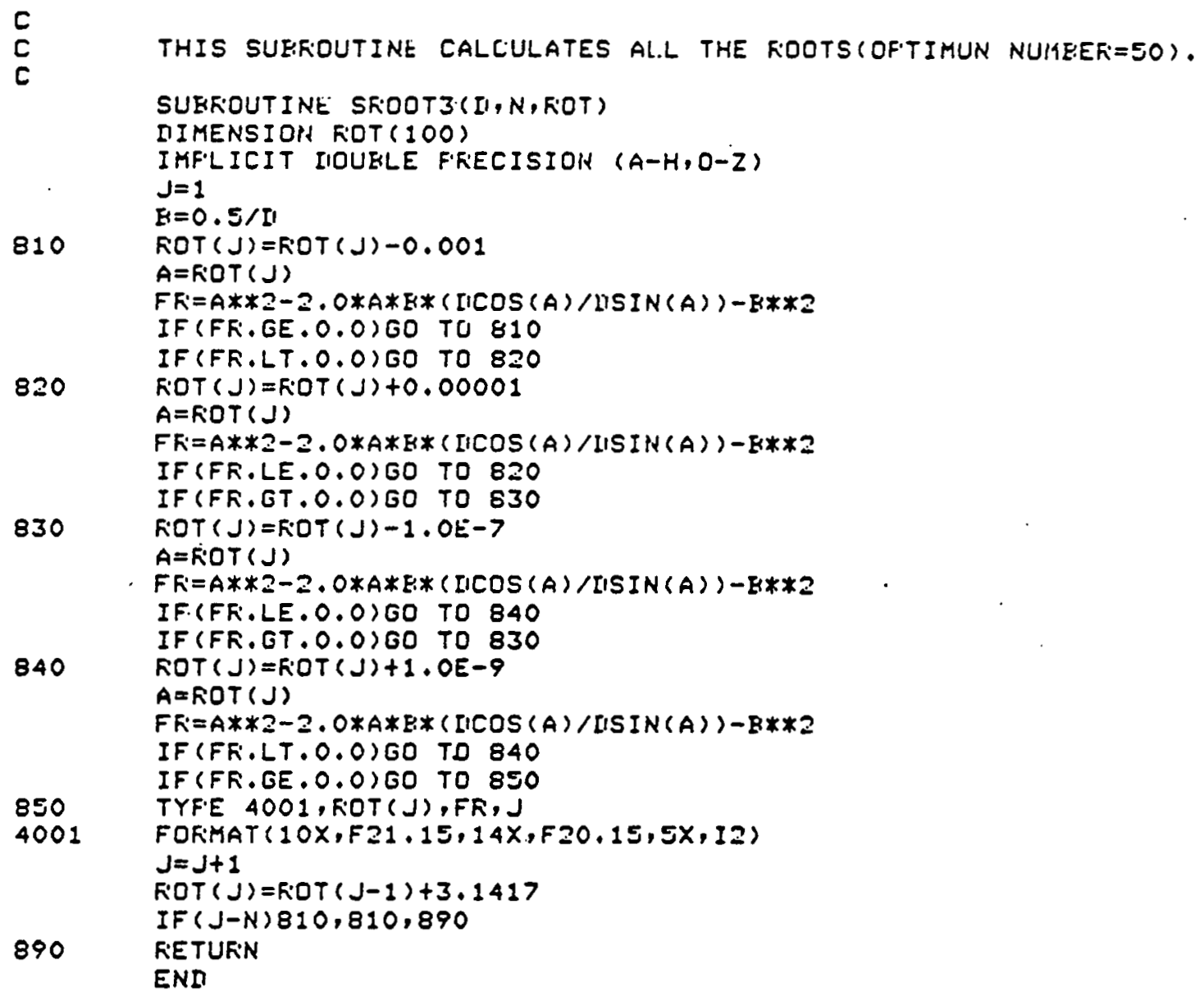




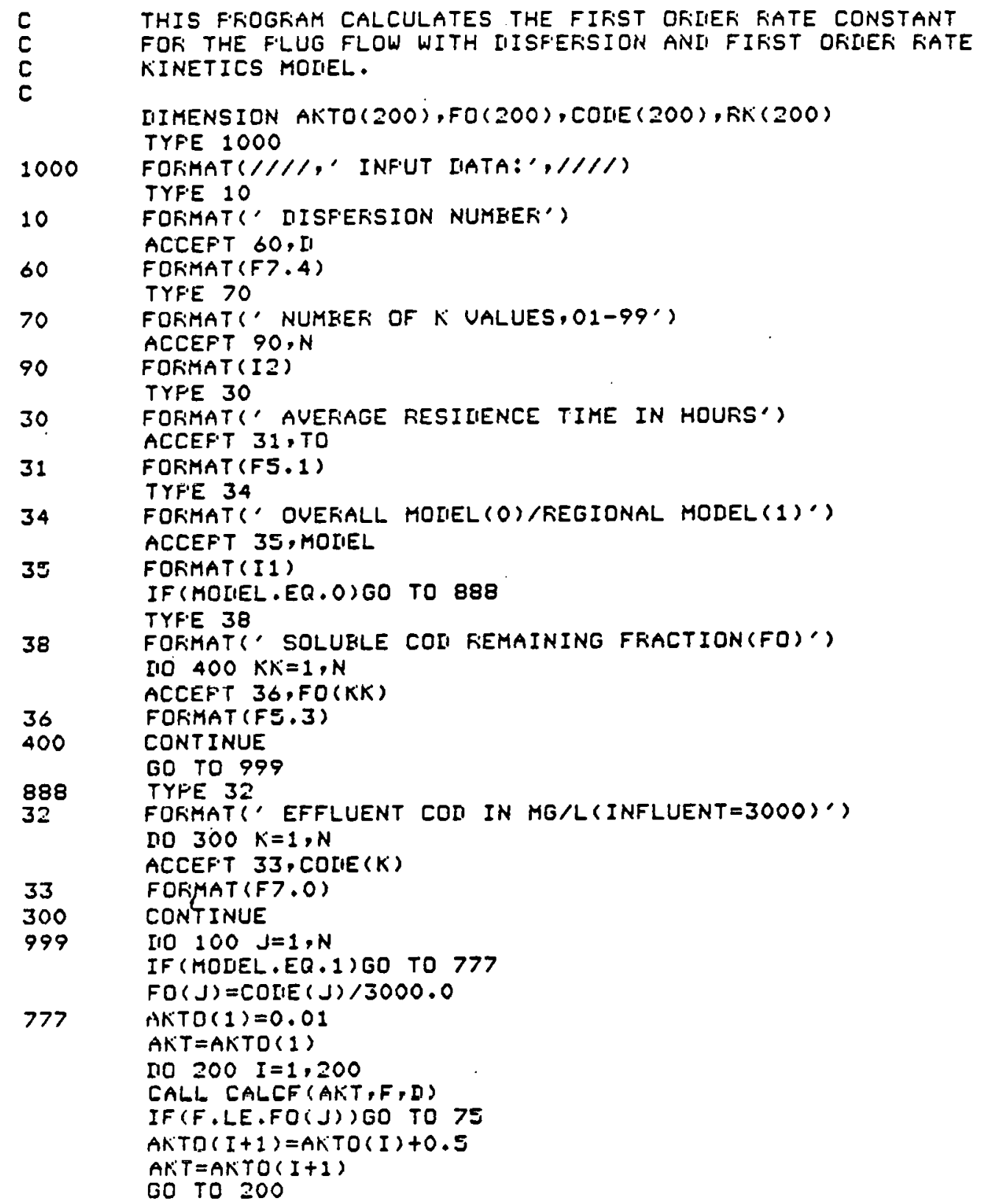




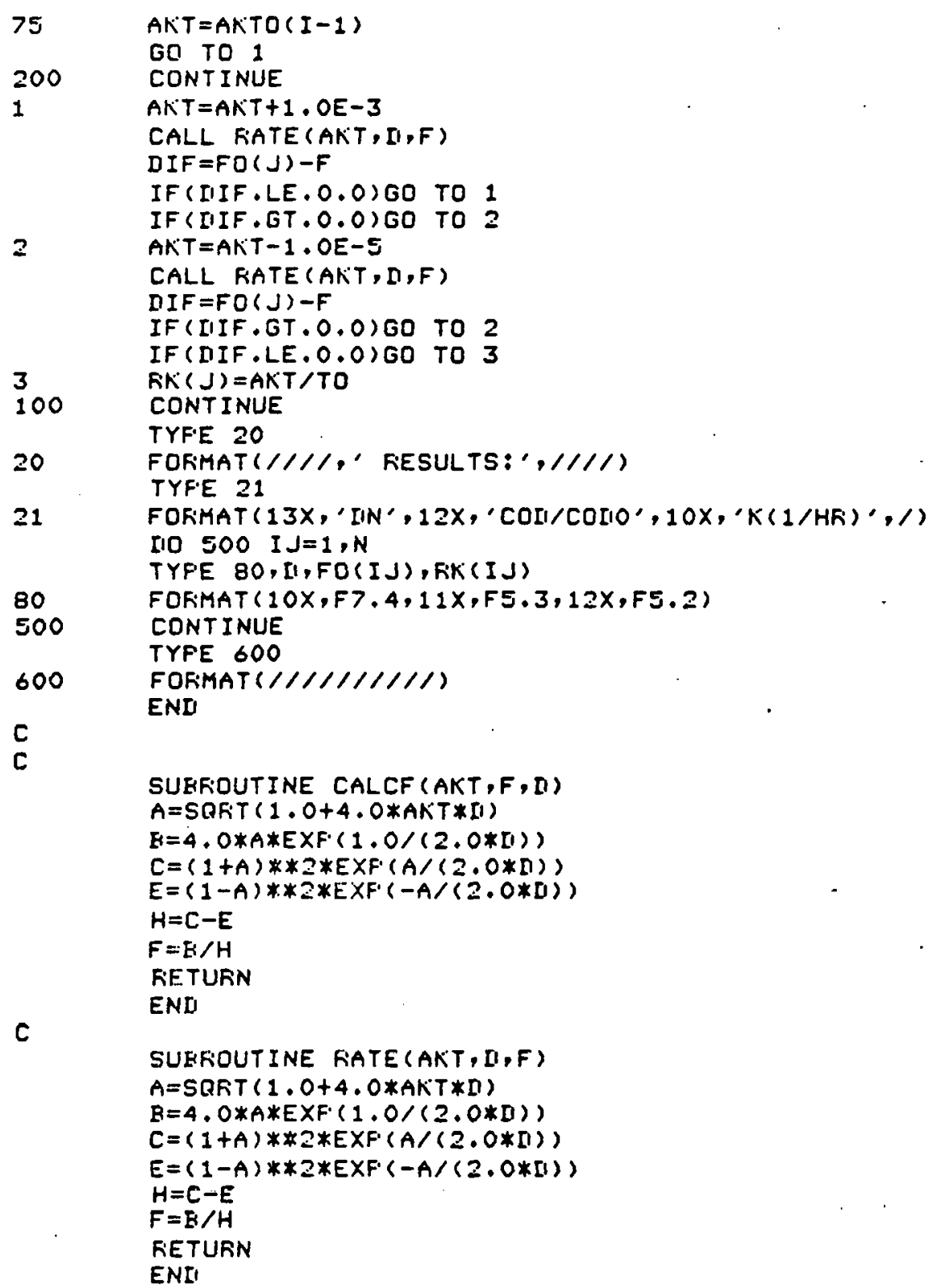

C

SUEROUTINE CALCF (AKT,F,D)

$A=S B K T(1.0+4.0 * A K T * I 1)$

$E=4.0 * A * E X F \cdot(1.0 /(2.0 *[1))$

$C=(1+A) * * 2 * E \times F \cdot(A /(2,0 * n))$

$E=(1-A) * * 2 * E \times F \cdot(-A /(2,0 *[1))$

$\mathrm{H}=\mathrm{C}-\mathrm{E}$

$F=E / H$

FETURN

END

c 
10. LIST OF REFERENCES

1. R. K. Genung, W. W. Pitt, Jr., G. M. Davis, and J. H. Koon, "Energy Conservation and Scale-Up Studies for a Wastewater Treatment System Based on a Fixed-Film, Anaerobic Bioreactor," Biotechnology and Bioengineering Symposium, No. 10, 1979, E. L. Gaden, Editor, Interscience Publication published by John Wiley and Sons.

2. J. C. Young and P. L. McCarty, "The Anaerobic Filter for Waste Treatment," Proceedings of the 22nd Industrial Waste Conference, Part Two, Purdue University, Lafayette, IN, 1967, pp. 559-574.

3. A. T. E1-Shafie and D. E. Bloodgood, "Anaerobic Treatment in a Multiple Upflow Filter System," J. Water Pollut. Control Fed., Vo1. 45, No. 11, November 1973, pp. 2345-2357.

4. J. A. Fisher, J. C. Hovious, G. W. Kumke, and R. Conway, "Pilot Demonstration of Basic Designs for Anaerobic Treatment of Petrochemical Wastes," Chemical Engineering Progress Symposium Series, Vol. 67, No. 107, 1971, pp. 485-494.

5. A. H. Plummer, Jr., J. F. Malina, Jr., and W. W. Eckenfelder, Jr., "Stabilization of a Low Solids Carbohydrate Waste by an Anaerobic Submerged Filter," Proceedings of 23rd Annual Purdue Industrial Waste Conference, Lafayette, IN, 1968, pp. 462-473.

6. J. C. Jennett and N. D. Dennis, Jr., "Anaerobic Filter Treatment of Pharmaceutical Waste," J. Water Pollut. Control Fed., Vol. 47, No. I, January 1975, pp. 104-121.

7. R. E. Pailthorp, G. A. Richter, and J. W. Filbert, "Anaerobic Secondary Treatment of Potato Process Wastewater," Industrial Processes D1vision, CH2M/H111, Corval11s, Oregon, 1971.

8. D. W. Taylor and Burm, R. J., "Full-Scale Anaerobic Trickling Filter Evaluation," AIChE Symp. Ser., No. 129, 1973, pp. 30-37.

9. G. A. Richter and J. A. Mackie, "Low Cost Treatment for High Strength Waste," Industrial Processes Division, CH2M/Hill, Corvallis, OR, 1971.

10. J. B. Coulter, S. Soneda, and M. B. Ettinger, "Anaerobic Contact Process for Sewage Disposal," Sewage Ind. Wastes, 29, 1957, pp. 468-477.

11. M. B. Ettinger, J. L. Witherow, and J. B. Coulter, "Chemical and Hydraulic Characteristics of the Anaerobic Contact Process for Sewage Treatment," in Biological Treatment of Sewage and Industrial Wastes, Vo1. 2, by J. McCabe and W. W. Eckenfelder, Jr., Reinhold Publishing Corp., New York, 1958, pp. 145-155. 
12. G. J. Schroepfer and N. R. Ziemke, "Development of the Anaerobic Contact Process, I. Pilot-Plant Investigations and Economics," Sewage Ind. Wastes, Vol. 31, No. 2, 1959, pp. 164-190.

13. W. A. Pretorius, "Anaerobic Digestion of Raw Sewage," Water Res., Vo1. 5, Pergamon Press, Great Britain, 1971, pp. 681-687.

14. W. A. Pretorius, "Complete Treatment of Raw Sewage with Special Emphasis on Nitrogen Removal," in Advanced Water Pollution Research Proceedings of the 6th International Conference, Pergamon, Oxford, 1973, pp. 685-693.

15. W. L. Griffith and A. L. Compere, "Bench-Scale Anaerobic FixedF11m System Tests on a Low-Temperature, Low-Strength Synthetic Wastewater," (Unpublished).

16. Metcalf and Eddy, Wastewater Engineering, McGraw-Hill Book Company, New York, 1972.

17. J. S. Jeris and P. L. McCarty, "The Biochemistry of Methane Fermentation Using C-14 Tracers," J. Water Pollut. Control Fed., Vol. 37, No. 2, 1965, pp. 178-192.

18. P. L. McCarty et al., "Individual Volatile Acids in Anaerobic Treatment," J. Water Pollut. Control Fed., Vol. 35, No. 2, 1963, pp. $1505-151 \overline{6}$.

19. A. J. Kaplovsky, "Volatile Acid Production During the Digestion of Seeded, Unseeded, and Limed Fresh Solids," Sewage Ind. Wastes, Vol. 23, No. 6, 1951, pp. 713-721.

20. P. L. McCarty, "Anaerobic Waste Treatment Fundamentals," Part One, Chemistry and Microbiology, Public Works, September, 1964, pp. 107112.

21. M. H. Cheng et al., "Heavy Metals Uptake by Activated Sludge," J. Water Pollut. Control Fed., Vol. 47, No. 2, 1975, pp. 362-376.

22. I. J. Kugelman and P. L. McCarty, "Cation Toxicity and Stimulation in Anaerobic Waste Treatment," J. Water Pollut. Control Fed., Vol. 47, No. 2, 1975, pp. 362-376.

23. M. Hotchkiss, "Studies on Salt Action. VI. The Stimulating and Inhibitive Effects of Certain Cations on Bacterial Growth," J. Bacteriol., Vo1. 8, 1923, pp. 141 .

24. A. W. Lawrence and P. L. McCarty, "The Role of Sulfide in Preventing Heavy Metal Toxicity in Anaerobic Treatment," J. Water Pollut. Control Fed., Vo1. 37, No. 3, 1965, pp. 392-406.

25. T. D. Hayes and T. L. Theis, "The Distribution of Heavy Metals in Anaerobic Digestion," J. Water Pollut. Control Fed., pp. 61-72, 1978. 
26. F. E. Mosey et al., "Factors Affecting the Availability of Heavy Metals to Inhibit Anaerobic Digestion," Water Pollut. Control Vol. 70, 1971, pp. 668-680.

27. A. W. Lawrence, "Application of Process Kinetics to Design of Anaerobic Processes," In Anaerobic Biological Treatment Processes, Advances in Chemistry Series 105, American Chemical Soc., Washington, DC, 1971, pp. 163-189.

28. J. E. Bailey and D. F. Ollis, Biochemical Engineering Fundamentals, McGraw-H111 Book Company, New York, 1977.

29. I. J. Kugelman and K. K. Chin, "Toxicity, Synergism, and Antagonism in Anaerobic Waste Treatment Processes," In Anaerobic Biological Treatment Processes, Advances in Chemistry Series 105, American Chemical Society, Washington, D.C., 1971, pp. 55-90.

30. Y. T. Shah, Gas-Liquid-Solid Reactor Design, McGraw-Hill Book Company, 1979, pp. 60-104.

31. H. A. Thomas and J. E. McKee, "Longitudinal Mixing in Aeration Tanks," Sewage Works J., Vo1. 16, 1944, p. 42.

32. E. T. Van Der Laan, "Notes on the Diffusion-Type Model for the Longitudinal Mixing in Flow," Chem. Eng. Sci., Vol. 7, 1958, pp. 187-191.

33. O. Levenspiel and W. K. Smith, "Notes on the Diffusion-Type Model for the Longitudinal Mixing of Fluids in Flow," Chem. Eng. Sci., Vol. 6, 1957, pp. 227-233.

34. P. L. Timpany, "Variations of Axial Mixing in an Aeration Tank," Thesis presented to McMaster University at Hamilton, Ontario, Canada in 1966 in partial fulfillment for the requirements for the degree of Master of Engineering.

35. J. F. Wehner and R. H. Wilhelm, "Boundary Conditions of Flow Reactor," Chem. Eng. Sc1., Vol. 6, 1956, pp. 89.

36. N. L. Nemerov, Liquid Waste of Industry, Theories, Practices and Treatment, Addison-Wesley Publishing Company, Massachusetts, 1971, pp. 415-431.

37. J. G. Dean et al., "Removing Heavy Metals from Wastewater," Environ. Sci. Techno1., Vo1. 6, No. 6, 1972, pp. 518-522.

38. M. Sittig, Environmental Sources and Emissions Handbook, Environmental Technology Handbook No. 2, Noyes Data Corporation, Park Ridge, New Jersey, 1975.

39. L, A, Kle1n et al., "Sources of Metals in New York City Wastewater," J. Water Pollut. Control Fed., Vol. 46, No. 12, 1974, pp. 2653-2662. 
40. J. A. Davis and J. Jacknow, "Heavy Metals in Wastewater in Three Urban Areas," J. Water Pollut. Control Fed., Vol. 42, No. 9, 1975, pp. 2292-2297.

41. G. N. McDermott et al., "Nickel in Relation to Activated Sludge and Anaerobic Digestion Processes," J. Water Pollut. Control Fed., Vol. 37, No. 2, 1965, pp. 163-177.

42. G. N. McDermott et al., "Copper and Anaerobic Sludge Digestion," J. Water Pollut. Control Fed., Vol. 33, No. 5, 1963, pp. 655-662.

43. E. F. Barth et al., "Summary Report on the Effects of Heavy Metals on the Biological Treatment Processes," J. Water Pollut. Control Fed., Vol. 37, No. 1, 1965, pp. 86-96.

44. P. L. McCarty, "Anaerobic Treatment Fundamentals. Part Three. Toxic Materials and Their Control," Public Works, November 1964, pp. 91-94.

45. Radiological Health Handbook, United States Department of Health, Education and Welfare, Public Health Service, January 1970, pp. 252.

46. J. C. Young and P. L. McCarty, "Anaerobic Filter for Waste Treatment, " J. Water Pollut. Control Fed., Vol. 41, No. 5, 1969, pp. R160-R173.

47. Martin, Monique and Lindquist, Lars., "The pH Dependence of Flourscein F1uorescence," J. Lumin., Vo1. 10, 1975, pp. 381-390.

48. Standards Methods for the Examination of Water and Wastewater, 14 th edition, American Public Health Assn., New York, NY, 1975.

49. Ampule COD (Chemical Oxygen Demand), Operating Procedures Manual, Oceanography International Corporation, 512 West Loop, Post Office Box 2980, College Station, TX 77840.

50. Methods for Chemical Analysis of Water and Wastes, Environmental Protection Agency Report No. EPA-625/6-74-003, Office of Technology Transfer, Washington, DC, 1974, pp. 155-156.

51. R. C. Stover et al., "Evaluation of Metals in Wastewater Sludge," J. Water Pollut. Control Fed., Vol. 48, No. 9, 1976, pp. 2165-2175.

52. M. Knonova and V. P. Bel'Chikova, "Use of Sodium Pyrophosphate to Separate and Characterize Organoiron and Organoaluminum Compounds in So11," Sov. Soil Sci., Vol. 2, No. 3, 1970, pp. 351-364.

53. J. A. McKeague et al., "Differentiation of Forms of Extractable Iron and Aluminum in Soils," Soll Sc1. Soc. Am., Proc., Vol. 35, No. 1,1971, pp. 33-38. 
54. L. N. Alexandrova, "The Use of Sodium Pyrophosphate for Isolating Free Humic Substances and Their Organic-Mineral Compounds from the So11," Sov. Sol1 Sci., No. 2, 1960, pp. 190-197.

55. W. P. M. Van Swaail et al., "Residence Time Distribution in the Liquid Phase of Trickle Flow in Packed Columns," Chem. Eng. Sc1., Vol. 24, 1969, pp. 1083-1095.

56. J. Raghruman and Y. B. G. Varma, "A Model for Residence Time Distribution in Multistage Systems with Cross-Flow Between Active and Dead Regions," Chem. Eng. Sci., Vol. 28, 1973, pp. 585-591.

57. J. Raghruman and V. Mohan, "A Markov Chain Model for Residence Time and Contact Time Distributions in Packed Beds," Chem. Eng. Sc1., Vol. 30, 1975, pp. 549-553.

58. 0. Levenspiel and J. Dayan, Longltudinal Dispersion in Packed Beds of Porous Adsorbing Solids," Chem. Eng. Sc1., Vol. 23, 1968, pp. $1327-1334$.

59. H. E. Hoelscher and R. Chao, "Simultaneous Axtal Dispersion and Adsorption in a Packed Bed," A.I.Ch.E. J., Vol. 12, No. 2, 1966, pp. $271-278$.

60. W. C. Clements, "A Note on Determination of the Parameters of the Longitudinal Dispersion Model from Experimental Data," Chem. Eng. Sci., Vol. 24,' 1969, pp. 957-963.

61. J. F. Andreus and S. P. Graef, "Dynamic Model and Simulation of the Anaerobic Digestion Process," In Advances in Chemistry Series 105, American Chemical Society, Washington, D.C., 1971, pp. 126-162.

62. G. M. Fair et al., Elements of Water Supply and Wastewater Disposal, Second edition, John Wiley and Sons, Inc., New York, 1971, pp. 710.

63. A. M. Buswel1 and C. S. Boruff, "The Relation Between the Chemical Composition of Organic Matter and the Quality and Quantity of Gas Produced During Sludge Digestion," Sewage Works J., Vol. 4, No. 3, 1932, pp. 454-460.

64. P. L. McCarty, Anaerobic Waste Treatment Fundamentals, Public Works, Oct. 1964, pp. 123.

65. J. S. Fritz and G. H. Schenk, Quantitative Analytical Chemistry, Second Edition, Allyn and Bacon Inc., Boston, 1971, pp. 618.

66. C. N. Sawyer and P. L. McCarty, Chemistry for Environmental Eng1neering, Third Edition, McGraw-Hi11 Book Company, 1978, pp. 172.

67. A. P. Banta and R. Pomerov, "Hydrogen-Ion Concentration and Bicarbonate Equilibrium in Digesting Sludge," Sewage Works j., Vol. 6, 1934, pp. 234. 
68. B. Atkinson et al., "Kinetics, Mass Transfer, and Organism Growth in a Biological Film Reactor," Trans. Inst. Chem. Engrs., Vol. 45, 1967, pp. T257-T264.

69. B. Atkinson and I. S. Daoud, "The Analogy Between Micro-Biological Reactions and Heterogeneous Catalysis," Trans. Inst. Chem. Engrs., Vol. 46, 1968, pp. T19-T24.

70. B. Atkinson et al., "A Theory for the Biological Film Reactor," Trans. Inst. Chem. Engrs., Vol. 46, 1968, pp. T245-T250.

71. A. W. Lawrence and P. L. McCarty, "Kinetics of Methane Fermentation," J. Water Pollut. Control Fed., Vol. 41, No. 2, 1969, pp. R1-R17.

72. D. Thirumurthi, "Design Principles of Waste Stabilization Ponds," J. Sanit. Eng. Div., Am. Soc. Civ. Eng., April 1969, pp. 311-330. 
ORNL/TM-7837

INTERNAL DISTRIBUTION

1. R. S. Carlsmith

2-6. R. K. Genung

7. S. B. Gough

8. W. L. Griffith

9. C. W. Hancher

10. J. R. Hightower

11. R. L. Jolley

12. T. W. Oakes

13. J. J. Perona

14. W. W. Pitt, Jr.

15-19. A. L. Rivera

20. S. E. Shumate II

21. M. G. Stewart

22-23. C. H. Shappert

24. L. H. Stinton

25. V. C. A. Vaughen
26. J. F. Walker, Jr.

27. S. K. Whatley

28. M. E. Koons

29. L. Burris (Consultant)

30. C. R. Choppin (Consultant)

31. W. H. Corcoran (Consultant)

32. S. W. Drew (Consultant)

33. A. M. Squires (Consultant

34. M. E. Wadsworth (Consultant)

35. Laboratory Records

36. Laboratory Records

37. ORNL Patent Section

38. Central Research Library

39. ORNL Y-12 Library

Document Reference Section.

EXTERNAL DISTRIBUTION

40. Office of Assistant Manager for Energy Research and Development DOE-ORO, P.O. Box E, Oak Ridge, TN 37830.

41-67. Technical Information Center, Oak Ridge, TN 37830. 


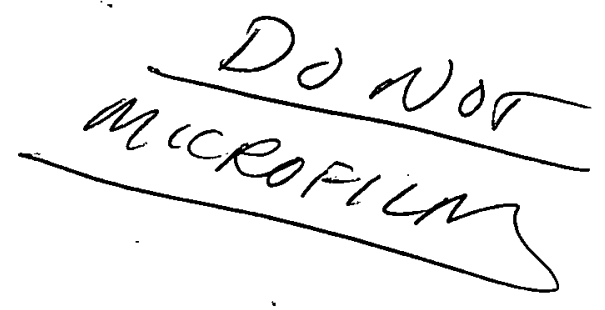

